\title{
A Pilot Golden Eagle Population Study in the Altamont Pass Wind Resource Area California
}

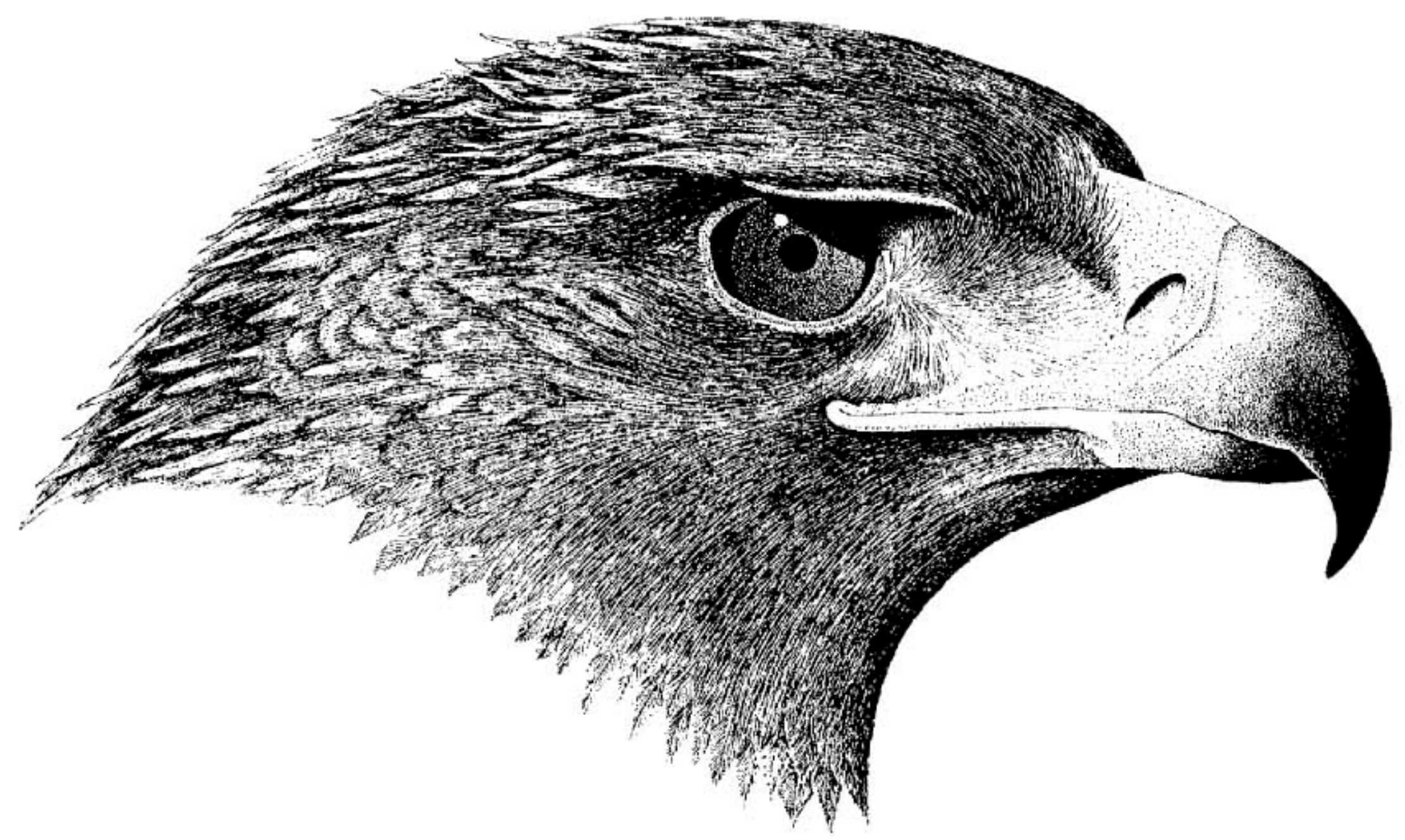

Prepared by

Predatory Bird Research Group

Long Marine Laboratory

University of California

Santa Cruz, California

Prepared for

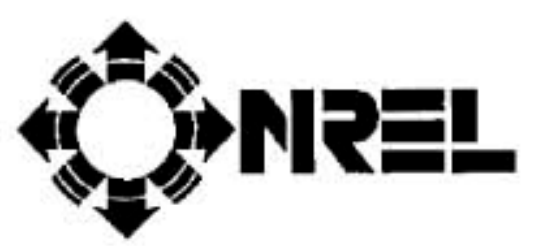

National Renewable Energy Laboratory

May 1995 


\section{A Pilot Golden Eagle Population Study in the Altamont Pass Wind Resource Area California}

Prepared by

Predatory Bird Research Group

Long Marine Laboratory

University of California

Santa Cruz, California

NREL technical monitor: Holly Davis

Prepared for

\section{NPEI}

National Renewable Energy Laboratory

1617 Cole Boulevard

Golden, Colorado 80401-3393

A national laboratory of the U.S. Department of Energy

Managed by Midwest Research Institute

for the U.S. Department of Energy

under contract No. DE-AC36-83CH10093

Prepared under Subcontract No. XCG-4-14200

May 1995

NREL/TP-441-7821 UC Category:1210 DE95009220 
This publication was reproduced from the best available camera-ready copy submitted by the subcontractor and received no editorial review at NREL.

\section{NOTICE}

This report was prepared as an account of work sponsored by an agency of the United States government. Neither the United States government nor any agency thereof, nor any of their employees, makes any warranty, express or implied, or assumes any legal liability or responsibility for the accuracy, completeness, or usefulness of any information, apparatus, product, or process disclosed, or represents that its use would not infringe privately owned rights. Reference herein to any specific commercial product, process, or service by trade name, trademark, manufacturer, or otherwise does not necessarily constitute or imply its endorsement, recommendation, or favoring by the United States government or any agency thereof. The views and opinions of authors expressed herein do not necessarily state or reflect those of the United States government or any agency thereof.

Available to DOE and DOE contractors from:

Office of Scientific and Technical Information (OSTI)

P.O. Box 62

Oak Ridge, TN 37831

Prices available by calling (615) $576-8401$

Available to the public from:

National Technical Information Service (NTIS)

U.S. Department of Commerce

5285 Port Royal Road

Springfield, VA 22161

(703) $487-4650$ 
Predatory Bird Research Group

University of California

Santa Cruz, California

\section{PROJECT TEAM}

Principal Investigator

Grainger Hunt

Project Managers

Brian Walton

Tery Drager

Consultants

Pete Bloom

Ron Jackman

Hans Peeters

Biologists

Jennifer Barg

Teresa Brown

Lois Culp

Daniel Driscoll

James Gilardi

John Gilardi

Alex Kolker

Brian Latta

Janet Linthicum

Charles Quinn

Robert Richmond 


\section{EXECUTIVE SUMMARY}

During 1994, the Predatory Bird Research Group, University of California, Santa Cruz, conducted a preliminary field investigation of the ecology of golden eagles (Aquila chrysaetos) in the vicinity of the Altamont Pass Wind Resource Area (WRA). The facility contains about 6,500 wind turbines on $189 \mathrm{~km}^{2}$ just east of San Francisco Bay in California. Grassland and oak savanna habitats surrounding the WRA support a substantial population of golden eagles. Each year, the U.S. Fish and Wildlife Service receives reports from the wind industry of about 30 golden eagle casualties occurring at the WRA, with over 90 percent attributed to collisions with wind turbines. The purpose of this pilot study was to clarify and set in motion a research program that will identify (1) the effect of turbine-related mortality on the golden eagle population, (2) factors attracting eagles to the WRA, and (3) conditions that increase the risk of turbine strikes.

To show the distribution of the population potentially impacted and to obtain survival data, we radio-tagged 31 adult and subadult eagles in the WRA vicinity during January and February 1994 and an additional 25 juveniles from nests surrounding the WRA in spring. Each transmitter contained a mortality sensor and was expected to last five years. Throughout 1994, we determined the location and status of each eagle in twice-weekly airplane roll-call surveys.

Of the 31 winter-tagged eagles, 5 were members of pairs breeding near the WRA. Of the remaining 26 birds, 19 were subadults and seven were non-breeding adults (floaters). Over the course of the year, four $(15 \%)$ of the 26 non-breeders either departed the region or their radios failed. The remainder traveled within the northern Diablo Range which extends from the Oakland Hills southeast to San Luis Reservoir, an area of about $3,500 \mathrm{~km}^{2}$, for which we developed a digitized (GIS) vegetation map from satellite photographs. Our findings suggest that at least three-quarters of the golden eagles frequenting the WRA vicinity in winter are yearround residents of the Diablo Range.

Three (11\%) of the 26 itinerant subadults and floaters died during 1994: one from lead poisoning and two from collisions with wind turbines. One of the five breeders was killed in its territory by another eagle. We recorded no fatalities among the tagged sample of 25 juveniles, but we censored two transmitters early on; one detached from the eagle and the other malfunctioned, leaving a sample of 23 tagged juveniles. Of these, two left the study area and another may have had a failed transmitter. The remaining 20 birds were alive in or near the study region in December 1994, most within $30 \mathrm{~km}$ of the WRA.

Determining the population significance of turbine-related mortality will require an increased sample of radio-tagged eagles, several more years of monitoring survival, and knowledge of the reproductive rate. To the latter end, we conducted a nest search in the area within $30 \mathrm{~km}$ of the WRA boundary. In all, we observed pairs at 54 locations, but some were on private property and could not be closely observed. We were able to locate and record the activities of eagles at 37 nesting territories. Eagles laid eggs at $32(86 \%)$ of these. Three pairs failed in the egg 
stage, and the remaining 29 pairs fledged 47 young. Rates of reproductive success, brood size, and productivity per occupied nest compared favorably with those of ten populations of golden eagles studied elsewhere in North America and Europe. In an $820 \mathrm{~km}^{2}$ section of oak savanna where we were given access to conduct a detailed survey, we calculated a density of one pair per $22 \mathrm{~km}^{2}$, a value among the highest recorded for the species.

We identified 339 prey items from collections made at golden eagle nests in the study area. The only prey species common to every pair was the California ground squirrel (Spermophilus beecheyii). It represented 69 percent of prey numbers and 64 percent of prey biomass identified from remains. The second most important species was the black-tailed jackrabbit (Lepus californicus) at eight percent biomass; the third was the black-tailed deer (Odocoileus hemionus) at six percent. In all, mammals accounted for 92 percent of prey biomass, followed by seven percent birds, and one percent reptiles. These proportions reflect very closely the food habits of breeding eagles studied in other parts of North America.

To investigate the occurrence and behavior of golden eagles within the WRA we conducted weekly ground-based surveys from late May through November during which we recorded all sightings and activities of eagles. Routine examination of 4,543 turbine towers of 21 types yielded 249 sightings of golden eagles of which 155 were flying and 94 were perched; 23 of these were on turbine towers, all of the lattice-type. The ground-based data suggest that an average of 14-17 eagles occupied the WRA during the months of survey, while the aerial telemetry surveys point to a considerable flux in individual tenure. Both tagged and untagged eagles were most commonly recorded in the northwestern and southern extremes of the WRA. A comparable ground survey conducted on an adjacent area of grassland without turbines revealed a higher average density of eagles. 


\section{TABLE OF CONTENTS}

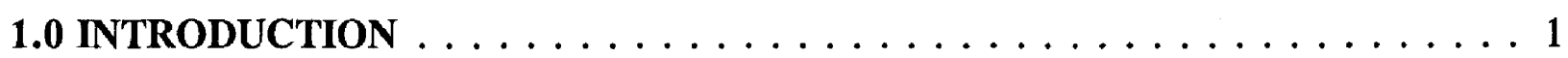

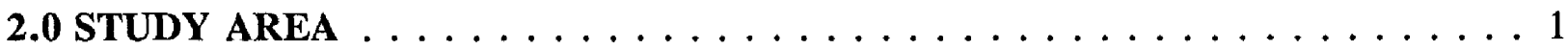

3.0 THE GOLDEN EAGLE: BACKGROUND INFORMATION . . . . . . . . . 8

3.1 Natural History of Golden Eagles . . . . . . . . . . . . . . . 8

3.2 Population Ecology of Golden Eagles ... . . . . . . . . . . 25

4.0 STRATEGY FOR DETECTING A POPULATION IMPACT . . . . . . . . . . 32

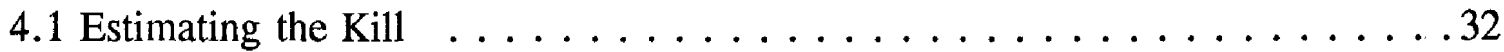

4.2 Identifying the Population(s) Potentially Impacted . . . . . . . . . . 33

4.3 Estimating Natality . . . . . . . . . . . . . . . . . . . . . . . . . . . . . . .

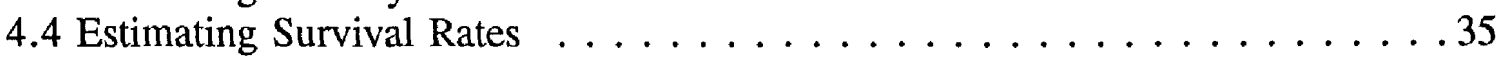

4.5 Assembling a Life Table . . . . . . . . . . . . . . . . . . . . . . .

5.0 IDENTIFYING POPULATIONS POTENTIALLY IMPACTED . . . . . . . . 36

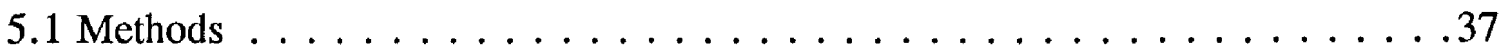

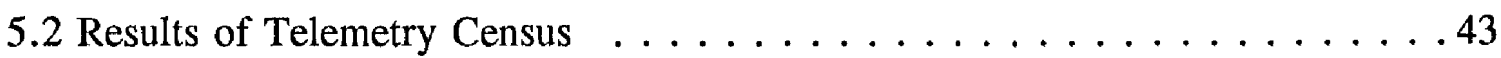

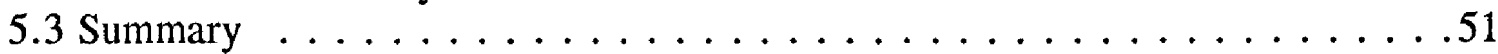

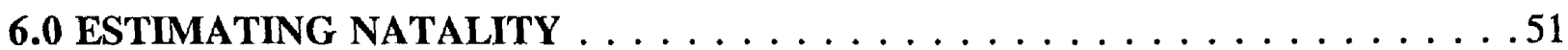

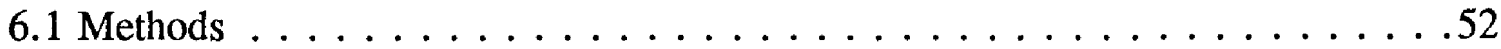

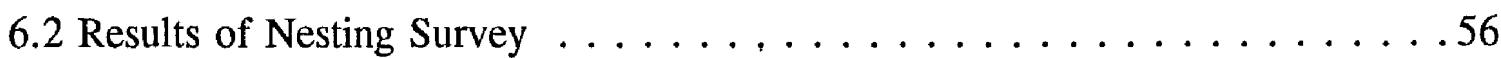

6.3 Estimating the Cohort in the $30-\mathrm{km}$ Zone . . . . . . . . . . . . . 61

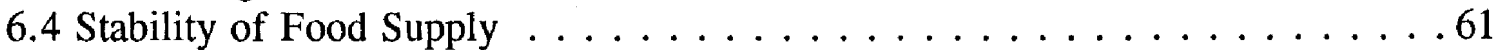

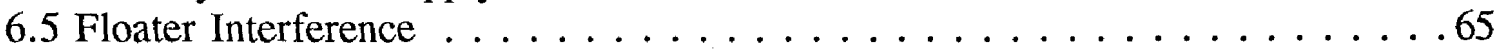

7.0 ESTIMATING SURVIVAL $\ldots \ldots \ldots \ldots \ldots$

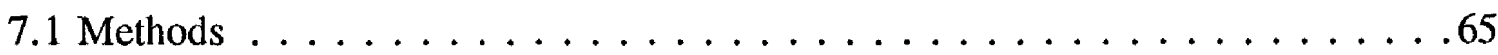

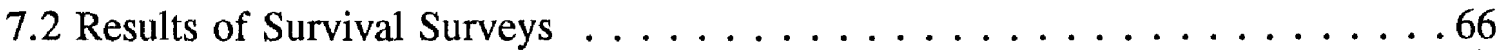

7.3 Emigrants or Fatalities? . . . . . . . . . . . . . . 68

7.4 Preliminary Estimate of Survival Rates . . . . . . . . . . . . . 69

8.0 ESTIMATING A POPULATION IMPACT $\ldots \ldots \ldots \ldots \ldots \ldots \ldots$

8.1 What We Have Learned . . . . . . . . . . . . . . . . . . . . . . . .

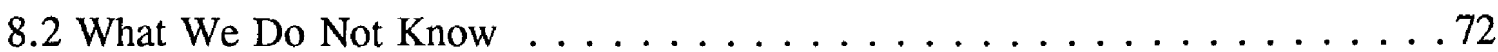

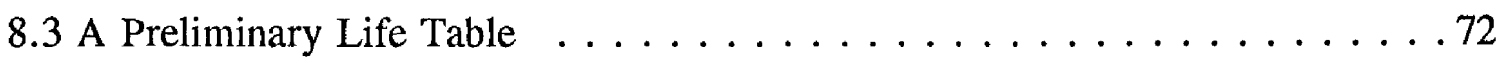


TABLE OF CONTENTS (continued)

9.0 GOLDEN EAGLE OCCURRENCE IN THE WRA $\ldots \ldots \ldots \ldots \ldots . \ldots 74$

9.1 Sighting of Eagles in the WRA . . . . . . . . . . . . . .74

9.2 Movements of Breeders in Relation to the WRA . . . . . . . . . . .991

9.3 Movements of Subadults, Floaters, and Juveniles in Relation to the WRA . . 93

10.0 PRELIMINARY MANAGEMENT RECOMMENDATIONS . . . . . . . . 98

11.0 PLANS FOR CONTINUED RESEARCH $\ldots \ldots \ldots \ldots$. . . . . . . . . 99

ACKNOWLEDGEMENTS $\ldots \ldots \ldots \ldots \ldots \ldots$. . . . . . . . . . . . 100

APPENDICES

APPENDIX A: GLOSSARY $\ldots \ldots \ldots \ldots \ldots 1$

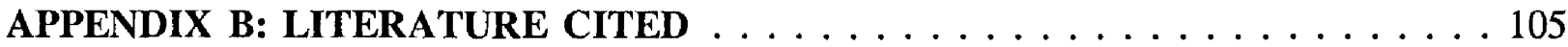

APPENDIX C: FORMS USED IN DATA COLLECTION $\ldots \ldots \ldots \ldots$

APPENDIX D: PREY ITEMS IDENTIFIED FROM 20 GOLDEN EAGLE NESTS 137

APPENDIX E: RELOCATIONS OF 4 RADIO-TAGGED BREEDERS … . . . 149

APPENDIX F: RELOCATIONS OF 7 RADIO-TAGGED FLOATERS $\ldots \ldots \ldots 155$

APPENDIX G: RELOCATIONS OF 20 RADIO-TAGGED SUBADULTS $\ldots \ldots 163$

APPENDIX H: DISPERSAL OF 22 RADIO-TAGGED JUVENILES . . . . . . . . 185

APPENDIX I: HOW WE ESTIMATED THE PROPORTION OF FLOATERS . . . 209 


\section{LIST OF TABLES}

Table 3.1 Summary of principal prey species identified in golden eagle studies throughout their range $\ldots \ldots \ldots \ldots \ldots \ldots \ldots \ldots$

Table 3.2 Comparison of nesting density for 27 golden eagle studies in the western United States, Scotland, and Sweden . . . . . . . . . 28

Table 5.1 Information on 32 golden eagles radio-tagged at or near Altamont Pass in $1994 . \ldots \ldots \ldots$. . . . . . . . . . . . . . . . . . . . 39

Table 5.2 Tenure and status of 11 radio-tagged adult golden eagles in the Diablo Range study area . . . . . . . . . . . . . . . . 44

Table 5.3 Tenure of 21 radio-tagged subadult golden eagles in the Diablo Range . . 46

Table 5.4 Tenure of 25 radio-tagged juvenile golden eagles in the Diablo Range . . . 49

Table 6.1 Golden eagle productivity at breeding areas within about $30 \mathrm{~km}$ of the

Table 6.2 Comparison of productivity for 11 golden eagle populations in the western United States, one in Scotland, and one in Sweden . . . . . . . 60

Table 6.3 Number and estimated biomass (grams) of prey identified from remains collected in 20 golden eagle nests in $1994 \ldots \ldots$. . . . . . . . . 64

Table 8.1 Floater numbers (at equilibrium) change to similar values when the survival rate is reduced by three percent for adults and thirteen percent for juveniles. . . . . . . . . . . . . . . 75

Table 9.1 Ground squirrels per $\mathrm{km}$ and golden eagles per $\mathrm{km}^{2}$ per road survey in the WRA, 20 June through 24 August $1994 \ldots \ldots$. . . . . . . . . 83

Table 9.2 Observations of golden eagles perching on Kenetech wind turbines, 23 May through 23 November $1994 \ldots \ldots$. . . . . . . . . . 86

Table 9.3 Observations of red-tailed hawks perching on Kenetech and nonKenetech wind turbines, 23 May through 12 November 1994 . . . . . . 87

Table 9.4 Observations of red-tailed hawks perching on sixty-foot Kenetech wind turbines, 23 May through 12 November $1994 \ldots \ldots$. . . . . . . 88

Table 9.5 Perchability indices of wind turbine tower types based on perching observations of red-tailed hawks and golden eagles . . . . . . . . 89

Table 9.6 Summary of range movements recorded during eight radio-tracking days of the breeding adult female golden eagle (AF03) at the Morgan Territory nesting area $\ldots \ldots \ldots \ldots \ldots \ldots$ 


\section{LIST OF FIGURES}

Figure 2.1 Topographical features of the Diablo Range $\ldots \ldots \ldots \ldots \ldots$. . . . 2

Figure 2.2 Vegetation types: Diablo Range Study Area $\ldots \ldots \ldots \ldots \ldots$

Figure $3.1 \quad$ Age structure in stable and unstable populations . . . . . . . . . 30

Figure 5.1 Capture locations of 11 adults and 2.1 subadults radio-tagged in $1994 \ldots 38$

Figure 5.2 Relocations of 7 floaters in the Diablo Range, Jan-Oct 1994 . . . . . . . 45

Figure 5.3 Relocations of 19 subadults in the Diablo Range, Jan-Oct 1994 . . . . . . 47

Figure 5.4 Relocations of 22 juveniles in the Diablo Range, Jun-Oct 1994 . . . . . 50

Figure 6.1 Locations of occupied breeding territories in $1994 \ldots \ldots \ldots 7$

Figure 9.1 Road survey segments in the WRA . . . . . . . . . . 76

Figure 9.2 Sightings of golden eagles during road surveys in the WRA, May-Nov 1994 . . . . . . . . . . . . . . . . . . . . . . . . . . 81

Figure 9.3 Number of golden eagles and red-tailed hawks observed per $\mathrm{km}^{2}$ per road survey, 23 May through 23 November $1994 \ldots \ldots$. . . . . 82

Figure 9.4 Golden eagle kills at Kenetech turbines in 1993 and 1994) . . . . . . . 84

Figure 9.5 Relocations of 19 radio-tagged subadults in the WRA vicinity, Jan-Oct 1994 . . . . . . . . . . . . . . . . . . . . . . . . . . . . .94

Figure 9.6 Relocations of 7 radio-tagged floaters in the WRA vicinity, Jan-Oct 1994 . . . . . . . . . . . . . . . . . . . . . . . . . . 95

Figure 9.7 Relocations of radio-tagged juveniles in the WRA vicinity, Jun-Oct $1994 \ldots \ldots$. . . . . . . . . . . . . . . . . . . . . 96

Figure 9.8 Relocations of eagles tagged at Site 300, Jan-Oct $1994 \ldots \ldots 9$ 


\subsection{INTRODUCTION}

Orloff and Flannery (1992) estimated that several hundred raptors are annually killed by turbine collisions, wire strikes, and electrocutions at the Altamont Pass Wind Resource Area (WRA). The most common fatalities were those of red-tailed hawks (Buteo jamaicensis), American kestrels (Falco sparvarius), and golden eagles (Aquila chrysaetos), with lesser numbers of turkey vultures (Cathartes aura), common ravens (Corvus corax), barn owls (Tyto alba), and others. The numbers of discovered fatalities among certain species did not always correspond to their observed abundance in the WRA. Although Orloff and Flannery witnessed no turbine strikes, they believed that the tendency of hawks and eagles to dive directly on prey rendered them more vulnerable to collisions with structures than did the more tentative scavenging flights of turkey vultures and ravens.

Among the species of raptors killed at Altamont Pass, the one whose local population is most likely to be impacted is the golden eagle. Besides its being less abundant than the others, the breeding and recruitment rates of golden eagles are naturally slow, increasing their susceptibility to decline as a result of mortality influences. Golden eagles are a species of special concern in California (California Department of Fish and Game 1992), and reductions have been documented in the southern part of the state (Harlow and Bloom 1987). Moreover, the golden eagle is a species afforded special federal protection because of its inclusion within the Bald Eagle Protection Act as amended in 1963. There are no provisions within the Act which would allow the killing ("taking") of golden eagles by WRA structures.

This report, in partial fulfillment of National Renewable Energy Laboratory (NREL) Subcontract No. XCG-4-14200, details the results of field studies conducted during 1994 ${ }^{1}$. The primary purpose of the investigation is to lay the groundwork for determining whether or not turbine strikes and other hazards related to energy at Altamont Pass may be expected to affect golden eagles on a population basis. We also seek an understanding of the physical and biotic circumstances which attract golden eagles to the WRA within the context of the surrounding landscape and the conditions under which they are killed by wind turbines. Such knowledge may suggest turbine-related or habitat modifications that would result in a lower incidence of eagle mortality.

\subsection{STUDY AREA}

The study area, defined by the movements of golden eagles we radio-tagged near the WRA, is bounded to the north by the Sacramento River Delta, to the east by the San Joaquin Valley, to the west by San Francisco Bay or, more accurately, by the urban area extending from Berkeley to San Jose, and to the south by State Highway 152 between Morgan Hill and San Luis Reservoir. Below, we describe the area in terms of topography (Fig. 2.1), vegetation (Fig. 2.2),

\footnotetext{
${ }^{I}$ KENETECH Windpower provided start up funding during January and February 1994. NREL support began March 1, 1994.
} 


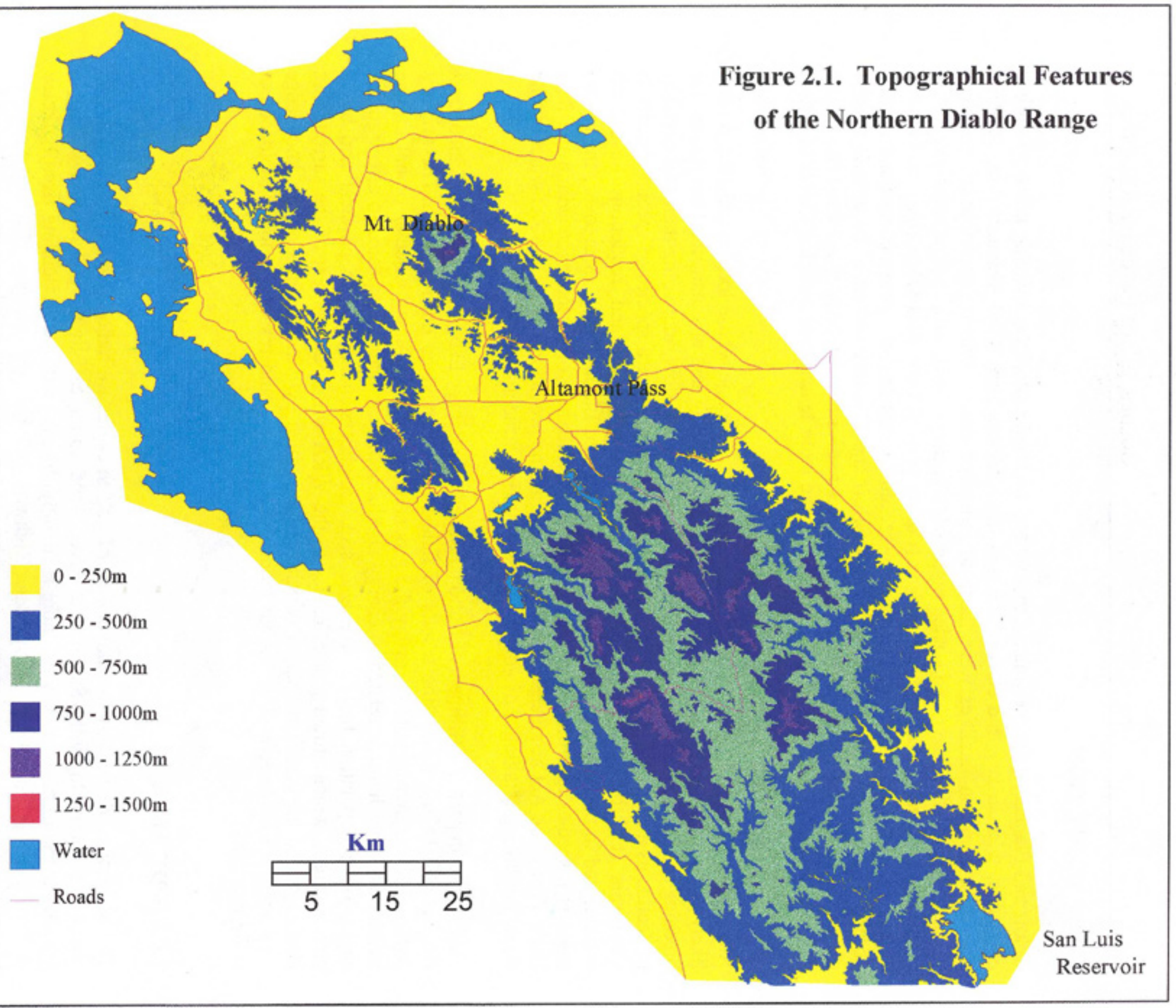




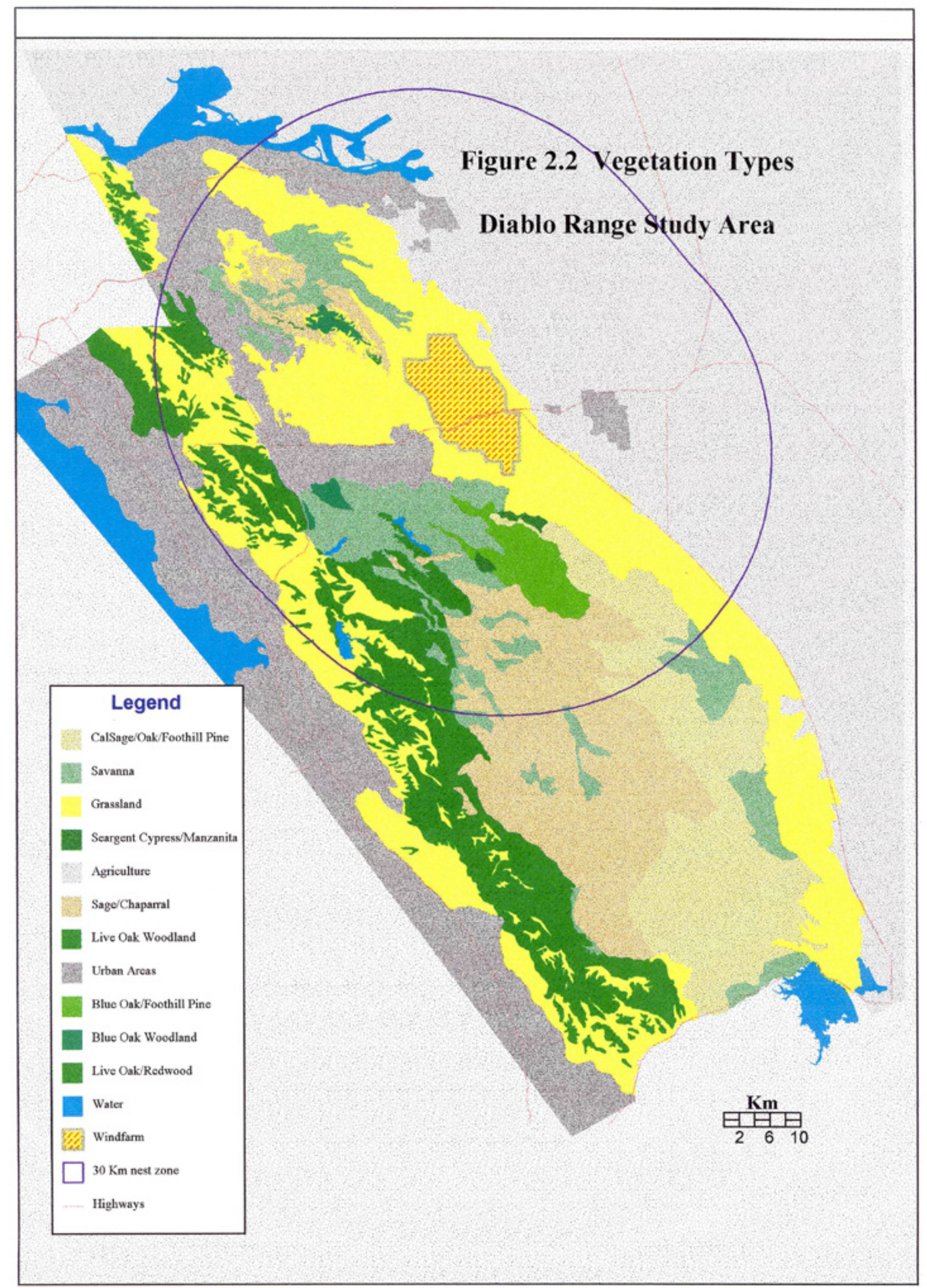


human population density, property ownership, and land use.

The WRA itself (ca. $189 \mathrm{~km}^{2}$ ) is an area of gently rolling hills, with elevations less than $500 \mathrm{~m}$. It is primarily grassland, composed almost entirely of European annual grasses growing in compacted soils, with occasional stands of oak, eucalyptus, and buckeye. Human density is sparse, with privately owned ranches scattered and widely spaced; the land is grazed by cattle and punctuated with rows of about 6,500 wind turbines.

To the east of the WRA, the grassland slopes gradually down to the San Joaquin Valley, which is essentially flat, at an elevation of less than $200 \mathrm{~m}$. The valley is almost entirely agricultural, with scattered towns.

Extending north from the WRA to Antioch, and east of Mt. Diablo State Park, is a region of gently rolling hills. The habitat is primarily grassland with scattered stands of oak and eucalyptus and a few small orchards. Human density is fairly low, with privately owned ranches more closely spaced than in the WRA. Black Diamond Mines Regional Park, managed by the East Bay Regional Park District (EBRPD) and the Concord Navy Base are situated in this region. Most of the area is grazed by cattle.

To the northwest of the WRA is a region typified by a series of ridges running from northwest to southeast. The southwest-facing slopes are largely grassland, while those facing northeast are primarily blue oak (Quercus douglasii) savanna and woodland. The land is composed of privately owned ranches with one large parcel to the south (Los Vaqueros) owned by the Contra Costa Water District (CCWD). Almost all of this area is under pastoral use.

Further to the northwest is Mt. Diablo State Park with considerably steeper slopes, and peaks exceeding $1000 \mathrm{~m}$. Habitats are diverse and include blue and live oak (mainly Q. agrifolia) woodland, chaparral, sage scrub, savanna, and grassland. Property in this sparsely-inhabited area is owned and managed by EBRPD (Morgan Territory Regional Park), the Walnut Creek Open Spaces District, and by private entities. Land use is both recreational (hiking, horseback riding, and mountain biking) and pastoral.

To the north and west of Mt. Diablo are the urban centers of Concord and Walnut Creek. Further west, between highways 580 and 680 , are rolling hills with a mosaic of live oak/bay/redwood woodland and grassland. There are relatively few people. The land is owned by EBMUD (San Leandro Reservoir), EBRPD (Las Trampas) and private entities. Some of the area is used recreationally, and cattle grazing is widespread.

The Livermore Valley lies to the west of the WRA. North of the town of Livermore is the Tassajara grassland region composed of rolling hills, with sparsely scattered stands of oak and eucalyptus, and elevations of less than $250 \mathrm{~m}$. The human population is low to moderate, but increasing. All the land is privately owned, with many cattle ranches, but also smaller properties owned by commuters. Livermore is a town of 63,000 people, and nearby Pleasanton supports 55,000; both are growing. 


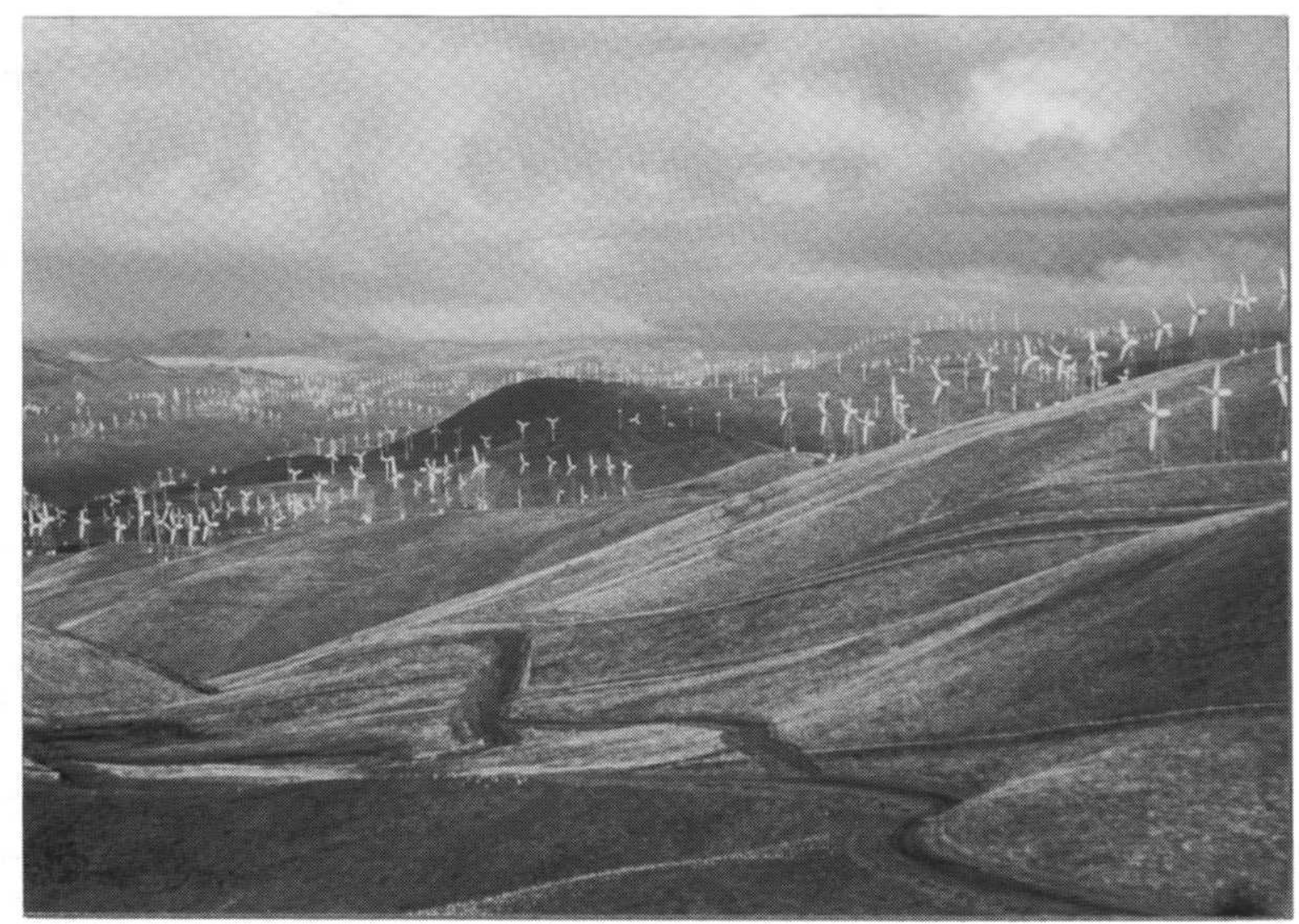

The Altamont Pass Wind Resource Area (photo by Daniel Driscoll)

Just south of Livermore is a relatively unpopulated region of rolling hills, increasing in altitude as one moves south into the Diablo Range. The area is mainly valley oak and blue oak savanna with three reservoirs: Del Valle, San Antonio and Calaveras. The land is managed by large, private ranches (e.g., Patterson), San Francisco Water District (SFWD), and EBRPD. There is recreation around Del Valle Reservoir and the area is grazed.

South of Livermore Valley lies the Diablo Range, a large, sparsely inhabited mountainous region bounded to the east by the San Joaquin Valley, to the west by San Jose and the Salinas Valley, and to the south by Highway 152 . It covers an area of roughly $3,500 \mathrm{~km}^{2}$ and contains several peaks over $1000 \mathrm{~m}$, with Mount Hamilton the tallest at 1,300 m. The northern portion of the range supports blue oak/foothill pine (digger pine, Pinus sabianiana, and Coulter pine, $P$. coulteri) and a small area of serpentine formation (Cedar Mountain) dominated by Sargent cypress (Cupressus sagentii) and manzanita (Arctostaphylos sp.). An expanse of coast live oak/bay (Umbellularia californica) woodland, with scattered grassland extends from north to south along the western part of the range. The central portion is primarily covered with black sage (Salvia mellifera) and chaparral, with scattered areas of oak savanna. To the east, as elevation declines and the hills become drier, California sagebrush (Artemesia californica) is 
dominant, with occasional blue oak and foothill pine. Further east are regions of blue oak savanna, followed by grassland. Much of the Diablo Range is under private ownership, primarily by large cattle ranches (for example, the N3 Ranch occupies ca. $162 \mathrm{~km}^{2}$ ). A large portion to the north is owned by the EBRPD (Sunol Regional Park and Ohlone Wilderness), and to the south lies the extensive Henry Coe State Park. Most of the range is grazed by cattle.

While performing our nest surveys and tracking radio-tagged eagles, we identified a number of general habitat categories in and around the Diablo range. We have subdivided these into more specific vegetation categories in Figure 2.2. In characterizing these general habitats we concentrated primarily on vegetational structure rather than plant species composition. The reason for this is that habitat structure directly influences prey vulnerability; specifically, golden eagles forage most effectively in open landscapes. In describing the habitat categories below, we comment on their apparent suitability for eagles.

1) Oak Savanna, being grassland with scattered trees, is unquestionably the preferred habitat for nesting golden eagles in the area. Characteristics include California ground squirrel (Spermophilus beecheyii) colonies and a variety of suitable nest trees and views of the surrounding landscape. Our surveys suggest that nesting eagles achieve their highest densities in savanna habitats.

2) Open Grassland is generally unsuitable for eagle nests because of the lack of trees to support them. However, it provides the archetypal foraging habitat for this species. One of the eagle pairs we observed nested successfully on a transmission tower situated in open grassland.

3) Woodlands contain denser aggregations of trees than is typical of savanna and probably support lower densities of nesting eagles. Although California ground squirrels may achieve high densities in oak woodland, the more enclosed nature of woodlands reduces prey visibility and opportunities for low level hunting flights ("contour hunting"), the eagle's dominant foraging mode in this region. Differences between savanna and woodland are often indistinct; for example, savanna, prevalent at lower elevations, typically grades into woodland on the slopes south of Livermore. Another feature bearing upon eagle nesting distribution is that high ridges surrounded at lower elevations by fairly dense woodland may themselves be exposed grasslands, highly suitable for eagle foraging. Types of woodland in the Diablo Range include blue oak, blue oak/foothill pine, coast live oak, canyon/interior live oak, and valley oak woodland. The relatively moist north- and northeast-facing slopes and canyon bottoms are wooded while the drier hilltops and south- to southwest-facing slopes may be grassy or covered with sage scrub.

4) Woodland Bordering Grassland appears to be important to eagles. Our observations suggest that eagles nest more consistently in woodlands on the edges of open grasslands than in woodlands without access to grasslands. In the future, we should probably refer to woodland within an arbitrary five $\mathrm{km}$ of open grasslands or savanna as a specific habitat category. 


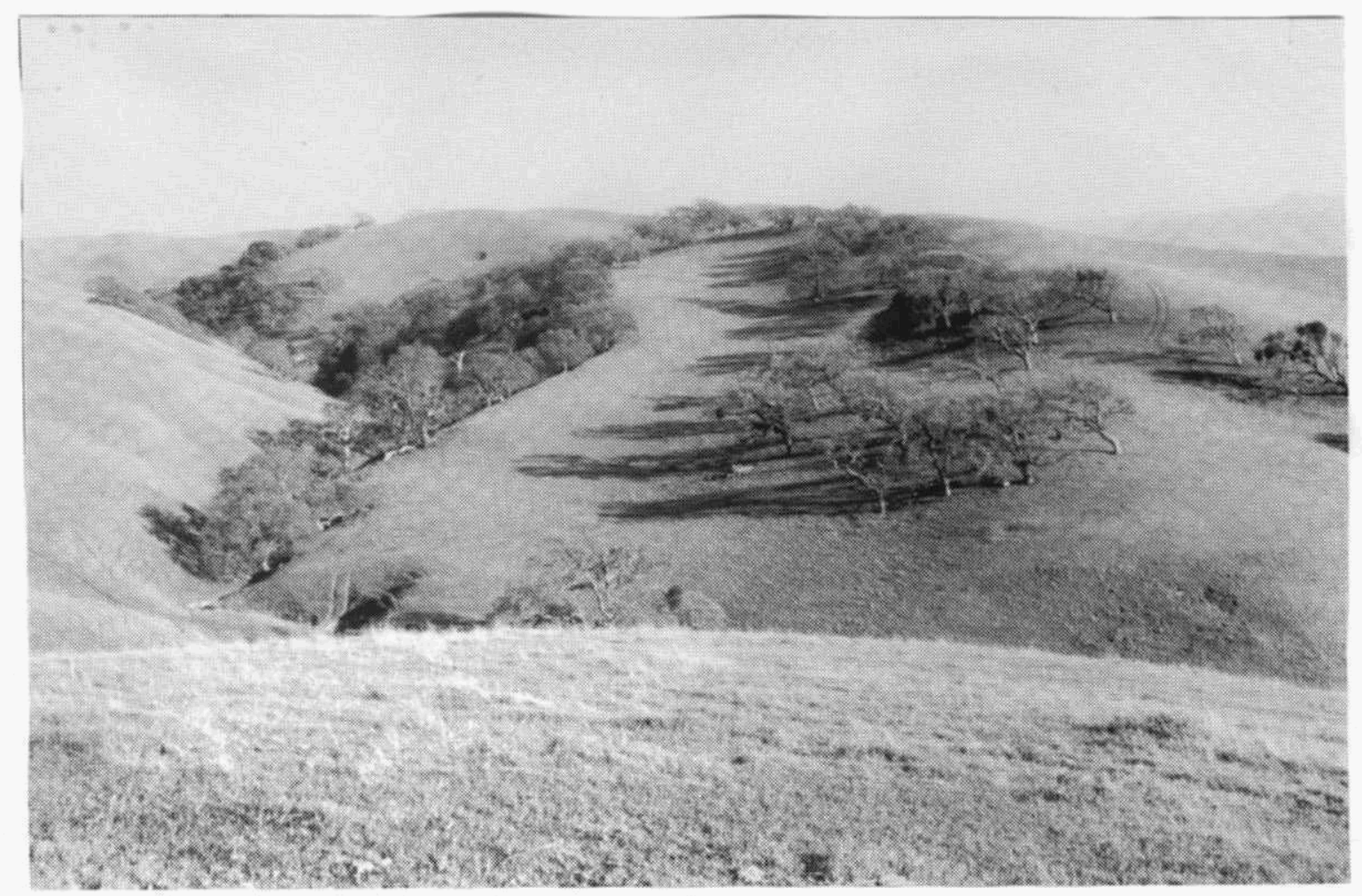

Oak Savanna near San Antonio Reservoir (photo by John Gilardi)

5). Chaparral/ Scrub offers relatively little opportunity for eagles to forage and contains few suitable nesting structures. Chaparral is a dense, frequently impenetrable thicket of broad leaved, sclerophyllic ("hard-leaved", in reference to the hard, stiff, thick, heavily cutinized, and generally evergreen nature of the leaves) shrubs, usually of 1-2 $\mathrm{m}$ in height and occasionally attaining $3 \mathrm{~m}$. Typical species include chamise (Adenostomata fasciculatum), toyon (Heteromeles arbutifolia), Ceanothus spp., coyote brush (Baccharis pilularis), manzanita (Arctostaphylos spp.), scrub oak (Quercus dumosa) and poison oak (Rhus diversiloba). Sage scrub is generally less dense than chaparral, and composed of smaller shrubs, generally less than $1.5 \mathrm{~m}$ tall. Typical species include California sagebrush, black sage, coyote brush, yerba santa (Eriodycton californicum) and monkey flower (Mimulus spp.).

6.) Other habitats within the study area include urban and agricultural areas. Neither are suitable for eagle nesting, although, in one case, there is an eagle nest in a narrow strip of savanna surrounded on three sides by tract houses. 


\subsection{THE GOLDEN EAGLE: BACKGROUND INFORMATION}

The genus Aquila (Family Accipitridae) contains nine species, only one of which, the golden eagle ( $A$. chrysaetos), inhabits the western hemisphere. Other species include the tawny or steppe eagle (A. rapax) breeding in Africa and Asia, the imperial eagle (A. heliaca) in Eurasia, the lesser spotted eagle (A. pomarina) in Europe, the greater spotted eagle $(A$. clanga) primarily in Asia, Wahlberg's eagle (A. wahlbergi) and Verreaux's or black eagle (A. verreauxi) in Africa, Gurney's eagle (A. gurneyi) in New Guinea, and the wedge-tailed eagle (A. audax) in Australia (Brown and Amadon 1968). The golden eagle breeds throughout most of North America and Eurasia, south to Morroco.

The breeding range of golden eagles in North America extends from northern Alaska and Canada southward through the mountainous regions to central Mexico and western Texas (Boeker and Ray 1971, Berns 1979). The estimated number of breeding pairs of golden eagles in the United States is 17,514 pairs (Phillips and Blom 1988). Murphy (1977a) estimated the wintering population in the western states at 40,000 birds; Olendorff et al. (1981) estimated over 60,000 . Hamerstrom et al. (1975, in Harlow and Bloom 1987) estimated a total population of 100,000 golden eagles for all of North America.

\subsection{Natural History of Golden Eagles}

Golden eagles are among the largest birds of prey, with wingspans reaching $2.3 \mathrm{~m}$ and weights approaching $7 \mathrm{~kg}$. As in most raptors, females are substantially larger than males. Fourteen females we captured near the WRA in winter averaged $5.0 \mathrm{~kg}$ (range $4.4-6.2 \mathrm{~kg}$ ) while 17 males averaged $3.7 \mathrm{~kg}$ (range $3.2-4.5 \mathrm{~kg}$ ), a difference of 26 percent. The size distinction between the eagle sexes most likely relates to their divergent roles during the breeding season. Until the young are half-grown, the female guards the nest while the male provides food. The larger size of the female increases her effectiveness in brooding and nest defense, while the foraging capability of the smaller male is enhanced by his ability to carry larger prey relative to his own weight and to achieve higher rates of acceleration.

Golden eagles do not acquire adult plumage until their fifth calendar year of life. Coloration of all age classes is primarily dark brown, but juveniles may be much darker than older eagles and are characterized by conspicuous patches of white in the upper half of the tail and in the wing at the carpal joint, although the latter characteristic may be subdued in some populations. During the first four years of life, the white areas gradually disappear through successive annual molting, the latter process being incomplete in any one year so that feathers of several different growth-years are being replaced simultaneously. The resulting, somewhat complex pattern of molt allows for accurate age determination of eagles (in hand) four years old and younger and allows observers in the field to distinguish between juvenile, subadult, and adult eagles. From a distance, the latter appear entirely brown with a golden tinge at the nape. 


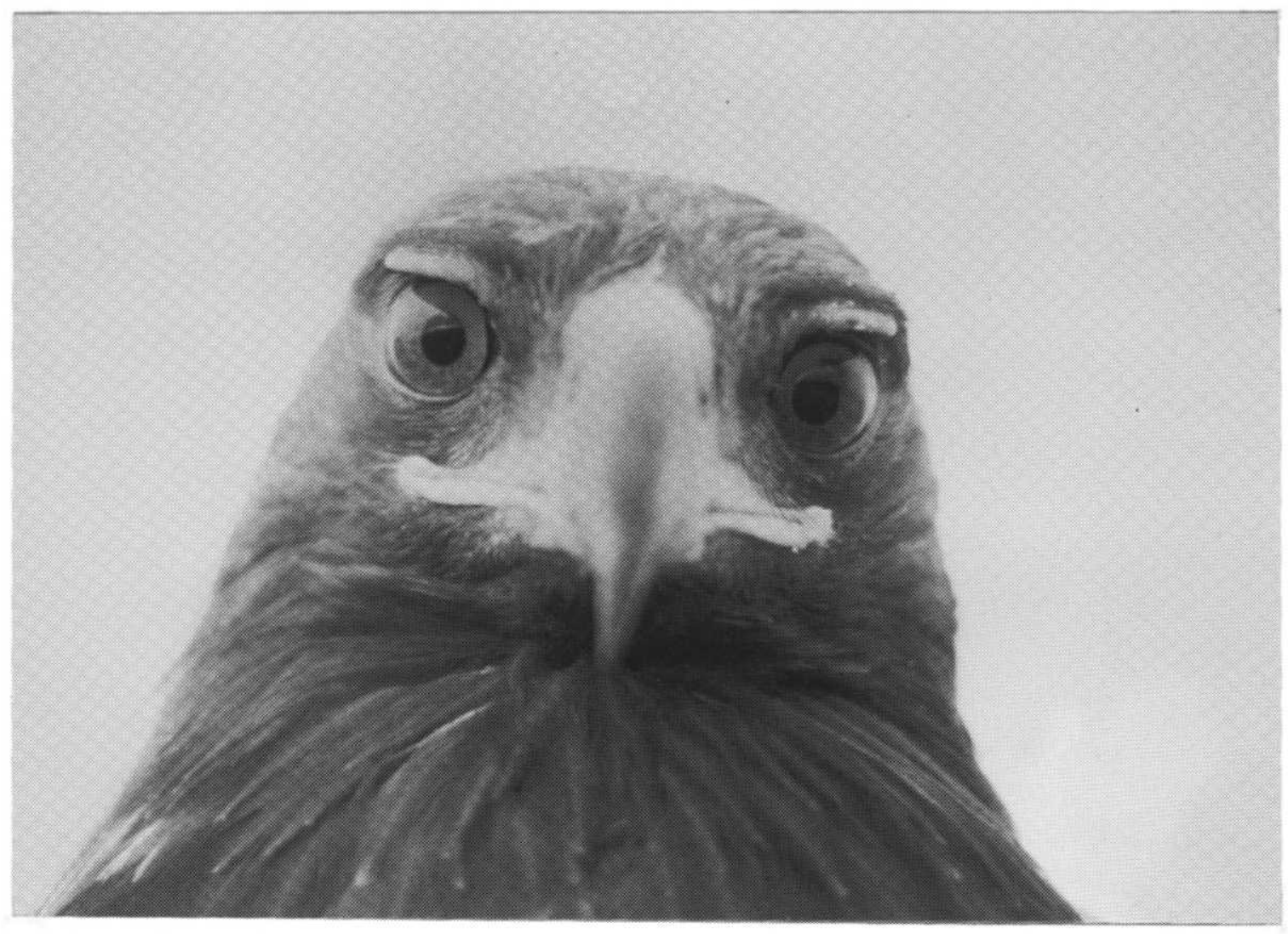

Golden Eagle (photo by Daniel Driscoll)

3.1.1 Habitat. Golden eagles prefer open, tilted landscapes in which to find and pursue their predominantly mammalian prey. In the western United States, eagles inhabit mountains and foothills, desert plateaus, and arid basins. In Scotland, eagles live in open mountains and moorlands, characterized by short vegetation, and avoid closed canopy woodland, open water, and improved farmland close to habitation (Watson et al. 1992a). Large open areas created by clearcuts in historically forested western Washington were recently colonized by nesting golden eagles (Bruce et al. 1982). Drinking and bathing sites may be a critical component of territories in arid country (Charlet and Rust 1991). Thompson et al. (1982) found that eagles were more productive when nesting adjacent to wetlands; these attracted prey in arid southeast Oregon.

Golden eagles in the interior central Coast Ranges of California utilize primarily grazed grasslands, open shrublands, and rolling oak savanna habitat (Estep and Sculley 1989). Because of increasing urbanization, much of the remaining golden eagle habitat in central and southern California lies in "islands" of relatively inaccessible mountainous country, primarily private ranches used for livestock grazing (Thelander 1974). 
Some golden eagle populations nest exclusively on cliffs (West Norway - Bergo 1984a, Northwest Territories - Poole and Bromely 1988). Other populations nest mostly on cliffs (93\% in eastern New Mexico/western Texas - Boeker and Ray (1971); 87\% in Utah - Camenzind (1969); 96\% in Scotland - Watson and Dennis (1992); 97\% in Alaska - Ritchie and Curatolo (1982); 62\% cliffs, 29\% Douglas-fir trees in Montana - McGahan (1968). Still other populations nest mostly in trees (82\% trees in central California - Carnie (1954); $92 \%$ Douglasfir trees in Western Washington - Bruce et al. (1982); $96 \%$ in pines, cottonwoods, and snags in Montana/Wyoming - Phillips et al. (1990); 86\% trees in NE Wyoming - Menkens and Anderson (1987)). Most European populations are found nesting on cliffs; however, nests in trees are the majority in Sweden, Finland, the former Czechoslovakia, and the Baltic States (Watson and Dennis 1992). Golden eagles probably prefer nesting on cliffs, where available, because of updrafts and defensibility. For example, eagles nest on cliffs in northern Saskatchewan and avoid trees, even though suitable nesting trees are prevalent (Houston and Wylie 1985); where cliffs are not available in the forested regions of Sweden, eagles nest mostly in pine trees (Tjernberg 1985).

Cliffs chosen by eagles are generally tall (100-200 m height - Bergo 1984a, 12-92 m - Carnie $1954)$, and nests are usually placed in the upper portion. Golden eagles occasionally nest on the ground (e.g. in old ferruginous hawk nests) and in artificial structures (Camenzind 1969), including transmission line towers. When nesting in trees, eagles select dominant or codominant trees in the nesting stand, and usually place the nest in the upper third of the tree (Menkens and Anderson 1987). Trees used as nests in California include foothill pine, ponderosa pine, oak spp., eucalyptus, sycamore, and cottonwood (Sumner 1929b, Dixon 1937, Connolly et al. 1976, Schlorff 1986). Cliff nesting habitat is uncommon in the interior Coast Ranges of California (Estep and Sculley 1989). Golden eagle nests in trees and on cliffs tend to be smaller than those of bald eagles (Haliaeetus leucocephalus) (Bruce et al. 1982, Grubb and Eakle 1987).

Golden eagle pairs often construct alternate nests ( $\mathrm{n}=1-8$, Bergo 1984a; $\mathrm{n}=0-3$, Phillips et al. 1990), and they repair and maintain these supernumerary nests until eggs are laid (McGahan 1968). Eleven of 21 Utah pairs had more than one nest located from $25 \mathrm{~m}$ to $2 \mathrm{~km}$ apart (Camenzind 1969). Regarding usage of alternates, habits of individual pairs vary greatly; some pairs use the same nest year after year, even while continuing to maintain several alternates (Boeker and Ray 1971).

Nests of studied populations often show preferred directional orientation, or at least avoidance of particular compass directions. These differences are probably explained best as temperaturedependent nest-site selection, operating to reduce effects of thermal stress on nestlings (Mosher and White 1976). Examples include: avoidance of northerly orientation in Norway related to delayed snow melt (Bergo 1984a); avoidance of southern exposure in Scotland possibly to avoid overheating nestlings (Watson and Dennis 1992); 55 percent western orientation in Utah (Camenzind 1969); predominantly southeast-facing orientation (probably temperature-dependent) in interior Alaska (Ritchie and Curatolo 1982); non-northerly in Northwest Territories (Poole and Bromley 1988). 


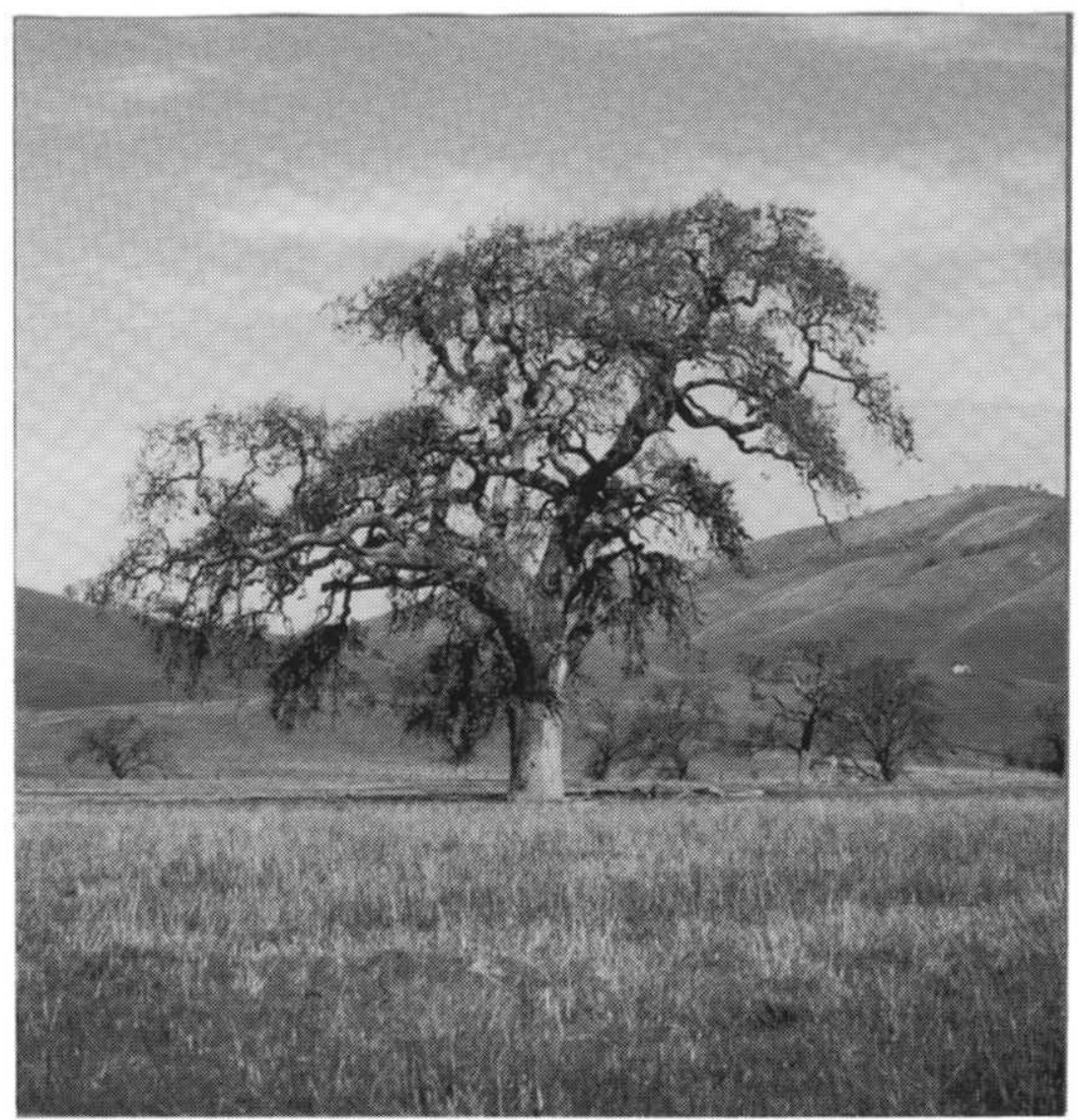

Valley oak (photo by John Gilardi)

Human development has impacted portions of the golden eagle's historical range throughout the world. In Scotland, extensive afforestation (i.e., planting even-aged stands of exotic conifers) reduced the availability of eagle foraging habitat (Marquiss et al. 1985, Watson 1992). When eagles do hunt wooded terrain, they concentrate on openings between stands of trees, openings which are not available in nursery stands. Extensive agricultural projects tend to decrease prey populations (e.g., jackrabbit densities, Beecham and Kochert 1975); Craig et al. (1986) showed that eagles wintering in southeast Idaho preferred native shrub-steppe habitats over converted farmlands.

Since the late 1970s, the number of occupied golden eagle territories in the Snake River Birds of Prey Area (SW Idaho) has declined from a maximum of 35 territories to 28 territories occupied in 1993 (Lehman et al. 1993). Some of the territories have been vacant for more than 11 years and are presumed lost; however, three new territories emerged with nests associated with transmission line towers (only one of these is consistently active). The overall net loss in golden eagle nesting territories is apparently linked to loss of foraging habitat through wildfire 
and conversion to agriculture. Wildfire has changed the native shrub-steppe vegetation to grassland dominated by cheatgrass and other exotics, with correspondingly lower jackrabbit densities (Lehman et al. 1993).

Effects of livestock grazing in the west may be beneficial because moderate grazing tends to stimulate net primary production of herbaceous foods utilized by jackrabbits, cottontails, and ground squirrels (Kochert 1987). Grazing also favors prey species that require low cover, and generally increases the vulnerability of prey to golden eagles.

3.1.2 Food Habits. Prey species reported from studies of nesting golden eagles are generally of wide variety (Carnie 1954, Olendorff 1976); however, the bulk of food almost always comes from a few predominant mammalian species (Table 3.1). Olendorff (1976) compiled data from published North American golden eagle food habits studies conducted primarily during the nesting season throughout North America. In his overall sample of 7,094 prey items, 83.9 percent were mammals and 14.7 percent were birds. More specifically, he reported the frequency of various prey groupings in the eagle diet as follows: rabbits and hares (leporids; $54.0 \%$ ), marmots, ground squirrels and prairie dogs (sciurids; $21.8 \%$ ), game birds $(8.0 \%$ ), hooved mammals $(4.4 \%)$, passerine birds $(3.2 \%)$, deer $(1.9 \%)$, domestic livestock (1.4\%), mammalian predators $(1.2 \%)$, avian predators $(0.9 \%)$, and waterfowl $(0.5 \%)$.

In terms of foraging strategy, Steenhof and Kochert (1988) described golden eagles as generalists and specialists. The fluctuating nature of their favorite prey (i.e., jackrabbits), and their searching- rather than pursuing-type hunting style probably favor a wide food niche; however, the year-round availability of jackrabbits and a pair's residency on territory also encourages specialization.

Carnie (1954) studied the golden eagles nesting in the inner Coast Range of California (our present study area) and found eagles utilizing jackrabbits (29\%), ground squirrels (26\%), and deer $(13 \%)$. Other species of note included magpies $(6 \%$, mostly young birds taken from the nest or recently fledged), gopher snakes (5\%), and Sacramento perch (4\%). Eagles inhabiting more northern portions of the inner Coast Range (characterized by rugged, wooded areas) captured mostly ground squirrels from the open tops of ridges. In the south, terrain was more open and rolling, and eagles took more jackrabbits from the wide ridge tops and fields (Carnie 1954). Deer were used in areas of more mountainous terrain.

Anecdotal records of prey found in one southern California golden eagle nest by Sumner (1929a, 1929b) included: California ground squirrel, cottontail, pocket gopher, long-eared woodrat, crow, meadowlark, and gopher snake.

Estep and Sculley (1987) consider California ground squirrels to be the most important prey species for golden eagles nesting in the interior Coast Range of California. They summarized ground squirrel habitat requirements for the region as grasslands and savannas on slopes and flat terrain, the largest populations being associated with low grass height (maintained by grazing or arid conditions) with scattered trees, shrubs, or rock outcrops as cover for burrows; 
Table 3.1. Summary of principal prey species identified in golden eagle studies throughout their range. Percentages represent frequencies of animal numbers; percent biomass used when available (BM). Prey were identified primarily from breeding populations.

\begin{tabular}{|c|c|c|}
\hline Prey Species & Location & Study \\
\hline $\begin{array}{l}\text { Varying hare }(59 \%) \\
\text { Arctic ground squirrel }(27 \%)\end{array}$ & interior Alaska & Ritchie and Curatolo (1982) \\
\hline $\begin{array}{l}\text { Arctic hare }(34 \% \mathrm{BM}) \\
\text { Waterfowl ( } 40 \% \mathrm{BM}) \\
\text { Arctic ground squirrels }(16 \% \mathrm{BM})\end{array}$ & NW Territories & Poole and Bromley (1988) \\
\hline $\begin{array}{l}\text { Columbian gnd. squirrel ( } 82 \% \text { BM) } \\
\text { Blue grouse }(12 \% \mathrm{BM})\end{array}$ & SW Alberta & Boag (1977) \\
\hline $\begin{array}{l}\text { Mountain beaver } \\
\text { Snowshoe hare }\end{array}$ & W Washington & Bruce et al. (1982) \\
\hline $\begin{array}{l}\text { Yellow-bellied marmots ( } 73 \% \text { BM) } \\
14 \% \text { BM) }\end{array}$ & E Washington & $\begin{array}{l}\text { Marr and Knight Tetraonids (grouse; } \\
\text { (1983) }\end{array}$ \\
\hline $\begin{array}{l}\text { Yellow-bellied marmots }(71 \% \text { BM) } \\
\text { Mule deer (fawns; } 16 \% \text { BM) }\end{array}$ & E Washington & Knight and Erickson (1978) \\
\hline $\begin{array}{l}\text { Black-tailed jackrabbits }(69 \%) \\
\text { Anas sp. }(20 \%)\end{array}$ & SE Oregon & Thompson et al. (1982) \\
\hline $\begin{array}{l}\text { Black-tailed jackrabbits (60\% BM) } \\
\text { Mtn. cottontail (11\% BM) } \\
\text { Ring-necked pheasant (12\% BM) }\end{array}$ & SW Idaho & $\begin{array}{l}\text { U.S.D.I. (1979), } \\
\text { Beecham and Kochert (1975) }\end{array}$ \\
\hline $\begin{array}{l}\text { Black-tailed jackrabbits (26\%) } \\
\text { Mountain cottontails ( } 30 \%) \\
\text { Townsend ground squirrels (22\%) }\end{array}$ & SW Idaho & $\begin{array}{l}\text { Collopy (1983) } \\
\text { observed } \\
\text { foraging }\end{array}$ \\
\hline $\begin{array}{l}\text { White-tailed jackrabbit (37\%) } \\
\text { Cottontail (33\%) }\end{array}$ & Montana & McGahan (1968) \\
\hline $\begin{array}{l}\text { Prairie dogs }(66 \% \text { BM }) \\
\text { Cottontails (14\% BM) }\end{array}$ & $\begin{array}{l}\text { SE Montana } \\
\text { N Wyoming }\end{array}$ & $\begin{array}{l}\text { Phillips et al. } \\
\text { (1990) }\end{array}$ \\
\hline $\begin{array}{l}\text { Leporids (62\% BM) } \\
\text { Sciurids (prairie dogs; } 23 \% \text { ) }\end{array}$ & SW Wyoming & $\begin{array}{l}\text { MacLaren et } \\
\text { et al. (1988) }\end{array}$ \\
\hline $\begin{array}{l}\text { Black-tailed jackrabbit }(52 \%) \\
\text { Cottontails }(18 \%) \\
\text { Rock squirrels }(11 \%)\end{array}$ & $\begin{array}{l}\text { W Texas/ } \\
\text { New Mexico }\end{array}$ & $\begin{array}{l}\text { Mollhagen } \\
\text { et al. (1972) }\end{array}$ \\
\hline
\end{tabular}


Table 3.1. (Continued)

\begin{tabular}{|c|c|c|}
\hline Prey Species & Location & Study \\
\hline $\begin{array}{l}\text { Leporids ( }>75 \%) \\
\text { Prairie dogs }\end{array}$ & $\begin{array}{l}\text { Front Range } \\
\text { (NM, CO, WY) }\end{array}$ & Boeker and Ray (1971) \\
\hline $\begin{array}{l}\text { Black-tailed jackrabbit (37\%) } \\
\text { Rock squirrel (16\%) }\end{array}$ & C Arizona & Eakle and Grubb (1986) \\
\hline $\begin{array}{l}\text { Black-tailed jackrabbit ( } 88 \% \text { BM) } \\
\text { Mountain cottontail ( } 3 \% \mathrm{BM})\end{array}$ & NE California & Bloom and Hawks (1982) \\
\hline $\begin{array}{l}\text { Gray squirrels (48\%) } \\
\text { Jackrabbits }(26 \%) \\
\text { Deer (fawns) }(10 \%)\end{array}$ & $\begin{array}{l}\text { Mendocino Co., } \\
\text { California }\end{array}$ & Connolly et al. (1976) \\
\hline $\begin{array}{l}\text { Ground and tree squirrels } \\
\text { Rabbits } \\
\text { Waterfowl }\end{array}$ & S California & Dixon (1937) \\
\hline $\begin{array}{l}\text { Jackrabbits }(29 \%) \\
\text { Ground squirrels }(26 \%) \\
\text { Deer }(13 \%)\end{array}$ & $\begin{array}{l}\text { Coast Range, } \\
\text { C California }\end{array}$ & Carnie (1954) \\
\hline $\begin{array}{l}\text { Tetraonids (grouse) } \\
\text { Lagomorphs } \\
\text { Sheep, deer }\end{array}$ & Scotland & Watson et al. (1992a) \\
\hline $\begin{array}{l}\text { Lagomorphs (rabbits, hares) } \\
\text { Tetraonids (1985) } \\
\text { Large mammals (sheep, goat, deer) }\end{array}$ & SW Scotland & Marquiss et al. \\
\hline $\begin{array}{l}\text { Lagomorphs } \\
\text { Sheep } \\
\text { Waterbirds }\end{array}$ & W Scotland & Watson et al, (1992b) \\
\hline $\begin{array}{l}\text { Tetraonids (grouse; } 38 \% \mathrm{BM}) \\
\text { Hares }(30 \% \mathrm{BM}) \\
\text { Reindeer fawns }(17 \% \mathrm{BM})\end{array}$ & Sweden & Tjernberg (1981) \\
\hline
\end{tabular}


California ground squirrels apparently avoid dense vegetation and tall grass habitats (see Section 6.4.2 for more details on ground squirrel populations in the study area).

Golden eagle nests are generally kept clean during incubation as adults carry food debris away (Camenzind 1969). Throughout the chick cycle, the adults, particularly the female, regularly remove prey remains from nests, although this habit varies greatly between pairs (Tjernberg 1981). In some cases, food brought to the nest exceeds that consumed by eaglets; old items, often whole or partially eaten, accumulate in the nest and often become partially buried (Boag 1977, Poole and Bromley 1988).

Prey delivery rates to nests in Idaho averaged 1,417 grams per day (g/day) and peak delivery rate occurred during the 7 th week of chick development at 2,219 g/day, or 2.6 prey items per day (Collopy 1984). This coincided with peak consumption rates by nestlings which occurred from the 7th to 9 th weeks. The size of prey delivered by adults did not differ significantly between males and females (Collopy 1984). Prey deliveries declined to 1.6 prey items per day just prior to fledging, a behavior Collopy believed to coax the young into leaving the nest.

Golden eagles readily utilize available carrion in winter (Boag 1977, Bowen 1980, Tjernberg 1981), including mule deer and cattle carcasses, and in some areas carrion may be the dominant winter food (Knight et al. 1979, Marr and Knight 1983). Eagles often exploit waterfowl concentrations in winter and are very capable of capturing live ducks and geese (Sharp 1951, Marr and Knight 1983).

Several researchers have documented golden eagles killing the young of large ungulates and domestic livestock (Wiley and Bolen 1971, Carnie 1954, Goodwin 1977, Tjernberg 1981). Bruns (1970) reported that a golden eagle grasped a $32 \mathrm{~kg}$ young antelope on the back for 20 minutes until it died. Some deer fawns taken by eagles are stillborn (Carnie 1954, Connolly $e t$ al. 1976). Woodgerd (1952) examined 512 "stomachs" of golden eagles killed for bounty (initiated to curtail eagle depredation on game) in Montana. He found that 59 percent contained remains of rabbits, 16 percent those of antelope, and 6 percent held the remains of domestic sheep (some contained $>1$ food item).

Bloom and Hawks (1982) pointed out that in the western Great Basin, where golden eagles capture mostly jackrabbits, their habits actually benefit the livestock industry, since rabbits compete with cattle for range resources. The largest problems with eagles taking domestic livestock occur in open rangeland situations where eagles take significant numbers of lambs (Harlow and Bloom 1987, Phillips and Blom 1988). Most livestock depredations are believed to involve non-nesting, immature, or migrating eagles (Murphy 1977a), and percentages of livestock in food remains recovered from nests are usually very small (McGahan 1968, Bloom and Hawks 1982). Most non-lethal methods to control eagle depredations on lambs (i.e, scare tactics, live-trapping/relocation) have been ineffective (Phillips and Blom 1988).

Several studies showed that the composition of prey taken by eagles reflects the general availability of prey species in foraging areas (Tjernberg 1981, Smith and Murphy 1973), a 


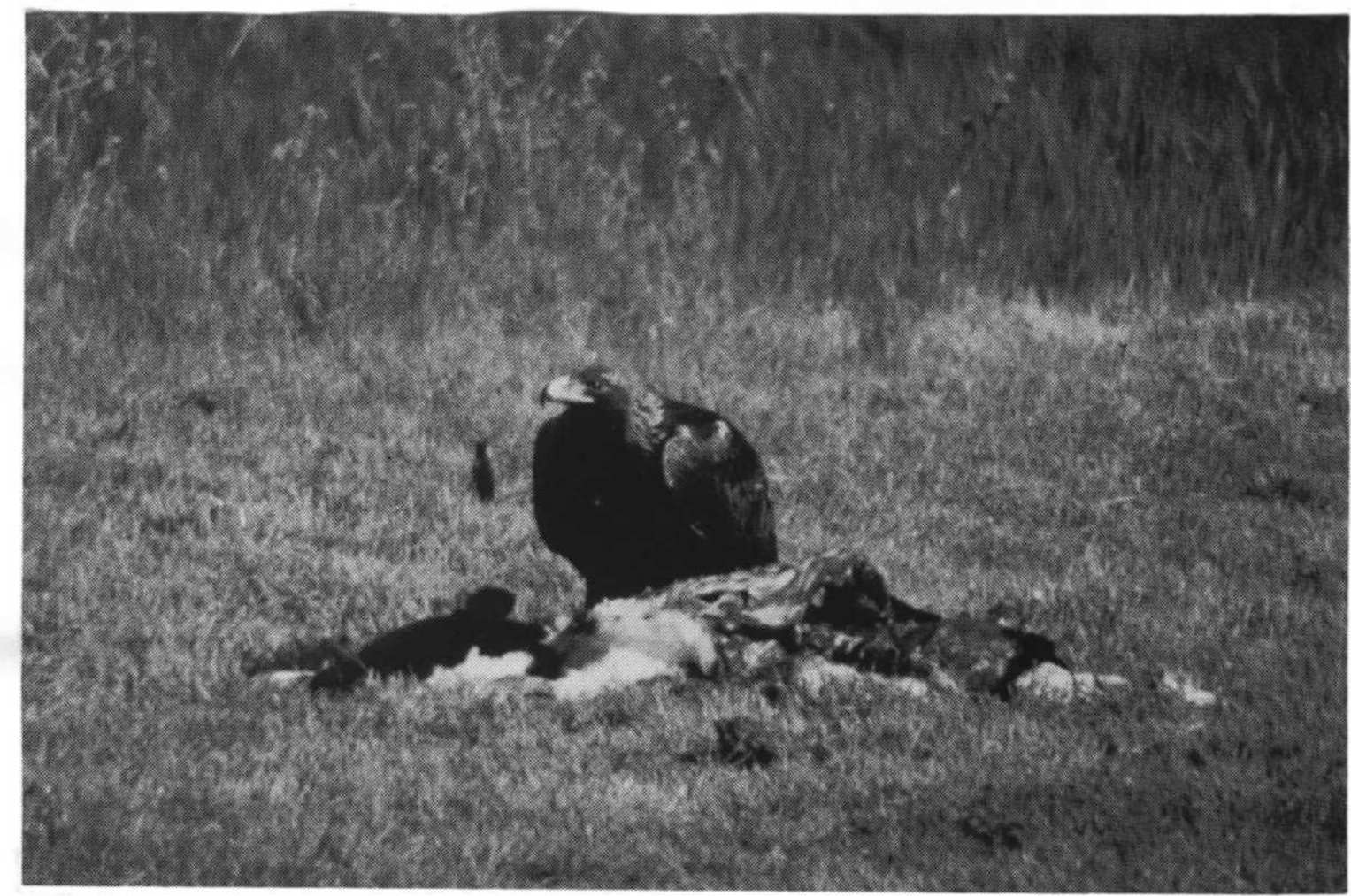

Golden eagle feeding on calf carrion (photo by Hans Peeters)

pattern believed to be characteristic of raptors (Knight and Erickson 1978, Hunt et al. 1992b). For example, eagle diet reflected high densities of blue grouse and Columbian ground squirrels found near Albertan nests (Boag 1977). However, Steenhof and Kochert (1988) reported that golden eagles in Idaho preferred larger prey types and avoided smaller, more numerous rodents, but conceded that the frequency of their preferred prey (jackrabbits) in the diet correlated with observed frequencies in the environment. Preference for larger prey probably works to maximize net energy intake (Steenhof and Kochert 1988). Marr and Knight (1983) reported that greater habitat diversity near nests did not necessarily increase dietary diversity.

Some researchers found greater frequencies of adult ground squirrels than juveniles in prey remains (Boag 1977, Poole and Bromley 1988). Golden eagles often capture nestling birds, including corvid fledglings (Tjernberg 1981).

When populations of preferred prey species decline, eagles respond by exploiting a greater diversity of prey species (Bloom and Hawks 1982, Marr and Knight 1983). In Idaho, populations of the two principal prey species of golden eagles fluctuate: black-tailed jackrabbit (Lepus californicus) populations are cyclic (peaks approximately every 10 years) and Townsend's 
ground squirrel populations are strongly affected by climatic variation (Steenhof and Kochert 1988). Over a two-year period when jackrabbit densities declined, the proportion of jackrabbits in the diet of golden eagles fell from 72 to 21 percent (Steenhof and Kochert 1988). The eagles responded by exploiting a more diverse diet, but returned to mostly jackrabbits when jackrabbit populations recovered. Eagles in eastern Washington apparently switched to yellow-bellied marmots during years when rabbit populations were depressed (Knight and Erickson 1979).

The proportion of breeding attempts, breeding success, and the rate of young fledged can be affected negatively during poor prey years (Kochert 1980). Phillips $e$ t al. (1990) reported a positive relationship between number of young fledged per pair and cottontail abundance. In Scotland, Watson et al. (1992a) found a positive correlation between nesting density and a carrion index, and between productivity (number of fledged young) and a live prey index. Since the winter diet of golden eagles in Scotland is mostly carrion sheep and deer, it follows that winter food availability may be an important factor regulating breeding attempts and nesting density (Watson and Langslow 1989, Watson et al. 1992a). Jackrabbit abundance positively influenced winter eagle densities in Idaho (Kochert 1980).

3.1.3 Foraging Behavior. When not hunting in the vicinity of the nest, golden eagles typically soar on upslope winds and thermals to gain altitude, then glide off to more remote foraging locations (Bergo 1987). Often, eagles take an indirect route back to the nest with prey (Carnie 1954), probably to take advantage of ascending air currents (Dixon 1937).

Golden eagle hunting patterns consist of high soaring flights interspersed with low coursing flights over slopes and draws (Carnie 1954), a term we refer to as "contour hunting." Slow gliding along slopes was the principal hunting method used in Norway (Bergo 1987). Perching does not appear to be a primary means of finding prey; however, successful forages are sometimes initiated from perches (Carnie 1954). When using large transmission towers, eagles typically perch on upper, outer sections, presumably for a more elevated view and to facilitate take off when hunting (Smith 1985).

Dekker (1985) observed that golden eagles hunting ground squirrels used surprise tactics which varied under different weather conditions: during calm, overcast, or rainy days eagles perched on posts, hillsides, or in trees and glided or flapped at low levels over colonies; during sunny, windy weather eagles soared and stooped or dropped to glide low (1-3 $\mathrm{m}$ ) over slopes, following terrain contours. Captures occurred by grasping squirrels in passing flight or suddenly halting on the prey, killing it on the ground (Dekker 1985). Dixon (1937) observed eagles using fences, and even moving trucks, as cover while approaching unsuspecting waterfowl. Anecdotal accounts by Dixon had eagles waiting at a ground squirrel burrow until the rodent emerged, and following a farmer's plow and catching ground squirrels scattered by the activity. Adding to the evidence of individual variation among golden eagles, Carnie (1954) reported that adjacent pairs hunting in similar habitats captured different proportions of available prey (i.e., fawns vs. ground squirrels). 


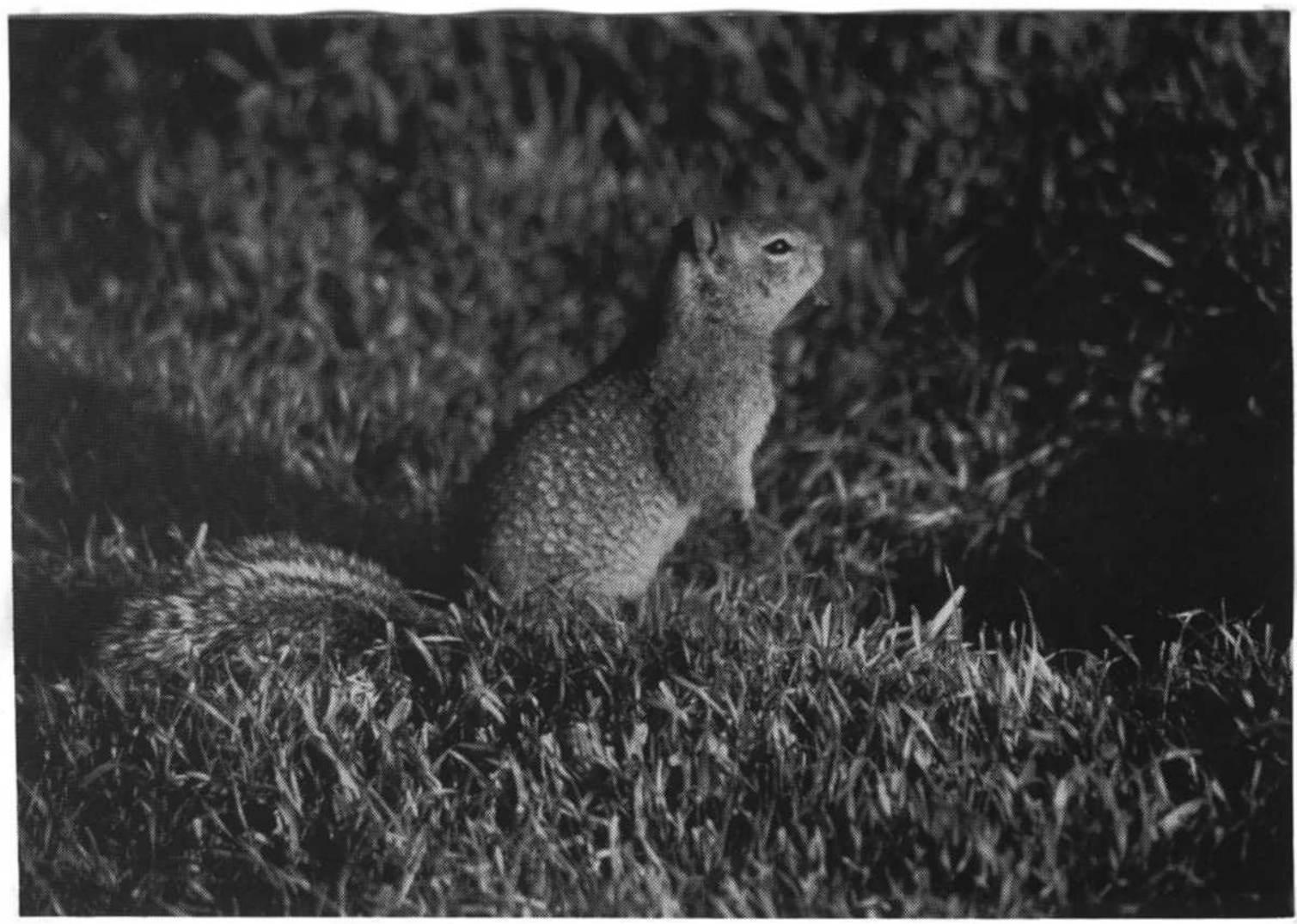

California ground squirrel (photo by John Gilardi)

Golden eagles are also known to obtain prey through intra- and inter-specific piracy (e.g. taking ground squirrels from red-tailed hawks; Dekker 1985). Dixon (1937, also Hans Peeters, pers. comm.) wrote that eagles in southern California hunted and killed red-tailed hawks (usually immatures) and great horned owls during periods when food was scarce.

Collopy (1983a) separated golden eagle foraging behavior into solo-hunting (foraging alone) and tandem hunting (foraging in pairs); actual attack modes were described as a pounce or a stoop. Males solo-hunted more often during the early breeding season when females brooded young. Tandem hunting occurred later in the nesting season, the male usually leading. Hunting eagles typically coursed slowly over slopes, quartering the ground, usually oriented into the wind (Collopy 1983a). Males were more successful hunters than females (23\% vs. $12 \%$ success); solo-hunting was more successful than tandem ( $29 \%$ vs. $8 \%)$, for unknown reasons possibly related to the type of prey (Collopy 1983a). Carnie (1954) described tandem hunting where one bird coursed low while the other maintained a soaring flight. 
3.1.4 Breeding Behavior. Both sexes partake in nest building or reconstruction (Bergo 1987), although, according to Dixon (1937), the female chooses the nest location. The females perform most of the incubation (65-99\% in Norway - Bergo 1987, 83\% in SW Idaho - Collopy 1984) and apparently only females incubate at night (Collopy 1984). The males do most of the hunting and often bring food to the incubating female, although females occasionally forage for themselves during incubation (Collopy 1984). Males provide most of the food during early brood rearing ( $95 \%$ biomass) and spend very little time brooding or feeding young; in one study, the females' greatest contribution occurred during the 7th to 9th weeks when they brought in 43 percent of biomass to the nest (Collopy 1984). Collopy and Edwards (1989) found that during the brood cycle, females spent most of their time on the nest, perching, arranging nest material, and brooding or feeding young.

Nesting and egg-laying dates vary with geographic location. In general, initiation of nesting is later in more northern latitudes: interior Alaska, mid-April to mid-May (Ritchie and Curatolo 1982); northern Sweden, late March/early April (Tjernberg 1983); New Mexico mid-February, Colorado/Wyoming March (Boeker and Ray 1971); Utah late February/March (Camenzind 1969); southern California early February to early March (Dixon 1937). In the Diablo Range of California, golden eagles begin courtship flights in January, and eggs are laid most commonly in mid- to late-February (Carnie 1954, this study).

Golden eagles typically lay one to three eggs (usually two), with four-egg clutches being rare (Sumner 1929a, Dixon 1937, Bent 1937, Carnie 1954, Brown and Amadon 1968, McGahan 1968, Beecham and Kochert 1975, Hoechlin 1976, Brown 1977, Terres 1980). Egg size averages $74.5 \mathrm{~mm}$ in length and $58 \mathrm{~mm}$ in breadth, with a range of 89 to $67.5 \mathrm{~mm}$ in length and 66.6 to $49.4 \mathrm{~mm}$ in breadth (Bent 1937). Although early records indicate the duration of incubation to be 28-35 days (Sumner 1929b, Bent 1937, Carnie 1954), later studies confirmed periods of 42-45 days (6-6.5 weeks) (Brown and Amadon 1968, Camenzind 1969, Hoechlin 1976, Terres 1980).

During the first three weeks after hatching, golden eagle nestlings are covered with white down; dark pin feathers, especially remiges and rectrices, begin to unsheathe in about four weeks (Hoechlin 1976). Collopy (1984) found that females brooded nestlings nightly until about four weeks (range 2.5-6 weeks); brooding or sheltering ceased when young were about six weeks old. At five weeks of age young eaglets start stretching their wings over their backs (Camenzind 1969), and begin pulling small pieces of food from prey carcasses, activities that coincide with the ability to stand (Collopy 1984). Self-feeding is more developed by the 8th week when still partially-sheathed dark feathers cover the entire body (Hoechlin 1976). Female nestlings feed themselves more per day than males, according to Collopy (1984). Sumner (1929a,b) documented a weight loss during the eighth week in development of golden eagle chicks in southern California, and speculated it may have been due to increased exercise, since food was available in the nest. 
Wing exercising begins around the 9th week (Hoechlin 1976). The young remain in the nest for 9-10 weeks, fledging at 65-70 days of age (Sumner 1929a, Sumner 1929b, Bent 1937, Carnie 1954, Brown and Amadon 1968, Hoechlin 1976, Brown 1977, Terres 1980).

Walker (1987) observed the development of three juvenile golden eagles in England; upon first fledging, they remained very close to the nest, preening, exercising, and being fed by their parents. Adults encouraged movements by enticement with prey, and flying ability developed slowly, partly a consequence of incomplete flight feather growth. The juveniles gained higher perches by short, flapping flights or on foot until about three weeks after fledging when circling flight was first observed. Juveniles perched, at first on the ground and then in trees, for up to 8 hours at a time; the fledglings rarely returned to the nest after fledging.

Adult golden eagles, especially the males, provide food to the juveniles for a period of time after fledging, and young eagles soon learn to recognize carrion and so obtain food on their own (Walker 1988). The timing of juvenile independence varies and is possibly related to the availability of live prey for the adults (Walker 1988). In one instance, full independence was gained in 10.5-12 weeks after fledging, marked by territorial defense displays by adults directed toward the young (Walker 1987).

Golden eagles often attempt to renest if the nest is disturbed or the eggs destroyed (Camenzind 1969), with the period between loss and laying reported to be about 28 days (Dixon 1937). Authors have reported a few instances of polygyny in golden eagles (e.g., Great Britain - Dennis 1983).

One of the least vocal of raptors, golden eagles vocalize under certain conditions: 1) while incubating, females may call from the nest when sighting the male with prey, 2) infrequently, calls may be directed at intruders, 3) pairs vocalize during nest building (Bergo 1987). Most golden eagles do not attempt to defend their nests from human intrusion, rather they fly out of sight and wait for the intruder to leave (Camenzind 1969).

Breeding golden eagles display a particular flight pattern called "undulating flight", a series of steep dives and upward swoops in waves with wing-flapping at each apex. Undulating flight was considered to be an act of eagle courtship and pair bonding (Bent 1937), but is probably used mostly as a territorial display to advertising occupancy (see Harmata 1982; also Dixon 1937, Bergo 1987, Collopy and Edwards 1989). Soaring and exposed perching are other forms of advertising territorial occupancy (Bergo 1987). Mock attack and evasion flight between mates resemble actual aggressive flights with intruders, and may also be related to courtship (Bergo 1987). Bergo (1987) found that females tended to be more involved with territorial encounters than males. Fresh greenery brought to the nest during the breeding may be a form of advertisement (Newton 1979), may act to camouflage the nest (Bergo 1987), or serve other functions such as pest control.

Factors which lower nesting success include abandonment of nests, inclement weather (wind destruction and wet snow), infertile eggs, and eggs destroyed by trampling (Beecham and 
Kochert 1975, Phillips et al. 1990). Human disturbance caused at least 85 percent of known nest failures in New Mexico (Boeker and Ray 1971); Camenzind (1969) reported one female was shot on the nest while incubating, and noted that humans also took eggs from nests. Watson and Dennis (1992) observed that easily accessible nests were less productive than inaccessible nests, though nesting failure was unrelated to distance to public roads. An index of human disturbance within territories was positively correlated with nesting failures (Watson and Dennis 1992). Inattentiveness by the male was blamed in one nesting failure in Idaho (Collopy 1984).

During low prey years golden eagles may respond with fewer nesting attempts and lower nestling survival (U.S.D.I. 1979); poor nesting success was associated with a major decline of cottontails in Montana and Wyoming (Phillips et al. 1990). If prey abundance is low prior to egg-laying, eagles may choose not to nest (Tjernberg 1983). This and other factors such as their sensitivity to disturbance during incubation and their lack of aggressive defense against human intruders, point to a conservative parental investment strategy which may be adaptive for this long-lived raptor once established in a territory (Collopy 1984; see also Hunt et al. 1992a for parallels in bald eagles).

Some golden eagle populations show a high frequency of subadults attempting to breed. While these may be responding to large (temporary) increases in prey populations, subadult breeding may also be the result of a reduced eagle population. For example, adults may be depleted by shooting, with numbers of unoccupied nesting territories available for occupancy by subadults (Newton 1979, Steenhof $\boldsymbol{e t}$ al. 1983). Several authors have documented instances of golden eagles in subadult plumage breeding successfully (Bates 1976, Teresa 1980, Steenhof $e t$ al. 1983, Bergo 1984b). In West Norway, Bergo (1984b) reported that 46-58 percent of pairs included at least one individual in subadult plumage (in 19\% of cases, both individuals were subadults) and speculated that the population had been below carrying capacity for some time. Steenhof et al. (1983) found lower nest success in Idaho pairs containing subadults (43\%) than full adults $(74 \%)$, probably because of lack of experience by the younger birds. Subadult nesting in Idaho was inversely correlated with winter adult densities, but unrelated to jackrabbit abundance (Steenhof et al. 1983). When eagle populations were high, adult eagles filled most of the territory vacancies. There is some evidence that subadults occupy inferior territories: nesting sites chosen by pairs with subadults had more evidence of human activity, and were closer to intensively farmed areas, roads, and human habitation where a higher turnover rate (e.g. from shooting) might be expected (Steenhof et al. 1983).

3.1.5 Seasonal Movements. In many parts of their range, adult golden eagles reside year round in their territories (Idaho - Beecham and Kochert 1975; Coast Range, California - Carnie 1954; Front Range of central Rockies - Boeker and Ray 1971). Non-breeding segments of golden eagle populations are believed to be nomadic (Lockie and Ratcliffe 1964, in Beecham and Kochert 1975). Steenhof et al. (1984) discovered from banding data that eagles $(n=6)$ banded in the nest in Idaho returned to breed in their natal region (7-65 km from natal territories). Prior to this, eagles had apparently dispersed in all directions, but 78 percent of all sightings/recoveries were made within $100 \mathrm{~km}$ of natal areas. 
In southern latitudes golden eagle populations tend to be sedentary, showing only local or intrarange movements during the year. For the inner Coast Range of central California (our study area), Carnie (1954) reported that seven recoveries of 33 young eagles banded in nests were all within the Coast Range and that this indicated "no extensive movement of the population". In Idaho, 14 of 16 eagles banded as nestlings and later recovered were found within $174 \mathrm{~km}$ of natal territories; exceptions included one found dead near Willows, California (644 km SW) and a second recovered $563 \mathrm{~km}$ southeast in Juab Co., Utah (Beecham and Kochert 1975). In addition, Beecham and Kochert (1975) reported that 12 of 14 sightings (all months except July) of marked young eagles were within $80 \mathrm{~km}$ of their Idaho study area. Again, two birds were located far from the study area: $483 \mathrm{~km}$ southeast (6-month-old) and $507 \mathrm{~km}$ northwest (2-yearold).

Based on five recoveries of nestlings banded in the Front Range of the Rocky Mountains, Boeker and Ray (1971) concluded that young eagles there did not wander far from their natal areas and that the population was separate from the wintering population of eastern New Mexico and western Texas (see below, Boeker and Ray 1971). Radio-tagged Spanish imperial eagles all dispersed from natal areas, established temporary settlements in areas lacking breeding pairs, and led a generally nomadic lifestyle within $110 \mathrm{~km}$ of nests (Ferrer 1993). Returns to natal areas by immature Spanish imperial eagles increased during November-December, the time of nest building.

Migrant golden eagles arrive in interior Alaska in early spring; they have been observed as early as mid-March in the Brooks Range (Ritchie and Curatolo 1982). During fall and winter, there is a general southward migration of golden eagles from northern regions (McGahan 1968). Wintering eagles begin arriving in New Mexico in October, numbers peak in DecemberFebruary, and eagles leave in March (Boeker and Ray 1971). A 10-year-old eagle, banded as a nestling in Oregon, was killed by a sheep herder in Baja California during November (Rodriguez-Estrella et al. 1991). A young eagle (7 months) shot in Texas during its first winter, was 1,290 miles south of its banding location in Montana (McGahan 1968). Two one-year-olds were found 210 and $350 \mathrm{mi}$. southeast of their Montana banding location.

Subadults represent about one-third of the general wintering population, based on several aerial surveys summarized by Olendorff et al. (1981). Subadult intrusions into breeding territories were most frequent during autumn/winter and pre-laying periods; intruders were 3.5 times more frequent in newly established territories compared with traditional breeding sites (Bergo 1987).

To our knowledge, nest site fidelity has been little studied in golden eagles and is presumed to be similar to that in bald eagles where pairs consistently return to traditional sites (Jenkins and Jackman 1993); however, Marzluff et al. (1993) found at least one case of an adult female attempting to breed in an adjacent territory. According to Dixon (1937), old birds "banished" from territories by younger eagles may remain around the margin of the territory for a period of time. 
Rapid replacement of breeding adults that have died (e.g., shot on territory) indicate a surplus of non-breeding birds in the population (Phillips et al. 1984, Tjernberg 1985, Haller 1982). Dixon (1937) reported a short time for replacement following deaths of breeding eagles in San Diego County, indicating an "ample supply of birds of breeding age in the region." We will discuss this concept of floating populations of nonbreeding adults in Section 3.2.

3.1.6 Lethal Agents. Very few studies of mortality using radio-telemetry have been conducted on golden eagles. Of 30 Spanish imperial eagles (Aquila adalberti) radio-tagged in Spanish nests, 14 lived at least six months, 10 at least 1 year, and 7 survived at least two years (Ferrer 1993). In a radio-telemetry study of resident breeding golden eagles in Idaho, there were no reported fatalities (Marzluff et al. 1993).

By examining labels on museum specimens, Bortolotti (1984a) found that golden eagles had been trapped and poisoned (strychnine) throughout their range in Alaska, Canada, and the western U.S. (71\% of known fatalities). Most were killed in winter, especially December $(26 \%)$. Deaths were incidental to poisons and traps set for wolves and coyotes. Other causes of death were shooting (often for collecting) and from injuries sustained from attacks on porcupines. Six times as many females died from traps/poisoning than males, and spacial segregation of sexes was offered as the most likely explanation (Bortolotti 1984a). Shooting was the principal cause of death for 26 golden eagle carcasses found along road transects in Utah (Ellis et al. 1969), and man caused the deaths of at least $45 \%$ of 22 eagles found dead in Montana (McGahan 1968).

In one study, 41 of 129 (32\%) young died before fledging; causes of nestling death included heat prostration and siblicide, others disappeared and may have also been killed by siblings (Beecham and Kochert 1975). Other causes of nestling death include disease (trichomoniasis) and falling from the nest (Boeker and Ray 1971).

Edwards and Collopy (1983) examined the phenomenon of siblicide, and speculated that if food was limited and siblicide was size-related, then siblicide was more likely to occur in two-chick broods if a female hatched before a male (see Bortolotti 1986 for a fascinating evolutionary discussion). Edwards et al. (1988) went on to test this hypothesis and found that decreased food availability (i.e., low jackrabbit numbers in Idaho) appeared to mediate shifts from a preponderance of males to an even ratio, presumably through siblicide. A lively discussion ensued between Bortolotti (1989), Arnold (1989), and Edwards and Collopy (1989) concerning sex ratios at the population level and methodologies used to determine sex bias in nestlings.

Ten post-fledging fatalities examined by Beecham and Kochert (1975) revealed that four died of trichomoniasis, two of impact injuries, one by shooting, and two of unknown causes. In addition, Beecham and Kochert examined 28 dead immature and adult golden eagles: 43 percent died of electrocution (all immatures), 21 percent by impact injuries, and 11 percent were shot. Four of five band recoveries of immatures had been shot (Boeker and Ray 1971). Dixon (1937) believed that individual golden eagles "... vary a great deal as to wildness, and those raised around civilization were often tame and more likely shot." In Europe, there is also considerable 
evidence of eagle persecution, including nest destruction, poisoning of adults (Watson and Dennis 1992), and shooting (Tjernberg 1985).

Some believe that the most significant lethal agent affecting golden eagles in North America is the pervasiveness of lead in the environment (Harlow and Bloom 1987). Five of 16 golden eagles recovered in Idaho in the mid-1980s died of lead poisoning (Craig et al. 1990). Sublethal lead poisoning ( $>0.6 \mathrm{ppm}$ lead in blood) may contribute to death occurring proximally from other causes (e.g., necrotic colitis, Craig et al. 1990). Thirty-six percent of 162 golden eagles sampled in southern California had been exposed to lead, and 2.5 percent had levels indicative of clinical lead poisoning. The impact of this level of lead on the population is unknown but possibly detrimental (Pattee et al. 1990). Lead shot is now banned for most waterfowl hunting in the U.S., but lead may still derive from bullet fragments contained in other types of wildlife.

Other toxic compounds may also contaminate golden eagles, reducing productivity and causing fatalities. Lockie et al. (1969) reported poor breeding success during the early 1960s in Scotland due to high concentrations of dieldrin, an organochlorine added to sheep dip preparations. While no relationship was found between levels of organochlorines (e.g., DDE, HEOD, PCB's) and golden eagle productivity during the past decade in Scotland, certain coastal eagles did accumulate very high levels of these toxins (and mercury) which contributed to local fatalities (Newton and Galbraith 1991).

Because of their large wingspan, eagles, primarily golden eagles, account for the majority (between $70 \%$ and 90\%) of electrocution fatalities in the western U.S. (O'Neil 1988, Benson 1982, Olendorff et al. 1981, citing Benson 1981a, Boeker and Nickerson 1975, Peacock 1980, and Olendorff 1972). Benson (1981a,b) wrote that immatures comprise most (up to $98 \%$ ) of the golden eagle electrocution fatalities found below powerlines. The preponderance of immature fatalities probably resulted from their inexperience in flying and perching and from their tendency to hunt from perches more often than adults. Factors increasing electrocution fatalities include inclement weather, especially snowfall (i.e., snow apparently causes greater featherwetting), power pole configuration ( $<60$ in. span between conductors), power pole location, prey densities, and prey types (e.g. cottontails are hunted from perches more often than jackrabbits) (Benson 1981a, O'Neil 1988). Increased prey densities attracted more wintering eagles to Idaho, and electrocution deaths correspondingly increased (Kochert 1980). Elevation above surrounding terrain and association with prey concentrations are important in determining which poles are preferred by raptors (Olendorff $e t$ al. 1981 citing Benson 1981a, Boeker and Nickerson 1975, Nelson and Nelson 1976, and Pearson 1979). Power poles located on hilly grasslands were twice as lethal as poles on flat, agricultural ground (O'Neil 1988).

More electrocutions occur on electrical distribution lines $(<69 \mathrm{kv})$ than high voltage transmission lines (Olendorff et al. 1981). On distribution lines, the wire-to-wire or wire-toground distances are often close enough together to allow large raptors to span the connection with their wings (also tails). Olendorff et al. (1981) and Galvin et al. (1979 in Williams and Colson 1989) provide information to industry on the design of "safe" power pole configurations and describe remedial modifications to existing powerlines (Marshall 1940). While economics 
prevent modification of all existing lines, alterations of "preferred" power poles with dangerous configurations can help reduce raptor electrocutions.

Golden eagles also utilize distribution line poles and transmission line towers as nesting substrate (Olendorff et al. 1981). To avoid electrocutions of nesting birds and power outages caused by nest sticks contacting live conductors, artificial nest structures can encourage eagles to nest in safe places on towers (Olendorff $e t$ al. 1980; Call 1979; Nelson unpubl. docs., in Olendorff $e t$ al. 1981). Powerline collisions are not generally considered a serious problem (Olendorff 1986). In general, a raptor's keen eyesight, usually slow flapping flight (and soaring) and maneuverability allow them to avoid collisions with powerlines; however, the potential for line strikes apparently increases when a bird is distracted (pursuing prey or while engaged in territorial defense) or when visibility is poor in fog or low light (Olendorff and Lehman 1986, Avery 1978, Bevanger 1994). Olendorff and Lehman (1986) compiled field observation records of 88 known or suspected powerline collisions; golden eagles accounted for nine $(10 \%)$ of them. Weather (high winds, snow) was a factor in two instances; four birds collided with transmission lines, four collided with distribution lines, and all known collisions $(n=8)$ resulted in death of the birds.

\subsection{Population Ecology of Golden Eagles}

To approach the question of population impact with an effective research strategy we must first review what is known of the components of a healthy golden eagle population and how nature regulates the numbers of each component. We must also understand the normal mechanisms that govern the density of pairs in an area and the factors that affect reproductive success from year to year (see Newton 1989 for an overview of raptor population regulation).

3.2.1 Spacing of Pairs. In general, the density of nesting raptors is ultimately determined by the availability of food and nesting sites; spacing is acquired by territoriality (Newton 1979). In the southwestern U.S., Boeker and Ray (1971) found that nesting density in golden eagles was related to nest site availability and habitat. Collopy and Edwards (1989) reported that territory size was inversely related to the amount of good jackrabbit habitat (black greasewood) available, and Dixon (1937) reported larger territories contained more agricultural and residential development in San Diego Co., California. Brown and Watson (1964) believed that territory size was adequate to provide food in all seasons and in different years and that breeding density was little changed over many years, and not related to prey numbers. Gargett (1975) described the dynamics of 18 black eagle territories which, over a three year period, remained constant in number. A vacated territory was incorporated by neighbors, a new territory was established partially in a vacant area and partially by appropriating portions of two adjacent territories.

By using radio-telemetry on nesting adult golden eagles, Marzluff et al. (1993) found extreme individual variation in ranging habits between pairs $\left(9-514 \mathrm{~km}^{2}\right)$. Home range variability was explained by differences in habitat between territories and individual preferences by the resident adults. Black eagle territories were larger when necessary to encompass sufficient amounts of 


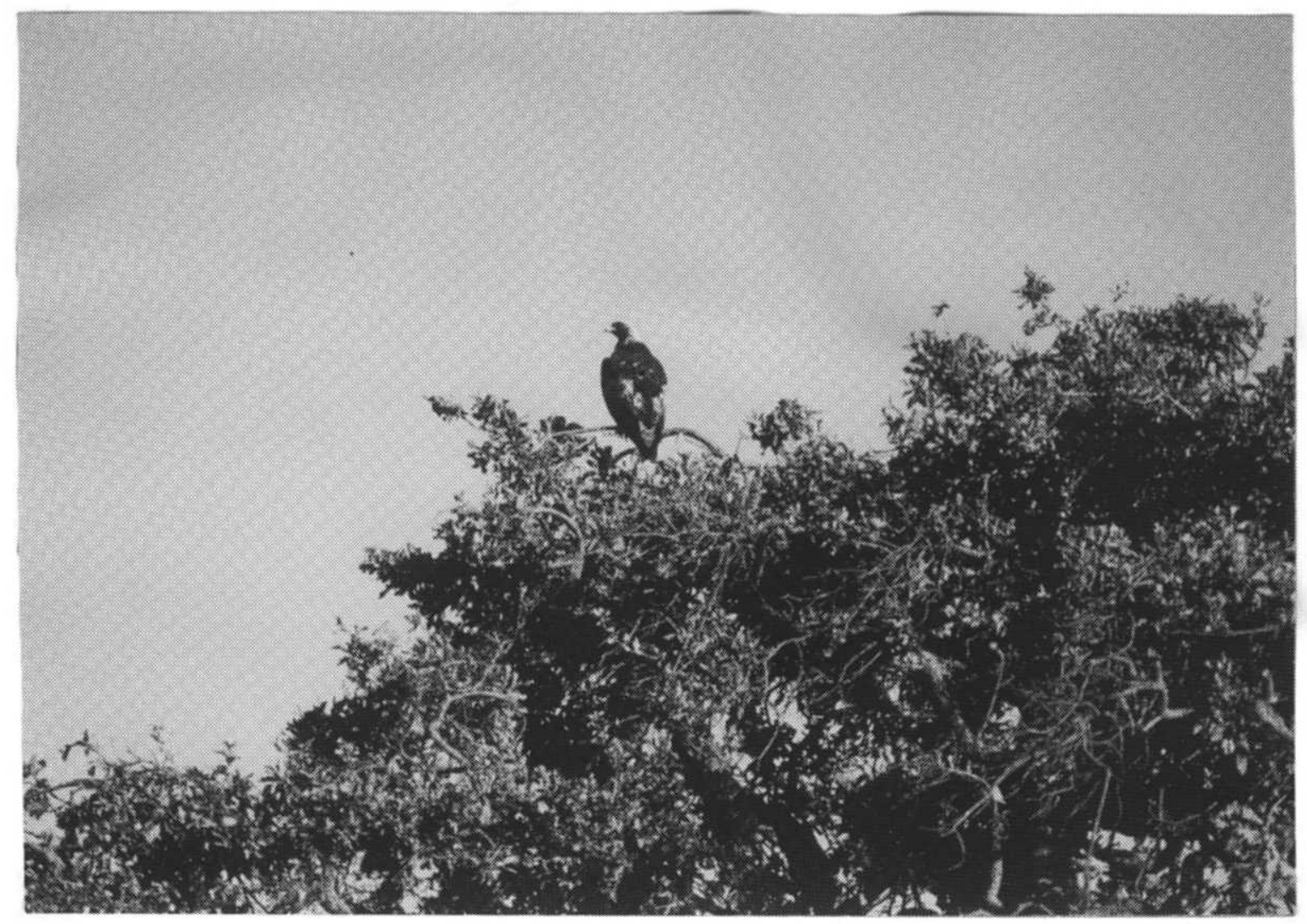

Adult golden eagle in nest tree (photo by Hans Peeters)

preferred foraging habitat (Gargett 1975). In Sweden, the distance to the nearest neighbor was greater in forested areas than in mountainous regions where prey densities and prey availability were greater (Tjernberg 1985).

Some believe that while golden eagles are known to defend the immediate area around their nests most aggressively, they are less defensive of foraging areas, even sharing portions of hunting ranges (Brown and Watson 1964). Thelander (1974) noted that in areas where nest sites were limited (e.g., small, isolated mountain ranges) eagles often nested relatively close together. However, based on radio-telemetry, Marzluff et al. (1993) found that golden eagles were resistant to adjusting their ranging behavior when prey densities declined, possibly because of territorial defense of foraging areas; rather, the birds focused on exploiting alternate prey within familiar home ranges.

The spacing of golden eagle nesting sites appears to be regular or uniform rather than random (Smith and Murphy 1982a, Watson and Rothery 1985), indicating that choice of nest sites is governed by territorial considerations (Tjernberg 1985). Gargett's (1975) study of black eagles 
in Rhodesia showed that territorial aggression was greatest towards floaters (non-breeding adults); encounters with established, neighboring pairs were few.

Tjernberg (1985) reported that nearest neighbor distances between pairs in Sweden averaged 10, 16 , and $17 \mathrm{~km}$, depending on the richness of habitat; he also cited reports of average distances in other areas: 7-8 km (Scotland), 7-25 km (France), and $10 \mathrm{~km}$ in Switzerland. In southeastern Montana and northern Wyoming, nearest neighbor distances of primarily tree-nesting golden eagles averaged $4.4 \mathrm{~km}$ (range $=1.7-7.3 \mathrm{~km}, \mathrm{n}=30$ pairs) (Phillips et al. 1990), but in abundant prey years, the nesting density may have increased slightly from one pair per $35 \mathrm{~km}^{2}$ to one per $29 \mathrm{~km}^{2}$ (op. cit.). Table 3.2 lists nesting densities and home range sizes for 27 studies of golden eagles.

3.2.2 Population Segments. The four population segments, as they are called, include breeders, floaters, subadults, and juveniles. The numbers of each are controlled by differing factors. Breeders are individuals four years old (near-adults) or older (adults) which defend territories containing a nest from which young can potentially fledge. The overall number of active nests in a region is limited by the availability of habitat and prey. To be useful, each breeding area must contain a cliff, tree, or manmade structure capable of supporting a large nest. This must be isolated from other breeding golden eagles and disturbance factors, and be reasonably close to available prey. In addition, nest sites normally provide a view of the surrounding landscape and are associated with rising air currents suitable for soaring. In evolutionary terms, a location is serviceable to an eagle pair when the mortal risk and physiological cost of a breeding attempt there are outweighed by the promise of reproductive success (see Hunt 1988).

In many regions, there is a low probability that all of these physiographic and biotic features are juxtaposed, so that eagle pairs tend to be scattered in the landscape. Where breeding locations are more abundantly distributed, pairs are nevertheless regularly spaced as a result of territorial behavior (Bergo 1987, see Section 3.2.1).

When all serviceable breeding locations (SBLs) are occupied by pairs, floaters accumulate in the population. Floaters are adults which, in order to breed, must either wait for a vacancy or forcefully evict a territory owner (Gargett 1975). Floating segments are well known in golden eagle populations (Haller 1982, Tjernberg 1985) and in those of other raptors (Hunt 1988, McCrary et al. 1992). According to Haller (1982), if the number of floater eagles is large relative to the number of breeders, the frequent incursions of floaters attempting to usurp breeding territories may cause nests to fail and therefore reduce the population birth rate. This inverse relationship between natality and the number of floaters is an example of a densitydependent feedback mechanism regulating the overall number of eagles in the population (Lack $1954,1966)$ but not necessarily the number of breeding pairs (see below).

Although reproduction and mortality may vary from year to year, the number of serviceable breeding territories tends to remain more or less constant so long as a moderate number of floaters remains to fill vacancies as they occur. In this way, the floating segment safeguards the 
Table 3.2. Comparison of nesting density for 27 golden eagle studies in the western United States, Scotland, and Sweden. Linear figures are means (or ranges) of distances between nests; area figures are mean (or range) territory size. Methods for determining territory size varied.

\begin{tabular}{|c|c|c|c|c|}
\hline Region & $\begin{array}{l}\text { \# of } \\
\text { Prs }\end{array}$ & $\begin{array}{l}\text { Linear } \\
(\mathrm{km})\end{array}$ & $\begin{array}{l}\text { Area } \\
\left(\mathrm{km}^{2}\right)\end{array}$ & Source \\
\hline Alaska & 9 & 15.3 & & Ritchie and Curatolo (1982) \\
\hline SW Idaho & 56 & & 73 & Kochert (1972) \\
\hline SW Idaho & 56 & 5.0 & & Beecham and Kochert (1975) \\
\hline SW Idaho & 34 & & 99 & U.S. Dept. of Interior (1979) \\
\hline SW Idaho & 4 & & 32.7 & Collopy and Edwards (1989) \\
\hline SW Idaho & 9 & & 9-514 & Marzluff et al. (1993) \\
\hline Montana & 19 & $1.6-16.4$ & 172 & McGahan (1968) \\
\hline S Cent. Mont. & 23 & & 142 & Reynolds (1969) \\
\hline SE Mont/N Wyom & 16 & & 41 & Lockhart et al. (1978) \\
\hline SE Mont/N Wyom & 30 & $1.7-7.3$ & 29 & Phillips et al. (1990) \\
\hline Wyoming & 320 & 5.3 & 60 & Phillips et al. (1984) \\
\hline NE Colorado & 12 & & 217 & Olendorff (1975) \\
\hline W Cent. Utah & 14 & $1.1-25.9$ & $98-155$ & Camenzind (1969) \\
\hline Utah & 34 & $1.1-10.3$ & & Smith and Murphy (1982) \\
\hline Utah & - & & 23 & Smith and Murphy (1973) \\
\hline W Utah & 24 & & 119 & Edwards (1969) \\
\hline NE Nevada & 88 & & 251 & Page and Seibert (1973) \\
\hline S California & 27 & & 93 & Dixon (1937) \\
\hline W Cent. Calif. & 3 & & $23-39$ & Estep and Sculley (1987) \\
\hline W Cent. Calif. & 37 & & 22 & This Study \\
\hline Scotland & 14 & & 41 & Watson (1957) \\
\hline Scotland & 13 & & 70 & Lockie (1964) \\
\hline Scotland & 4 & & $35-40$ & Marquiss et al. (1985) \\
\hline Scotland & 144 & & $38-68$ & Watson et al. (1992) \\
\hline Sweden & $50-106$ & $10.2-17.0$ & $98-155$ & Tjernberg (1985) \\
\hline W Norway & 58 & 16 & & Bergo (1984a) \\
\hline W Norway & 3 & & $32-100$ & Bergo (1984b) \\
\hline
\end{tabular}


stability of the breeding segment. If very low mortality prevails, an accumulating population of floaters may, by interfering with natality, operate to eventually reduce itself to an equilibrium level (Hunt 1988). Therefore, within limits, an increased mortality rate may have no adverse consequence on the reproductive potential of a population (see Hansen and Hodges 1985, Hansen 1987, Hunt et al. 1992a).

Juveniles are eagles less than one year old, and subadults are from one to three years of age. The number of juveniles in each yearly cohort is restricted first by output from a limited number of serviceable breeding locations, and further by mortality factors. Numbers of eggs, nestlings, and fledglings may decline as a result of food scarcity, weather events, floater interference, human disturbance, predation, parasitism, etc. After fledging, the itinerant juveniles and subadults experience further attrition, both natural and human-related, although the causes and relative rates of mortality affecting these nomadic life stages are not as well quantified as they are for nestlings.

3.2.3 What is a Population Impact? There are a number of factors to consider in determining whether or not WRA-related fatalities are affecting golden eagles on a population basis. First, there is the question of which population(s) of golden eagles might be affected by fatalities at the WRA. Specifically, what proportion of those eagles frequenting the WRA environs (especially during seasons of turbine activity) represent populations breeding locally versus those from relatively far away?

Next is the issue of the net effect of WRA-related fatalities on the dynamics of the population(s) identified above. The most extreme impact would be the extirpation or substantial reduction of a breeding population within a large area. Such a result could be brought about by mortality reducing (1) the breeding segment directly, (2) the floating segment, reducing it to numbers insufficient to replenish losses to the breeding segment from other causes, and/or (3) the numbers of younger eagles, the consequence of which would be a reduction in the flow of recruits to the floating and breeding segments (Figure 3.1).

If research reveals that the breeding segment is not expected to decline, the population may nevertheless be impacted by a decrease in floater numbers. Floater reduction would make the breeding segment more vulnerable to future changes in mortality or natality. A proper impact assessment therefore requires an analysis of the effects of turbine-related mortality on the floaterto-breeder ratio at equilibrium (see Hunt 1988) in a closed population. The reason to assume closure is that an unfavorable balance of demographic parameters might well be masked by the buffering effect of immigration. Is the latter an acceptable condition of population maintenance when the recipient population acts as a mortality drain for those surrounding it?

Finally, there is the possibility that WRA-related mortality has no net effect on either the number of breeding pairs or the regional population because the latter is at equilibrium with its food supply; that is, the mortality occurring at the WRA is compensated by greater survivorship stemming from lessened competition. Similarly, the average number of eagles occupying the region might be set, not by starvation, but by emigration in response to territorial strife (see 


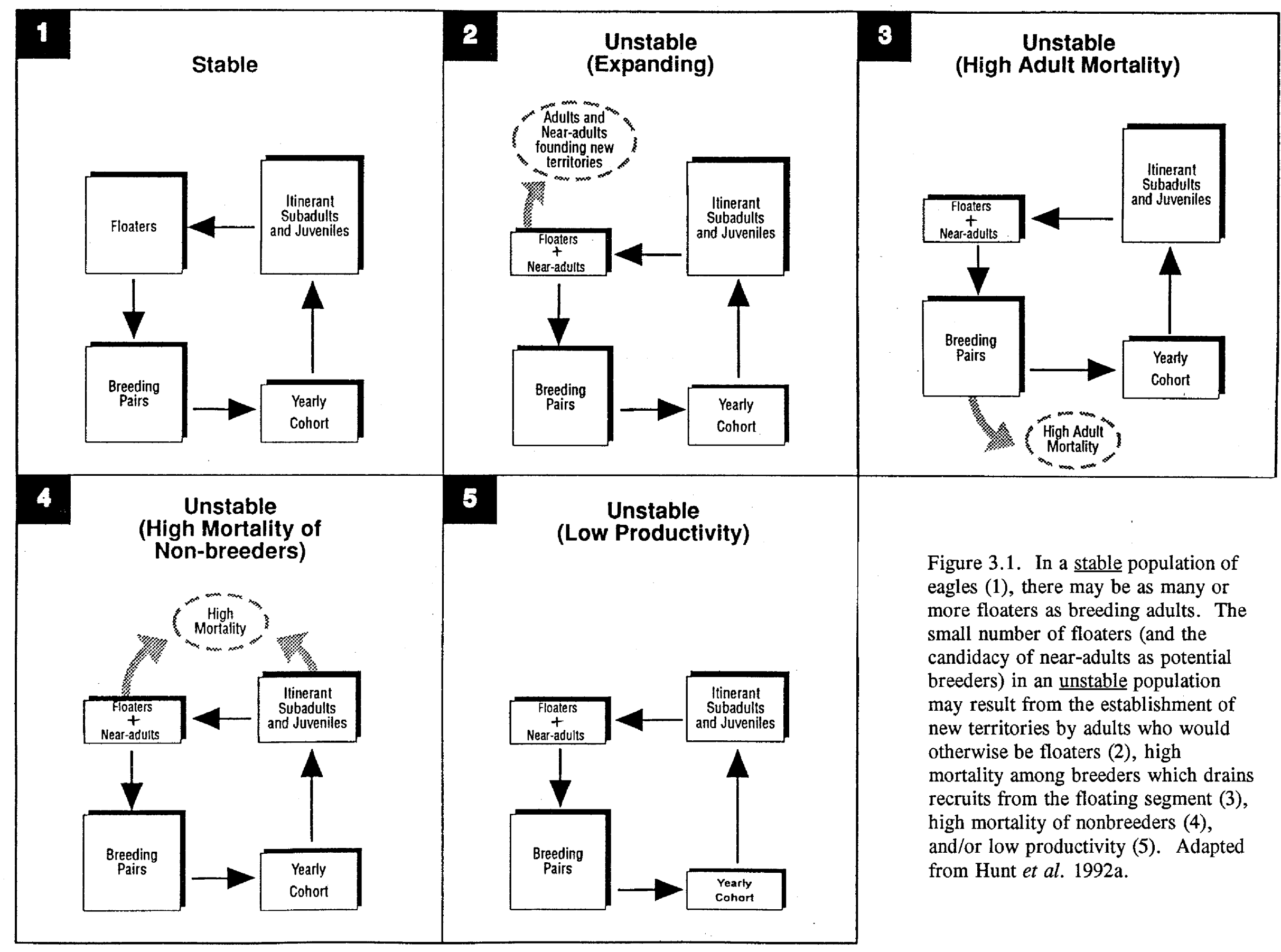


Gonzalez et al. 1989). The latter alternative is simply another way of defining a "source population," and we would consider the loss of that function to be a deleterious effect.

The issue of "compensatory mortality" deserves further comment. If floater interference significantly reduces natality, than reductions in the floating segment from WRA turbine kills might have no net effect on the population. Likewise, if density-dependent food competition normally causes starvation or increases the death rate from factors arising secondarily from starvation, turbine-related mortality may have no population consequence. Unfortunately, none of these factors are easily examined, particularly without control populations. However, in reflecting on the possibility that WRA mortality is compensatory, we observe that while the distribution of golden eagle breeding habitat in California is limited by the chance juxtaposition of SBL components (see Section 3.2.2), there appears to be an abundance of survival habitat that is surely accessible to dispersing birds. In other words, density-dependent starvation seems unlikely.

A primary indication of a possible deleterious effect of WRA fatalities on the eagle nesting population would be the frequent discovery of subadults or near-adults as members of breeding pairs, especially in prime habitat. This might suggest that excessive mortality had drained the floating population to a point at which there were insufficient numbers of adults to fill vacancies.

A healthy population of golden eagles is one in which the breeding segment is buffered by a substantial floating segment of non-breeding adults (Figure 3.1). Especially in an environment where food supplies are relatively stable from year to year, floater pressure should tend to drive up the age of first breeding such that virtually all breeders are mature adults (over four years old). We would expect younger birds (i.e., near-adults) to be less competitive because they are less experienced than adults and, for evolutionary reasons, they are less inclined to risk a violent territorial encounter with an older, more experienced eagle (Hunt 1988). The common appearance of eagles lacking full-adult plumage as members of breeding pairs, especially in territories known to be occupied in the past by adults, might indicate a declining population. On the other hand, if a breeding population is rapidly expanding in response to a newly exaggerated food supply, pairs of younger birds might create territories in formerly unsuitable terrain (see Section 3.1.4).

Poor reproduction would definitely not be an indication of a WRA impact. As mentioned above, in conditions of ample food availability, low reproductivity might be caused by territorial strife associated with an overabundance of floaters. Frequent territorial interactions with floaters and near-adults during courtship and incubation would probably be a clear sign of a robust population. 


\subsection{STRATEGY FOR DETECTING A POPULATION IMPACT}

To predict an impact on a golden eagle population by WRA-related mortality, without relying on the buffering effect of immigration from other populations, we must establish whether the overall demographic performance of that population is sufficient to absorb the losses incurred on the WRA. To do so we must (1) identify the population at risk, (2) quantify the reproductive rate, and (3) estimate the annual survivorship of each population segment, including that of nonbreeding adults (floaters) whose well-being is critical to that of the breeding segment. We must take into consideration any large scale yearly variation in birth rates or death rates that may result, say, from normal fluctuations in food supply, weather, habitat modification, or floater interference. If we wish to go further and compare the number of annual fatalities with the size of the population we identify as vulnerable, we would do well to estimate the size of the yearly cohort of fledglings.

\subsection{Estimating the Kill}

On the basis of periodic carcass surveys conducted at selected sites on the Altamont Pass WRA from March 1989 to February 1991, Orloff and Flannery (1992) reported 124 dead raptors, vultures, and ravens. Identified in the sample were 16 golden eagles, 54 red-tailed hawks, 20 American kestrels, and an assortment of others, including 8 owls. Sixty-two percent of the deaths in the entire sample were ascribed to collisions with turbines, 8 percent to wire strikes, 9 percent to electrocutions, and 21 percent to unknown causes. In a subsample in which there was a high certainty of cause of death, the rate of turbine collision mortality increased to 84 percent. By extrapolating from their survey sites to the entire WRA, Orloff and Flannery estimated that 39 golden eagles were annually killed, but recognized that the estimate contained a large potential for error.

Since Orloff and Flannery's study, the wind energy companies have been making an effort to report all bird deaths encountered by industry personnel working at the WRA to authorities at Alameda County and the U.S. Fish and Wildlife Service (USFWS). According to Special Agent Cynthia Struzik (USFWS Enforcement Division) there were 27 golden eagle kills at the WRA reported to her 1993, of which 26 could be attributed to turbine strikes and one to electrocution. From January through November 1994, her records include 31 golden eagles recovered in the WRA, of which 28 were determined to be turbine strikes; 2 were wire strikes, and 1 an injury of unknown cause. These records suggest that at least 93 percent of golden eagle casualties in the WRA are caused by turbine blade strikes.

To estimate age structure of golden eagles killed at the WRA, Pete Bloom examined plumage characteristics of a sample of 35 individuals collected by D. Weingart (KENETECH Windpower) and Agent Struzik during 1993 and 1994. None of these birds were in their first calendar year of life, 5 were in their second year, 11 in their third, 4 in their fourth, 2 could only be described as "after second year," and 13 were adults, that is, after fourth year. The sample included 8 females, 11 males, and 16 eagles of undetermined sex. 
Orloff and Flannery (1992) were unable to detect a seasonal trend in raptor mortality rate. Part of the difficulty lay in estimating the kill month for the remains they collected, many of which had been there for extended periods. In any case, Orloff and Flannery's sample of 16 dead eagles, only a portion of which could be dated, was too small for a seasonal assessment. From October through February, when there are relatively few windy days, there are far more raptors (but not necessarily more golden eagles) in the area than during the windy season. Therefore, it is not surprising that in recent collections by Weingart and Struzik of turbine kills of raptors of all species (corrected for kill month), the greater number of kills occurred outside the windy season.

Clearly, Orloff and Flannery's estimate of 39 eagles annually killed in the WRA remains plausible. However, the question of accuracy looms large in that no current estimate of error is feasible. This is because of the complications associated with unknown geographic and seasonal variation in kill rate, scavenging rate, effects of turbine type, and variable distributions of habitat and prey within and near the WRA. Other than the reporting of carcasses by industry workers incidental to their work on the turbines, there is no systematic sampling procedure that could estimate the kill over the entire WRA.

\subsection{Identifying the Population(s) Potentially Impacted}

The first step in assessing the impact of WRA-related mortality on golden eagles is to identify the population potentially at risk. It is fair to assume that if the fatalities are affecting the eagles on a population basis, those most likely to experience reduction are those native to the area. Adult eagles whose nests lie beyond a certain distance would not be expected to visit the WRA during the breeding season, nor would their young be apt to do so with the frequency of those dispersing from nests nearer the facility.

It is unlikely that substantial numbers of migrant or nomadic eagles from elsewhere, say, greater than $200 \mathrm{~km}$ distant, are currently being killed in the WRA in numbers sufficient to impact their natal populations. We recognize that eagles originating in areas where food supplies are seasonally restricted (e.g., heavy snow or ground squirrel estivation) are apt to migrate varying distances. However, we believe that a hypothesis that alien eagles from specific populations far removed would visit an area as small as the WRA $\left(181 \mathrm{~km}^{2}\right)$ at levels sufficient to jeopardize those populations is unparsimonious. Instead, we anticipate a dilution-by-distance in risk probability relative to the WRA.

In any case, radio-telemetry offers the best, if not the only, way to estimate and quantify the geographic sources of eagles to the WRA. Transmitters of sufficient power are detectable at considerable distances in airplane surveys and are equally locatable in all habitats within an area (Hunt 1987). Therefore, our technique is to tag a statistically valid sample of golden eagles in and around the WRA and to determine in subsequent surveys the proportion that remain in the surrounding region. If that proportion is high, then the hypothesis of an impact on that population by WRA-related mortality is worthy of being tested. If, instead, a substantial 
proportion of the tagged sample departs to unknown areas and remains absent during the breeding season, then it would be necessary to employ transmitters appropriate to satellitetracking to determine whether the source populations-were particulate or diffuse in distribution. If particulate, then a demographic assessment of those populations might be indicated.

\subsection{Estimating Natality}

After the region is identified which contains the golden eagle population potentially impacted, we can seek to evaluate the nesting population residing there to determine whether it tends to augment itself with sufficient numbers of young each year to offset the annual mortality at the WRA. The number of fledglings per nest required to buffer the loss is unknown at this time, and properly estimating it depends on knowledge of both the kill rate and survivorship of each population segment.

We should recognize at the onset that, to reach the goal of impact determination, it is not essential to estimate accurately the total numbers of eagle pairs in the identified region. Rather, we must, in the light of survival data, determine whether or not enough eagles annually fledge, either per nest or from the population as a whole, to render the WRA-related death rate inconsequential.

However, if we judge that the actual number of pairs in the region is close to that required to withstand a WRA impact, then an accurate estimate of the nesting population might be indicated. Ideally, to accomplish this, we would employ a technique of stratified random sampling, so that within each habitat type, defined by vegetation, topography, land use practices, and disturbance factors, we might survey from a randomly selected series of points or transects. These must be of sufficient quantity and appropriate distribution to provide statistically valid means and confidence intervals for the numbers of occupied breeding areas (i.e., pairs with nests) in each habitat (Krebs 1989). From that result, subsets of data on the proportions of successful pairs, and the numbers of fledglings per successful nest, would produce an estimate of the size of the annual fledgling cohort in the selected region for the years of survey. The remaining task would be, and must be regardless of the strategy applied, to predict the longer term variation in natality as a function of changes in prey base, weather, or habitat. Reductions in natality resulting from increased floater interference would not be regarded as negative from a demographic standpoint.

In designing the field research appropriate to stratified random sampling, we should be aware that the mountains of central California contain a mosaic of private ranches, many of which are currently inaccessible to us. Large amounts of time are required in obtaining permission to survey almost any ranch, and some ranchers grant only one-time visits. Apparently, the two primary reasons that ranchers are hesitant to allow access are, (1) exposure to liability suits, and (2) fear that we will find an endangered species on their land and thereby jeopardize its profitability. 
Moreover, in January, February, and early March, when eagle pairs are most apt to signal the locations of their nests by courting flights and undulation displays, and when nests in deciduous oaks are temporarily conspicuous, there is frequent rain. When the roads are muddy, most ranchers do not allow driving because of rut formation. Given these restraints, and the fact that most golden eagle territories are difficult to access even in the best of habitats, we caution that the practicality of a highly systematized survey is a matter involving considerable uncertainty.

For such reasons, our technique in 1994 was simply to find as many nests as possible on the properties where permission was given to conduct surveys, and, in allocating our time, we tended to search areas we intuitively regarded as the most promising. Many of the nests in our sample were previously known by others, and we initially established habitat "search images" on the basis of these known nests, impressions that may or may not be valid for the larger study region.

\subsection{Estimating Survival Rates}

Each population segment experiences natural and man-caused attrition, the rate of which probably differs for each segment owing to differences in exposure. For example, one would think that breeders, particularly those which remain on territory year-round in west-central California, may have the least difficulty surviving, although there are surely mortal consequences stemming from the physiological wear and tear of reproduction and the bodily risks of frequent territorial defense. Juveniles and young subadults, being less experienced in foraging and in avoiding the many dangers encountered in their itinerancy, might be expected to show lower rates of survival.

When we began this study we were completely unaware of the extent to which the yearly sum of WRA fatalities contributes to the overall death rate of the golden eagle population residing in the region. Because of the difficulty of finding dead eagles visually, the large area involved, and the likelihood that carcasses are often scavenged before they are found, a relatively large proportion of total fatalities (from all causes) are never found.

In comparison, transmitters are readily discovered, especially during airplane surveys, not only in the vicinities of turbines but elsewhere, and without the bias associated with relative degrees of visual conspicuousness. Except in cases where transmitter function is destroyed by the lethal agent, telemetry offers the opportunity of finding all fatalities within the surveyed area, not just those caused by the WRA structures.

By radio-tagging a statistically valid sample of each population segment (see Section 4.2) and by periodically accounting for all working transmitters within the study area by the twice-weekly airplane roll-call census, we can record each raptor death within a few days of its occurrence (each transmitter will contain a mortality sensor). Given a sufficient sample of radio-tagged birds and total fatalities, we can estimate the mortality rate resulting from WRA collisions versus that from other causes. 
An uncertainty with this technique arises when a transmitter is no longer detected in the surveyed area. In such a case, the researcher cannot distinguish between the possibilities that the eagle has emigrated or that the transmitter has failed. A partial solution lies in censoring from the sample the missing or failed transmitter on the assumption that the eagle carrying it has the same probability of being alive or dead as those still being detected in the surveys. For golden eagles, such an assumption does not recognize cases in which the transmitter is destroyed by the lethal agent, as might occur during an electrocution or possibly a turbine strike. Another factor to consider is that individuals, particularly juveniles, which leave the study area, may do so because they are incapable of competing for food with resident eagles. In such circumstances, the emigrants might not be expected to perform better elsewhere and may die of starvation or related causes outside the surveyed area. To accommodate these possibilities, it is reasonable to express survivorship in terms of best case and worst case scenarios.

Bunck (1987) lists five assumptions necessary for estimating survival rates from telemetry data: 1) the population must be sampled at random; 2) radio-tagging must not affect survival; 3 ) the fate of each radio-marked animal is independent of all others; 4) censoring of any individual (e.g., through transmitter failure) is independent of fate; and 5) the exact time of death is known.

\subsection{Assembling a Life Table}

The research steps we have described in sections 4.1 (WRA kill estimation), 4.2 (population identification), 4.3 (cohort estimation), and 4.4 (survivorship estimation) are the ingredients of a golden eagle life table from which one can very likely predict, in the absence of immigration, whether the identified breeding segment would be expected to decline as a result of WRA influences. If a decline is not expected under the discovered mortality regime, the life table can be used to predict the condition of the floating segment whose well-being is essential to the breeding segment. To what extent immigration from other regions may supplant missing floaters and thereby buffer the breeding population from decline cannot be predicted from the life table.

\subsection{IDENTIFYING POPULATIONS POTENTIALLY IMPACTED}

Golden eagles are considered an uncommon, permanent (breeding) resident and migrant in California (Harlow and Bloom 1987, Zeiner et al. 1990). Nesting populations exist in Great Basin habitats of northeastern California (Bloom and Hawks 1982), in the Southern Transverse Ranges (Dixon 1937, Scott 1985), the Central Coast ranges (Carnie 1954, Estep and Sculley 1989), the Sierra Nevada (Thelander 1974, Schlorff 1986), and the Mojave-Colorado desert (Thelander 1974, Scholff 1986). From the results of a statewide survey, Thelander (1974) estimated that California supported 500 territorial pairs of golden eagles, and except for their extirpation from most of the San Joaquin Valley, their historical range (throughout California) remains unchanged (Harlow and Bloom 1987, Schlorff 1986). 
Remsen (1978) reported that golden eagle numbers were reduced from historical levels near human population centers, the most noticeable declines of the breeding population occurring in coastal southern California (Scott 1985, Harlow and Bloom 1987). Thelander (1974) resurveyed sites in southern California and the Inner Coast Ranges of central California that were previously inventoried by Dixon (1937) and Carnie (1954) respectively. He found an inverse relationship between unoccupied nesting territories and areas of housing development. Over 50 percent of the territories studied by Carnie (1954) east of San Francisco Bay had been eliminated by urban sprawl by 1974. Active territories in the Southern Transverse Ranges remain in remote areas such as military installations or large private ranches (Schlorff 1986). Off-road vehicle use, habitat destruction, and shooting may account for a recent trend of low golden eagle breeding activity in the Mohave-Colorado desert region (Schlorff 1986).

Other portions of California contain golden eagles in varying densities. The northern Sierra Nevada and Cascade Mountains contain nesting pairs up to 10,000 feet in elevation. Eagles generally avoid areas of continuous forest or closed-canopy vegetation, and nests found in forested land are often close to grassy valleys, meadows, or sagebrush flats (Schlorff 1986). The sport of rock climbing has impacted certain nest sites in the southern Sierra Nevada/White Mountains (Schlorff 1986). The more open grassland and sage-scrub habitats within the Great Basin Region of northeastern California contain greater nesting densities, with few threats to the population (Thelander 1974, Schlorff 1986).

\subsection{Methods}

To begin to identify the source populations of eagles entering the WRA, we radio-tagged 32 adults and subadults in the vicinity of the WRA; we tagged 31 of these in winter. In late spring and early summer, we radio-tagged an additional 25 juveniles in the area within about $30 \mathrm{~km}$ of the WRA.

5.1.1 Capture and Tagging of Adults and Subadults. We employed two methods to capture the adults and subadults: a radio-controlled bow-net as described by Jackman et al. (1994) and a pit trap developed by Bloom (1987). Once captured, each eagle was safely secured, hooded, and handled carefully to avoid stress. Figure 5.1 shows the capture locations of the 32 radiotagged eagles (11 adults and 21 subadults), and Table 5.1 gives details on age, sex, and physical condition of each bird.

We fitted each eagle with a 65-gram, two-stage Biotrack transmitter with an estimated battery life of five years. Each unit, weighing 1.3 -1.8 percent of eagle body weight, was equipped with a mortality sensor designed to activate when the transmitter remains motionless for four hours (see Section 7.1). We attached the transmitters in back-pack configuration using $1.3 \mathrm{~mm}$ teflon ribbon held together with waxed cotton embroidery thread over the carina, a procedure that allows the transmitter to eventually fall off (see Garcelon 1985, Hunt et al. 1992b). This method, in wide use during the past decade, is harmless to the birds, and there is no effect of

capture or transmitter application that is known to modify eagle behavior (although see Marsluff 


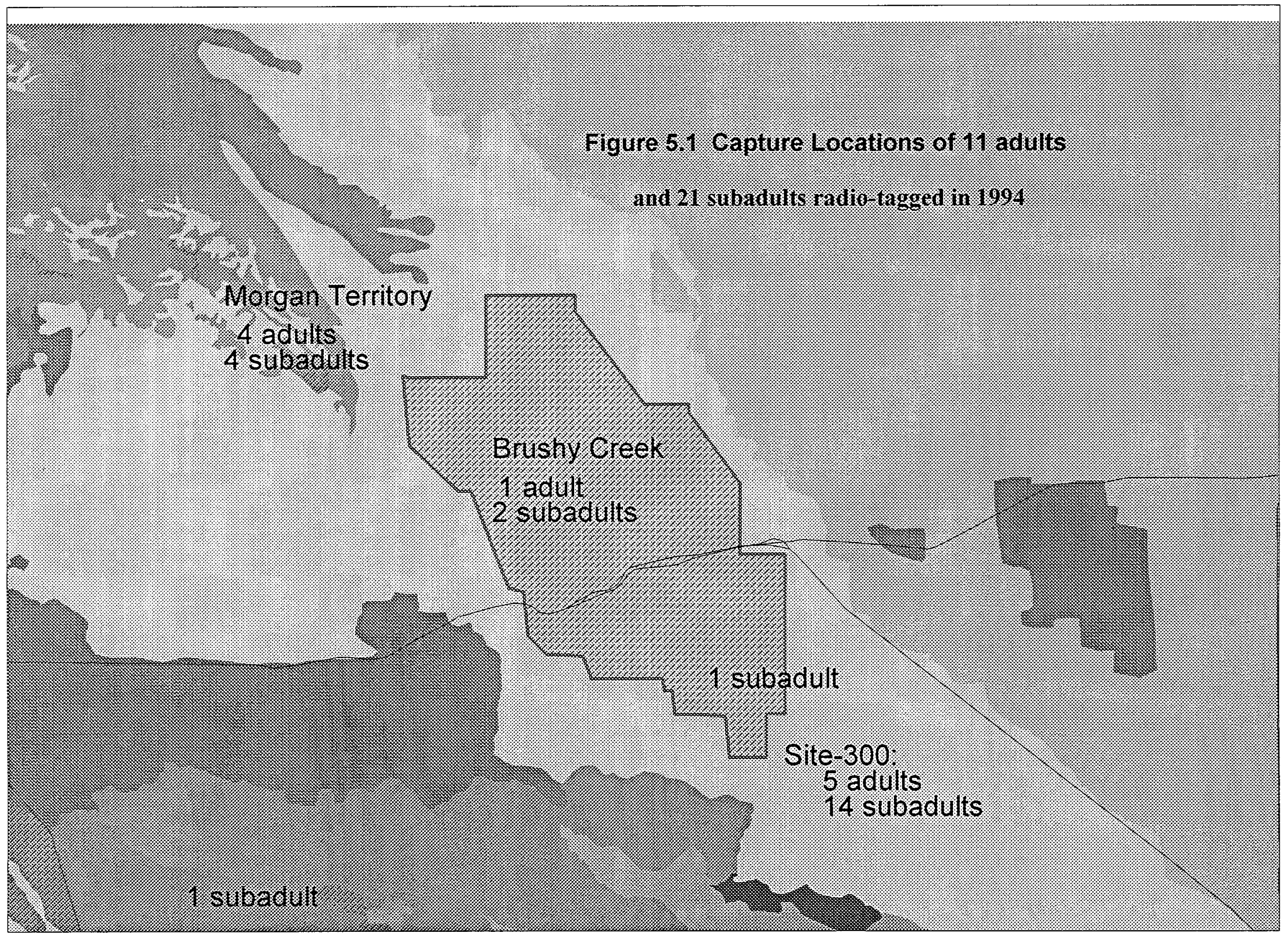


Table 5.1 Information on 32 golden eagles radio-tagged at or near Altamont Pass in 1994.

\begin{tabular}{|c|c|c|c|c|c|c|c|c|}
\hline Class & Sex & ID & Date & Capture Location & Age & Wt & Keel & Comments \\
\hline Adult & $\mathrm{F}$ & AF01 & 08-Jan & Morgan Territory & $>4$ & 5.0 & 3.8 & Blind in one eye; plumage ragged \\
\hline Adult & $\mathrm{F}$ & AF02 & 25-Jan & Site 300 & $>4$ & 5.3 & 4 & \\
\hline Adult & $\mathrm{F}$ & AF03 & 02-Feb & Morgan Territory & $>4$ & 6.2 & 4.5 & \\
\hline Adult & $\mathrm{F}$ & $\mathrm{AF} 04$ & $28-F e b$ & Morgan Territory & $>4$ & 4.8 & 3 & \\
\hline Adult & $\mathrm{F}$ & AF05 & 01-Mar & Site 300 & $>4$ & 5.1 & 3.8 & \\
\hline Adult & $\mathrm{M}$ & AM01 & 05-Jan & Morgan Territory & $>4$ & 3.9 & 3.5 & \\
\hline Adult & M & $\mathrm{AM02}$ & 17-Jan & Site 300 & $>4$ & 4.1 & 3.3 & Appears very old; foot injuries, new and old \\
\hline Adult & M & AM03 & 19-Jan & Site 300 & $>4$ & 3.2 & 3 & \\
\hline Adult & M & AM04 & 19-Jan & Site 300 & $>4$ & 4.3 & 4.5 & \\
\hline Adult & M & AM05 & 31-Jan & Hodges Ranch & $>4$ & 3.7 & 3 & \\
\hline Adult & M & AM06 & 14-Feb & WRA & $>4$ & 4.0 & 3.5 & Grease on wings and tail; matted feathers \\
\hline Subadult & $\mathrm{F}$ & NF01 & 06-Jan & Site $\mathbf{3 0 0}$ & 4 & 4.4 & 3.8 & \\
\hline Subadult & $\mathrm{F}$ & NF03 & $07-F e b$ & Site 300 & 4 & 4.6 & 3.5 & Talon wound in left thigh; brood patch? \\
\hline Subadult & $\mathrm{F}$ & NF04 & 02-Mar & Morgan Territory & 4 & 5.5 & 4 & \\
\hline Subadult & $\mathrm{F}$ & NF05 & 29-Jul & WRA & 4 & 4.3 & 3.5 & \\
\hline Subadult & M & NM01 & 26-Jan & Site 300 & 4 & 3.4 & 3 & \\
\hline Subadult & M & NM02 & 23-Feb & Site 300 & 4 & 3.3 & 3 & ' \\
\hline Subadult & M & NMO3 & 23-Feb & Site 300 & 4 & 3.6 & 3.5 & \\
\hline Subadult & $\mathrm{F}$ & SF01 & $02-\mathrm{Feb}$ & Site 300 & 4 & 5.5 & 3.5 & \\
\hline Subadult & $\mathrm{F}$ & SF02 & 02-Feb & Morgan Territory & 4 & 4.8 & 3.5 & \\
\hline Subadult & $\mathrm{F}$ & SF03 & 04-Feb & Site 300 & 3 & 5.0 & 3.5 & \\
\hline Subadult & $\mathrm{F}$ & SF04 & 07-Feb & Site 300 & 2 & 4.4 & 3 & \\
\hline Subadult & $\mathrm{F}$ & SF05 & $12-\mathrm{Feb}$ & WRA & 3 & 5.1 & 3.5 & \\
\hline Subadult & $\mathrm{F}$ & SF06 & 14-Jan & Site 300 & 3 & 4.5 & 3.5 & \\
\hline Subadult & $\mathrm{M}$ & SM01 & 11-Jan & Site 300 & 3 & 3.9 & 3.5 & \\
\hline Subadult & $\mathrm{M}$ & SM02 & 12-Jan & Site 300 & 3 & 3.3 & 3.5 & \\
\hline Subadult & $\mathrm{M}$ & SM03 & 19-Jan & Site 300 & 3 & 3.9 & 3.5 & \\
\hline Subadult & $\mathbf{M}$ & SM04 & 27-Jan & Morgan Territory & 2 & & 3 & \\
\hline Subadult & $\mathbf{M}$ & SM05 & 04-Feb & Site 300 & 3 & 4.0 & 3.5 & \\
\hline Subadult & $\mathbf{M}$ & SM06 & $11-$ Feb & Site 300 & 3 & 3.7 & 3 & \\
\hline Subadult & $\mathrm{M}$ & SM07 & 25-Feb & WRA & 3 & 3.6 & 3.5 & Grease on secondaries; wound on toe \\
\hline Subadult & M & SM08 & $28-F e b$ & Morgan Territory & 3 & 3.5 & 3.5 & Beak has deep groove, cere to tip \\
\hline
\end{tabular}

Age = calendar year of life; weights are in $\mathrm{Kg}$; "keel" refers to condition of breast muscle; $\mathbf{O}=$ emaciated; $\mathbf{5}=$ plump. 
1994). On the back of each transmitter we encased a paper Visual Identification (VID) symbol in clear epoxy, the code consisting of a single alphanumeric symbol. We fitted each adult with a standard aluminum (silver) U.S. Fish and Wildlife Service band on the left tarsus; all other eagles were banded on the right tarsus. We recorded morphological characteristics on "Cap Forms" (Appendix C). Plumage characteristics recorded included iris color and molt characteristics. We determined the physical condition of each bird on the basis of weight, body condition, and crop condition. We recorded weight within $0.1 \mathrm{~kg}$ using a Pesola scale, aided by a triangular bandage to secure the eagle. Measurements of crop condition included three categories: full, partial, and empty. We measured body condition using a five-point scale based on breast muscle and sternum keel protrudence (Hunt et al. 1992a) as follows:

1. Sternum keel bladed with minimal breast muscle

2. Sternum keel bladed with more prominent breast muscle

3. Sternum keel protrudes slightly above breast muscle (normal)

4. Sternum keel flush with breast muscle

5. Sternum keel inundated in breast muscle

5.1.2 Tagging Juveniles. We radio-tagged 24 of our sample of 25 juveniles as nestlings during 21 May - 1 July; we caught the remaining bird on 4 July, about two weeks after fledging. Based on our past experience radio-tagging juvenile bald eagles, we had intended to tag the entire sample of juvenile golden eagles as eight-week-old fledglings. However, on our first nest climbs, we noted a distinct deficiency in pectoral development as compared to the bald eagles, a factor that made it impossible to properly fit the transmitter attachment ribbons. Accordingly, we postponed our nest climbs until the young were more fully developed at 9-10 weeks, an age when the birds were more likely to fly from the nest. We found that we were obliged to select nests in relatively open country so as to avoid risk of loss or injury from premature flights.

We utilized three methods to access tree nests; 1) climbing spikes and flip ropes, 2) freeclimbing with a belay rope, and, 3 ) throwing a weighted tennis ball over a branch near the nest, pulling the rope over the branch, then climbing up a fixed line. Upon reaching the nest we secured the eaglets, placed leather falconer's hoods over their heads to calm them, and put polypropylene booties (candle lantern cases) on their feet to protect them from injuring themselves or their sibling(s). We then lowered the eaglets to the ground, in a padded, ventilated bag for processing.

We fitted each nestling with a standard aluminum U.S. Fish and Wildlife Service band on the right tarsus, recorded morphological characteristics, and fitted each transmitter, according to techniques described in Garcelon (1985, and see above), with an increased spacing of 7-9 cm between the transmitter and the eagle to allow for growth. The VID symbols on the transmitter backs consisted of a number over a letter (ie: 1/A, 1/C, 1/H, 1/Y). The numbers in VID symbols will correspond to the banding year if the study continues $(1=1994,2=1995,3=1996$, etc.). 


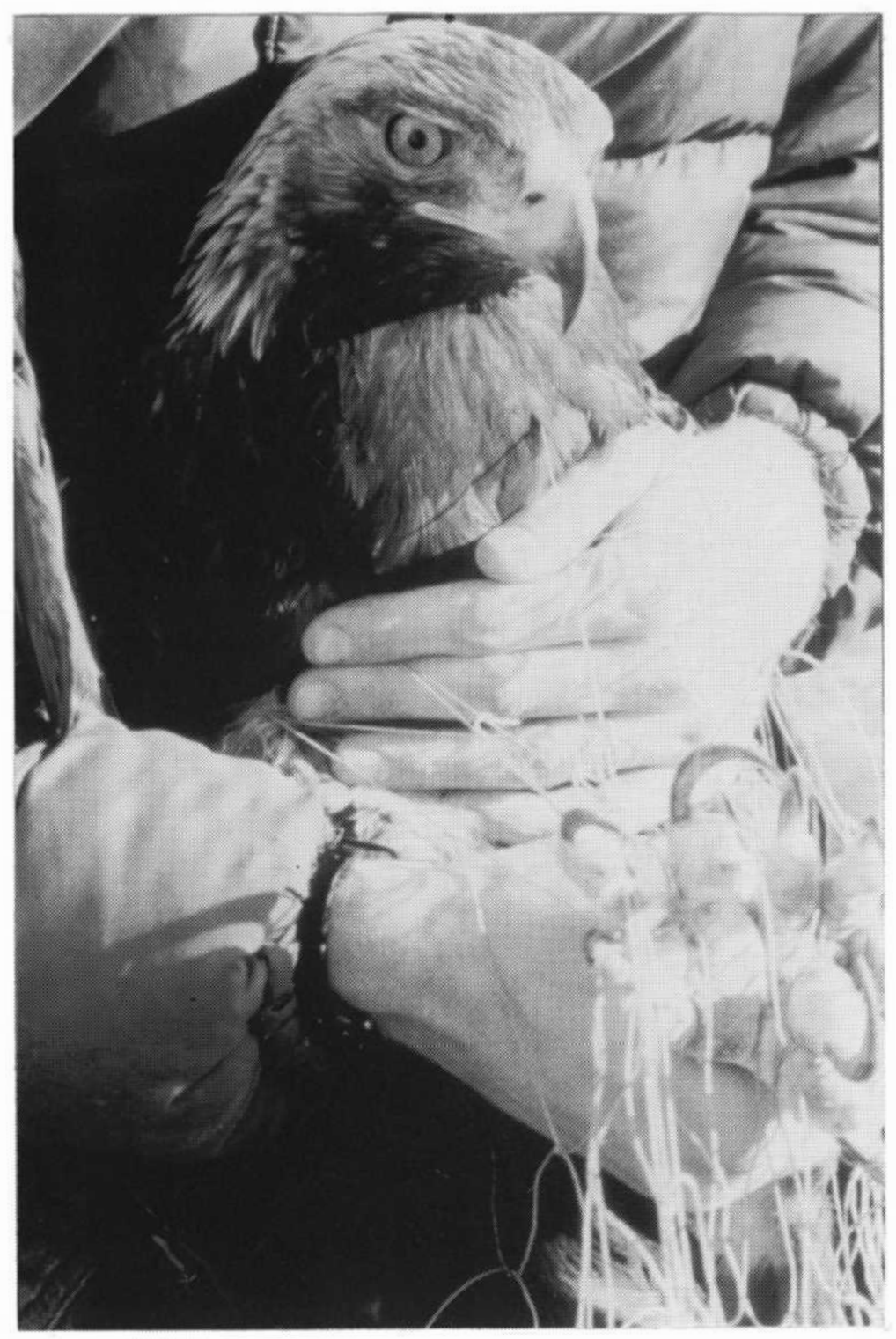

Golden eagle captured in the bow net (photo by Brian Latta)

We weighed each eaglet and measured standard morphological characteristics; standard body measurements included hallux length, tarsus width (dorsal/ventral and lateral), wing chord length, eighth primary length, tail length, culmen length, and beak depth. Hallux length, culmen length, beak depth, wing chord length, eighth primary length, and tail length measurements followed Bortolotti (1984b,c). Tarsus width (dorsal/ventral and lateral) measurements followed Garcelon et al. (1985). Methods of tail length measurement varied from Bortolotti's to include length of the central retrices from the distal end to the sheath. When hatch dates were not 
known, we aged the eagles on the basis of plumage characteristics as reported by Hoechlin (1976).

5.1.3 Roll Call Census. Weather permitting, we conducted roll-call censuses of the study area twice per week by airplane, beginning 14 January 1994. For this purpose we used a single engine Cessna (Skylane 182) fitted with side-facing antennas on the wing struts and a switch box in the cabin enabling separate monitoring of antennas. In each survey flight, we scanned all transmitter frequencies at 1.5 -second intervals along a course designed to locate all the birds in the sample. On one of the weekly surveys we searched the entire study region from the Oakland Hills south through the Diablo Range to San Luis Reservoir; on the alternate survey we censused suitable habitats within about $30 \mathrm{~km}$ of the WRA boundary ("30-km zone"). Because of the large number of transmitters, we found that strict adherence to a prescribed survey route was inefficient and unnecessary. Instead, we traveled first (at relatively low altitude for maximum locational accuracy) to areas of expected occurrence and concentration, areas which may differ in location from month to month. By quickly finding those birds whose locations could be anticipated, we are able to reduce the scan time to a point at which a systematic search for the remaining transmitters became practical; the search pattern we adapted is shown in Appendix C. During searches for missing transmitters, we climbed to a higher altitude, e.g., 8,500 feet MSL, for maximum receptivity at distance.

We chose the 3-4 day interval between surveys as the minimum at which we could expect accurate necropsy results for discovered fatalities; in this respect, our schedule of flights has been successful (see Section 7). At the time of this writing, we have not tested the accuracy of telemetry relocations obtained during the flights, but will do so at the soonest opportunity; for now, we estimate routine accuracy as marked by GPS (see Glossary) as within $0.6 \mathrm{~km}$ of the transmitter (see Marzluff et al. 1994). In general, we tried to obtain the most accurate fixes in the area within about $30 \mathrm{~km}$ of the WRA, but where habitat was homogeneous (e.g., extensive rangeland), we were less concerned with position accuracy. For various reasons (e.g., weather, airspace restrictions), we were occasionally unable to fly over the bird; such fixes were labeled "soft locations."

When each bird was located, we attempted to determine whether or not it was soaring. We identified this behavior on the basis of alternating rises and falls in signal strength as a result of changes in the orientation of the transmitting antenna relative to the receiving antenna. We occasionally saw the eagle we were attempting to locate, particularly when it was perched or flying low in open grassland.

We recorded position fixes on computer forms in degrees, minutes, and hundredths of minutes latitude and longitude. Later, we overlaid these fixes on maps depicting vegetation (digitized from satellite photographs) and other features, using AtlasGIS ${ }^{\mathrm{TM}}$, a computer mapping program. 


\subsection{Results of Telemetry Census}

5.2.1 Adults. Five of the 11 radio-tagged adults (one, a near-adult) were either breeders or gave the appearance of being breeders (Table 5.2 and Appendix E). Two tagged females, AF02 and AF03, produced young from nests lying $8.5 \mathrm{~km}$ and $9.5 \mathrm{~km}$ from the WRA boundary. At a third territory, about $12 \mathrm{~km}$ from the WRA, adult male AM01 was apparently mated with adult female AF01. The latter, noted at capture as blind in one eye and with ragged plumage, was killed by another eagle in late January. A four-year-old female, NF04 (the possible assassin), replaced AF01 as AM01's mate at what appeared to be an active nesting territory. We judged this on the basis of the behavior of the pair and from the very restricted range of relocations of both birds during the nesting season. However, we were unable to obtain access to the private property frequented by the pair.

At least six, and probably all seven of the remaining adults in the tagged sample were floaters, some of which travelled widely (Figure 5.2 and Appendix F), while others frequented specific areas for extended periods. One of the six left the study region twice for the area around King City, about $185 \mathrm{~km}$ to the south. The seventh eagle, AM06, departed the study area in late February, only two weeks after tagging, its itinerary unknown until 5 October when it reappeared near the WRA and has since remained. Given the date of its departure, it seems unlikely that it bred elsewhere in California.

5.2.2 Subadults. We tagged all but one of the 21 subadults in winter, from 6 January to 2 March (Table 5.3). One of these, four-year-old NF04, is an apparent breeder and, its itinerary being qualitatively different from those of the other subadults, we place it in the sample of breeders. Another bird, NF05, tagged in the WRA on 29 July, quickly departed the study area. It had moved $26 \mathrm{~km}$ south of the capture site by 1 August and $177 \mathrm{~km}$ southeast by 4 August. We have no further information on this bird.

Of the refined sample of 19 subadults tagged in winter (6 January - 2 March), three (15.7\%) subsequently died (see Section 7.2) and four (21\%) either departed the study area or have failed transmitters. The remaining 12 eagles $(63 \%)$ currently reside in or near the study region (Figure 5.3 and Appendix G). Among the four birds whose transmitters disappeared from the roll call surveys are the following:

Subadult Female SF01 (4th calendar year). Tagged at Site 300 on 2 February, the last detection was on 29 March.

Subadult Male SM05 (3rd calendar year). Tagged at Site 300 on 4 February 1994, the last detection was on 7 June.

Subadult Female NF01 (4th calendar year). The last detection of this widely-ranging bird, tagged on 6 January at Site 300 , was on 12 July. 
Table 5.2. Tenure and status of 11 radio-tagged adult golden eagles in the Diablo Range study area.

\begin{tabular}{|c|c|c|c|c|c|c|c|c|c|c|c|c|c|}
\hline Bird & Tagged & Jan & $\mathrm{Feb}$ & Mar & Apr & May & Jun & Jul & Aug & Sep & Oct & Nov & Status \\
\hline AM01 & 05-Jan & $\mathrm{O}$ & 0 & $\mathrm{O}$ & $\mathrm{O}$ & $\mathrm{O}$ & $\mathrm{O}$ & $\mathrm{O}$ & $\mathrm{O}$ & $\mathrm{O}$ & $\mathrm{O}$ & $\mathrm{O}$ & Possibly bred with NF04 \\
\hline AF01 & 08-Jan & $X$ & & & & & & & & & & & Killed by eagle ca. 30 Jan. \\
\hline $\mathrm{AM} 02$ & 17-Jan & $\mathrm{O}$ & $\mathrm{O}$ & $\mathrm{O}$ & $\mathrm{O}$ & $\mathrm{O}$ & $\mathrm{O}$ & $\mathrm{O}$ & $\mathrm{O}$ & $\mathrm{O}$ & $\mathrm{O}$ & $\mathrm{O}$ & Floater \\
\hline AM03 & 19-Jan & $\mathrm{O}$ & $\mathrm{O}$ & $\mathrm{O}$ & $\mathrm{O}$ & $\mathrm{O}$ & $\mathrm{O}$ & $\mathrm{O}$ & $\mathrm{O}$ & $\mathrm{O}$ & $\mathrm{O}$ & $\mathrm{O}$ & Floater \\
\hline AM04 & 19-Jan & $\mathrm{O}$ & $\mathrm{O}$ & $\mathrm{O}$ & $\mathrm{O}$ & $\mathrm{O}$ & $\mathrm{O}$ & $\mathrm{O}$ & $\mathrm{O}$ & 0 & $\mathrm{O}$ & $\mathrm{O}$ & Floater \\
\hline $\mathrm{AF} 02$ & 25-Jan & $\mathrm{O}$ & $\mathrm{O}$ & $\mathrm{O}$ & $\mathrm{O}$ & $\mathrm{O}$ & $\mathrm{O}$ & $\mathrm{O}$ & $\mathrm{O}$ & $\mathrm{O}$ & $\mathrm{O}$ & $\mathrm{O}$ & Breeder (2 young) \\
\hline AM05 & 31-Jan & $\mathrm{O}$ & $\mathrm{O}$ & 0 & $\mathrm{O}$ & $\mathrm{O}$ & $\mathrm{O}$ & $\mathrm{O}$ & $\mathrm{O}$ & $\mathrm{O}$ & $\mathrm{O}$ & $\mathrm{O}$ & Floater \\
\hline $\mathrm{AF03}$ & 02-Feb & & $\mathrm{O}$ & 0 & $\mathrm{O}$. & $\mathrm{O}$ & $\mathrm{O}$ & $\mathrm{O}$ & $\mathrm{O}$ & $\mathrm{O}$ & $\mathrm{O}$ & $\mathrm{O}$ & Breeder \\
\hline AM06 & 14-Feb & & 0 & & & & & & & & $\mathrm{O}$ & 0 & Floater? \\
\hline AF04 & 28-Feb & & $\mathrm{O}$ & 0 & & $\mathrm{O}$ & $\mathrm{O}$ & $\mathrm{O}$ & 0 & $\mathrm{O}$ & $\mathrm{O}$ & $\mathbf{N}$ & Floater \\
\hline AF05 & 01-Mar & & & 0 & $\mathrm{O}$ & 0 & $\mathrm{O}$ & $\mathrm{O}$ & $\mathrm{O}$ & $\mathrm{O}$ & $\mathrm{O}$ & $\mathrm{O}$ & Floater \\
\hline
\end{tabular}

$\mathbf{O}=$ present in study area $\mathbf{N}=$ found outside study area; $\mathbf{X}=$ died. 


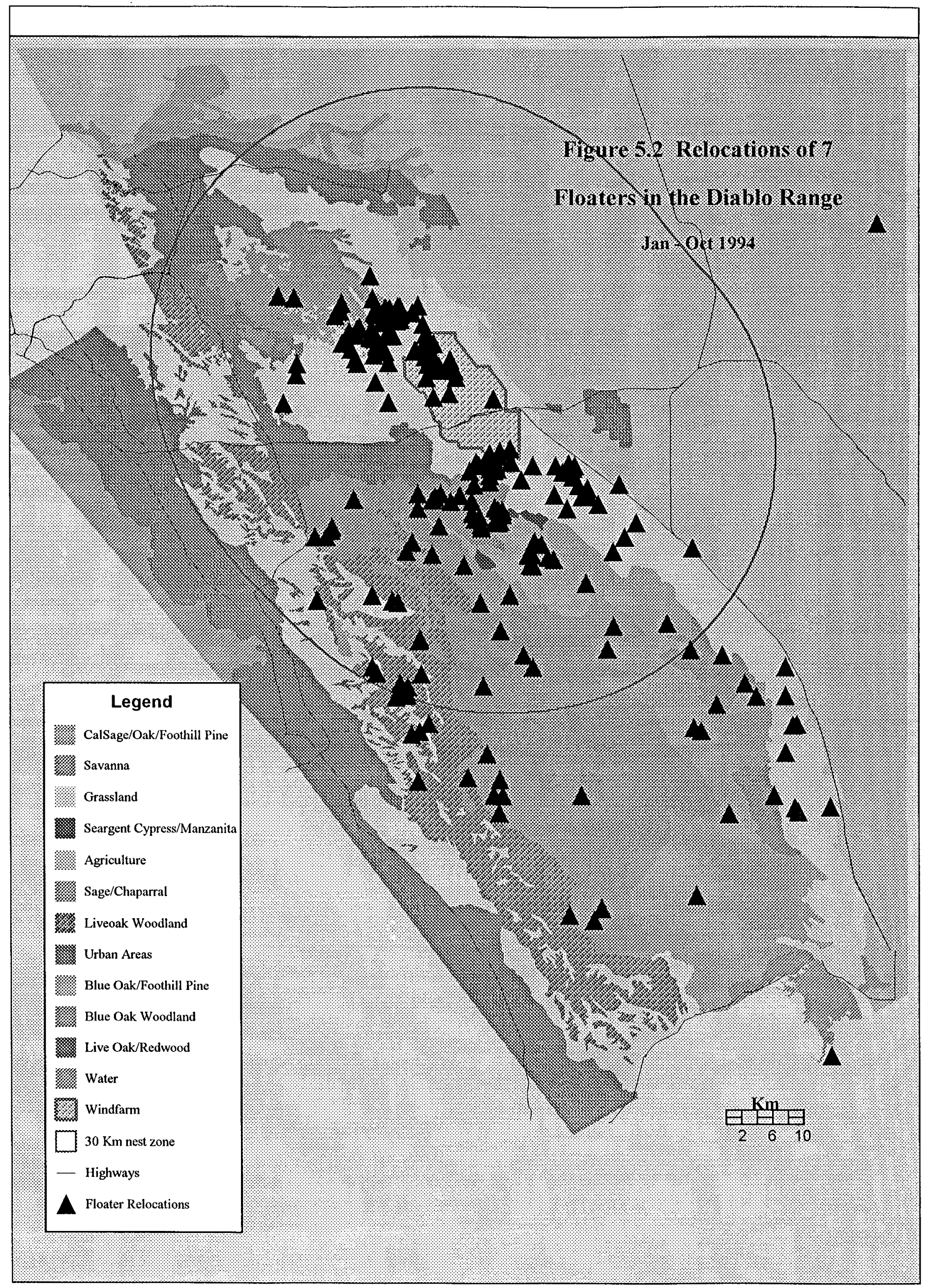


Table 5.3. Tenure of 21 radio-tagged subadult golden eagles in the Diablo Range study area.

\begin{tabular}{|c|c|c|c|c|c|c|c|c|c|c|c|c|c|}
\hline Bird & Tagged & Jan & Feb & Mar & Apr & May & Jun & Jul & Aug & Sep & Oct & Nov & Status \\
\hline NF01 & 06-Jan & 0 & $\mathrm{O}$ & $\mathrm{O}$ & $\mathrm{O}$ & $\mathrm{O}$ & 0 & $\mathrm{O}$ & & & & & \\
\hline SM01 & 11-Jan & $\mathrm{O}$ & $\mathrm{O}$ & $\mathrm{O}$ & $\mathrm{O}$ & $\mathrm{O}$ & $\mathrm{O}$ & $\mathrm{O}$ & $\mathrm{O}$ & $\mathrm{O}$ & $\mathrm{O}$ & $\mathrm{O}$ & \\
\hline SM02 & 12-Jan & $\mathrm{O}$ & $\mathrm{O}$ & $\mathrm{O}$ & $\mathrm{O}$ & $\mathrm{X}$ & & & & & & & Killed by wind turbine blade \\
\hline SF06 & 14-Jan & 0 & $\mathrm{O}$ & $\mathrm{X}$ & & & & & & & & & Died of lead poisoning \\
\hline SM03 & 19-Jan & 0 & $\mathrm{O}$ & $\mathrm{O}$ & $\mathrm{O}$ & $\mathrm{O}$ & $\mathrm{O}$ & 0 & $\mathrm{O}$ & $\mathrm{O}$ & 0 & $\mathrm{O}$ & \\
\hline NM01 & 26-Jan & $\mathrm{O}$ & $\mathrm{O}$ & 0 & $\mathrm{O}$ & $\mathrm{O}$ & 0 & $\mathrm{O}$ & $\mathrm{O}$ & $\mathrm{O}$ & 0 & 0 & \\
\hline SM04 & 27-Jan & $\mathrm{O}$ & $\mathrm{O}$ & $\mathrm{O}$ & 0 & $\mathrm{O}$ & $\mathrm{O}$ & $\mathrm{O}$ & $\mathrm{O}$ & $\mathrm{O}$ & $\mathrm{O}$ & 0 & \\
\hline $\mathrm{SF02}$ & 02-Feb & & $\mathrm{O}$ & 0 & $\mathrm{O}$ & $\mathrm{O}$ & $\mathrm{O}$ & $\mathrm{O}$ & $\mathrm{O}$ & 0 & $\mathrm{O}$ & 0 & \\
\hline SF01 & 02-Feb & & $\mathrm{O}$ & $\mathrm{O}$ & & & & & & & & & \\
\hline SF03 & 04-Feb & & $\mathrm{O}$ & $\mathrm{O}$ & 0 & $\mathrm{O}$ & $\mathrm{O}$ & $\mathrm{O}$ & $\mathrm{O}$ & $\mathrm{X}$ & & & Killed by wind turbine blade \\
\hline SM05 & 04-Feb & & $\mathrm{O}$ & $\mathrm{O}$ & $\mathrm{O}$ & $\mathrm{O}$ & $\mathrm{O}$ & & & & & & \\
\hline NF03 & 07-Feb & & $\mathrm{O}$ & $\mathrm{O}$ & $\mathrm{O}$ & $\mathrm{O}$ & 0 & $\mathrm{O}$ & & & & & . \\
\hline SF04 & 07-Feb & & $\mathrm{O}$ & $\mathrm{O}$ & $\mathrm{O}$ & $\mathrm{O}$ & 0 & $\mathrm{O}$ & 0 & 0 & $\mathrm{O}$ & $\mathrm{O}$ & \\
\hline SM06 & 11-Feb & & $\mathrm{O}$ & $\mathrm{O}$ & $\mathrm{O}$ & $\mathrm{O}$ & $\mathrm{O}$ & 0 & $\mathrm{O}$ & 0 & $\mathrm{O}$ & $\mathrm{O}$ & \\
\hline SF05 & 12-Feb & & $\mathrm{O}$ & $\mathrm{O}$ & $\mathrm{O}$ & $\mathrm{O}$ & $\mathrm{O}$ & 0 & 0 & 0 & 0 & 0 & \\
\hline NM03 & 23-Feb & & $\mathrm{O}$ & 0 & 0 & $\mathrm{O}$ & 0 & 0 & 0 & 0 & 0 & 0 & \\
\hline $\mathrm{NM} 02$ & 23-Feb & & $\mathrm{O}$ & $\mathrm{O}$ & $\mathrm{O}$ & $\mathrm{O}$ & 0 & $\mathrm{O}$ & $\mathrm{O}$ & O & $\mathrm{O}$ & 0 & \\
\hline SM07 & $25-\mathrm{Feb}$ & & 0 & 0 & 0 & $\mathrm{O}$ & $\mathrm{O}$ & $\mathrm{O}$ & $\mathrm{O}$ & $\mathrm{O}$ & $\mathrm{O}$ & $\mathrm{O}$ & \\
\hline SM08 & $28-\mathrm{Feb}$ & & 0 & $\mathrm{O}$ & $\mathrm{O}$ & 0 & $\mathrm{O}$ & $\mathrm{O}$ & $\mathrm{O}$ & $\mathrm{O}$ & $\mathrm{O}$ & $\mathrm{O}$ & \\
\hline NF04 & 02-Mar & & & $\mathrm{O}$ & $\mathrm{O}$ & 0 & $\mathrm{O}$ & $\mathrm{O}$ & $\mathrm{O}$ & O & 0 & 0 & Apparent mate of AM01 \\
\hline NF05 & 29-Jul & & & & & & & & $\mathrm{O}$ & & & & \\
\hline
\end{tabular}

$\mathbf{O}=$ present in study area; $\mathbf{X}=$ died. 


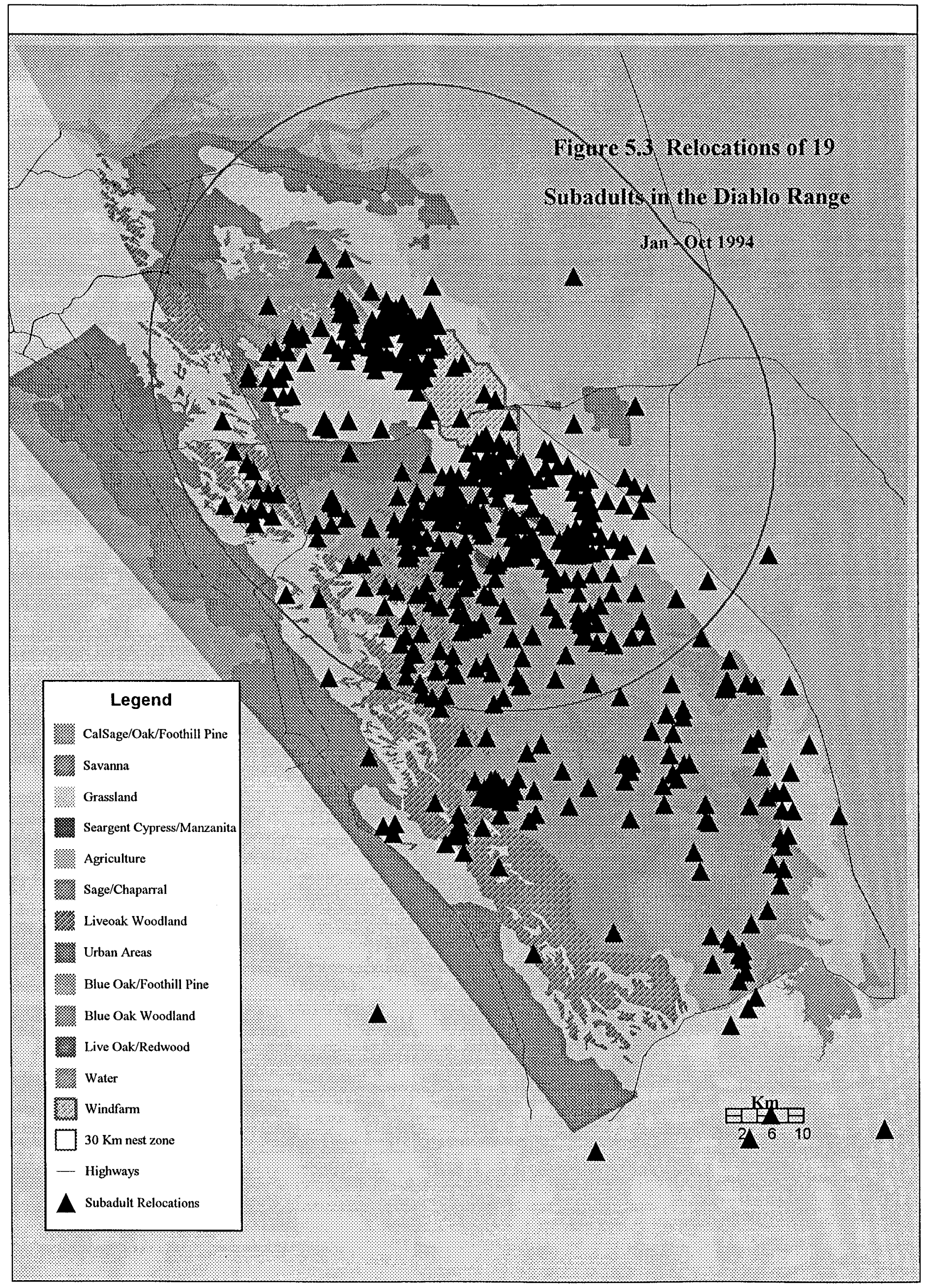


Subadult Female NF03 (4th calendar year). We last detected this bird near San Luis Reservoir at the southeastern edge of the study region on 12 July, the same day as the last detection of NF01. Like NF01, NF03-ranged widely in the study region. On 7 February, the date of tagging, we noted that this bird had what appeared to be a brood patch; there was also a talon wound in the left thigh.

5.2.3 Juveniles. The original sample of 25 juveniles, tagged from 21 May through 4 July, decreased to 23 by the last week of July (Table 5.4). The two birds no longer detected in the surveys at that time included:

Juvenile Female JF01 (Adelaide Nest). The transmitter attachment threads separated on ca. 13 July, allowing the instrument to fall off in the nest vicinity (see Section 5.1 for methods).

Juvenile Male JM04 (Welch Creek Nest). The transmitter apparently failed during 24-26 July in the nest area. An extremely weak signal received from the nest area on 14 August suggested that the antenna had malfunctioned.

At highly variable ages, the radio-tagged juveniles began soaring in the vicinities of their natal territories. The frequency of soaring behavior, as crudely determined by telemetry, appears to be a good measure of approaching independence for most young raptors (see Hunt 1992a,b). Among our sample of tagged juvenile eagles, we detected no soaring in June ( $\mathrm{n}=71$ determinations of soaring or not soaring). In July, eight (32\%) of 25 juveniles were detected soaring $(n=104), 16(70 \%)$ of 23 in August $(n=174)$, and 20 of $22(91 \%)$ in both September and October ( $\mathrm{n}=140$ and 137 determinations). Dates of first soaring did not appear to correlate with hatching date, nor did dispersal dates (see below).

As another measure of dispersal chronology, we also examined the tendency of 23 tagged juveniles to remain within an arbitrary $3 \mathrm{~km}$ of the nest. We detected none of 23 birds beyond that perimeter before 4 August. Nine eagles had ventured out by mid-August, 13 by midSeptember, 16 by mid-October, and all 23 by mid-November. Like the dates of first soaring, these dispersal dates did not seem to relate to hatch date. Although we do not know how long the parents fed the tagged birds while they remained in the nest vicinity, our data suggest a lengthy and highly variable dependency period.

Figures 5.4 and Appendix $\mathrm{H}$ show the patterns of juvenile dispersal within the study area during June - October. As of the date of this report, three of the 23 juveniles have either departed the area covered in the airplane surveys or their transmitters have failed; in chronological order of disappearance, these birds include:

Juvenile Male JM15 (Sibley Nest). This bird disappeared from the survey during 15-17 August. Whether it departed the study area or its transmitter failed is unknown; the eagle had been soaring ca. $5 \mathrm{~km}$ southeast of the nest on 1 August, the only detection greater than $3 \mathrm{~km}$ from the nest. 
Table 5.4 Tenure of 25 radio-tagged juvenile golden eagles in the Diablo Range study area.

\begin{tabular}{|c|c|c|c|c|c|c|c|c|c|c|}
\hline Bird & Nest & Tagged & May & Jun & Jul & Aug & Sep & Oct & Nov & Status \\
\hline JF01 & Adelaide & 21-May & $\mathrm{O}$ & $\mathrm{O}$ & $\mathrm{O}$ & & & & & Transmitter fell off in mid-July \\
\hline JM01 & Adelaide & 21-May & $\mathrm{O}$ & $\mathrm{O}$ & $\mathrm{O}$ & $\mathrm{O}$ & $\mathrm{O}$ & $\mathrm{O}$ & $\mathrm{O}$ & \\
\hline JF04 & Shell Ridge & 01-Jun & $\mathrm{O}$ & $\mathrm{O}$ & $\mathrm{O}$ & $\mathrm{O}$ & $\mathrm{O}$ & $\mathrm{O}$ & $\mathrm{O}$ & \\
\hline JM07 & Del Valle South & 01-Jun & $\mathrm{O}$ & $\mathrm{O}$ & $\mathrm{O}$ & $\mathrm{O}$ & $\mathrm{O}$ & $\mathrm{O}$ & $\mathrm{O}$ & \\
\hline JF05 & Mines Road & 02-Jun & $\mathrm{O}$ & $\mathrm{O}$ & 0 & $\mathrm{O}$ & $\mathrm{O}$ & $\mathrm{O}$ & $\mathrm{O}$ & \\
\hline JF06 & Lindl & 02-Jun & $\mathrm{O}$ & $\mathrm{O}$ & $\mathrm{O}$ & $\mathrm{O}$ & 0 & $\mathrm{O}$ & $\mathrm{O}$ & \\
\hline JM08 & Mines Road & 02-Jun & $\mathrm{O}$ & $\mathrm{O}$ & $\mathrm{O}$ & $\mathrm{O}$ & $\mathrm{O}$ & $\mathrm{O}$ & $\mathrm{O}$ & \\
\hline JM09 & Lindl & 02-Jun & $\mathrm{O}$ & 0 & $\mathrm{O}$ & $\mathrm{O}$ & $\mathrm{O}$ & $\mathrm{O}$ & $\mathrm{O}$ & \\
\hline JM04 & Welch Creek & 03-Jun & $\mathrm{O}$ & $\mathrm{O}$ & $\mathrm{O}$ & & & & & Evidence of radio failure \\
\hline JM05 & Vasco Road & 04-Jun & $\mathrm{O}$ & $\mathrm{O}$ & $\mathrm{O}$ & $\mathrm{O}$ & $\mathrm{O}$ & $\mathrm{O}$ & $\mathrm{O}$ & \\
\hline JM13 & Mt. Allison & 04-Jun & $\mathrm{O}$ & $\mathrm{O}$ & $\mathrm{O}$ & $\mathrm{O}$ & $\mathrm{O}$ & $\mathrm{O}$ & $\mathrm{O}$ & \\
\hline JF08 & Pipe Cross & 05-Jun & $\mathrm{O}$ & $\mathrm{O}$ & $\mathrm{O}$ & $\mathrm{O}$ & $\mathrm{O}$ & $\mathrm{O}$ & $\mathrm{O}$ & \\
\hline JM14 & Foley's & 06-Jun & $\mathrm{O}$ & $\mathrm{O}$ & $\mathrm{O}$ & $\mathrm{O}$ & $\mathrm{O}$ & $\mathrm{O}$ & $\mathrm{O}$ & Last detected on 11 Nov \\
\hline JM15 & Sibley & 06-Jun & $\mathrm{O}$ & $\mathrm{O}$ & $\mathrm{O}$ & $\mathrm{O}$ & & & & Radio failure? \\
\hline JM16 & Niles Canyon & 07-Jun & $\mathrm{O}$ & $\mathrm{O}$ & $\mathrm{O}$ & $\mathrm{O}$ & 0 & $\mathrm{O}$ & $\mathrm{O}$ & \\
\hline JF10 & Calaveras Creek & 08-Jun & $\mathrm{O}$ & 0 & $\mathrm{O}$ & $\mathrm{O}$ & $\mathrm{O}$ & $\mathrm{O}$ & $\mathrm{O}$ & \\
\hline JM06 & Los Vaqueros & 08-Jun & $\mathrm{O}$ & $\mathrm{O}$ & $\mathrm{O}$ & $\mathrm{O}$ & $\mathrm{O}$ & $\mathrm{O}$ & $\mathrm{O}$ & \\
\hline JF09 & Pipe Cross & 14-Jun & $\mathrm{O}$ & $\mathrm{O}$ & $\mathrm{O}$ & $\mathrm{O}$ & $\mathrm{O}$ & $\mathrm{O}$ & & Last detected on 16 Oct \\
\hline JF12 & Indian Creek & 15-Jun & $\mathrm{O}$ & $\mathrm{O}$ & $\mathrm{O}$ & $\mathrm{O}$ & $\mathrm{O}$ & $\mathrm{O}$ & $\mathrm{O}$ & \\
\hline JM10 & Camino Diablo & 15-Jun & $\mathrm{O}$ & $\mathrm{O}$ & 0 & $\mathrm{O}$ & $\mathrm{O}$ & $\mathrm{O}$ & $\mathrm{O}$ & \\
\hline JM11 & Camino Diablo & 15-Jun & $\mathrm{O}$ & 0 & $\mathrm{O}$ & $\mathrm{O}$ & $\mathrm{O}$ & $\mathrm{O}$ & $\mathrm{O}$ & \\
\hline JM17 & High Corral & 29-Jun & $\mathrm{O}$ & $\mathrm{O}$ & $\mathrm{O}$ & $\mathrm{O}$ & $\mathrm{O}$ & $\mathrm{O}$ & $\mathrm{O}$ & \\
\hline JM18 & High Corral & 29-Jun & $\mathrm{O}$ & $\mathrm{O}$ & $\mathrm{O}$ & $\mathrm{O}$ & $\mathrm{O}$ & $\mathrm{O}$ & $\mathrm{O}$ & \\
\hline JF13 & Eagle's Run Tower & 01-Jul & $\mathrm{O}$ & $\mathrm{O}$ & $\mathrm{O}$ & $\mathrm{O}$ & $\mathrm{O}$ & 0 & $\mathrm{O}$ & \\
\hline JM03 & Wally's & 04-Jul & $\mathrm{O}$ & $\mathrm{O}$ & $\mathrm{O}$ & $\mathrm{O}$ & $\mathrm{O}$ & $\mathrm{O}$ & $\mathrm{O}$ & \\
\hline
\end{tabular}

$\mathbf{O}=$ present in study area; $\mathbf{X}=$ died. 


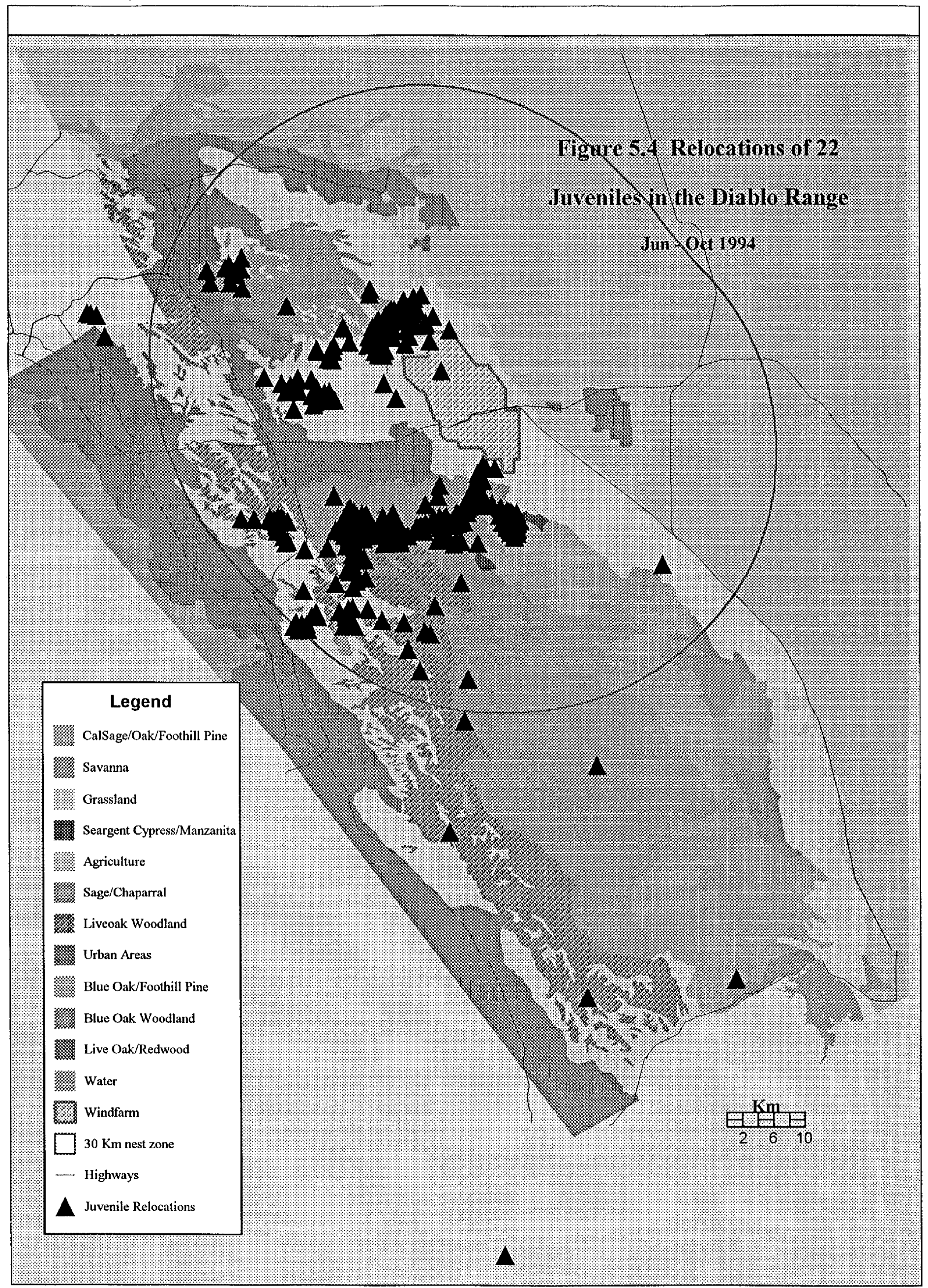


Juvenile Female JF09 (Pipe Cross Nest). We first detected this eagle outside the 3-km perimeter of its nest on 25 September, the first day we recorded it soaring. After this, it frequented an area about 10-25 km southeast of its nest until we detected it on 12 October near San Luis Reservoir. However, on 27 October, we located a strong, but widely-spaced and intermittent signal (suggesting impending transmitter failure) in the nest vicinity, and again, on 2 November, we located this same type of signal in the area JF09 had frequented during 29 September - 5 October. We have since obtained no other signals.

Juvenile Male JM14 (Foley Nest). We first recorded JM14 soaring on 27 July, and first outside the 3-km nest perimeter on 11 August when it had traveled about $10 \mathrm{~km}$ south. It was near the WRA on 10 and 14 September. The last detection was on 11 November at Mt. Stakes in the Diablo Range about $45 \mathrm{~km}$ southeast of its nest.

In mid-November the two juvenile males from the High Corral Nest left the study region. Their whereabouts were unknown to us until late-December when we found one (JM17) around Hollister near the southern edge of the study region and its sibling (JM18) near King City about $185 \mathrm{~km}$ south. Before their emigration, we had detected neither bird outside a 3-m radius from the nest. We noted on the date of tagging, 29 June, that both siblings appeared undernourished, and one had a severely infected tongue.

\subsection{Summary}

Our results to date show that most of the 31 eagles radio-tagged in winter remained in the Diablo Range study area. Of the 27 birds for which we have thus far received no indication of mortality, five (19\%) have disappeared from the surveys; all were subadults. One of these (NF05), tagged in summer, departed immediately after release; the other four either emigrated or had failed radios. Five of the seven floaters have remained constantly in the study area; one was absent from March to September, another took occasional trips to an area about $180 \mathrm{~km}$ to the southeast. At this point in our investigation, we may tentatively conclude that at least threequarters of the eagles present at Altamont Pass in winter are resident in west-central California, particularly the region surrounding the WRA.

\subsection{ESTIMATING NATALITY}

During this pilot year of study we focused our surveys for golden eagle nests in the area lying within about $30 \mathrm{~km}$ of the WRA boundary. We chose this distance for practical reasons and because it is about the maximum distance a nesting adult golden eagle might be expected in poor habitat to travel for the purpose of foraging. Thus, we selected the preliminary study area as 
that containing all nests from which breeders might conceivably venture into the WRA on a regular basis. ${ }^{2}$

\subsection{Methods}

Our first task in developing a preliminary estimate of the breeding population was to search for eagle pairs and nests in the areas surrounding active territories shown to us by local biologists. In this way we quickly developed a "search image" for the nesting situation. From an airplane we looked at the distribution of such habitats within the study area and began to seek permission for access to ranches, regional parks, and water district properties where conditions seemed most favorable.

6.1.1 Nest Search. Our main technique for locating nests was to walk or drive in areas of habitat we presumed suitable for eagle nesting and to search for adult pairs. Where pairs were seen or suspected, we observed the terrain for long periods from stationary vantage points.

Eagles were most conspicuous in January and February when they were engaged in courtship or territorial displays prior to egg laying. Before the blue oaks and other deciduous trees acquired their leaves, eagles and their nests were more visible than at later times when we searched for adults soaring together or carrying prey to nests.

We were much aided in our nest search by people who knew of nesting pairs. Hans Peeters, Kent Carnie (The Peregrine Fund, Boise, ID), Joe DiDonato (East Bay Regional Parks), Jones \& Stokes, Inc., and Gary Beeman (private) provided us with locations of nest sites that had been active during the last decade. As mentioned, our initial visits to these known nesting areas gave us an early understanding of preferred habitat upon which to base our surveys.

Our ability to access land within the survey area was highly variable; obtaining permission from landowners required letter writing and numerous phone calls. Road conditions were often poor in winter when rains muddied the ranch roads, particularly in the higher country south of Livermore, e.g., Sunol/ Ohlone Wilderness, N3 Ranch, and Connolly Ranch.

We revisited areas to see whether the eagles were incubating where we had seen them courting in January and February. We later returned to nests where we had observed incubation to determine whether broods were present and to count the number and ages of young.

At each nest, usually during banding operations, we tabulated gross habitat conditions including, (1) topographical setting, (2) nest tree characteristics, (3) vegetational association and ground cover profiles in the area, and (4) grazing practices. Appraising the physical and biotic

\footnotetext{
${ }^{2}$ Our telemetry data suggests that the maximum distances traveled by nesting aduits are much shorter, a consequence of a generally rich habitat.
} 


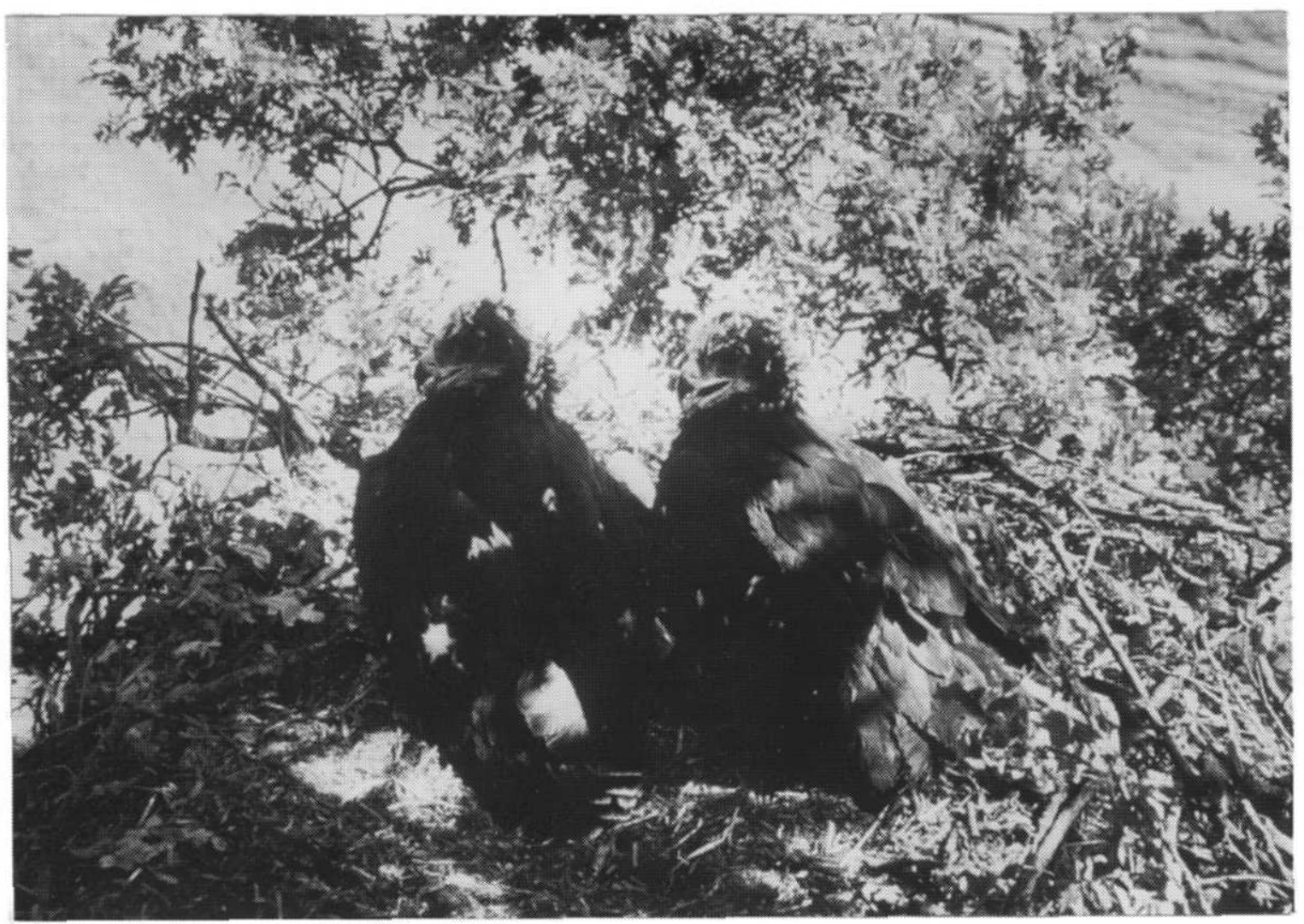

Golden eagle fledglings in the Diablo Range (photo by Daniel Driscoll)

circumstances at known nests increased our efficiency in discovering additional ones.

During climbs, we recorded nest characteristics on the forms shown in Appendix C. Data included the diameter of the inner soft material and the whole nest on the four cardinal directions (N-S, E-W, NE-SW, NW-SE), and depth of the inner nest (from rim to inner nest surface at center), and whole nest (from rim to base). We measured the diameter of the largest and smallest nest sticks, and an additional ten randomly selected sticks. We recorded the condition of the nest (good, poor, remnant, fallen), as well as the elevation, latitude-longitude, directional aspect, degree of slope, direction of wind exposure, and nest type (cylinder, bowl, inverted cone, or disk), and identified the vegetative species used for nest lining and sticks.

We also quantified characteristics of the nest tree. We recorded the nest location (on the main bole or on a limb), the horizontal distance from the trunk to the nest (if on a limb), shading effect (on nest) of the canopy, species, status (live, dead-top, percent canopy, snag characteristics), and the nest tree's affiliation with other trees. We also measured the distance and diameter of major branches supporting the nest, the height of the nest, and tree height and 
diameter. Among 36 nests we examined, $23(64 \%)$ were in oak trees, $7(19 \%)$ in pines, $3(9 \%)$ in sycamores, $1(3 \%)$ in a cypress, and $2(6 \%)$ on transmission towers.

In addition, we characterized the principal habitat within $0.5 \mathrm{~km}$ and $1.0 \mathrm{~km}$ of the nest, and the land use characteristics (e.g., grazing). We also visually estimated ground squirrel densities in the nest vicinity on a five-point scale from low (1) to high (5).

In reporting our results on reproduction we followed Postupalsky (1974) who attempted to standardize reproductive data by basing calculations on the number of occupied breeding areas. This method takes into consideration any elements that may act to reduce the productivity of the population by preventing pairs from laying eggs.

6.1.2 Areas Surveyed. Using (1) color aerial photographs obtained from NASA $\left(9^{\prime \prime}=16 \mathrm{mi}\right)$, (2) CALVEG, a digitized vegetation map provided by the California Department of Fish and Game, and (3) the "HARDWOODS" distribution map prepared by California Department of Forestry, we separated the region within about $30 \mathrm{~km}$ of the WRA into eight survey areas.

1. Deer Valley/ Briones Valley, mostly in private ownership and containing two historic nest sites, lies northwest of the WRA and east of Mt. Diablo. It is composed of a series of ridges running from northwest to southeast. The southwest-facing slopes are predominantly grassland, and the northeast-facing ones are blue oak woodland. We were unable to adequately explore this area during 1994; access was denied on several ranches.

2. Mt. Diablo Region contains diverse habitat including chaparral and sage scrub, grassland, and blue oak/ foothill pine woodland. There was one active nest in blue oak woodland at the edge of a suburban area and another in blue oak/ foothill pine woodland within Mt. Diablo Park.

3. Morgan Territory Area, south of Mt. Diablo, contains north-facing slopes and canyon bottoms of predominantly coast live oak/ bay woodland; ridges and hilltops support grassland. Some of the land is privately owned, some is within the East Bay Regional Parks District and Mt. Diablo State Park. Muddy roads limited our exploration during rainy periods. Two nests were situated at the edge of this region, where it borders grassland.

4. Tassajara Grassland lies south of Morgan Territory to Highway 680. It is primarily grassland with a few eucalyptus groves and stands of oak. Ownership is mainly in small parcels, but the region is fairly easy to survey due to the network of public, paved roads. There is one active nest.

5. WRA and Eastern Slope Grassland consists primarily of open grassland with occasional small stands of oak, buckeye and eucalyptus; nest structures are thus limited. Although many eagles frequent this region and have nested here historically, we found only one nest (on a transmission tower); another, near Brushy Peak, fell within the past couple of years. 
6. Area West of Highway 680 is a mosaic of coast live oak/ bay woodland and grassland and contains one large reservoir (Calaveras); the western front overlooks San Francisco Bay. There are four active nests in our sample.

7. San Antonio Grassland/Savanna, lying south of Livermore, contains three reservoirs surrounded by grassland and oak savanna. Thus far, we know of ten active nests and two additional pairs of unknown status. We were able to explore the area in fair detail, a survey that was much enhanced by Hans Peeters who has monitored a number of pairs in the area for the past twenty years.

8. Sunol/Ohlone Wilderness is a mountainous region with coast live oak/ bay woodlands on north-facing slopes and with grassland and sage scrub on hilltops and south-facing slopes. Obtaining access was difficult in the southern part of this region and was hindered by muddy road conditions. Joe DiDonato provided history on some of the pairs. We observed six nests, plus seven additional pairs.

6.1.3 Habitat Mapping and Nest Distribution. We purchased maps on CD-ROM of the study area and its geographical features, such as roads, rivers, and bodies of water from Strategic Mapping, Inc., Santa Clara, California. We adapted these digitized maps to form a base map of the study area, using AtlasGIS ${ }^{\mathrm{TM}}$, an IBM-PC-based geographical information program similar to Arc Info. To this base map, we added additional layers such as vegetation types and topography. For the latter, we digitized the 250-meter contours of the study area from USGS topographical maps at a scale of 1:100,000 (Fig. 2.1). We used aerial photographs obtained from NASA/Moffett Field to determine the distribution of habitat types (see above). These layers were digitized into a habitat map of the study area (Fig. 2.2).

We entered locations of eagles, nests, and courting pairs, as obtained from the nest survey and from the roll-call aerial telemetry surveys, into the GIS database (.dbf). We determined latitudelongitude coordinates by means of hand-held Geographical Positioning System (GPS) devices. From within AtlasGIS ${ }^{\mathrm{TM}}$, the layers of vegetation types, roads, rivers, and nest distribution could be viewed in any particular combination and at any scale; distances, areas, and point counts were easily measured.

6.1.4 Methods of Determining Food Habits. During visits to nesting territories to band and radio-tag nestlings, we collected prey remains (i.e., bones, fur, feathers, castings) from both in and below nests. Collections below nests were often sparse, possibly due to activities of scavengers. We bagged all prey remains and labeled them for later identification.

Certain biases are possible in the estimation of raptor food habits based solely on prey remains, most notably the overestimation of the larger prey species whose bones are more persistent than smaller ones (Mollhagen et al. 1972). However, Collopy (1983b) concluded that golden eagle dietary studies, based on prey remains analysis, were as accurate as direct observation in determining the frequency and percent biomass of prey brought to the nest, at least for pairs feeding mostly on rabbits. Based on our bald eagle prey studies (Hunt $e$ t al. 1992a, 1992c), we 
believe that analysis of remains and castings provides a relatively accurate representation of prey utilization. Multi-year collections from nests will refine our prey data set and allow for comparisons between sub-groups within the population.

The amount of material collected from nests varied greatly, probably due to differences in cleaning habits between individual adults. Other researchers have noted this variability (Boag 1977, Tjernberg 1981, Poole and Bromley 1988). In our study, prey items often accumulated to the point of being a sanitation problem in some nests. We counted and removed excess carcasses (mostly ground squirrels) if decomposed; however, we left fresh prey items in nests after identification. Some nests contained very few prey remains, apparently because of the tendency of certain eagles to clean their nests.

We identified bird, mammal, and herptile remains by comparison with reference samples from the Museum of Vertebrate Zoology study collection at the University of California, Berkeley. We estimated numbers of birds and mammals by grouping like parts (e.g., rabbit legs); we counted only one individual per small collection of feathers or fur. We counted one individual per casting for ground squirrels; larger species represented only by castings were judged on a case-by-case basis, based on number and size of castings. We identified mammal hair remains using hair keys (Moore et al. 1974), comparison with mammal study skins, and microscopic examination (Lois Culp, data). We obtained prey weights (biomass) from standards in the literature (Burt and Grossenheider 1964, U.S.D.I. 1979, Steenhof 1983, Dunning 1984). We used $4,130 \mathrm{~g}$ to represent biomass of large mammalian prey such as deer (Bloom and Hawks 1982).

\subsection{Results of Nesting Survey}

We observed golden eagle pairs at 54 locations in or near the $30-\mathrm{km}$ zone (Figure 6.1). An additional six territories were reported to us, but, for various reasons, we were unable to visit them. We were able to locate nests and observe the activities of the eagles at 37 sites (Table 6.1).

Golden eagle pairs laid eggs at $32(86.5 \%)$ of the 37 breeding areas with known reproductive outcome. Three of these failed in the egg stage, and 29 pairs successfully fledged 47 young. Nest success (the percentage of occupied nests producing young, Postupalsky 1974) was 78.4 percent for the 37 pairs, with a mean brood size (number of young fledged per successful nest) of 1.62. Productivity, expressed as the number of young fledged per occupied nest, was 1.27.

We compared the reproductive data from our study area with those from 13 other populations in the western United States, Scotland, and Sweden (Table 6.2). Data for nest success were often unavailable, since percentages for most populations were based on active nests (pairs which laid eggs) rather than occupied breeding areas. Our sample of eagles fledged a similar number of young per successful nest (mean brood size) as other populations; however, productivity (number of young fledged per occupied nest) was much higher in our study area, likely due to 


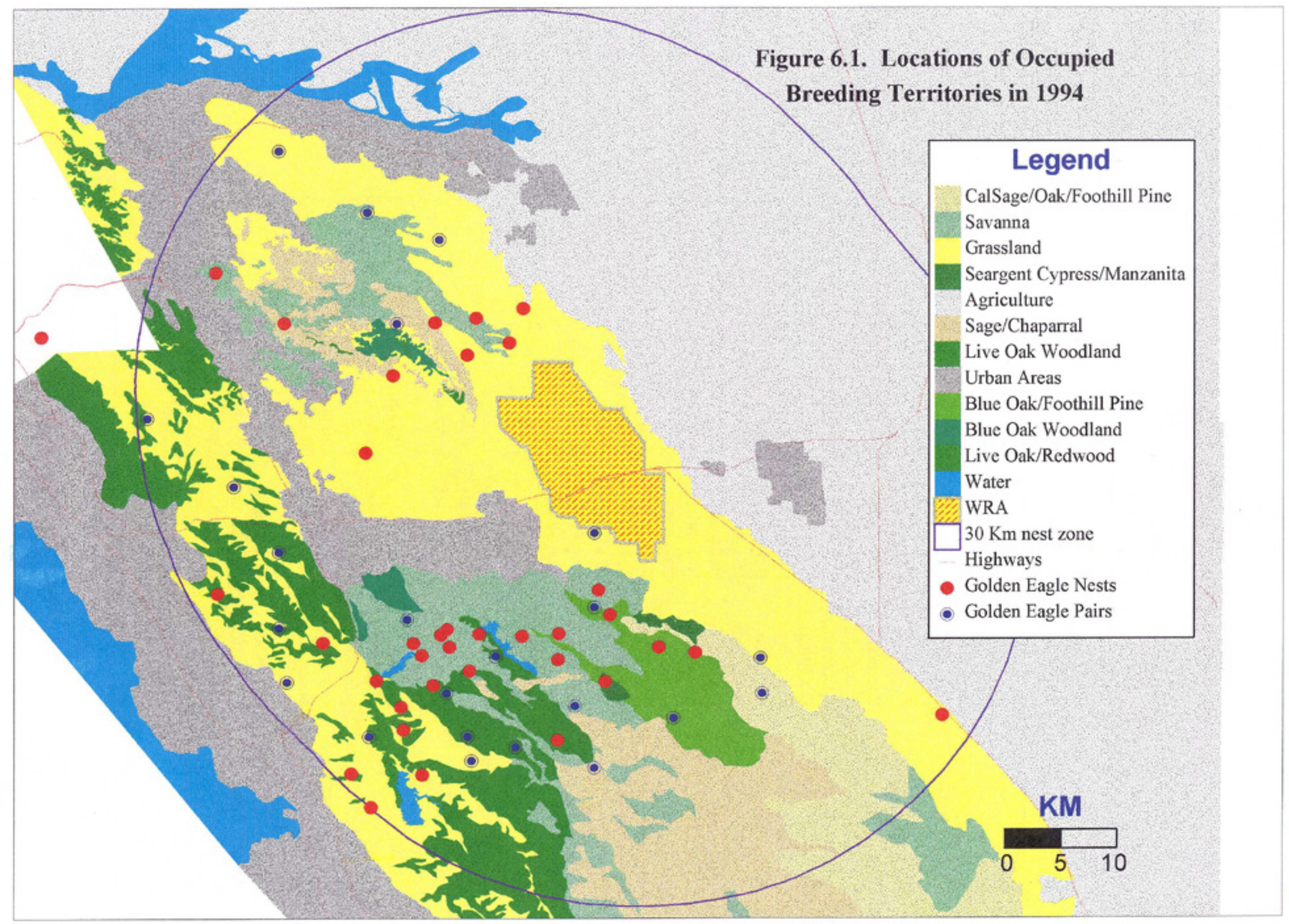


Table 6.1. Golden eagle productivity at breeding areas within about $30 \mathrm{~km}$ of the Altamont Pass Wind Resource Area in the Diablo Range of California, 1994. ${ }^{1}$

\begin{tabular}{|c|c|c|c|c|c|}
\hline Breeding Area & Status & Incubation & Hatching & $\begin{array}{l}\text { Young } \\
\text { Hatched }\end{array}$ & $\begin{array}{l}\text { Young } \\
\text { Fledged }\end{array}$ \\
\hline Adelaide & Successful & 2 February & 16 April & 2 & 2 \\
\hline Apperson & Occupied & N/A & $\mathrm{N} / \mathrm{A}$ & 0 & 0 \\
\hline Beartrap Ridge & Occupied & Unknown & Unknown & $?$ & $?$ \\
\hline Beeman & Unknown & Unknown & Unknown & $?$ & $?$ \\
\hline Black Diamond & Occupied & Unknown & Unknown & $?$ & $?$ \\
\hline Calera Creek & Successful & 23 February & 7 April & 2 & 2 \\
\hline Calaveras Creek & Successful & 28 February & 18 April & 2 & 2 \\
\hline Camino Diablo & Successful & 26 February & 12 April & 2 & 2 \\
\hline Corral Hollow & Occupied & N/A & N/A & 0 & 0 \\
\hline Concord Navy Base & Unknown & Unknown & Unknown & $?$ & $?$ \\
\hline Daup Cabin & Occupied & Unknown & Unknown & $?$ & $?$ \\
\hline Del Valle South & Successful & 15 February & 1 April & 1 & 1 \\
\hline Deer Valley & Occupied & Unknown & Unknown & $?$ & $?$ \\
\hline Eagle's Run & Successful & 16 February & 4 April & 1 & 1 \\
\hline Eden Canyon & Unknown & Unknown & Unknown & $?$ & $?$ \\
\hline Foley & Successful & 20 February & 4 April & 1 & 1 \\
\hline 14 Mile House & Occupied & Unknown & Unknown & $?$ & $?$ \\
\hline High Corral & Successful & 23 March & 4 May & 2 & 2 \\
\hline Hollow & Failed & 4 February & N/A & 0 & 0 \\
\hline Indian Creek & Successful & 14 February & 31 March & 1 & 1 \\
\hline I-5 Tower & Successful & 7 February & 24 March & 2 & 2 \\
\hline La Costa Creek & Successful & Unknown & Unknown & 2 & 2 \\
\hline Los Vaqueros & Successful & 26 February & 12 April & 1 & 1 \\
\hline Lindl & Successful & 13 February & $30 \mathrm{March}$ & 3 & 3 \\
\hline Lydia Lane & Successful & 23 February & 9 April & 1 & 1 \\
\hline Lover's Leap & Occupied & Unknown & Unknown & $?$ & $?$ \\
\hline Marciel & Unknown & Unknown & Unknown & $?$ & $?$ \\
\hline Marino & Occupied & $\mathrm{N} / \mathrm{A}$ & N/A & 0 & 0 \\
\hline Mendenhall & Successful & 20 February & 6 April & 1 & 1 \\
\hline Mexican House & Occupied & Unknown & Unknown & $?$ & $?$ \\
\hline Mines Road & Successful & 13 February & 30 March & 2 & 2 \\
\hline Morgan Territory & Successful & 17 February & 3 April & 2 & 2 \\
\hline Morrison Canyon & Occupied & Unknown & Unknown & $?$ & $?$ \\
\hline Mount Allison & Successful & 23 February & 10 April & 2 & 2 \\
\hline N3 Bathtub & Occupied & Unknown & Unknown & $?$ & $?$ \\
\hline N3 Coulter & Occupied & N/A & N/A & 0 & 0 \\
\hline Niles Canyon & Successful & 28 February & 7 April & 1 & 1 \\
\hline Pine Canyon & Successful & 20 February & 6 April & 2 & 2 \\
\hline
\end{tabular}


Table 6.1. (continued).

\begin{tabular}{|c|c|c|c|c|c|}
\hline Breeding Area & Status & Incubation & Hatching & $\begin{array}{l}\text { Young } \\
\text { Hatched }\end{array}$ & $\begin{array}{l}\text { Young } \\
\text { Fledged }\end{array}$ \\
\hline Patterson & Failed & Unknown & N/A & 0 & 0 \\
\hline Patterson Pass & Occupied & Unknown & Unknown & $?$ & $?$ \\
\hline Pegleg Ridge & Occupied & Unknown & Unknown & $?$ & $?$ \\
\hline Pipe Cross & Successful & 17 February & 3 April & 2 & 2 \\
\hline Rocky Ridge & Occupied & Unknown & Unknown & $?$ & $?$ \\
\hline Rose Peak & Occupied & Unknown & Unknown & $?$ & $?$ \\
\hline Round Valley South & Successful & 17 February & 3 April & 2 & 2 \\
\hline San Leandro & Unknown & Unknown & Unknown & $?$ & $?$ \\
\hline Seeno & Occupied & Unknown & Unknown & $?$ & $?$ \\
\hline Shell Ridge & Successful & 13 February & 30 March & 1 & 1 \\
\hline Sibley & Successful & $1 \mathrm{March}$ & 15 April & 1 & 1 \\
\hline South Livermore & Occupied & Unknown & Unknown & $?$ & $?$ \\
\hline SRI & Failed & 15 March & N/A & 0 & 0 \\
\hline Stone Ridge & Unknown & Unknown & Unknown & $?$ & $?$ \\
\hline Sulphur Spring & Occupied & Unknown & Unknown & $?$ & $?$ \\
\hline Tunnel Creek & Successful & Unknown & Unknown & 2 & 2 \\
\hline Upper Indian Creek & Occupied & Unknown & Unknown & $?$ & $?$ \\
\hline Vasco Road & Successful & 23 February & 9 April & 1 & 1 \\
\hline Wally's & Successful & 15 February & 1 April & 2 & 2 \\
\hline Walpert Ridge & Successful & 17 February & 10 April & 2 & 2 \\
\hline Welch Creek & Successful & 17 February & 3 April & 1 & 1 \\
\hline William's Gulch & Occupied & N/A & $\mathrm{N} / \mathrm{A}$ & 0 & 0 \\
\hline $\begin{array}{l}\text { Knov } \\
\text { Occu }\end{array}$ & \multicolumn{2}{|c|}{$\begin{array}{l}\text { Known Breeding Areas } \\
\text { Occupied Breeding Areas }\end{array}$} & & 47 & 47 \\
\hline
\end{tabular}

1 Reproductive terminology follows Postupalsky (1974). 
Table 6.2. Comparison of productivity for 11 golden eagle populations in the western United States, one in Scotland, and one in Sweden. ${ }^{1}$

\begin{tabular}{|c|c|c|c|c|c|c|}
\hline Region & Pairs & Years & $\begin{array}{l}\text { Nest } \\
\text { Success }\end{array}$ & $\begin{array}{l}\text { Mean } \\
\text { Brood Size }\end{array}$ & Productivity & Source \\
\hline Southwest Idaho & $25-56$ & 4 & & 1.6 & & Beecham and Kochert (1975) \\
\hline SW Idaho & $50-55$ & 7 & & 1.4 & 0.75 & U.S. Department of Interior (1979) \\
\hline Westcentral Utah & $9-14$ & 2 & & & 0.84 & Camenzind (1969) \\
\hline Central Utah & 16 & 6 & & & 0.69 & Murphy (1975) \\
\hline Northeast Wyoming & $85-140$ & 5 & & 1.5 & 0.81 & Phillips and Beske (1990) \\
\hline Southwest Wyoming & $10-17$ & 7 & & & 0.83 & S. Platt in Phillips et al. (1990) \\
\hline SE Montana \& Northern Wyoming & $10-30$ & 11 & $54 \%$ & 1.3 & 0.78 & Phillips et al. (1990) \\
\hline Montana & $21-30$ & 2 & & 1.6 & & McGahan (1968) \\
\hline Southeast Oregon & $7-18$ & 15 & $51 \%$ & 1.7 & 1.08 & Thompson et al. (1982) \\
\hline New Mexico, Texas \& Colorado & $27-57$ & 6 & & 1.4 & & Boeker and Ray (1971) \\
\hline Porcupine River, Alaska & $3-9$ & 3 & & 1.5 & & Ritchie and Curatolo (1982) \\
\hline California & 44 & 1 & & 1.4 & & Thelander (1974) \\
\hline California & 22 & 1 & & 1.4 & & Schlorff (1986) \\
\hline Westcentral California & 37 & 1 & $78.4 \%$ & 1.6 & 1.27 & This Study \\
\hline Scotland & 5 & 13 & & & 0.80 & Watson (1957) \\
\hline Scotland & $141-144$ & 4 & & & $0.19-1.00$ & Watson et al. (1992) \\
\hline Sweden & $50-106$ & 6 & $53 \%$ & 1.2 & 0.64 & Tjernberg (1983) \\
\hline
\end{tabular}

1 Reproductive terminology follows Postupalsky (1974). 
a higher percentage of occupied breeding areas which were active.

We were interested in how the observed density of pairs around the Altamont WRA might compare with densities reported for other populations of golden eagles. For this purpose we selected a portion of the study area (southwest section) where we were fairly certain we had located most of the pairs. In this $820 \mathrm{~km}^{2}$ section we recorded 37 occupied breeding areas of which at least 22 pairs laid eggs; this resulted in a density of $22 \mathrm{~km}^{2}$ per pair. This value appears to be among the highest known for golden eagles; see Table 3.2 for a comparison with 26 other studies. We caution the reader, however, that the habitat in the area we selected is especially favorable for nesting eagles, and we believe that lower densities will prevail in most other portions of the Diablo Range.

Remarkably, we recorded no nestling deaths. In bald eagles, a general average of 15 percent of the young die prior to fledging (Stalmaster 1987, Hunt et al. 1992a), and in some areas nestling mortality rates for golden eagles are similar to that average. McGahan (1968) reported a mortality rate of 13.6 percent in south-central Montana, but 32.5 percent of the nestlings died during a study in southwestern Idaho, by Beechham and Kochert (1975). Siblicide (one eaglet killing its nestmate) is apparently a common behavior among golden eagles in populations where food supplies are limited (Bent 1937, Brown and Amadon 1968, Newton 1979).

\subsection{Estimating the Cohort in the 30-km Zone}

If we assume that the performance of the 17 pairs of eagles about which we have no reproductive information was the same as that demonstrated by the 37 pairs of known reproductive outcome, then the number of young from the combined sample of 54 pairs increases from 47 (known) to 69 (projected). If we add in the six inaccessible pairs reported to us by others but not observed by us, the projected number of young increases to 76 . Finally, if we conservatively estimate that 20 additional pairs exist in unsurveyed habitat, our total projection for the $30-\mathrm{km}$ zone is 80 pairs producing about 100 eaglets. It is quite possible that this is an overestimate of the number of young for the $30-\mathrm{km}$ zone, because we are assuming that productivity in all habitats occupied by eagles equals that in savanna where we have concentrated our surveys. However, a cohort of 100 young would surely be an underestimate for the entire study area, which is almost twice the size of the $30-\mathrm{km}$ zone.

\subsection{Stability of Food Supply}

Our data on reproductive success in the $30-\mathrm{km}$ zone is based on only one year of work and cannot, of itself, be expected to reflect a yearly average. Even a nesting study conducted over several years would not provide sufficient data to quantify natality over the longer term. More appropriate would be an evaluation of extrinsic factors that control the birth rate. 


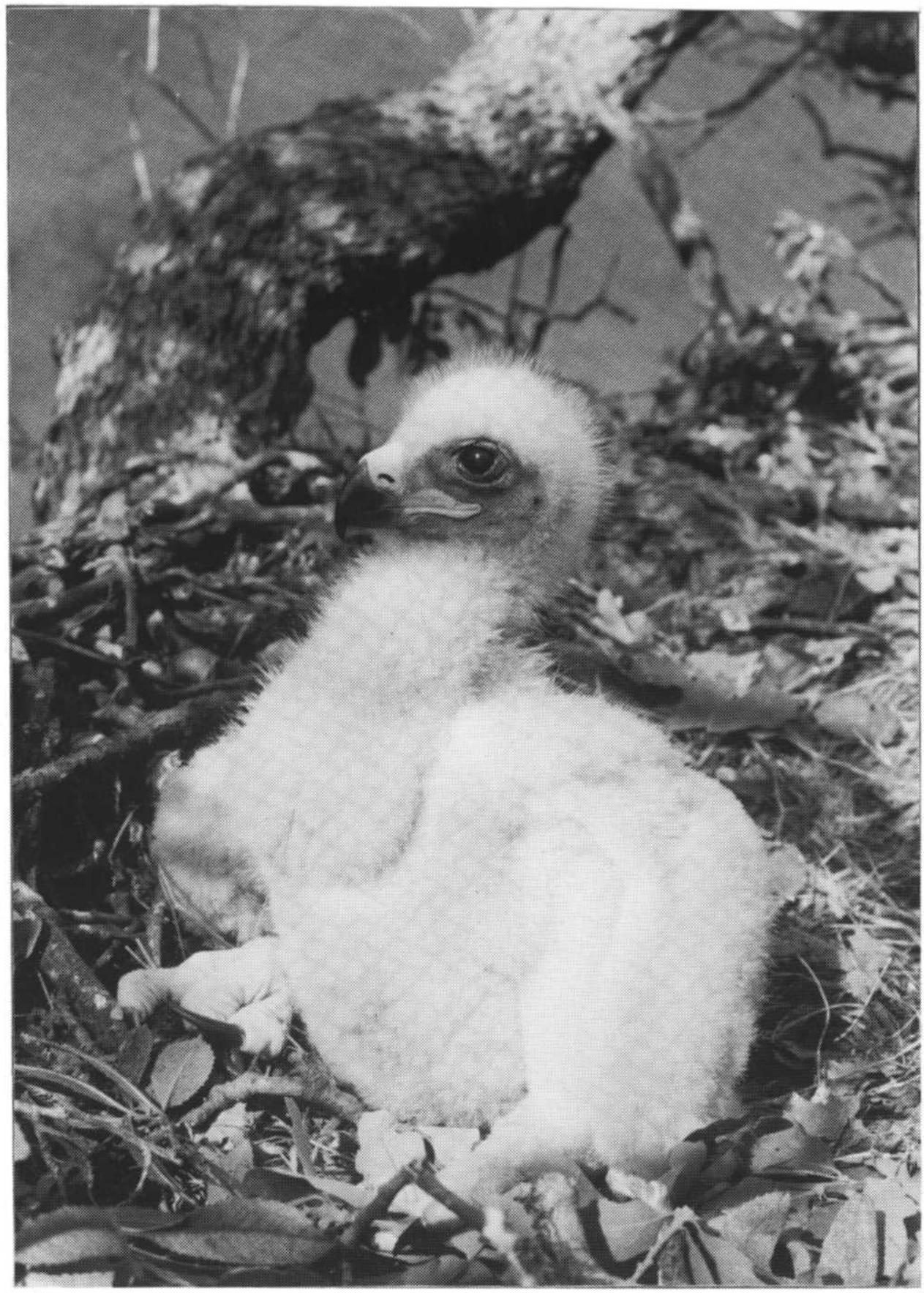

Golden eagle nestling at about two and one-half weeks of age (photo by John Gilardi) 
One of the most obvious of these is the food supply. Reproductive success of many raptor populations is linked to fluctuations in prey abundance (Newton 1979), a relationship known to influence the productivity of golden eagle populations dependent on cyclic populations of jackrabbits (Murphy 1975, Kochert 1980, Thompson et al. 1982, Phillips et al. 1990) and certain other prey species (Brown and Watson 1964, Tjernberg 1983, Watson et al. 1992b).

Clearly, we must determine the diets of breeders in the various habitats where significant densities of pairs occur, and we must estimate the degree to which prey availability would be expected to fluctuate over the long term. If we determine that prey numbers are markedly susceptible to changes in land use practices, we should identify management options that would favor eagle reproduction and survival.

6.4.1 Diet of Nesting Eagles in the Study Area. We identified 339 prey items from our collections of prey remains made at golden eagle nests in the study area during the 1994 breeding season (Table 6.3). Separate prey tables for each active nest visited in 1994 are presented in Appendix D. Collections at some sites were small for reasons discussed above; we will therefore limit our discussion of prey selection to the population as a whole. Prey collections made during subsequent years will increase our sample size and hopefully allow for comparisons between pairs nesting in different habitats within the study area.

The only prey species common to every pair in our sample was the California (Beechey) ground squirrel (Appendix D). This species was by far the most important food item overall for golden eagles nesting in the northern Diablo Range, and represented 69 percent of prey numbers and 64 percent of prey biomass identified from remains (Table 6.3). The second most important species was the black-tailed jackrabbit at 8.0 percent (biomass); the third was black-tailed deer at 5.9 percent. In all, mammals accounted for 81.4 percent of prey individuals and 91.6 percent of prey biomass, followed by birds (13\% numbers, $7.0 \%$ biomass) and reptiles $(5.6 \%$ numbers, $1.4 \%$ biomass). These proportions reflect very closely the food habits of breeding eagles studied in other parts of North America (Olendorff 1976). Rabbits, although captured in low numbers by many of the pairs, were important at only one location, Sibley, located in the Oakland Hills.

Black-tailed deer were mostly fawns, and in very low numbers (1.2\% prey numbers, Table 6.3). This finding contrasts sharply with the high frequency of deer $(12.7 \%)$ identified in golden eagle prey remains from the same area by Carnie (1954); apparently deer populations are reduced in the interior Coast Ranges from 40 years ago. We also found fewer total rabbits in the eagles' diet in our study (5.3\% of prey numbers), compared with that of Carnie $(28.8 \%)$.

Many birds were taken as nestlings or as recent fledglings, especially yellow-billed magpies. Many of the prey species shown in Table 6.3 were not taken in large numbers, a diversity that reveals the opportunistic nature of this large predator.

6.4.2 Are Local Ground Squirrel Populations Stable? We were unable to find anything definitive in the literature concerning the stability of California ground squirrel populations over long periods. Local authorities (H. Peeters, pers. comm.; J. Gouvaia, Deputy Agricultural 
Table 6.3. Number and estimated biomass (grams) of prey identified from remains collected in 20 golden eagle nests in 1994.

\begin{tabular}{|c|c|c|c|c|}
\hline Species & No. & $\%$ & Biomass & $\%$ \\
\hline Calif. Ground Squirrel & 233 & 68.7 & 168,925 & 63.9 \\
\hline California Meadow Mouse & 11 & 3.2 & 550 & 0.2 \\
\hline Black-tailed Jackrabbit & 10 & 2.9 & 21,140 & 8.0 \\
\hline Rabbit (Leporidae) & 7 & 2.1 & 9,674 & 3.7 \\
\hline Black-tailed Deer (fawn) & 3 & 0.9 & 11,340 & 4.3 \\
\hline Domestic Cow & 2 & 0.6 & 8,260 & 3.1 \\
\hline Gray Fox & 2 & 0.6 & 6,350 & 2.4 \\
\hline Striped Skunk & 2 & 0.6 & 5,376 & 2.0 \\
\hline Badger & 1 & 0.3 & 4,130 & 1.6 \\
\hline Black-tailed Deer & 1 & 0.3 & 4,130 & 1.6 \\
\hline Muskrat & 1 & 0.3 & 1,171 & 0.4 \\
\hline Cottontail & 1 & 0.3 & 650 & 0.2 \\
\hline Fox Squirrel & 1 & 0.3 & 544 & 0.2 \\
\hline Unidentified Rodent & 1 & 0.3 & 50 & tr. \\
\hline Mammal Subtotal & 276 & 81.4 & 242,290 & 91.6 \\
\hline Yellow-billed Magpie & 10 & 2.9 & 1,780 & 0.7 \\
\hline Black-shouldered Kite & 6 & 1.8 & 1,998 & 0.8 \\
\hline Barn Owl & 3 & 0.9 & 1,398 & 0.5 \\
\hline Scrub Jay & 3 & 0.9 & 528 & 0.2 \\
\hline Great Horned Owl & 2 & 0.6 & 2,710 & 1.0 \\
\hline Red-tailed Hawk & 2 & 0.6 & 2,252 & 0.9 \\
\hline California Quail & 2 & 0.6 & 346 & 0.1 \\
\hline American Kestrel & 2 & 0.6 & 232 & 0.1 \\
\hline Western Meadowlark & 2 & 0.6 & 196 & 0.1 \\
\hline Brewer's Blackbird & 2 & 0.6 & 126 & tr. \\
\hline Unidentified Passerine & 2 & 0.6 & 112 & tr. \\
\hline Great Blue Heron & 1 & 0.3 & 2,390 & 0.9 \\
\hline Turkey Vulture & 1 & 0.3 & 1,467 & 0.6 \\
\hline Common Raven & 1 & 0.3 & 1,199 & 0.5 \\
\hline Mallard & 1 & 0.3 & 1,082 & 0.4 \\
\hline American Crow & 1 & 0.3 & 448 & 0.2 \\
\hline Northern Flicker & 1 & 0.3 & 142 & 0.1 \\
\hline Mourning Dove & 1 & 0.3 & 119 & tr. \\
\hline Starling & 1 & 0.3 & 82 & tr. \\
\hline Bird Subtotal & 44 & 13.0 & 18,607 & 7.0 \\
\hline Unidentified Snake & 15 & 4.4 & 2850 & 1.1 \\
\hline Gopher Snake & 2 & 0.6 & 404 & 0.2 \\
\hline Rattlesnake & 1 & 0.3 & 393 & 0.1 \\
\hline Alligator Lizard & 1 & 0.3 & 21 & tr. \\
\hline Reptile Subtotal & 19 & 5.6 & 3,668 & 1.4 \\
\hline Total & 339 & 100.0 & 26,565 & 100.0 \\
\hline
\end{tabular}


Commissioner, pers. comm.) believe that California ground squirrel populations are relatively stable from year to year, not cyclic like jackrabbit populations. State eradication programs often reduce local populations by $90-95$ percent; however, the squirrels usually rebound within one or two years.

California ground squirrels breed from February to April (usually one litter averaging about six young), with young squirrels emerging in late May and attaining mature size by November (7-8 mo. old; Evans and Holdenried 1943). Some adults apparently estivate or hibernate (males in July/August, females September/October); however, many young are active throughout the year (Tomich 1962, Evans and Holdenried 1943). Life span under normal conditions averages about two years (Evans and Holdenried 1943). In one study, squirrel densities were variable, but averaged about seven per acre (range $=3-17$ squirrels/acre); home ranges averaged about 0.5 acres (Evans and Holdenried 1943). Population numbers over a three-year study showed a sharp upswing every spring with the birth of young, followed by compensatory annual declines. Mortality factors affecting ground squirrels include disease (e.g., plague), predation (e.g., by coyotes, eagles, rattlesnakes), and poisoning. Outbreaks of epizootic Sylvatic plague periodically reduce ground squirrel numbers in some areas (Clark 1986). Fitch (1948, in Klitz 1982) estimated that one-half of the annual production of ground squirrels was eliminated by predation. Populations are apparently controlled to a large extent by climate and its effect on annual vegetation growth (Tomich 1962).

\subsection{Floater Interference}

Other than the death of AF01 described in Section 7.2.1 circumstantially suggesting territorial usurpation, we were unable to obtain information on the rate of floater interference within territories. We did observe frequent territorial defense against trespassing eagles. By radiotagging additional adults holding breeding territories, we hope in the future to obtain more information on floater effects on turnover and breeding success.

\subsection{ESTIMATING SURVIVAL}

To determine whether or not turbine-related fatalities are affecting golden eagles on a population basis, we must obtain a sufficient sample of radio-tagged birds and total fatalities to allow us to estimate the mortality rate due to turbine collisions versus that from other causes. To predict a population effect, we must measure the survival rates of the four population segments (see Section 4.4).

\subsection{Methods}

Our techniques of capturing and radio-tagging the sample of adults, subadults, and juveniles are given in Section 5.1.1 and our methods of aerial roll call census in Section 5.1.3. Each 
transmitter contains a mortality switch, actually a motion sensor, that activates when the transmitter remains motionless for four or more hours, causing the pulse rate to increase from approximately 60 beats per minute to about 92 beats per minute. The difference is instantly recognizable.

When we detected a mortality signal, we tried to obtain the most accurate possible location for the transmitter by flying within a few hundred feet of the ground. We then returned to base and reported the death, as required, to Special Agent Cynthia Struzik of the U.S. Fish and Wildlife Service and to Ron Jurek of the California Department of Fish and Game. We also contacted the landowner for permission to retrieve the dead bird, and, where appropriate, we phoned Denise Weingart of KENETECH Windpower who maintained an active database on bird mortality at the WRA.

As soon as possible, usually the next morning, we traveled with the wildlife agent to the fatality site where we sought to obtain all possible information on the cause of death. This involved note-taking, photographing and sketching the dead bird, and, on the WRA, assisting Ms. Weingart with her elaborate protocol on the placement and condition of the dead eagle. Upon completion of data gathering, Agent Struzik placed the carcass in a plastic bag, packed it in ice, and shipped it as soon as possible to the U.S. Fish and Wildlife Service laboratory in Madison, Wisconsin for necropsy; the results were later communicated to us.

\subsection{Results of Survival Surveys}

Section 5.2 describes the results of the aerial roll call censuses for radio-tagged golden eagles in which transmitters were monitored for pulse rate indicating survival/mortality.

7.2.1 Breeding Adult Fatality Records. We recorded one death among the four breeding adults we radio-tagged in winter, as follows:

Adult Female AF01. During ground tracking at Morgan Territory Regional Park on 31 January we found AF01 lying breast downwards on a ridge top. The carcass had been partially plucked, as is typical of a raptor kill, and considerable portions of the throat, neck, and back muscle tissue had been consumed. Talon wounds through the backs of the wings and into the sides of the body were of such dimensions and configuration as could only have been inflicted by the feet of another eagle. We found quantities of blood on the ground beneath the neck wounds, suggesting that the bird had died from hemorrhaging. Our assessment was that the bird had been killed by another eagle. Agent Struzik sent the carcass off for necropsy; the USFWS scientist who performed it agreed with our assessment. We had radio-tagged AF01 on 8 January at the Morgan Territory trap site about $2 \mathrm{~km}$ distant. During routine processing we noted that the bird was blind in one eye and possessed ragged plumage. AF01's weight and pectoral muscle mass were within the range of a normal, healthy bird. We located AF01 on seven subsequent occasions, always within a restricted area congruent with the territory of 


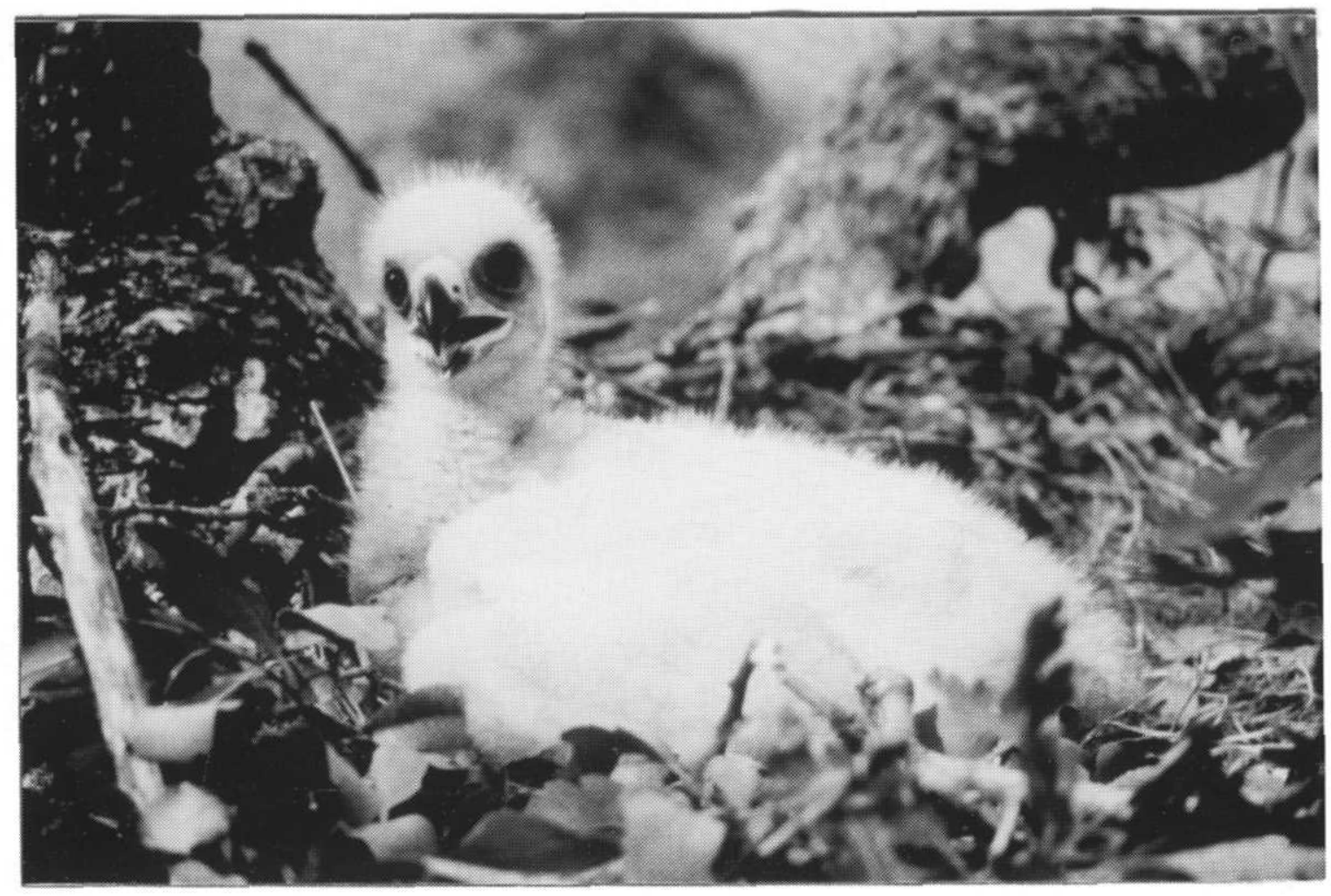

A three-week-old eaglet (photo by John Gilardi)

Adult Male AM01, her apparent mate. Approximately one month after AF01's death, we tagged a four-year-old female NF04 (NF = "near-adult female") who had joined AM01 in his territory. The two remained together throughout the breeding season and have continued to do so through the present time.

7.2.2 Subadult and Floater Fatality Records. As of the end of November, we have detected three deaths among our original sample of 21 subadults and 7 floaters, as follows:

Subadult Female SF06. We detected a mortality signal on 8 March in California Sage Foothill Pine habitat about $5 \mathrm{~km}$ southeast of Mt. Stakes in the central portion of the Diablo Range. We recovered the carcass on 10 March. Necropsy performed by the U.S. Fish and Wildlife Service laboratory at Madison, Wisconsin attributed the death to lead poisoning. We had tagged this bird at Site 300 (West OP), about $1 \mathrm{~km}$ south of the WRA boundary, on 14 January. We obtained 13 subsequent relocations during the aerial roll call surveys; on each occasion SF06 was either around Del Valle Reservoir just south of Livermore or within the interior Diablo Range. 
Subadult Male SM02. During a standard aerial roll call survey on 11 May we received a mortality signal within the WRA, near its southern boundary. We found the carcass the following day, obviously killed in a collision with the blades of a Type 13 structure (56-100 turbine on a 60-foot, horizontally-braced lattice tower), probably on 9 May. This bird, tagged on 12 January, had moved widely within the study region during the three months after capture. By the date of death, we had located it more often in the WRA than any other tagged eagle (Appendix G).

Subadult Female SF03. During an aerial roll call survey on 10 September, we detected a mortality signal from a subadult female (SF03) within the central WRA. On 11 September, we accompanied U.S. Fish and Wildlife Service and KENETECH Windpower personnel to the site for data collection. The eagle's left wing had been severed at the shoulder as a result of colliding with the blades of a Type 13 turbine tower. We had captured SF03 on 4 February at Lawrence Livermore Laboratories Site 300 (West OP) and monitored its movements during the remainder of February near San Luis Reservoir along the southeastern edge of the study region (Appendix G). SF03 was back at Site 300 in March, and ranged along the eastern slopes of the Diablo Range in following months. On 3 September, we found SF03 within the southern portion of the WRA, but on 7 September it visited a familiar location in the eastern Diablos near Crow's Landing air base.

7.2.3 Juvenile Fatality Records. Among the 25 juveniles we radio-tagged as nestlings from 21 May through 4 July, we detected no fatalities through 29 November. Of the sample, one of the transmitters became separated from the eagle on $13 \mathrm{July}$, and another failed about $25 \mathrm{July}$, reducing the effective sample to 23 individuals (see Section 5.2). At the time of this writing (November 29), three juveniles have either departed the area of the airplane surveys or their transmitters have failed; circumstantial evidence suggests that one and possibly two of the missing three transmitters failed (see Section 5.2).

\subsection{Emigrants or Fatalities?}

The fact that no fatalities have been detected among the 23 radio-tagged juveniles is surprising. Going into this study, we thought it obvious that juveniles fledging in the area would quickly experience difficulties in the WRA, especially since summer is the time of greatest turbine activity. We are equally surprised that Pete Bloom identified no juveniles in the sample of 35 turbine-killed golden eagles (see Section 4.1).

Two or three of the dispersing juveniles have apparently left the region (see Section 5.2). Among the remaining birds, some have frequented the nest vicinity for extended periods while others moved varying distances and adapted movement patterns appearing somewhat similar to those of subadults and floaters. 
In a study of juvenile dispersal in the Spanish imperial eagle (Aquila adalberti ${ }^{3}$ ), Gonzalez et al. (1989) found that young from the area of highest breeding density tended to disperse the farthest, and that birds venturing long distances tended to suffer higher mortality than those that remained in the natal vicinity. Gonzalez et al. described three dispersal phases on the basis of band recoveries and sightings: (1) age 4-6 months, "... characterized by short movements and exploratory flights...returning usually to the natal area," (2) age 7-15 months, some individuals traveling long distances while others remaining in the natal vicinity, and (3) after 16 months, recoveries being significantly closer to the natal area.

Thus far, nothing in our data on the dispersal of the 23 juveniles suggests a departure from the description by Gonzalez et al. If the similarities persist, we may expect an increase in juvenile emigration in the next few months, though not involving all individuals. We may also expect higher mortality rates among the emigrants. As the nesting season approaches, adults will become increasingly territorial, a factor that is believed to influence the dispersal of juvenile raptors (Newton 1979).

\subsection{Preliminary Estimate of Survival Rates}

Trent and Rongstad (1974) developed the following formula for estimating finite daily survival rates from telemetry data (see Krebs 1989):

$$
S=\frac{x-y}{---}
$$

where:

$$
\begin{aligned}
& \mathrm{S}=\text { estimate of finite daily survival rate } \\
& \mathrm{x}=\text { number of radio-days observed over period } \\
& \mathrm{y}=\text { total number of deaths observed over period }
\end{aligned}
$$

Yearly survival rates are calculated as $\mathbf{S}^{365}$

Confidence limits for these estimates can be obtained by using the standard limits (95\%) for the number of deaths in the Poisson frequency distribution as y values in the formula.

Assumptions of this technique for survival estimation include that, (1) each radio-day is an independent event in which the eagle either lives or dies - hence the expectation of a binomial

\footnotetext{
${ }^{3}$ Some believe Spanish and North African populations of Aquila heliaca to be a separate species $\underline{A}$. aldalberti.
} 
distribution, (2) the probability of dying is constant over the entire period - a snag with the eagle data because the turbines are not always spinning, and (3) that the day of death is known.

For the three fatalities among the aggregate sample of 19 itinerant subadults and 7 floaters (6,510 radio-days), we calculated a yearly survival rate of 0.845 (95\% C.L. $=0.635-0.955)$. We then computed a yearly survival value of 0.781 (C.L. $=0.513-0.935)$ for the subadults alone, considering that there were no deaths in the sample of floaters.

During our aerial roll call surveys, we recorded 10 of the 19 individual subadults within the WRA on at least one occasion. Considering this subsample of known WRA visitors on the assumption they were exposed to a greater risk of blade strike, we calculated a 0.762 yearly rate. Two of the 10 were killed by blade strikes. We detected four of the seven floaters within the WRA boundaries, two of them more often than all other tagged birds. As mentioned, no fatalities have been detected among the floaters, and none have been censored.

Likewise, we recorded no fatalities among the tagged sample of 25 juveniles, nor did we find any fatalities among a greater sample of nestlings (tagged and untagged) from hatching to fledging. Two transmitters were censored early on, one a detachment and one a failure, leaving a sample of 23 tagged juveniles. Of these, three may have left the region, although there is circumstantial evidence that at least one of them had a failed transmitter.

Among the five tagged breeders, one died near its territory, a victim of attack by another eagle. The dead bird had been blind in one eye and its plumage was noted as ragged, unusual factors that may have contributed to its vulnerability. In any case, our sample of breeders is too small for analysis.

Because the field study has been underway for a relatively short period (less than one year) and because sample sizes of both tagged eagles and fatalities are small, the confidence limits attached to our survival estimates are too large for any significant appraisal of population trends. In all of the calculations we assumed that eagles bearing transmitters that ceased to be detected during the surveys for unknown reasons (e.g., emigration, radio failure) had an equal probability of being alive or dead, so we censored the missing transmitters from the sample. The effect of censoring may be to overestimate the survival rate because lethal agents may exist that would render a transmitter inoperable (see Section 4.5). 


\subsection{ESTIMATING A POPULATION IMPACT}

The golden eagle population in the Diablo Range could be impacted by WRA-related mortality at several levels, the most serious being the decline or extinction of the breeding population. At another level would be a substantial reduction in the numbers of non-breeding adults (floaters), a population segment that stabilizes the breeding segment against loss (see Section 3.2.2 and 3.2.3). A potent indicator of floater reduction would be the frequent observation of subadults as members of breeding pairs. Such a population would be vulnerable to increased mortality from any source. Thirdly, the WRA fatalities may create conditions that require unacceptably high levels of immigration from other populations to maintain the breeding segment. Determining the level of acceptability would be a value judgement.

\subsection{What We Have Learned}

Obviously, our current knowledge of the golden eagle population nesting in the Diablo Range is insufficient to predict a population effect at any level. However, we have identified and made useful approximations of a number of conditions and values that relate to the development of such an assessment. Let us review these tentatively:

(1) Breeders were resident. Our data suggest that breeding pairs maintain their territories year round. Therefore, breeder survivorship can be easily addressed with a future field study involving telemetry or color marking.

(2) Most subadults and floaters present in winter were resident. The majority of eagles we radio-tagged in the vicinity of the WRA in January and February have remained within the study area. This result, if verified by continued surveys, identifies the northern Diablo range as the area containing the population potentially impacted.

(3) Estimated annual survival in our sample of 19 subadults was 78 percent. However, given the considerable girth of the confidence interval, this estimate is not to be applied to any serious calculation of population dynamics.

(4) Nesting density in one area of survey was among the highest reported for the species. There were 37 pairs observed within an area of $820 \mathrm{~km}^{2}$, or one pair per $22 \mathrm{~km}^{2}$. However, the habitat (oak savanna) in that particular area appears more favorable than most other parts of the study area.

(5) We observed very few subadults $(<2 \%)$ as members of breeding pairs.

(6) Nesting activity and success were higher than normal for golden eagles. Of 37 pairs with known reproductive outcome, 32 laid eggs $(86.5 \%)$. Of these, three failed in the egg stage, and 29 pairs (78.3\%) fledged young. 
(7) Brood size at fledging was higher than normal for golden eagles. The 29 pairs fledged 47 young for an average of 1.62 young per successful nest. Productivity, expressed as the number of young fledged per occupied nest, was 1.27.

(8) Nestling mortality was low. We recorded no reductions in brood size.

(9) Juvenile survivorship within the study area was high. We detected no fatalities among 23 radio-tagged juveniles during June through November.

(10) Some juveniles emigrated. Two or three of 23 juveniles apparently left the study region during August through November.

(11) The California ground squirrel made up 64 percent of biomass in the diet of nesting eagles. The next most important species was black-tailed jackrabbit at eight percent.

\subsection{What We Do Not Know}

On the subject of natality, most notably lacking in the data helpful to a demographic prediction are the facts necessary to even roughly estimate the number of young golden eagles annually fledging in the northern Diablo Range, how reproductive performance varies with habitat, and how cohort size might be expected to vary over time, say, a decade. Because temporal variation in reproduction almost certainly relates to the stability of the food supply, it will be necessary to understand the population dynamics of the California ground squirrel and possibly other species. Strengthening the mortality side of the demographic equation will require a continuation of the aerial roll call surveys and an increase in the tagged sample, particularly as regards an estimate of breeding adult turnover.

\subsection{A Preliminary Life Table}

As a matter of interest, let us apply some of our preliminary estimates to a hypothetical resident population of golden eagles for which the following speculative values remain constant from year to year:

(1) The number of occupied breeding areas $=80$

Justification: This is our estimate of the number of eagle pairs in the $30-\mathrm{km}$ zone (see Section 6.3) and no doubt a gross underestimate of the number of occupied territories in the entire study region which is roughly twice as large as the $30-\mathrm{km}$ zone.

(2) The number of fledged young per occupied breeding area $=1.27$. 
Justification: This is based on only one year of work and may be high (see Section 6.2). We are assuming for now, perhaps erroneously, that California ground squirrel populations are somewhat stable from year to year.

(3) Annual juvenile survival $=70$ percent.

Justification: We admit this a gloriously wild guess based on juvenile survival rates in bald eagles (Bowman et al. 1995, in press (71\%); Hunt et al. 1992a (70\%); Buehler et al. 1991 (100\%); Jenkins $1992(76.9 \%))$. But recall that among 23 juveniles tagged as fledglings mainly in June, no fatalities were detected (understandable in view of the fact that many remained with their parents for long periods). However, two $(8.6 \%)$ or three $(13.0 \%)$ have departed the area of our airplane surveys, and more may do so soon as the adults become territorial with the onset of the breeding season. The literature suggests higher mortality among emigrants than those remaining in the natal area (see Section 7.3), but the WRA may play a role here.

(4) Annual subadult survival $=78.1$ percent.

Justification: See our calculations in Section 7.4. But remember that the confidence limits of our estimate are so wide that we could easily be missing the true value by 20 percent.

(5) Annual floater survival $=88$ percent.

Justification: Obviously a ballpark figure, but isn't it reasonable that floaters, having run the gauntlet of situational risk factors for more years than subadults, would be less likely to have mortal accidents?

(6) Annual adult survival $=88$ percent.

Justification: We have found no solid references on breeding adult survival in golden eagles, but a recent study of bald eagles by Bowman et al. (1995, in press) at Prince Williams Sound, Alaska demonstrated an annual survival rate for breeders of 0.88 (SE $=0.03$ ). That population supports a considerable floating segment that clearly influences the turnover rate: 50 percent of the adults that died during the study were killed by other eagles. Yearly survival rates for other population segments at Prince Williams Sound included 0.71 for juveniles $(\mathrm{SE}=0.07)$ and 0.95 percent for subadults and near-adults (4-year-olds) $(\mathrm{SE}=0.04)$.

(7) Maximum physiological longevity $=20$ years.

Justification: This is the upper limit for a number of medium-sized raptors. Eagles probably live longer. 
If these values remain constant, and there is neither immigration nor emigration, this hypothetical population will maintain itself at an equilibrium level (mortality $=$ natality) of 126 subadults, 43 near-adults (4-year-olds), 120 floaters; and 160 breeders ( 80 pairs) producing an annual cohort of 101 young. The total population at fledging time will be 550 individuals (see Appendix I for an explanation of these calculations).

Table 8.1 explores the consequences of changing survivorship values in adults and juveniles while all other values remain constant. The values in Box A are as given above, but in Box B adult survivorship is reduced by three percent. The result is a 43 percent decline in the number of floaters, a factor that renders the population substantially more vulnerable to demographic forces. In contrast, a thirteen percent reduction in juvenile survival is required to effect the same impact on the floating segment. Clearly, the well being of a golden eagle population can be influenced by very subtle changes in adult survivorship. Recall that at least half the fatalities in the WRA involve adult eagles (see Section 4.1).

\subsection{GOLDEN EAGLE OCCURRENCE IN THE WRA}

\subsection{Sightings of Eagles in the WRA}

To best address the tasks of, (1) identifying factors which attract golden eagles to the WRA, (2) monitoring the WRA for eagles, and (3) observing activities and behaviors exhibited by eagles which might increase their risk of turbine strikes, we conducted weekly road surveys of the entire WRA. In doing so, we visually examined every turbine tower within sight of the survey roads and observation points to record occurrences of perched raptors and ravens; we additionally noted all flying raptors and ravens within sight. The surveyed area included both the North (Dyer) and South (Midway) sites of the WRA (see Section 2.0, Study Area).

9.1.1 Methods. To facilitate the observational surveys and subsequent analyses, we divided the WRA into 16 discrete segments (Figure 9.1) selected on the basis of topography offering the least obstructed view of large numbers of turbines located within areas of roughly comparable size. In mapping the 16 segments we designated standard observation points from which turbine rows could be viewed. To quantify the area and number of turbine towers examined in each survey segment, we delineated segment boundaries in the field on topographical maps and later digitized the boundaries in AtlasGIS ${ }^{\mathrm{TM}}$. Thus, we included no turbine tower in more than one segment. We assigned air space boundaries for flying birds by approximation during field observations.

We tabulated the number of turbine towers in each segment by type and visibility ranking. In all, we surveyed 24 of 26 types of turbine/tower configurations (Appendix C). We ranked the visibility of each type in the field to allow accurate comparisons of relative numbers and raptor use of turbines surveyed per segment. Tower visibilities were ranked as follows: 


\begin{tabular}{|c|c|c|c|}
\hline $\begin{array}{l}\text { Population } \\
\text { Segments }\end{array}$ & $\begin{array}{l}\text { Survival } \\
\text { Rate }\end{array}$ & $\begin{array}{l}\text { Segment } \\
\text { Size }\end{array}$ & A \\
\hline Juveniles & 0.7 & [101] & \\
\hline Subadults & 0.781 & 126 & \\
\hline Near-adults & 0.781 & 43 & \\
\hline Floaters & 0.88 & 120 & \\
\hline Breeders & 0.88 & 160 & \\
\hline $\begin{array}{l}\text { Population } \\
\text { Segments }\end{array}$ & $\begin{array}{c}\text { Survival } \\
\text { Rate }\end{array}$ & $\begin{array}{c}\text { Segment } \\
\text { Size }\end{array}$ & B \\
\hline Juveniles & 0.7 & [101] & \\
\hline Subadults & 0.781 & 126 & \\
\hline Near-adults & 0.781 & 43 & \\
\hline Floaters & 0.85 & 69 & \\
\hline Breeders & 0.85 & 160 & \\
\hline
\end{tabular}

\begin{tabular}{|c|c|c|c|}
\hline $\begin{array}{l}\text { Population } \\
\text { Segments }\end{array}$ & $\begin{array}{c}\text { Survival } \\
\text { Rate }\end{array}$ & $\begin{array}{c}\text { Segment } \\
\text { Size }\end{array}$ & C \\
\hline Juveniles & 0.7 & {$[101]$} & \\
\hline Subadults & 0.781 & 126 & \\
\hline Near-adults & 0.781 & 43 & \\
\hline Floaters & 0.88 & 120 & \\
\hline Breeders & 0.88 & 160 & \\
\hline $\begin{array}{l}\text { Population } \\
\text { Segments }\end{array}$ & $\begin{array}{c}\text { Survival } \\
\text { Rate }\end{array}$ & $\begin{array}{c}\text { Segment } \\
\text { Size }\end{array}$ & $\mathbf{D}$ \\
\hline Juveniles & 0.57 & [101] & \\
\hline Subadults & 0.781 & 103 & \\
\hline Near-adults & 0.781 & 35 & \\
\hline Floaters & 0.88 & 68 & \\
\hline Breeders & 0.88 & 160 & \\
\hline
\end{tabular}

Table 8.1. Floater numbers (at equilibrium) change to similar values when the survival rate is reduced by three percent for adults $(A, B)$ and thirteen percent for juveniles $(C, D)$. Changed values appear in bold type. This table shows that an eagle population is far more sensitive to changes in adult survival than to changes in natality or juvenile survival. 
Figure 9.1

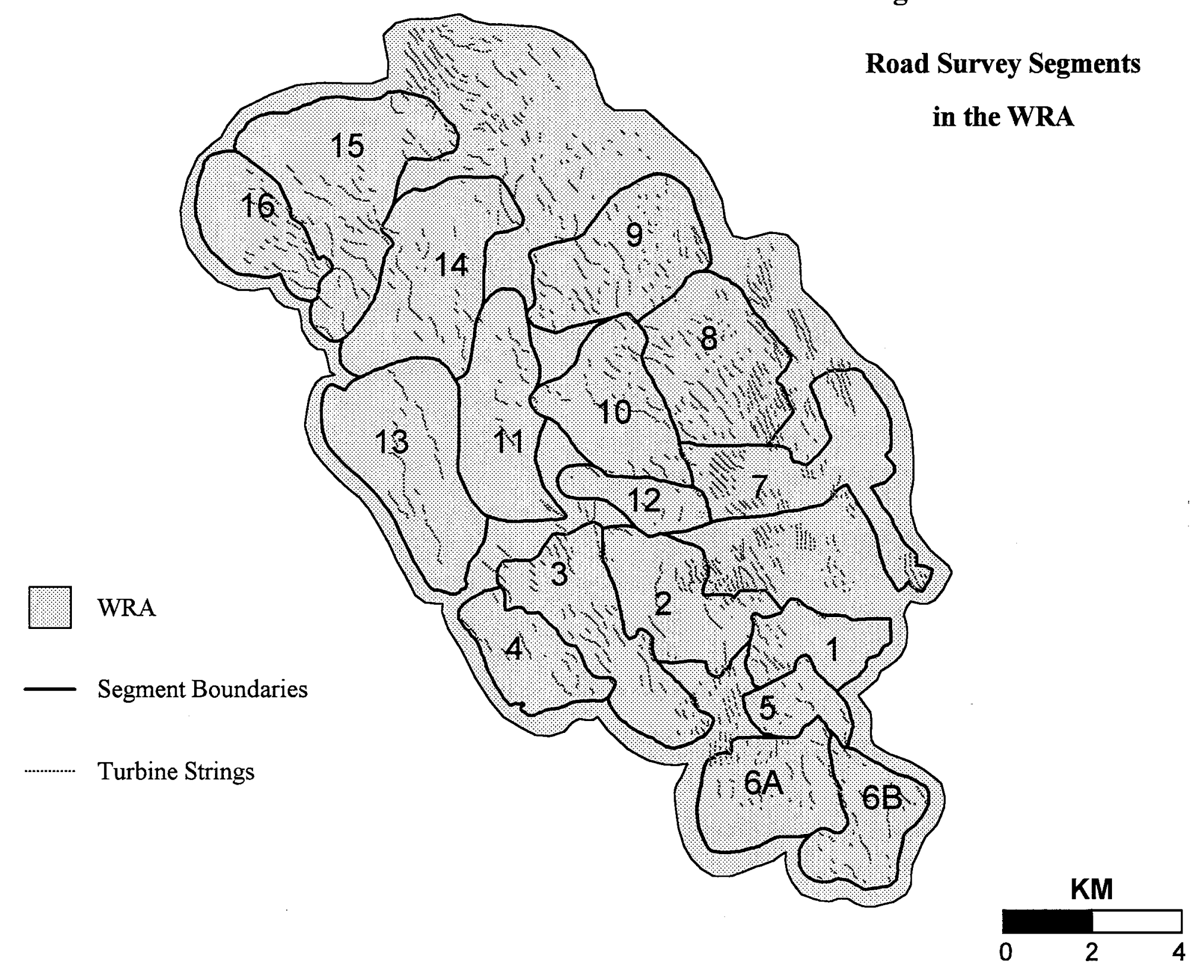


(1) all sides and perch locations were equally visible from ground level up, and the turbine tower was close enough to the observer to allow identification of a perched bird.

(2) the tower was close enough to the observer to allow an adequate scan of all visible perch locations and accurate identification of a perched bird, yet the tower was partially obstructed. When any part of the tower was not visible to the observer from the appropriate observation point, it was considered obstructed.

(3) all sides and perch locations were equally visible from ground level up, yet the tower was so distant that on occasion we would be unable to identify the species of a perched raptor.

(4) the tower was too far away to ensure all perch locations could be adequately scanned; perched birds would be difficult to detect or identify.

We conducted the entire road survey once per week; it required two days to complete. Surveys in segments 9 through 16 were normally run on Mondays, while those in segments 1 through 8 were done on Tuesdays. These weekly surveys began on 23 May and continued through 23 November. Each survey day began approximately one hour after sunrise; surveys lasted 7 to 10 hours, depending on weather, road conditions, and numbers of birds seen. To prevent bias associated with time-of-day influence on perching activity, we rotated segments each week: the initial segment surveyed one week was moved to the last position the following week.

During a typical road survey within a segment, the observers drove slowly $(<15 \mathrm{mph})$ along the standardized route, scanning all potential perches (including the ground), stopping to scan more distant turbine towers at specified observation points with binoculars and spotting scopes as necessary. The same pair of observers (Barg and Culp) conducted virtually all the road surveys. This provided consistency in identifying and aging eagles and other raptors, as well as in recording data. The use of two observers facilitated driving, record keeping, and observation.

We recorded all perched and flying golden eagles (and other perched raptors and ravens) on "obsforms" (Appendix C); observations of flying raptors other than eagles were simply tallied per segment, unless flying close to fully operating turbines in which case we recorded a complete data string. For golden eagles, we recorded a new data line each time activity changed, as appropriate to our objectives; however, we assigned these secondary observations to a different data type (see Appendix $\mathrm{C}$ ) to avoid census duplication (counting an eagle twice). Data recorded for each sighting included: date, time, species, age, activity, perch structure, perch type, turbine tower type, turbine activity, turbine row position, turbine blade rating, location (i.e., lat/long or turbine number), habitat, and weather (see Appendix C). From a high point in each survey segment we scanned all frequencies of radio-tagged eagles. In addition to standard data for visual observations we recorded the identity of the bird, compass bearing, activity (perched or soaring, see Section 5.1), and whether or not we were able to see the eagle. 


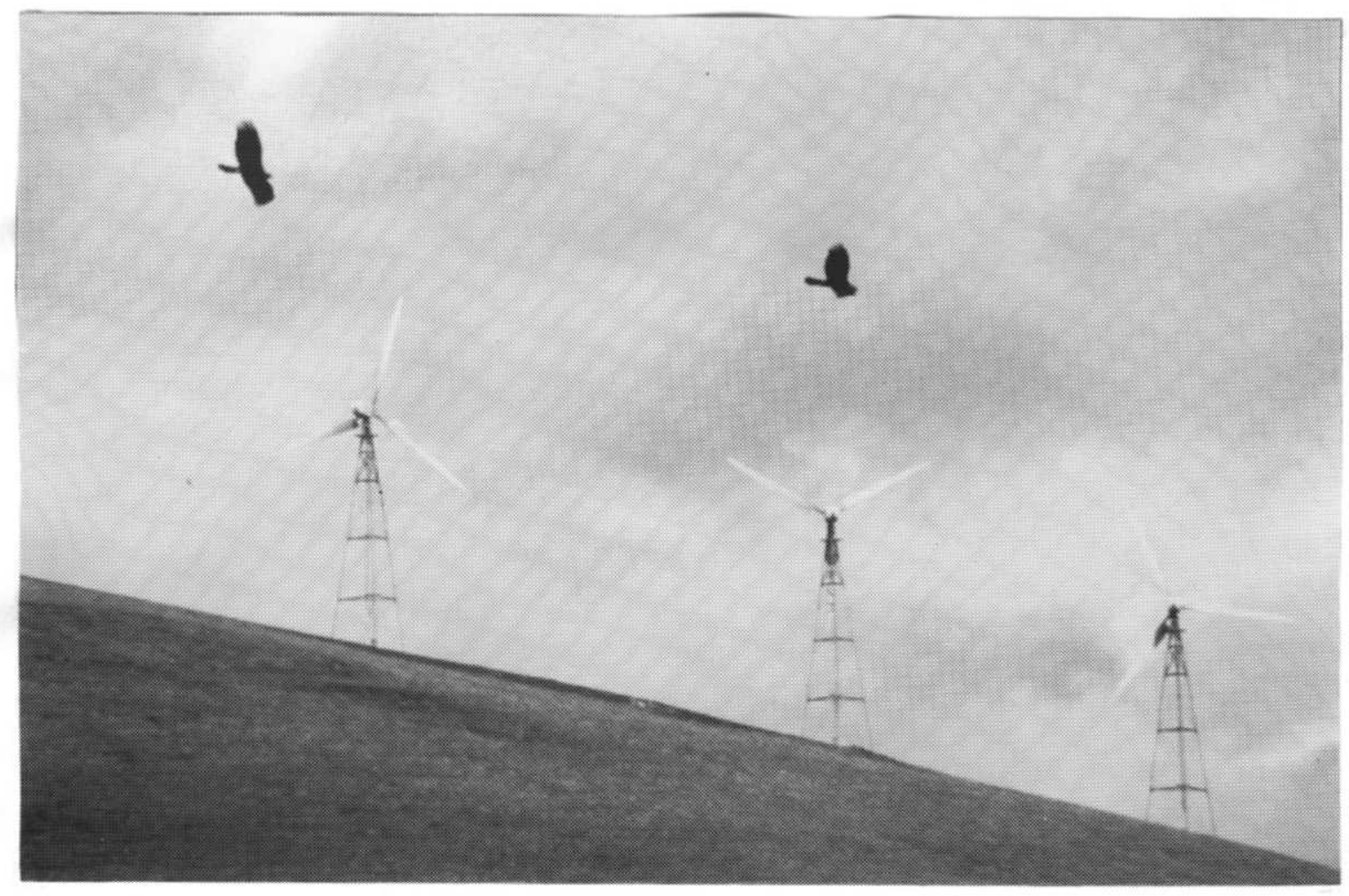

Two golden eagles in the WRA (photo by John Gilardi)

To compare eagle abundance, distribution, and behavior in the WRA to an area of similar habitat without turbines, we set up a comparable weekly road survey at nearby Site 300, an experimental test facility of the Lawrence Livermore Laboratory, University of California. Site 300 lies immediately adjacent to and south of WRA segments 6A and 6B (Figure 9.1). Site 300 is dominated by short grasses, and the terrain is similar to that found in the WRA; however there is no grazing, and the grass is annually burned. In contrast to the WRA, there are very few elevated perch sites; there are only occasional electrical poles and very few trees. During road surveys on Site 300, we used the same methodologies as those applied in the WRA (see above); we selected two survey segments, $\mathrm{AA}$ and $\mathrm{AB}$. We established observation points at locations offering visibility along standardized routes, and we identified sighting locations with GPS coordinates. We conducted the weekly surveys during 30 June through 23 November between 0900 and 1300 hours; each complete survey lasted approximately 2 hours. We began surveys with the second segment surveyed the prior week.

In the WRA, we conducted ground squirrel surveys along roads in each of the 16 road survey segments to determine if golden eagle distribution might be related to gross variation in ground squirrel abundance. We surveyed all 16 segments once during a two week period, completing 


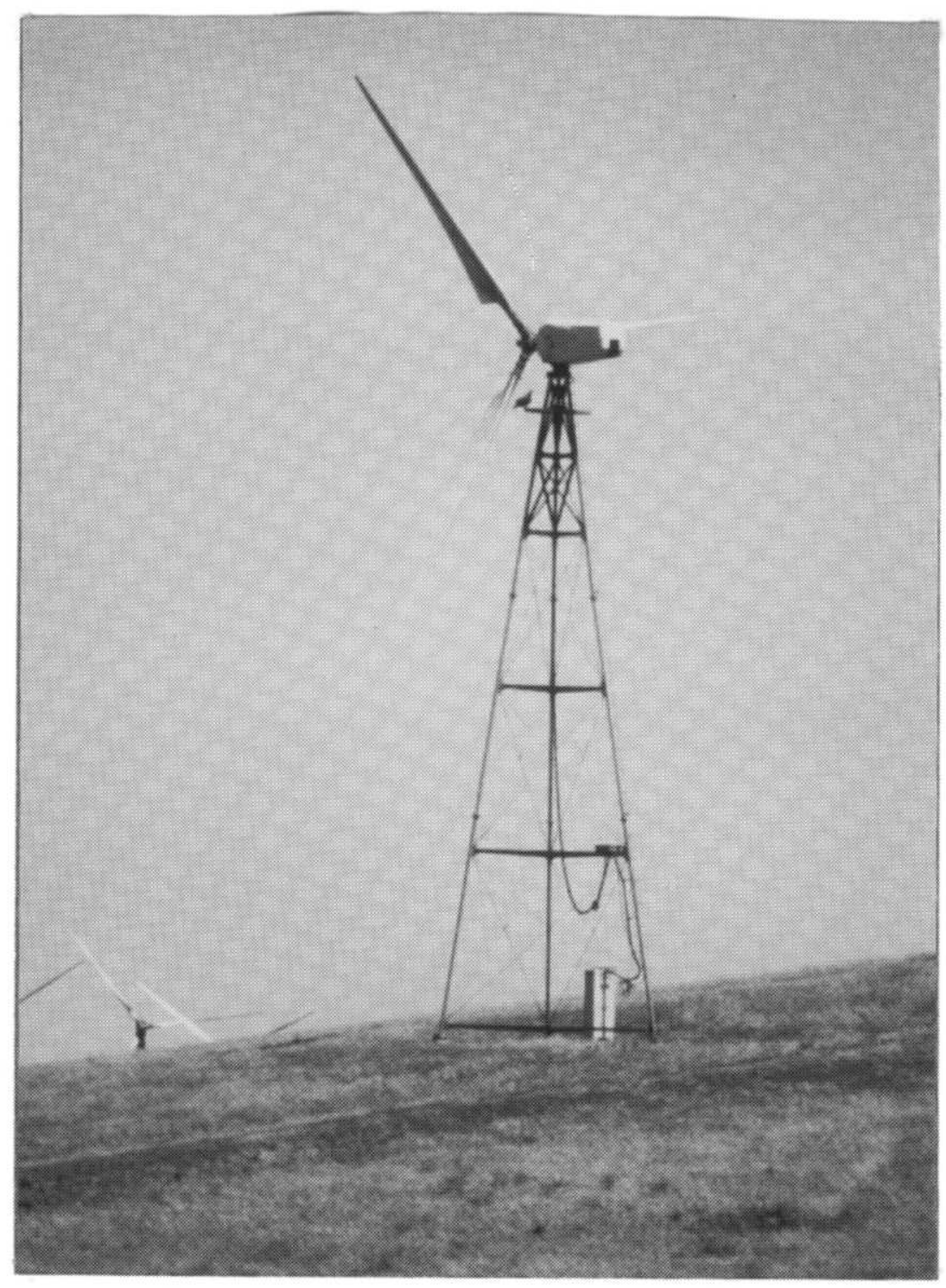

A golden eagle perched on a 60-foot Kenetech Type 13 tower (photo by Charles Quinn)

a total of four entire surveys from 20 June to 24 August. Individual surveys were conducted between 1000 and 1300 hours, the peak activity period for ground squirrels in the area. During each survey we drove standardized routes 2.3 to $7.5 \mathrm{~km}$ in length at about $10-15 \mathrm{mph}$ and counted all squirrels observed within a road's width $(\mathrm{ca} .=5.3 \mathrm{~m})$ to either side of the survey road and including the road itself. Data collected by the non-driving observer included: segment number, date, time, weather, number of ground squirrels, survey distance, and human activity. 
Because waterbirds may also be an important prey for golden eagles, especially in winter, we conducted waterbird censuses weekly during our regular road surveys in the WRA. We chose ponds on the basis of habitat quality and visibility and according to their distribution among the survey segments. We counted waterbirds from fixed points or while we travelled along a water body. Data recorded included date, time, numbers of birds, habitat, location, and weather.

9.1.2 Results of the Road Surveys. During the 27 weekly WRA road surveys from 23 May through 23 November we recorded 249 golden eagle sightings ( $\bar{X}=9.2$ per survey) and 2,841 sightings of red-tailed hawks $(X=105.2$ per survey). This ratio (1:11.4) of golden eagles to red-tailed hawks departs from that observed in turbine-related incidents (fatalities and injuries) in the WRA for the same period: KENETECH Windpower recorded 15 golden eagle and 87 redtailed hawk (1:5.8) incidents. This finding suggests that golden eagles are more vulnerable to being struck by turbine blades than are red-tailed hawks $\left(\chi^{2}=6.1, \mathrm{df}=1, \mathrm{p}<0.05\right)$. However, Orloff and Flannery (1992, pages 3-82 - 3-84) found evidence that dead golden eagles, being much larger than red-tailed hawks, were more likely to be seen by humans and less likely to be carried off by scavengers.

Figure 9.2 shows the distribution of golden eagle sightings in the WRA as recorded during road surveys. Similar to results from telemetry (see Section 9.3 below), concentrations of sightings appear greater at the northwestern and southern extremes of the WRA. Because the survey segments are of unequal size, we calculated the number of sightings per $\mathrm{km}^{2}$ per survey for both golden eagles and red-tailed hawks (Figure 9.3). Again, we see strong heterogeneity in the distribution of both species. We compared eagle distribution per $\mathrm{km}^{2}$ in each survey segment with the results of our ground squirrel surveys, but found no significant correlation (Table 9.1). However, we draw no conclusions from this, given the many variables involved. Figure 9.4 shows the distribution within the WRA of golden eagle turbine strikes during 1993 and 1994; see Figures 9.2 and 9.3 for comparisons with distributions of eagle sightings.

9.1.3 Behavior of Eagles in the WRA. Out of a total of 249 golden eagle sightings in the WRA during road surveys, we recorded 155 (62.2\%) eagles flying and $94(37.8 \%)$ perched. Of the flying eagles, we observed 140 soaring, gliding, or flap-flying $(90.3 \%)$, 11 contour hunting $(7.1 \%), 3(1.9 \%)$ hunting while hanging stationary in the wind (soar hunting), and 1 $(0.7 \%)$ that appeared to be hunting while flying ca. $30 \mathrm{~m}$ above the ground.

When perching in the WRA, eagles were recorded on the following perch types: 34 (36.2\%) on transmission towers, $33(35.1 \%)$ on the ground, $23(24.4 \%)$ on wind turbine towers, $2(2.1 \%)$ on electrical power poles, $1(1.1 \%)$ in a tree snag, and $1(1.1 \%)$ on a fence post.

In incidental observations made in the WRA during 26 April-22 May, we observed 34 instances of contour hunting, 6 cases of soar hunting, and 1 instance where an eagle was chasing prey on the ground. On 11 of these flights eagles attempted to capture prey. Four of 8 attempts while contour hunting were successful, one attempt while dropping from a ca. $20 \mathrm{~m}$ soar was unsuccessful, one attempt initiated from a perch was successful, and one attempt had an unknown outcome. 
Figure 9.2

Sightings of Golden Eagles

During Road Surveys in the WRA

May - Nov 1994

WRA

Segment Boundaries

Turbine Strings

$\square \quad$ Flying Eagles

A Perched Eagles

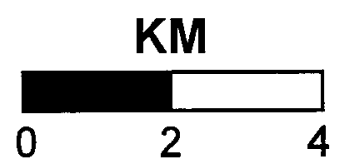


FIGURE 9.3 NUMBER OF GOLDEN EAGLES AND RED-TAILED HAWKS

OBSERVED PER KMํㄹ PER ROAD SURVEY

23 May through 23 November 1994

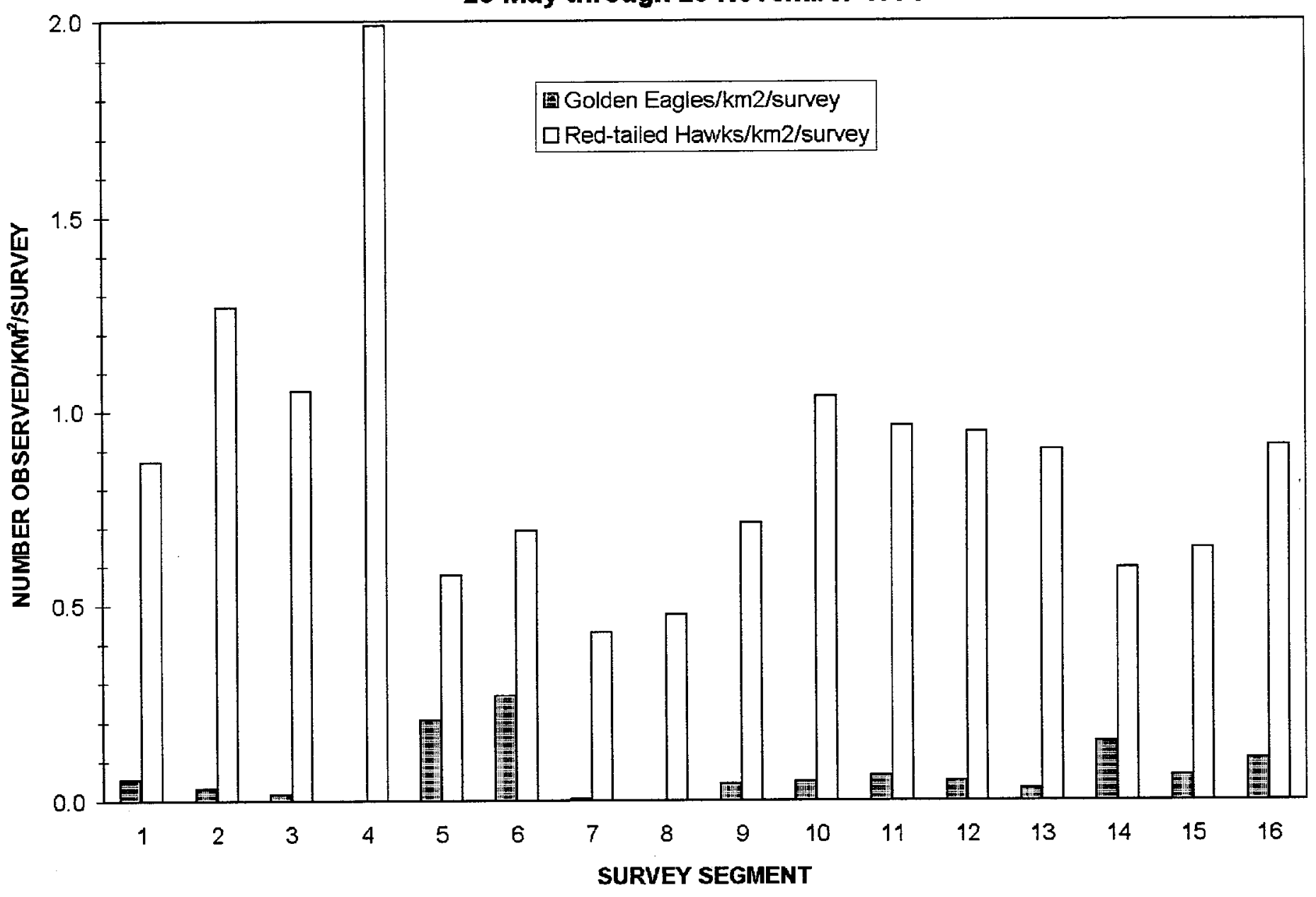


Table 9.1

GROUND SQUIRRELS PER KM AND GOLDEN EAGLES PER KM ${ }^{2}$ PER ROAD SURVEY BY SEGMENT IN THE WIND RESOURCE AREA

20 June through 24 August 1994

\begin{tabular}{|c|c|c|}
\hline Segment & Ground Squirrels/Km & Golden Eagles $/ \mathrm{Km}^{2}$ \\
\hline 1 & 0.45 & 0.073 \\
\hline 2 & 2.41 & 0.028 \\
\hline 3 & 0.42 & 0.000 \\
\hline 4 & 0.00 & 0.000 \\
\hline 5 & 3.33 & 0.112 \\
\hline 6 & 0.38 & 0.236 \\
\hline 7 & 1.01 & 0.000 \\
\hline 8 & 0.94 & 0.000 \\
\hline 9 & 3.60 & 0.022 \\
\hline 10 & 0.62 & 0.027 \\
\hline 11 & 6.40 & 0.037 \\
\hline 12 & 3.42 & 0.000 \\
\hline 13 & 2.18 & 0.009 \\
\hline 14 & 5.97 & 0.179 \\
\hline 15 & 2.00 & 0.062 \\
\hline 16 & 0.65 & 0.053 \\
\hline
\end{tabular}

$\mathrm{n}=16$

Critical value for $\mathrm{p}<.05=0.503^{*}$

Correlation coefficient $=0.139$

Not significant

* Critical value obtained from J. H. Zar. Biostatistical Analysis. Prentice-Hall, Englewood Cliffs, N. J. 1974. 


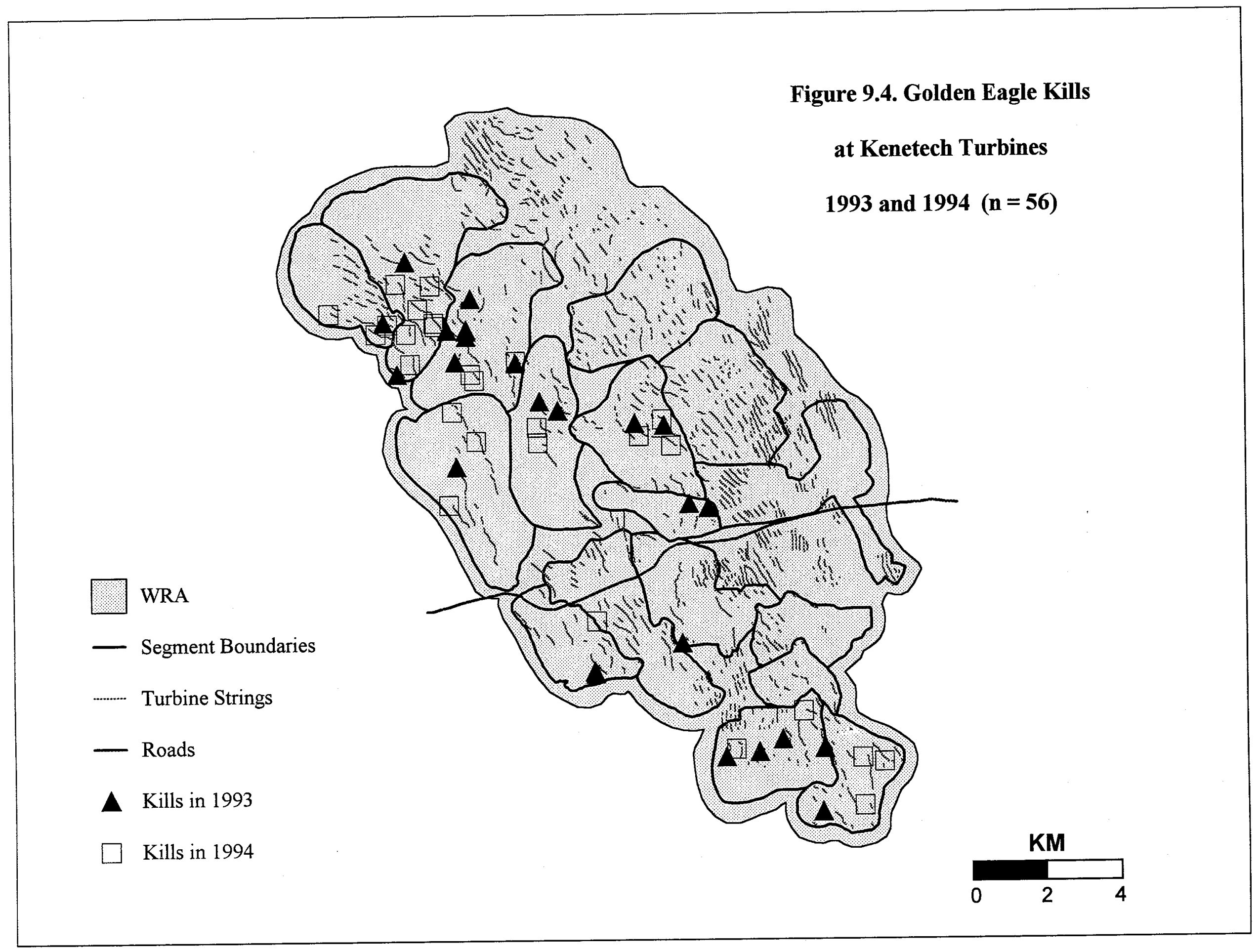


Table 9.2 shows that eagles perched on four turbine tower types and indicates the perching position on the tower. Eagles perched mainly on the 60-foot Type 13 wind turbine tower, the most common type and the one most often implicated in blade strike incidents; eagles chose the 4 th crossmember (counting up from the ground) most often.

While only 9.2 percent of 249 golden eagle sightings were of birds perched on turbine towers, there were 22.9 percent turbine perchings among 2,841 red-tailed hawk sightings. Like golden eagles, red-tailed hawks also utilized the 60-foot Type 13 wind turbines most often $(78.8 \%$ of turbine perchings; Table 9.3). Red-tailed hawks perched mainly on the catwalks, although they also used 3rd and 4th crossmembers extensively (Table 9.4). By comparing the numbers of surveyed turbine towers (total $=4,543$ towers with visibility rankings of 1,2 , or 3 , see methods) of each type with the numbers of red-tailed hawks observed perching on them, we constructed a "perchability index" for each tower type (Table 9.5). In our analysis we did not include towers with visibility ranking 4 because they could not be adequately examined.

Surprisingly, our data suggest that red-tailed hawks prefer the Kenetech 80 -foot Type 22 tower to all other tower configurations, including the 60-foot Type 13 for which the majority of perchings were recorded $\left(\chi^{2}=81.9\right.$, df $\left.=1, \mathrm{p}<0.001\right)$. Red-tailed hawks perched on the Type 22 towers almost four times as frequently as on the Type 13 towers relative to their availability. Although the sample total for golden eagles was low $(n=19)$, the data shown in Table 9.5 suggest a similar preference for the Type 22 towers over the Type 13 Towers $\left(\chi^{2}=\right.$ 5.0 with Yate's correction for small samples, $\mathrm{df}=1, \mathrm{p}<0.05$ ). None of the 56 golden eagle turbine strikes in 1993 and 1994 appeared to be associated with Type 22 turbines.

Among the tower configurations most conspicuously avoided by perching raptors were the tubular turbine towers of which there were some 723 visible (ranks 1-3) along the survey route, or approximately 16 percent of the surveyed turbines. Table 9.5 shows no records of golden eagles perching on them. Red-tailed hawks that perched on them did so on the catwalks, ladders, and platforms, but not on the nacelles (see Glossary).

Both red-tailed hawks and golden eagles appeared to avoid perching on operating turbine towers. We saw red-tailed hawks perching on operating turbines on 15 occasions $(2.3 \%$ of 651 tower perchings). On one occasion (4.3\% of 23 tower perchings) an eagle was associated with a spinning turbine. Prior to turbine activation, the eagle had perched on the third crossmember of an end-of-row 60-foot Type 13 tower on the side facing the blades (see illustration of this tower type in Appendix C). The eagle's back was to the blades when they began to move. The bird then turned, facing the blades, and remained perched while the blades reached full operating RPM. At that point the eagle dropped from the structure, flying beneath the arc of the blades, and departed the turbine row. In the case of the 15 red-tailed hawk perchings on operating turbines, 9 remained perched, 4 flushed from the turbines, 1 flew from its perch to another operating turbine, and 1 hunted from an operating turbine. The latter launched an unsuccessful attack on prey from the turbine, returned to the same structure, and repeated the entire sequence once more. 
Table 9.2

\section{OBSERVATIONS OF GOLDEN EAGLES PERCHING ON KENETECH WIND TURBINES \\ 23 May through 23 November 1994}

\section{Perch Site}

\# of Observations

\% of Observations

60-Ft. Type 13

2nd crossmember

2

3rd crossmember*

5

4th crossmember

7

30.4

Catwalk (platform)

2

Cable

1

Total number of perchings observed $=17$

80-Fit. Horizontal-braced Type 22

8th crossmember

1

4.3

Catwalk (platform)

1

Total number of perchings observed $=2$

80-Ft. Diagonal-braced Type 21

Catwalk (platform)

Total number of perchings observed $=1$

\section{0-Ft. Diagonal-braced Type 23}

Catwalk (platform)

1

4.3

Diagonal brace

1

4.3

Mid-height platform

1

4.3

Total number of perchings observed $=3$

Total number of turbine perchings $=23$

* The only instance of an eagle perching on a turbine which was operating was on the $3 \mathrm{rd}$ crossmember of a $60 \mathrm{ft}$. tower. 


\section{Table 9.3}

\section{OBSERVATIONS OF RED-TAILED HAWKS PERCHING ON KENETECH AND NON-KENETECH WIND TURBINES 23 May through 12 November 1994}

Turbine tower (Type)

Non-Kenetech

Holec/Windmatic (2)

Micon/SeaWest (4)

Flowind (9)

Enertech (10)

Energy Sciences, Inc. (15)

Fayette (16)
\# of Observations

3

1

3

14

4

14

\section{Kenetech}

33MVS, 80-Ft. lattice tower (12)

33MVS, 120-Ft. lattice tower (26)

60-Ft., lattice tower (13)

80-Ft., horizontal-braced (22)

80-Ft., diagonal-braced (21)

140-Ft., diagonal-braced (23)
2

1

513

44

17

35
\% of Observations
0.3

0.2

0.5

0.2

0.5

2.2

0.6

2.2

78.8

6.8

2.6

5.4

Total number of turbine perchings observed $=651$ 


\section{Table 9.4}

\section{OBSERVATIONS OF RED-TAILED HAWKS PERCHING \\ ON SIXTY FOOT KENETECH WIND TURBINES \\ 23 May through 12 November 1994}

Perch Site

\# of Observations

$\%$ of Observations

60-Ft. Type 13

1st crossmember

1

0.2

2nd crossmember

50

9.7

3rd crossmember

140

27.3

4th crossmember

97

18.9

5th crossmember

50

9.7

Catwalk (platform)

167

32.6

Ladder

2

0.4

Cable

3

0.6

Horizontal brace, unspecified

1

0.2

Turbine tower, unspecified

2

0.4

Total number of perchings observed $=513$ 
Table 9.5

PERCHABILITY INDICES* OF WIND TURBINE TOWER TYPES BASED ON PERCHING OBSERVATIONS OF RED-TAILED HAWKS AND GOLDEN EAGLES

\begin{tabular}{|c|c|c|c|c|c|}
\hline \multirow[b]{2}{*}{ Turbine Tower (Type) } & \multirow[b]{2}{*}{ Turbines } & \multicolumn{2}{|c|}{ Red-tailed Hawk } & \multicolumn{2}{|c|}{ Golden Eagle } \\
\hline & & Perchings & Index & Perchings & $\underline{\text { Index }}$ \\
\hline Tubular Towers & & - & & & \\
\hline Holec/Polenko (1) & 12 & 0 & .0000 & 0 & .0000 \\
\hline Micon (4) & 142 & 1 & .0070 & 0 & .0000 \\
\hline HMZ-Windmaster (7) & 35 & 0 & .0000 & 0 & .0000 \\
\hline $\begin{array}{l}\text { Danregn Vind } \\
\text { Kraft/Bonus (8) }\end{array}$ & 289 & 0 & .0000 & 0 & .0000 \\
\hline Fayette (16) & 216 & 13 & $.0602^{* *}$ & 0 & .0000 \\
\hline Danwin (17) & 7 & 0 & .0000 & 0 & .0000 \\
\hline Kenetech/W.E.G. (20) & 20 & 0 & .0000 & 0 & .0000 \\
\hline Kenetech, Kenetower (24) & 1 & 0 & .0000 & 0 & .0000 \\
\hline Kenetech, Tower 259 (25) & 1 & 0 & .0000 & 0 & .0000 \\
\hline \multicolumn{6}{|l|}{ Vertical axis } \\
\hline Flowind (9) & 142 & 3 & .0211 & 0 & .0000 \\
\hline \multicolumn{6}{|l|}{ Lattice Tower } \\
\hline Holec/Windmatic (2) & 28 & 3 & .1071 & 0 & .0000 \\
\hline Enertech (10) & 137 & 14 & .1022 & 0 & .0000 \\
\hline Wind Power Systems (11) & 18 & 0 & .0000 & 0 & .0000 \\
\hline Energy Sciences, Inc. (15) & 84 & 4 & .0476 & 0 & .0000 \\
\hline BSW/Wagner (18) & 17 & 0 & .0000 & 0 & .0000 \\
\hline Kenetech, 80-Ft. 33MVs (12) & 38 & 2 & .0526 & 0 & .0000 \\
\hline Kenetech, 120-Ft. 33MVS (26) & 1 & 1 & 1.0000 & 0 & .0000 \\
\hline Kenetech, 60-Ft. (13) & 2976 & 513 & .1724 & 17 & .0057 \\
\hline $\begin{array}{l}\text { Kenetech, } 80-F t \text {. } \\
\text { horiz. round-braced ( } 22 \text { ) }\end{array}$ & 68 & 44 & .6471 & 2 & .0294 \\
\hline $\begin{array}{l}\text { Kenetech, } 80-\mathrm{Ft} . \\
\text { diagonal-braced (21) }\end{array}$ & 117 & 17 & .1453 & 1 & .0085 \\
\hline $\begin{array}{l}\text { Kenetech, } 140 \mu \mathrm{Ft} \\
\text { diagonal-braced }(23)\end{array}$ & 194 & 35 & .1804 & 3 & .0155 \\
\hline $\begin{array}{l}\text { * The perchability index was calcu } \\
\text { number of turbines of each type }\end{array}$ & $\begin{array}{l}\text { culated by } d \\
\text { surveyed }\end{array}$ & $\begin{array}{l}\text { he total numb } \\
\text { iibilities } 1,2 \text {, }\end{array}$ & $\begin{array}{l}\text { f perchings o } \\
\text { 3). }\end{array}$ & urbine tower $t$ & by the \\
\hline
\end{tabular}


Orloff and Flannery (1992) found that turbines located at the ends of turbine rows (roughly $21 \%$ of total turbines) killed significantly greater numbers of raptors. In looking for such a tendency in our perching data, we indeed found both golden eagles and red-tailed hawks perching frequently on end-row turbines. Nine $(39.1 \%)$ of 23 eagle turbine perchings were on end-row turbines, not a large enough sample to test for a departure from randomness with respect to availability. However, $279(43.3 \%)$ of 644 perchings were so noted for red-tailed hawks $\left(\chi^{2}\right.$ $=183.7, \mathrm{df}=1, \mathrm{p}<0.001$ ) Among 56 records of golden eagles killed or injured by turbine blades in 1993 and 1994, 23 (41.1\%) were near end-row turbines.

During the road surveys we recorded 211 detections of radio-tagged eagles. Of these, we located 3 individuals visually on $10(4.7 \%)$ occasions; most of the remaining detections were of birds located outside the WRA at unknown distances. In survey segment 6A we observed AF05 8 times and JM09 once; we saw AM05 once in segment 15. In each case, we saw the eagle before using telemetry to identify it.

Distributional data collected from waterbird surveys in the WRA are not presented in this report. Commonly seen species of potential significance to golden eagles included great egret (Casmerodius albus), great blue heron (Ardea herodias), mallard (Anas platyrhynchos), and gadwall (Anas strepera). Had the surveys continued through winter, considerable numbers of these and other species would probably have been seen in association with the many stock ponds on the WRA.

9.1.4 Road Surveys at Site 300. We wished to compare golden eagle density at the WRA, where numerous turbine towers are available for perching, with Site 300 , an area adjacent to the WRA with comparable habitat but few perches. In 20 surveys in Site 300 survey segment AA $\left(9.6 \mathrm{~km}^{2}\right)$ during July-November, we saw 23 eagles, or 0.12 per $\mathrm{km}^{2}$ per survey. In 18 surveys in segment $\mathrm{AB}\left(10.8 \mathrm{~km}^{2}\right)$ we saw 45 eagles, or 0.23 per $\mathrm{km}^{2}$ per survey. These densities are higher than those observed in most survey segments in the WRA for the same period $(\bar{X}=0.08$ eagles per $\mathrm{km}^{2}$ per survey). Interestingly, the WRA segments showing the highest eagle density (segments 5 and 6) were those adjacent to Site 300. These comparisons suggest that perches such as turbine towers do not tend to attract eagles. However, there may be more variables affecting eagle distribution in the area. For example, there is no ground squirrel control program underway at Site 300 , and thus higher prey densities are likely there.

During road surveys at Site 300 we recorded 21 detections of radio-tagged eagles of which 4 (16\%) were located visually; these included SF04, AF05, and AF02. The 17 remaining detections were probably all from birds outside Site 300 .

Because of the greater tendency of red-tailed hawks to perch on turbine towers, we expected to see relatively low numbers of this species at Site 300. However, red-tailed hawk densities were relatively high at Site 300 , a phenomenon probably not related to differences in ground squirrel density; red-tailed hawks generally prey on smaller mammals. 


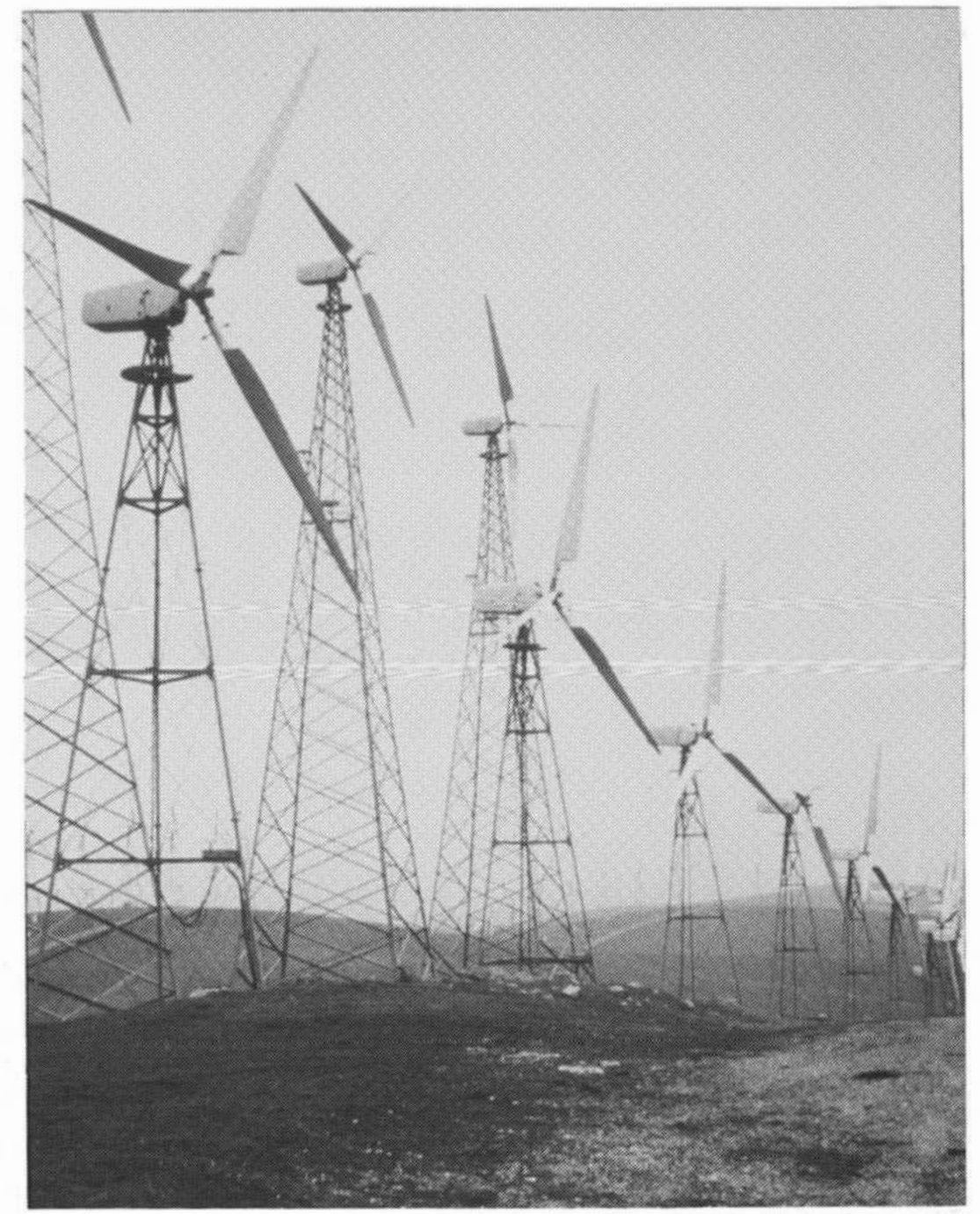

Kenetech lattice towers in the WRA (photo by Daniel Driscoll)

\subsection{Movements of Breeders in Relation to the WRA}

The death of a breeding adult has a potentially greater consequence to the population than the death of a younger eagle (Newton 1989). We must therefore identify the area of eagle breeding distribution where normally ranging adults may be expected to enter the WRA. Stated another way, we would like to quantify the degree of risk these birds experience as a function of nest distance (and possibly direction) to the WRA. Knowledge of the extent of eagle ranging, together with data on nesting density at various distances from the WRA, would identify that subpopulation of breeders subject to direct mortality in the WRA. 
As a test of a new technique to be applied in future years if proven effective, we tracked the movements of a radio-tagged adult female AF03 whose nest with large young was located about $9 \mathrm{~km}$ from the WRA. The technique required that one person observe the eagle with telemetry (often visually as well) from a ridge high above the nest and alert the airplane tracker via portable phone immediately when the eagle began to soar from the area. The airplane tracker, stationed at the Livermore airport ca. $12 \mathrm{~km}$ away, took off without delay and attempted to locate the bird within 15 minutes of the call. If the eagle appeared to be continuing outbound, we relocated it every few minutes until the completion of its flight.

Our results over eight tracking days were encouraging, both with respect to estimating the extent of ranging and in evaluating the usefulness of this technique. Most of the activity of this eagle was restricted to within $3 \mathrm{~km}$ of the nest (86\% total tracking time; Table 9.6), but on occasion the eagle traveled longer distances. One excursion took AF03 to a ridge $8.7 \mathrm{~km}$ east of the nest site and within $.75 \mathrm{~km}$ of the WRA boundary (the Morgan Territory nest site is located approximately $9.5 \mathrm{~km}$ west of the WRA). At no time during the biweekly airplane surveys did we locate AF03 within the WRA. But on one occasion, not during range tracking, AF03 had traveled $15.3 \mathrm{~km}$ south of the nest when we found her soaring over the town of Livermore. Such information, obtained on a larger scale in future years, would answer the question of the minimum safe distance of nests to the Altamont Pass WRA.

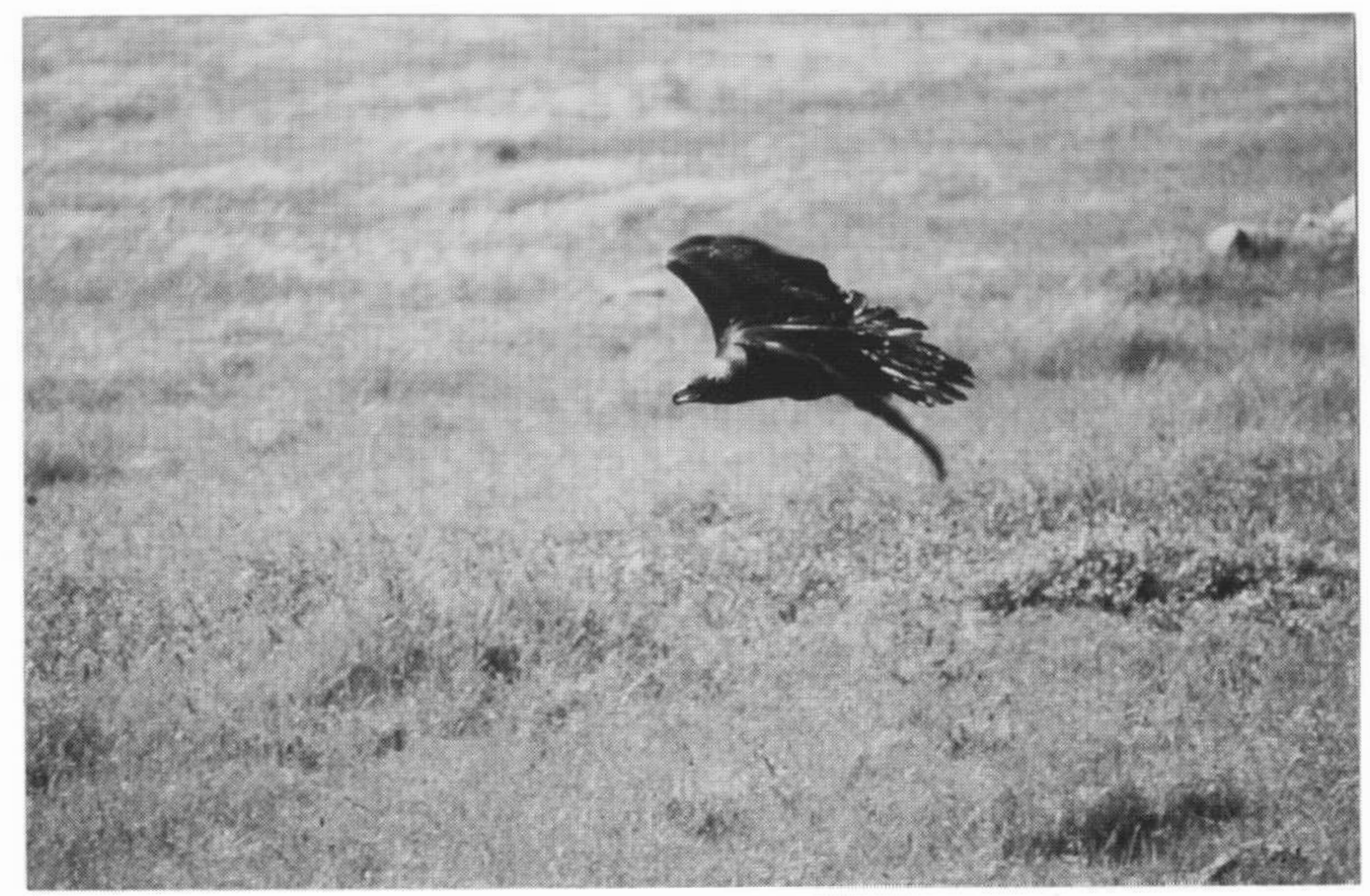

Contour hunting (photo by Hans Peeters) 
Table 9.6. Summary of range movements recorded during eight radio-tracking days (6 hour sessions) of the breeding adult female golden eagle (AF03) at the Morgan Territory nesting area. Time is given in minutes, and percent time is shown in parenthesis.

\begin{tabular}{lccccc} 
DATE & $0-1 \mathrm{KM}$ & $1-2 \mathrm{KM}$ & $2-3 \mathrm{KM}$ & $>3 \mathrm{KM}$ & TOTAL \\
\hline $5 / 24 / 94$ & $94(26.1)$ & $22(6.1)$ & $179(49.7)$ & $65(18.1)$ & 360 \\
$5 / 25 / 94$ & $286(79.4)$ & $7(1.9)$ & $40(11.1)$ & $27(7.5)$ & 360 \\
$5 / 30 / 94$ & $101(30.9)$ & $64(19.6)$ & $162(49.5)$ & $0(0)$ & 327 \\
$6 / 1 / 94$ & $170(47.9)$ & $4(1.1)$ & $151(42.5)$ & $30(8.5)$ & 362 \\
$6 / 2 / 94$ & $158(43.9)$ & $9(2.5)$ & $27(7.5)$ & $166(46.1)$ & 360 \\
$6 / 3 / 94$ & $9(2.5)$ & $351(97.5)$ & $0(0)$ & $0(0)$ & 360 \\
$6 / 9 / 94$ & $136(36.8)$ & $123(33.2)$ & $70(18.9)$ & $41(11.1)$ & 370 \\
$6 / 10 / 94$ & $93(25.7)$ & $156(43.1)$ & $42(11.6)$ & $71(19.6)$ & 362 \\
\hline TOTAL & $1,047(36.7)$ & $736(25.8)$ & $671(23.5)$ & $400(14.0)$ & 2,854
\end{tabular}

\subsection{Movements of Radio-Tagged Subadults, Floaters, and Juveniles in Relation to the WRA}

Figures 9.5, 9.6, and 9.7 show the relocations of 19 radio-tagged subadults and 7 floaters in the vicinity of the WRA as determined during the aerial roll-call surveys conducted from January through October. Like the visual observations of golden eagles obtained during the road census (Fig.9.2), the data suggests an avoidance of the central portion of the WRA. We wondered if the distribution might be an artifact of capture location (Fig. 5.1), namely that some birds were captured at Site 300, just south of the WRA boundary, others at Morgan Territory Regional Park, about $10 \mathrm{~km}$ northwest of the WRA, and still others in the WRA. To test this question, we refined the sample of relocations to include only those birds captured at Site 300 . Figure 9.8 again suggests that conditions within the central portion of the WRA are not as attractive to golden eagles as those to the northwest and south of its boundaries. 


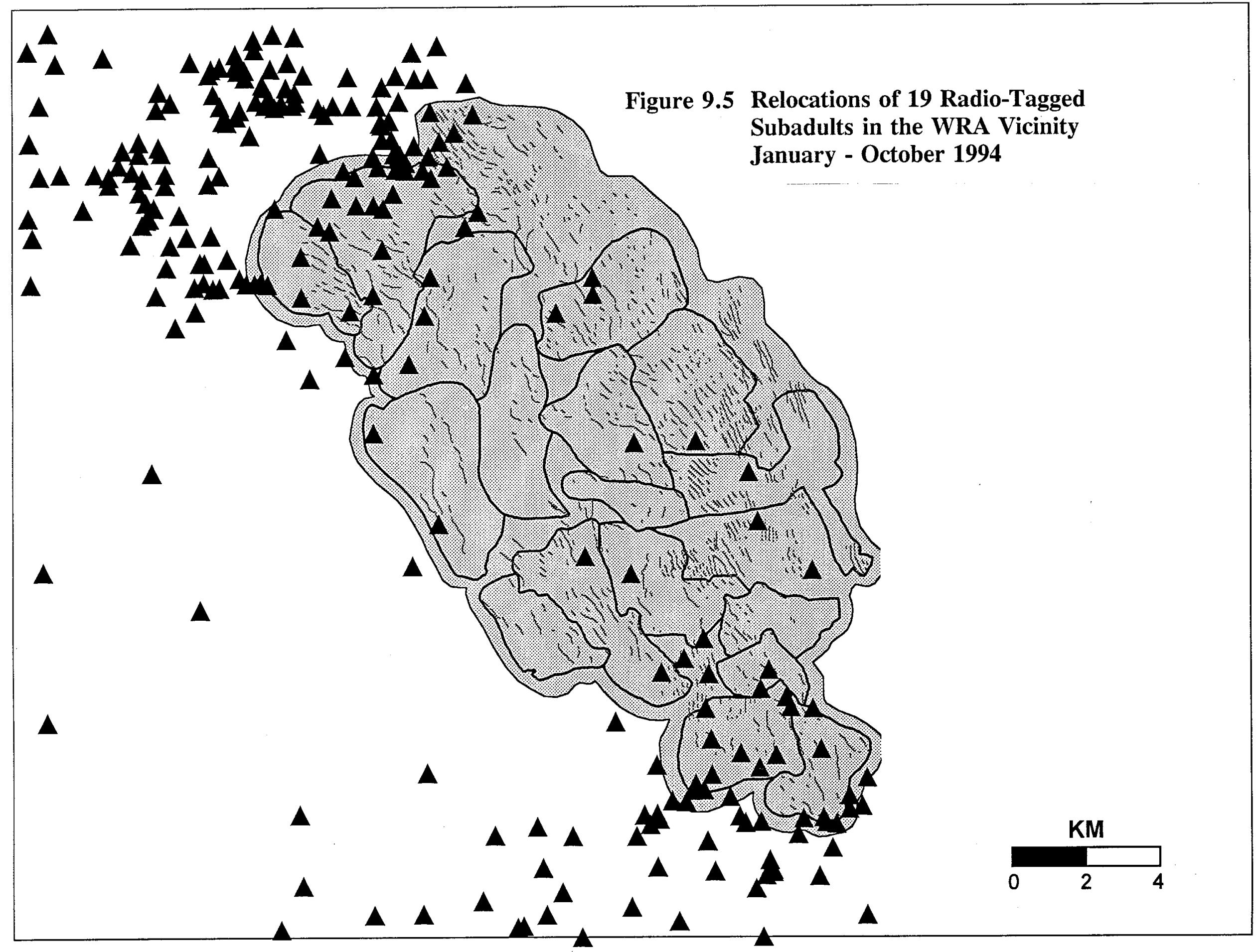




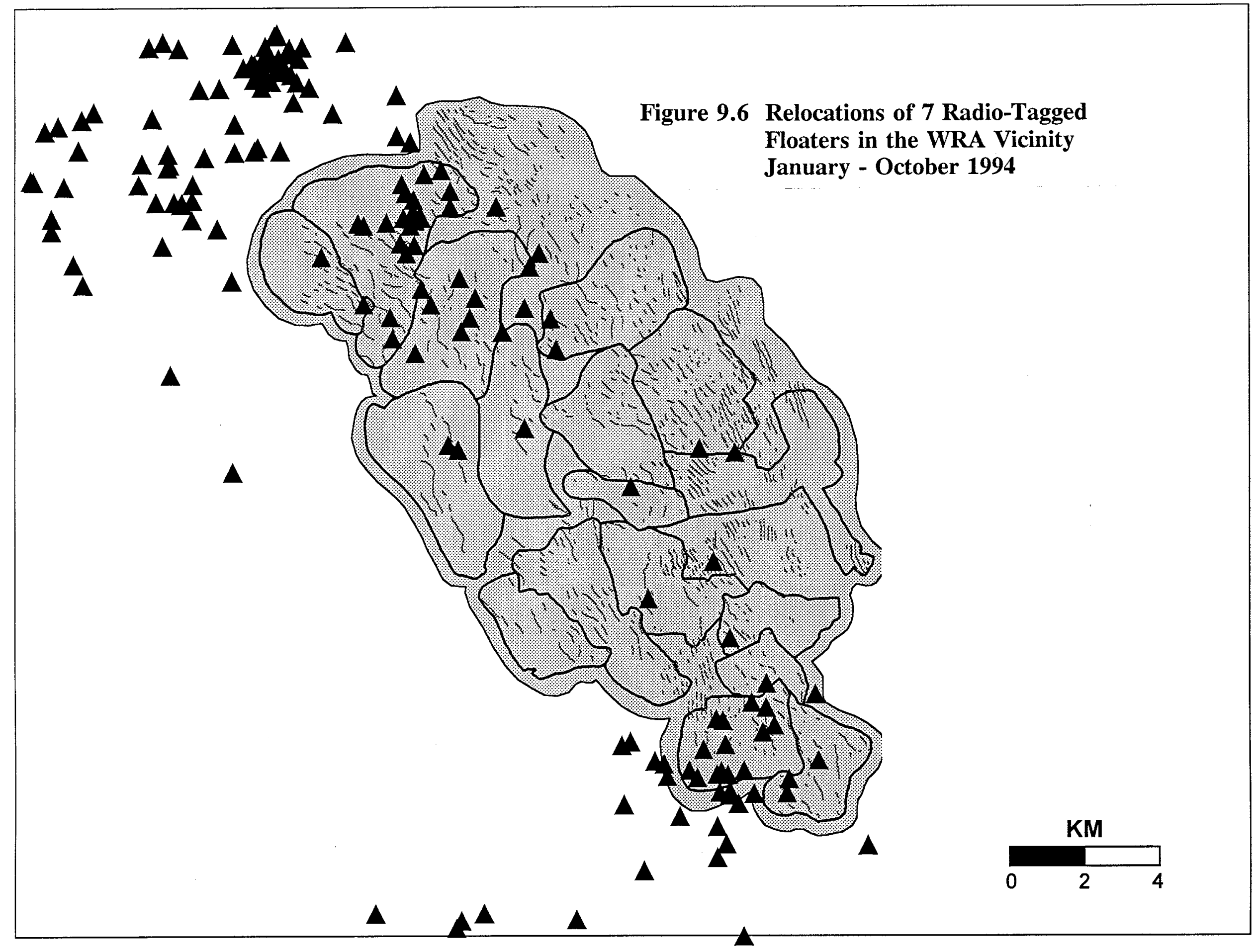




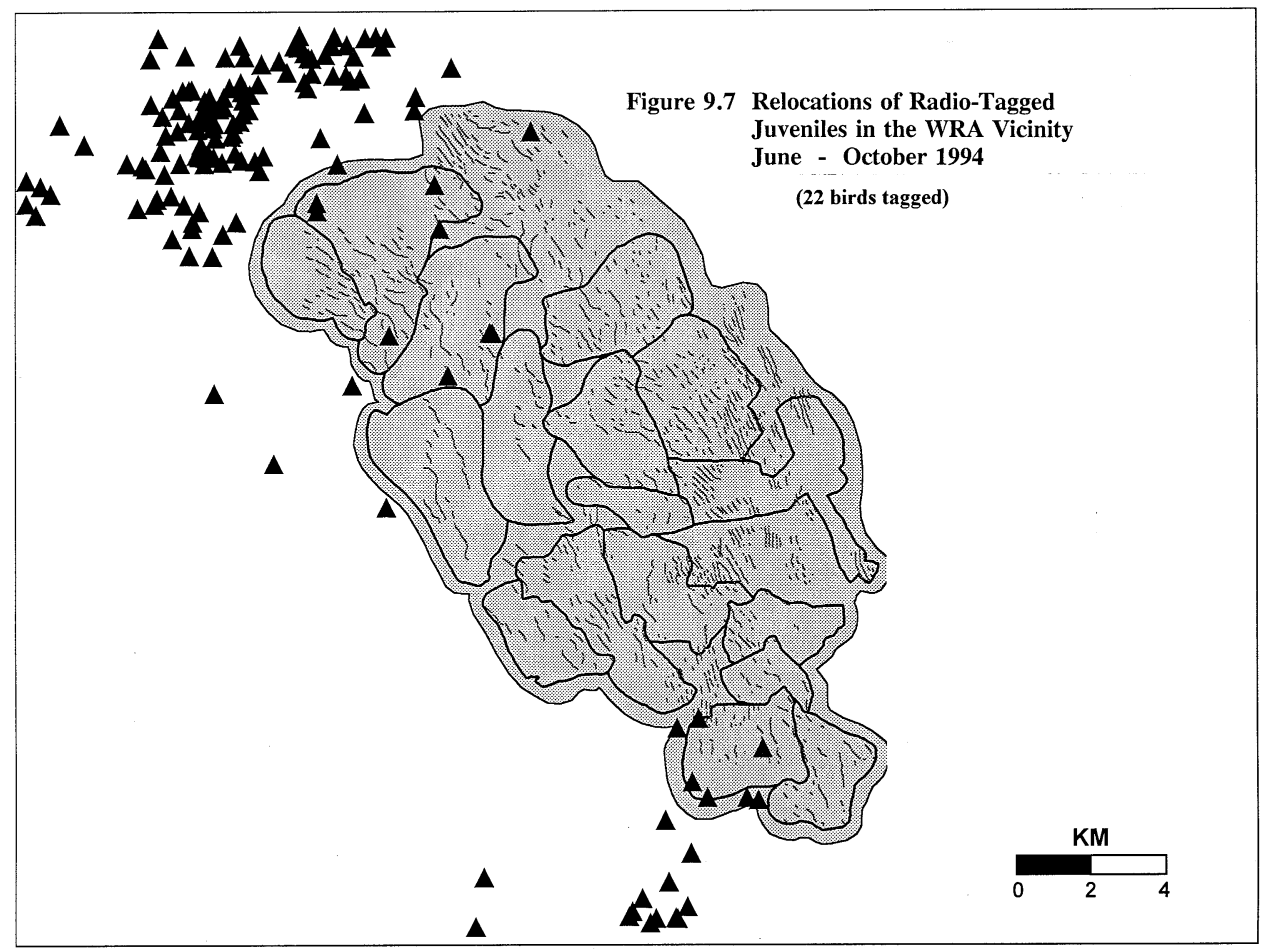




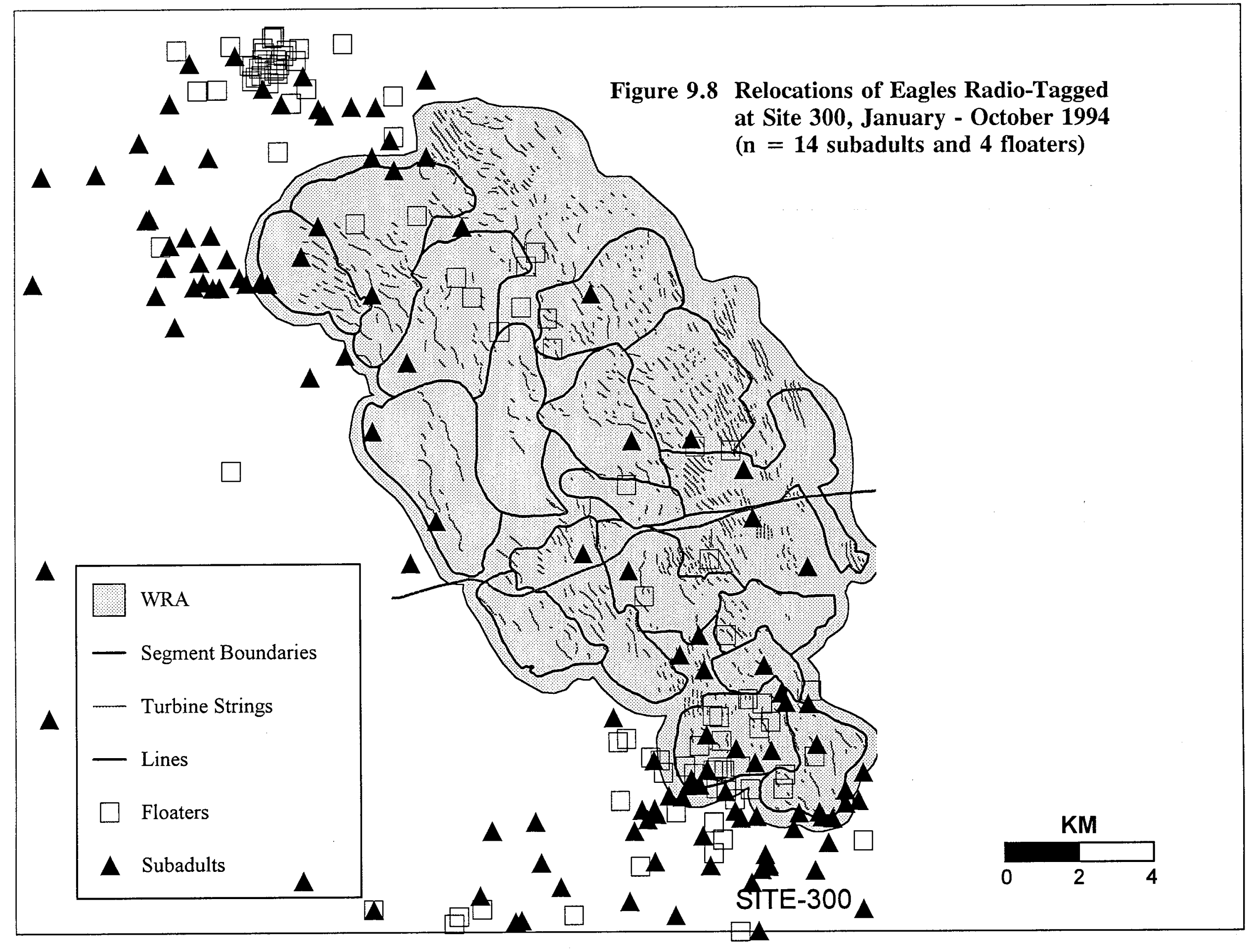




\subsection{PRELIMINARY MANAGEMENT CONSIDERATIONS}

In reviewing the results of this pilot year of investigation, we offer some highly preliminary recommendations aimed at improving the situation for golden eagles residing in the region surrounding the Altamont Pass Wind Resource Area. These recommendations mainly involve reducing habitat components for golden eagles within the WRA while maintaining and improving conditions outside the WRA.

Cattle ranching throughout the Diablo Range and its surrounding grasslands is of apparent benefit to golden eagle food supplies. Moderate grazing is known to stimulate the herbaceous foods of ground squirrels and rabbits while rendering them more conspicuous and vulnerable to eagles by reducing cover (Kochert 1987). In the interior Coast Range of California, ground squirrel populations are reported to reach their highest densities in areas of low grass height typical of grazed lands with scattered trees, shrubs, or rock outcrops; ground squirrels avoid tall grass habitats (Estep and Sculley 1987). Cattle ranching also provides eagles a source of carrion from dead cows, stillborn calves, and placentas.

One way of reducing the incidence of golden eagle turbine interactions would be to reduce food availability in the WRA. In many portions of the study area, including the WRA, ground squirrel control programs are ongoing and are, at least in the short term, effective in reducing numbers. We believe that increasing ground squirrel control measures within the WRA would decrease golden eagle occurrence there and consequently reduce the kill. However, control methods should take into consideration the possibility of secondary poisoning and the effects of reducing food supplies for other ground squirrel predators, e.g., kit fox and badger. An additional measure would be to remove or bury carrion associated with WRA cattle ranching.

Reducing prey and carrion availability in the WRA would decrease carrying capacity for eagles in the region. Our road surveys, covering $127 \mathrm{~km}^{2}$ during May through November, suggest a density of about 0.073 eagles per $\mathrm{km}^{2}$. Extrapolating to the entire WRA area, which occupies about $189 \mathrm{~km}^{2}$, we estimate that an average of about 14 eagles occupy the WRA at any one time. This minimum estimate relies on the assumption that we counted every eagle present per survey segment. Although eagles are highly conspicuous birds, it seems possible that we overlooked 20 percent of those present, a factor that increases our estimate of WRA carrying capacity to 17 eagles.

While the relationship between turbine strikes and the tendency of golden eagles to perch on turbine towers remains unknown, a cause-and-effect association seems highly plausible and consistent with observational data. We therefore recommend a carefully conducted field study to examine the relationship in both physical and statistical terms. Until the question is put to rest, we recommend that the industry avoid further construction of "perchable" towers. With regard to the physiological cost to eagles of reducing perching opportunities in the WRA, we maintain that such perches are of little or no importance to foraging eagles who rely primarily on contour hunting and often perch on the ground (see section 3.1.3 and 9.1.3). 
With regard to habitats outside the WRA, we have shown that oak savanna supports unusually high densities of nesting eagles. However, there appears to be a virtual absence of young oaks in grazed savanna habitats, a factor that will result in their gradual conversion to open grassland without trees for nesting. Provisions to exclude cattle and deer from small (1 acre), strategically-placed areas of savanna or grassland where young oaks could be planted, would provide future nesting opportunities for eagles and therefore maintain or even enhance productivity in the region.

\subsection{PLANS FOR CONTINUED RESEARCH}

Accurately determining the extent to which the golden eagle population in the northern Diablo Range is affected by turbine-related mortality will require an increased sample of radio-tagged eagles and several more years of monitoring survival. We must also predict long term variation in reproduction, and to do so will require knowledge of how prey populations in the area are expected to fluctuate. Appropriate to a conclusion regarding population effect would be an evaluation of the implications of urban encroachment on the future of the golden eagles in the area and the development of habitat management guidelines that would benefit eagles. 


\section{ACKNOWLEDGEMENTS:}

We thank the following agencies and individuals for their help:

Professor Tom Cade of the World Center for Birds of Prey conceived of this project and provided advice and encouragement throughout.

We thank Al Miller, Gerry Nix, and Holly Davis of the National Renewable Energy Laboratory; Dick Curry, Joan Stewart, Denise Weingart, Ron Barsic and the field maintenance and operations staff of KENETECH Windpower; George Lester, Ed Stewart, Frank Marino, Leo Bauer, and Rob Sears of the San Francisco Water Department; Terry Cox and Annette Phillips of the Contra Costa Water District; Steve Abbors and Joe Miyamoto of the East Bay Municipal Utility District; Jim Woolett and Milt Grissom of Lawrence Livermore Laboratory; Joe DiDonato, Roger Epperson, Ray Budzinski, Dan Reasor, Nancy Brownfield and Brad Gallup of the East Bay Regional Park District; Howard Cogswell of California State University, Hayward; Ray Torres and Larry Ferri of Mount Diablo State Park; Jim Smith of the Alameda County Department of Agriculture; Tom Gaines of SRI International; all the folks at Tri-Valley Helicopters; Sue Orloff of BioSystems Analysis, Inc.; Jim Estep and Stephanie Meyers of Jones \& Stokes Associates, Inc.; Kent Carnie, David Whitacre and Bill Heinrich of the World Center for Birds of Prey; Butch Olendorff, Mark Fuller, and Karen Steenhof of the Raptor Research Technical Center at U.S. Biological Survey; Ron Jurek and Debbie Osborn of the California Department of Fish and Game; Peter Lickwar, Mike Lockhart, Brad Bortner, and Skip Ambrose of the U.S. Fish and Wildlife Service; John Marzluff of Greenfalk; Jim Grier of North Dakota State University; Mike Nicholson of the Livermore Area Recreation and Parks Dept.; Paul Rankin of Concord Navy Base; Ron Arnold of the Hetch Hetchy Project; Dan Cather of the Walnut Creek Open Spaces District; John Colt and Kay Robinson of Henry Coe State Park; Lynn Hunsinger, Rick Standiford and Jim Bartolome of U.C. Berkeley I.H.M.P.; Cynthia Struzik and Scott Pearson of the U.S. Fish \& Wildlife Service Enforcement Branch; Gary Beeman; Richard Amarelo; Charles Krebs of the University of British Columbia; the Peeters (Pam and Julian) and the Meyers (Bobbie and John) for their help and support.

Special thanks to the many land owners who helped us with information about eagles and/or let us visit their property:

Pat and Mark Connolly, Loree Cornwell, John and Ann Lindl, Jay Hodges and the Hodges family trust, Dayton and Pearl Silva, Chuck Neuenschwander, Vibert Purviance, Joe Aljoe and Mr. Cherry of the N3 Cattle Co., Wally Breuner, Bill Blacklock, Coleman Foley, John Gomez, Joe Jesse, Carolyn Morgan, George Jones, Darlene Excel, Cindy and Richard White, Hugh Walker and Lois Walker, and Mike and Paul Marciel. 


\section{APPENDIX A: GLOSSARY}

Active Disturbance - potential disturbance to eagles by humans present in a sensitive area.

Active Nest - a nest in which eggs have been laid.

Adult - eagle in fully brown plumage, at least in its fifth calendar year.

AGL - above ground level.

Alternate Nest - a nest in a territory in addition to the existing active nest; usually constructed and used during previous years, it may be occupied again in the future.

Biomass Delivered - the weight (in grams) of that portion of a prey animal that is brought to the nest by an adult.

Breeding Area - an area containing one or more nests within the range of one mated pair of birds.

Catwalk - platform beneath or to the side of the nacelle on turbine towers; referred to as the platform by the wind industry.

Cohort - the total production of fledgling eagles within a defined area in a single year. This value forms the base number for a life table (see Life Table).

Contour Hunting - low coursing flights, usually within a few meters of the ground, in which the eagle is hidden by the terrain until very close to prey.

Eyrie - a raptor nest site.

Failed Nest - an active nest in which eggs did not hatch, or young died before reaching an advanced stage of development.

Fledge - to leave the nest for the first time.

Fledgling - an eaglet that has recently left the nest.

Floater - a non-breeding adult.

Floating Population - that population segment containing adults that are not members of breeding pairs or defending a serviceable breeding location.

Foraging Range - see Home Range. 
GPS - "global positioning satellite technology," a system employing a hand-held instrument for readily determining geographic position in latitude/longitude.

Home Range - the area frequented by a pair of eagles during the course of the nesting season (see Soaring Range).

Juvenile - a post-fledging eagle in its first calendar year.

Kiting - see Soar Hunting.

Life Table - an accounting of the chronology of survivorship among members of a cohort.

MSL - above mean sea level.

Mute - raptor excrement; "whitewash."

Mortality Switch - a mechanism within a telemetry transmitter that causes a discernible increase in pulse rate when the transmitter has remained motionless for four hours.

Nacelle - the box that covers the turbine motor.

Near-adult - eagle in its fourth calendar year.

Nest-Years - number of nests in a sample multiplied by the number of years.

Nestling - a baby eagle (eaglet) from hatching to fledging.

Occupied Breeding Area - an area containing a nest at which one or more of the following occurred: (1) young were raised; (2) eggs were laid; (3) an adult was observed sitting low in the nest, presumably incubating; (4) two adults were observed perched on or near the nest; (5) an adult and a bird in immature plumage were observed at or near the nest, if courtship behavior occurred; or, (6) recent repairs (fresh sticks or lining), mutes, or feathers were visible at or near the nest.

Passive Disturbance - an existing human development fixed permanently or semipermanently on the landscape (e.g., road, campground, house).

Perchability Index - calculated by dividing the total number of perchings on each turbine tower type by the number of turbines of each type surveyed (with visibility 1,2 , and 3 ; see turbine visibility ranking); used to assess the frequency of perching on each turbine tower type in relation to its availability.

Pirating - the act of stealing a prey item from another animal (kleptoparasitism). 
Prey Delivery - a prey item brought to the nest by an adult eagle.

Prey Item - a prey animal, or a part thereof, that is utilized by an eagle.

Prey Status - describes whether a prey item was taken alive, as carrion, was pirated, or was sick or injured prior to discovery by the eagle.

Roll-call Census - a telemetry survey, normally conducted by airplane at a fairly high altitude (to maximize reception) along a standard route, in which the transmitter frequencies of all eagles are scanned (for 3 seconds each). Upon detection of a transmitter, the biologist "locks in" the frequency, locates the transmitter, then continues the survey in scanning mode.

Serviceable Breeding Location (SBL) - an area, containing a nest site and foraging habitat, in which the expectation of reproductive output outweighs, in evolutionary terms, the risks of death and physiological exposure inherent in a nesting attempt. An SBL is optimal where its various components (habitat, food supply, absence of predators, etc.) combine to produce a maximum number of surviving young while minimizing reductions in parental survivorship and future fecundity (see Hunt 1988).

Siblicide - the killing of a nestling eagle by its sibling.

Site 300 - a testing area owned by the Lawrence Livermore National Laboratory. Site 300 lies just southeast of the WRA boundary.

Soar Hunting - hunting while hanging stationary in the wind at relatively low altitude (ca. 30 m AGL); also called "kiting."

Soaring Range - the area of soaring and territorial patrolling by a nesting pair of eagles; the soaring range may extend beyond the home range.

Study Region - that part of the Diablo Range extending from the Oakland Hills to San Luis Reservoir. We chose this area on the basis of the movements golden eagles radio-tagged in the WRA vicinity during Winter 1994.

Subadult - an eagle in its second or third calendar year.

Successful Nest - an active nest in which at least one young survived to an advanced stage of development.

Survey Segment - discrete area in which road surveys were conducted at the WRA (16 survey segments) and Site 300 (2 survey segments); selected on the basis of topography offering the least obstructed view of a large area that could be compared quantitatively with results from other survey segments. 
Territory - specifically, the area around the nest that is defended by a pair of adult eagles, or generally, an entire breeding area (the territory plus the rest of the home range).

Total Biomass - the live weight (in grams) of a prey animal.

Transmitter - a small radio unit attached to the back or tail-feather of an eagle which emits a radio pulse that is used to locate the eagle and determine its behavior.

Turbine-related Incident - fatality or injury caused by coming into contact with any part of a wind turbine tower; virtually always the result of a turbine blade strike.

Turbine Tower Type - a turbine/tower configuration distinctly different from other configurations with respect to perch site availability, turbine (not necessarily different in all cases), tower structure, and manufacturer (see Appendix $\mathrm{C}$ for illustrations).

Turbine Visibility Ranking - system of ranking the visibility of each turbine tower as viewed from standardized observation points along survey routes; the system allows comparison of relative numbers of turbines surveyed per segment (see 9.1.1 Methods).

Unoccupied Breeding Area - an area containing a nest where none of the criteria of occupancy are fulfilled (see Occupied Breeding Area).

VID Symbol - a unique visual identification symbol placed on the back of each transmitter to identify each eagle individually. VID symbols are usually placed on special leg bands (VID bands), but the tarsus of the golden eagle is feathered down to the foot, concealing the band.

WRA - the Altamont Pass Wind Resource Area, known locally as "the windfarm." 


\section{APPENDIX B: LITERATURE CITED}

Arnold, T.W. 1989. Sex ratios of fledgling golden eagles and jackrabbit densities. Auk 106(3):521-522.

Avery, M.L. [ed.]. 1978. Impacts of transmission lines on birds in flight: proceedings of a workshop. U.S. Fish and Wildl. Service, Biological Services Program, Washington, D.C. $151 \mathrm{pp}$.

Bates, G.G. 1976. Breeding of sub-adult golden eagle. Bird Study 23:284.

Beecham, J.J. and M.N. Kochert. 1975. Breeding biology of the golden eagle in southwestern Idaho. Wilson Bull. 87:506-513.

Benson, P.C. 1981a. Large raptor electrocution and power pole utilization: a study in six western states. Ph.D. Diss., Brigham Young Univ., Provo, UT. 98 pp.

Benson, P.C. 1981b. Large raptor electrocution and powerpole utilization: a study in six western states. Raptor Res. 14(4):125-126.

Benson, P.C. 1982. Prevention of golden eagle electrocution. Report No. EPRI-EA-2680 to Electric Power Research Institute, Palo Alto, CA. 90 pp.

Bent, A.C. 1937. Life Histories of North American Birds of Prey. Part 1. Smithsonian Institution, United States National Museum, Bulletin 167, U.S. Government Printing Office, Washington.

Bergo, G. 1984a. Habitat and nest-site features of golden eagle (Aquila chrysaetos L.) in Hordaland, West Norway. Fauna norv. Ser. C, Cinclus 7, 109-113.

Bergo, G. 1984b. Population size, spacing and age structure of golden eagle Aquila chrysaetos L.) in Hordaland, West Norway. Fauna norv. Ser. C, Cinclus 7, 106-108.

Bergo, G. 1987. Territorial behavior of golden eagles in western Norway. Brit. Birds $80: 361-376$.

Berns, V.D. 1979. Golden eagle nest on Kodiak Island, Alaska. Condor 81:218.

Bevanger, K. 1994. Bird interactions with utility structures: collision and electrocution, causes and mitigating measures. Ibis 136:412-425.

Bloom, P.H. 1987. Capturing and handling raptors. Pages 290-294 in B.A. GironPendleton, B.A. Millsap, K.W. Cline and D.M. Bird [eds.], Raptor Management Techniques Manual. Natl. Wildl. Fed., Washington, D.C. 
Bloom, P.H. and S.J. Hawks. 1982. Food habits of nesting golden eagles in northeast California and northwest Nevada. Raptor Res. 16(4):110-115.

Boag, D.A. 1977. Summer food habits of golden eagles in southwestern Alberta. Can. Field-Natur. 91:296-298.

Boeker, E.L. and P.R. Nickerson. 1975. Raptor electrocutions. Wildl. Soc. Bull. 3:79-81.

Boeker, E.L. and T.D. Ray. 1971. Golden eagle population studies in the southwest. Condor 73:463-467.

Bortolotti, G.R. 1984b. Age and sex variation in golden eagles. J. Field Ornithol. 55(1):54-66.

Bortolotti, G.R. 1984a. Trap and poison mortality of golden and bald eagles. J. Wildl. Manage. 48(4):1173-1179.

Bortolotti, G.R. 1984c. Sexual size dimorphism and age related size variation in bald eagles. J. Wildl. Manage. 48(1):72-81.

Bortolotti, G.R. 1986. Influence of sibling competition on nestling sex ratios of sexually dimorphic birds. Am. Nat. 127(4):495-507.

Bortolotti, G.R. 1989. Sex ratios of fledgling golden eagles. Auk 106(3):520-521.

Bowen, W.D. 1980. Coyote-golden eagle interactions at an ungulate carcass. J. Mammal. 61:376-377.

Brown, L.H. and D. Amadon. 1968. Eagles, Hawks and Falcons of the World. Volumes 1 and 2. McGraw-Hill Book Co., New York. 945 pp.

Brown, L.H. and A. Watson. 1964. The golden eagle in relation to its food supply. Ibis 106:78-100.

Brown, L.H. 1977. Eagles of the World. Universe Books, New York. 244 pp.

Bruce, A.M., R.J. Anderson and G.T. Allen. 1982. Observations of golden eagles nesting in western Washington. Raptor Res. 16(4):132-134.

Bruns, E.H. 1970. Winter predation of golden eagles and coyotes on pronghorn antelopes. Can. Field-Natur. 84:301-304. 
Buehler, D.A., J.D. Fraser, J.K.D. Seegar, G.D. Therres and M.A. Byrd. 1991. Survival rates and population dynamics of bald eagles on Chesapeake Bay. J. Wildl. Manage. 55(4):608-613.

Bunck, C.M. 1987. Analysis of survival data from telemetry projects. J. Raptor Res. 21:132-134.

Burt, W.H. and R.P. Grossenheider. 1964. A Field Guide to the Mammals. 2nd Edition. Houghton Mifflin Co., Boston. 284 pp.

California Department of Fish and Game. 1992. Special Animals List. Natural Diversity Data Base. Sacramento, CA. 28 pp.

Call, M. 1979. Habitat management guides for birds of prey. U.S. Bureau of Land Management Tech. Note No. T/N-338. Denver, CO. 70 pp.

Camenzind, F.J. 1969. Nesting ecology and behavior of the golden eagle Aquila chrysaetos L. In J.R. Murphy, et al. [ed.s], Nesting Ecology of Raptorial Birds in Central Utah. Brigham Young Univ. Sci. Bull.(Biol. Ser.) 10(4):4-15.

Carnie, S.K. 1954. Food habits of nesting golden eagles in the coast ranges of California. Condor 56(1):3-12.

Charlet, D.A. and R.W. Rust. 1991. Visitation of high mountain bogs by golden eagles in the northern great basin. J. Field Ornithol. 62(1):46-52.

Clark, J.P. 1986. Vertebrate Pest Control Handbook. Calif. Dept. of Food and Agriculture. Sacramento, CA. 200 pp.

Collopy, M.W. 1983b. A comparison of direct observations and collections of prey remains in determining the diet of golden eagles. J. Wildl. Manage. 47(2):360-368.

Collopy, M.W. 1983a. Foraging behavior and success of golden eagles. Auk 100(3):747749 .

Collopy, M.W. 1984. Parental care and feeding ecology of golden eagle nestlings. Auk 101:753-760.

Collopy, M.W. and T.C. Edwards. 1989. Territory size, activity budget and role of undulation flight in nesting golden eagles. J. Field Ornithol. 60:43-51.

Connolly, G.E., M.E. Fry and J. Fammatre. 1976. Prey remains at a golden eagle, Aquila chrysaetos, nest near Hopland, California. Calif. Fish and Game 62(1):85-86. 
Craig, E.H., T.H. Craig and L.R. Powers. 1986. Habitat use by wintering golden eagles and rough-legged hawks in southeastern Idaho. J. Raptor Res. 20:69-71.

Craig, T.H., J.W. Connelly, E.H. Craig and T.L. Parker. 1990. Lead concentrations in golden and bald eagles. Wilson Bull. 102:130-133.

Dekker, D. 1985 . Hunting behaviour of golden eagles, Aquila chrysaetos, migrating in southwestern Alberta. Can. Field-Natur. 99(3):383-385.

Dennis, R. 1983. Probable polygyny by golden eagle. Brit. Birds 76(7):310-311.

Dixon, J.B. 1937. The golden eagle in San Diego County, California. Condor 39(2):4956.

Dunning, J.B., Jr. 1984. Body weights of 686 species of North American birds. West. Bird Banding Assoc. Monograph No. 1.

Eakle, W.L. and T.G. Grubb. 1986. Prey remains from golden eagle nests in central Arizona. West. Birds 17:87-89.

Edwards, C.C. 1969. Winter behavior and population dynamics of American eagles in Utah. Ph.D. Diss. Brigham Young Univ., Provo, UT. 157 pp.

Edwards, T.C., Jr. and M.W. Collopy. 1983. Obligate and facultative brood reduction in eagles: an examination of factors that influence fratricide. $A u k$ 100:630-635.

Edwards, T.C., Jr., M.W. Collopy, K. Steenhof and M.N. Kochert. 1988. Sex ratios of fledgling golden eagles. Auk 105(4):793-796.

Edwards, T.C. and M.W. Collopy. 1989. Response to G.R. Bortolotti and T.W. Arnold. Auk 106:523-524.

Ellis, D.H., D.G. Smith and J.R. Murphy. 1969. Studies on raptor mortality in western Utah. Great Basin Nat. 29(3):165-167.

Estep, J.A. and R.D. Sculley. 1989. Habitat suitability index model: golden eagle (Aquila chrysaetos), interior central coast ranges of California. Report to the U.S. Bureau of Reclamation by Jones \& Stokes Associates, Inc., Sacramento, CA. 24 pp.

Evans, F.C. and R. Holdenried. 1943. A population study of the Beechey ground squirrel in central California. J. Mammal. 24:321-260.

Ferrer, M. 1993. Juvenile dispersal behaviour and natal philopatry of a long-lived raptor, the Spanish imperial eagle Aquila adalberti. Ibis 135:132-138. 
Fitch, H.S. 1948. Ecology of the California ground squirrel on grazing lands. Am. Midl. Nat. 39:513-596.

Galvin, M.T., K.D. Hoover and M.L. Avery. 1979. Management of transmission line rights-of-way for fish and wildlife. Vol. 1. U.S. Dept. Inter., Fish and Wildl. Serv., Off. Biol. Serv., FWS/OBS-79/22. Washington, D.C. 168 pp.

Garcelon, D.K., M.S. Martell, P.T. Redig and L.C. Buoen. 1985. Morphometric, karyotypic and laparoscopic techniques for determining sex in bald eagles. J. Wildl. Manage. 49(3):595-599.

Gargett, V. 1975. The spacing of black eagles in the Matopos, Rhodesia. Ostrich 46:1-44.

Goodwin, G.A. 1977. Golden eagle predation on pronghorn antelope. Auk 94:789-790.

Gonzalez, L.M., B. Heredia, J.L. Gonzalez and J.C. Alonso. 1989. Juvenile dispersal of Spanish imperial eagles. J. Field Ornithol. 60:369-379.

Grubb, T.G. and W.L. Eakle. 1987. Comparative morphology of bald and golden eagle nests in Arizona. J. Wildl. Manage. 51(4):744-748.

Haller, H. 1982. Populationsokologie des steinahlers in den Alpen. Ornithol Beob. 79:168211.

Hamerstrom, F., T. Ray, C.M. White and C.E. Braun. 1975. Conservation Committee report on status of eagles. Wilson Bull. 87(1):140-143.

Hansen, A.J. 1987. Regulation of bald eagle reproductive rates in Southeast Alaska. Ecol. 68(5):1387-1392.

Hansen, A.J. and J.I. Hodges. 1985. High rates of non-breeding bald eagles in southeastern Alaska. J. Wildl. Manage. 49:454-458.

Harlow, D.L. and P.H. Bloom. 1987. Status report: Buteos and the golden eagle. Pages 102-110 in B.G. Pendleton, [ed.], Proceedings of the Western Raptor Management Symposium and Workshop. Natl. Wildl. Fed. Scientific and Technical Series, No. 12, Washington, D.C.

Harmata, A.R. 1982. What is the function of undulating flight display in golden eagles? Raptor Res. 16:103-109.

Hoechlin, D.R. 1976. Development of golden eaglets in southern California. West. Birds 7:137-152. 
Houston, C.S. and K.A. Wylie. 1985. Golden eagles nest successfully in trees. Blue Jay 43(2):131-133.

Hunt, W.G. 1987. Radio telemetry in the study of raptor habitat selection. Raptor Res. 21(4):144-146.

Hunt, W.G. 1988. The natural regulation of peregrine population size. Pages 667-676 in T.J. Cade, J.H. Enderson, C.G. Thelander and C.M. White [eds.], Peregrine Falcon Populations, Their Management and Recovery. The Peregrine Fund, Inc., Boise, ID.

Hunt, W.G., R.E. Jackman, J. M. Jenkins, C.G. Thelander and R.N. Lehman. 1992b. A northward post-fledging migration of California bald eagles. Raptor Res. 26(1): 19-23.

Hunt, W.G., D.E. Driscoll, E.W. Bianchi and R.E. Jackman. 1992a. Ecology of bald eagles in Arizona. Report to U.S. Bureau of Reclamation by BioSystems Analysis, Inc., Santa Cruz, CA. Contract No. 6-CS-30-04470.

Hunt, W.G., J. M. Jenkins, R.E. Jackman and C.G. Thelander. 1992c. Ecology of bald eagles on a regulated river. Raptor Res. 26(4):243-256.

Jackman, R.E., W.G. Hunt, D.E. Driscoll and F. Lapsansky. 1994. Refinements to selective capture techniques for bald and golden eagles. Raptor Res. 28:268-273.

Jenkins, J.M. 1992. Ecology and behavior of a resident population of bald eagles. Ph.D. Diss. Univ. of California, Davis. $183 \mathrm{pp}$.

Jenkins, J.M. and R.E. Jackman. 1993. Mate and nest site fidelity in a resident population of bald eagles. Condor 95(4):1053-1056.

Klitz, W. 1982. Habitat management to control ground squirrel population. Cal-Neva Wildl. Trans. 1982:69-74.

Knight, R.L. and A.W. Erickson. 1978. Marmots as a food source of Golden Eagles along the Columbia River. Murrelet 59:28-30.

Knight, R.L., J.B. Athearn, J.J. Brueggeman and A.W. Erickson. 1979. Observations on wintering bald and golden eagles on the Columbia River, Washington. Murrelet 60:99-105.

Kochert, M.N. 1972. Population status and chemical contamination in golden eagles in southwestern Idaho. M.S. Thesis. Univ. of Idaho, Moscow. 
Kochert, M.N. 1980. Golden eagle reproduction and population changes in relation to jackrabbit cycles: Implications to eagle electrocutions. Pages 71-86 in R.P. Howard and J.F. Gore [eds.], Proceedings of a Workshop on Raptors and Energy Developments. Idaho Chapter, The Wildlife Society, Boise, ID.

Kochert, M.N. 1987. Responses of raptors to livestock grazing in the western United States. Pages 194-203 in B.G. Pendleton [ed.], Proceedings of the Western Raptor Management Symposium and Workshop. Natl. Wildl. Fed. Scientific and Technical Series, No. 12, Washington, D.C.

Krebs, C.J. 1989. Ecological Methodologies. Harper Collins, New York. 654 pp.

Lack, D. 1954. The Natural Regulation of Animal Numbers. Oxford, Clarendon Press. $343 \mathrm{pp}$.

Lack, D. 1966. Population Studies of Birds. Oxford, Clarendon Press.

Lehman, R.N., K. Steenhof, M.N. Kochert and L.B. Carpenter. 1993. Raptor abundance and reproductive success in the Snake River Birds of Prey Area. Pages 12-39 in K. Steenhof [ed.], Snake River Birds of Prey Research Project Annual Report. U.S. Dep. Inter., Bureau of Land Management, Boise, ID.

Lockhart, J.M., T.P. McEneaney and R.L. Phillips. 1978. The effects of coal development on the ecology of birds of prey in southeastern Montana and northern Wyoming. Pages 9-20 in U.S.D.I. Fish and Wildlife Service, Denver Service Center. Annual Progress Report.

Lockie, J.D. 1964. The breeding density of the golden eagle and fox in relation to food supply in western Ross, Scotland. Scot. Nat. 71:67-77.

Lockie, J.D. and D.A. Ratcliffe. 1964. Insecticides and Scottish golden eagles. Brit. Birds 57(3):89-101.

Lockie, J.D., D.A. Ratcliffe and R. Balharry. 1969. Breeding success and organo-chlorine residues in golden eagles in west Scotland. J. Appl. Ecol. 6:381-389.

MacLaren, P.A., S.H. Anderson and D.E. Runde. 1988. Food habits and nest characteristics of breeding raptors in southwestern Wyoming. Great Basin Nat. 48:548-553.

Marquiss, M., D.A. Ratcliffe and R. Roxburgh. 1985. The numbers, breeding success and diet of golden eagles in southern Scotland in relation to changes in land use. Biol. Conserv. $34: 121-140$.

Marr, N.V. and R.L. Knight. 1983. Food habits of golden eagles in eastern Washington. Murrelet 64:73-77. 
Marshall, W. 1940. "Eagle guard" developed in Idaho. Condor 42:166.

Marzluff, J.M., M.S. Vekasy and C. Coody. 1994. Comparative accuracy of aerial and ground telemetry locations of foraging raptors. Condor 96:447-454.

Marzluff, J.M., L.S. Schueck, M. Vakesy, B.A. Kimsey, M. McFadzen, R.R. Townsend and J.O. McKinley. 1993. Influence of military training on the behavior of raptors in the Snake River Birds of Prey Area. Pages 40-125 in K. Steenhof [ed.], Snake River Birds of Prey Research Project Annual Report. U.S. Dept. Inter., Bureau of Land Management, Boise, ID.

McCrary, M.D., P.H. Bloom and M.J. Gibson. 1992. Observations of the behavior of surplus adults in a red-shouldered hawk population. J. Raptor Res. 26:10-12.

McGahan, J. 1968. Ecology of the golden eagle. Auk 85(1):1-12.

Menkins, G.E., Jr. and S.H. Anderson. 1987. Nest site characteristics of a predominantly tree-nesting population of golden eagles. J. Field Ornithol. 58(1):22-25.

Mollhagen, T.R., R.W. Wiley and R.L. Packard. 1972. Prey remains in golden eagle nests: Texas and New Mexico. J. Wildl. Manage. 36:784-792.

Moore, T.D., L.E. Spence and C.E. Dugnolle. 1974. Identification of the dorsal guard hairs of some mammals of Wyoming. Wyoming Game and Fish Dept. Cheyenne Bull. No. 14.

Mosher, J.A. and C.M. White. 1976. Directional exposure of golden eagle nests. Can. Field-Natur. 90(3):356-359.

Murphy, J.R. 1975. Status of a golden eagle population in central Utah. Pages 91-96 in J.R. Murphy, C.M. White and B.E. Harrell [eds.], Population status of raptors. Raptor Res. Rep. No. 3. Raptor Res. Found., Inc., Vermillion, SD.

Murphy, J.R. 1977a. Status of eagle populations in the western United States. Pages 57-63 in R.D. Chancellor [ed.], Proc. of the World Conf. on Birds of Prey. 1-3 Oct. 1975. Vienna. I.C.B.P.

Nelson, M.W. and P. Nelson. 1976. Power lines and birds of prey. Idaho Wildl. Rev. 28:3-7.

Newton, I. 1979. Population Ecology of Raptors. Buteo Books. Vermillion, SD. 399 pp. 
Newton, I. 1989. Keynote address: Population limitation in raptors. Pages 3-12 in Proc. Northeast Raptor Management Symposium and Workshop. Natl. Wildl. Fed., Washington, D.C.

Newton, I. and E.A. Galbraith. 1991. Organochlorines and mercury in the eggs of golden eagles Aquila chrysaetos from Scotland. Ibis 133:115-120.

Olendorff, R.R. 1972. Eagles, sheep and power lines. Colo. Outdoors 21:3-11.

Olendorff, R.R. 1975. Population status of large raptors in northeastern Colorado, 1971-72. Pages 185-205 in J.R. Murphy, C.M. White and B.E. Harrell [eds.], Population Status of Raptors. Raptor Res. Rep. No. 3. Raptor Res. Found., Inc., Vermillion, South Dakota.

Olendorff, R.R. 1976. The food habits of North American golden eagles. Amer. Midl. Nat. 95(1):231-236.

Olendorff, R.R. 1986. Raptor collisions with utility lines and fences -- an annotated bibliography. Draft. U.S. Bureau of Land Management, Sacramento, CA.

Olendorff, R.R. and R.N. Lehman. 1986. Raptor collisions with utility lines: an analysis using subjective field observations. Pacific Gas and Electric Co., San Ramon, CA. 73 pp.

Olendorff, R.R., A.D. Miller and R.N. Lehman. 1981. Suggested practices for raptor protection on power lines: the state of the art in 1981. Raptor Res. Rept. No. 4.111 pp.

Olendorff, R.R., R.S. Motroni and M.W. Call. 1980. Raptor management--the state of the art in 1980. U.S. Bureau of Land Management Tech. Rep. No. T/T-345. Denver, CO. 56 pp.

O'Neil, T.A. 1988. An analysis of bird electrocutions in Montana. J. Raptor Res. 22(1):27-28.

Orloff, S. and A. Flannery. 1992. Wind turbine effects on avian activity, habitat use and mortality in Altamont Pass and Solano County Wind Resource Areas. Report to the Planning Departments of Alameda, Contra Costa and Solano Counties and the California Energy Commission, Grant No. 990-89-003 to BioSystems Analysis, Inc., Tiburon, CA.

Page, J.L. and D.J. Seibert. 1973. Inventory of golden eagle nests in Elko County, Nevada. CAL-NEVA Wildlife 1973:1-8.

Pattee, O.H., P.H. Bloom, J.M. Scott and M.R. Smith. 1990. Lead hazards within the range of the California condor. Condor 92(4):931-937. 
Pearson, D.C. 1979. Raptor protection study, LanfairValley - report of findings and recommendations. Company memorandum to files. Southern California Edison Co., Rosemead, CA. 7 pp.

Peacock, E. 1980. Powerline electrocution of raptors. Pages 2-5 in R.P. Howard and J.F. Gore [eds.], Proc. of a Workshop on Raptors and Energy Developments. Idaho Chapter, The Wildlife Society, Boise, ID.

Phillips, R.L. and F.S. Blom. 1988. Distribution and magnitude of eagle/livestock conflicts in the western United States. Pages 241-244 in A.C. Crabb and R.E. Marsh [eds.], Proc. Vertebr. Pest Conf. No. 13, Univ. of California, Davis.

Phillips, R.L., T.P. McEneaney and A.E. Beske. 1984. Population densities of breeding golden eagles in Wyoming. Wildl. Soc. Bull. 12:269-273.

Phillips, R.L. and A.E. Beske. 1990. Distribution and abundance of golden eagles and other raptors in Campbell and Converse Counties, Wyoming. U.S. Fish and Wildlife Service Technical Report 27. 31pp.

Phillips, R.L., A.H. Wheeler, N.C. Forrester, J.M. Lockhart and T.P. McEneaney. 1990. Nesting ecology of golden eagles and other raptors in southeastern Montana and northern Wyoming. U.S. Fish and Wildlife Service Technical Report 26. Denver Wild1. Res. Center, CO. 13 pp.

Poole, K.G. and R.G. Bromley. 1988. Interrelationships within a raptor guild in the central Canadian Arctic. Can. J. Zool. 66(10):2275-2282.

Postupalsky, S. 1974. Raptor reproductive success: some problems with methods, criteria and terminology. Raptor Res. Rep, No. 2:21-31.

Remsen, J.V., Jr. 1978. The species of special concern list: an annotated list of declining or vulnerable bird species in California. Calif. Dept. of Fish and Game, Fed. Aid Wildl. Restor. Proj. W-54-R-9. 54 pp.

Reynolds, H.V. III. 1969. Population status of the golden eagle in southcentral Montana. M.S. Thesis. Univ. of Montana, Missoula. $61 \mathrm{pp}$.

Ritchie, R.J. and J.A. Curatolo. 1982. Notes on golden eagle productivity and nest site characteristics, Porcupine River, Alaska, 1979-1982. Raptor Res. 16(4):123-127.

Rodriguez-Estrella, R., J. Llinas-Gutierrez and J. Cancino. 1991. New golden eagle records from Baja California. J. Raptor Res. 25(3):68-72.

Schlorff, R.W. 1986. Golden eagle status review. Calif. Dept. of Fish and Game. 11 pp. 
Scott, T.A. 1985. Human impacts on the golden eagle population of San Diego County from 1928 to 1981. M.S. Thesis. San Diego State Univ., San Diego, CA. 101 pp.

Sharp, W.M. 1951. Observations on predator-prey relations between wild ducks, trumpeter swans and golden eagles. J. Wildl. Manage. 15(2):224-226.

Smith, D.G. and J.R. Murphy. 1973. Breeding ecology of raptors in the eastern Great Basin of Utah. Brigham Young Univ. Sci. Bull. Biol. Ser. 18, No. 3. 76 pp.

Smith, D.G. and J.R. Murphy. 1982a. Spatial relationships of nesting golden eagles in central Utah. Raptor Res. 16(4):127-132.

Smith, J.C. 1985. Perching and roosting patterns of raptors on power transmission towers in southeast Idaho and southwest Wyoming. Raptor Res. 19(4):135-138.

Stalmaster, M.V. 1987. The Bald Eagle. Universe Books. New York, NY. 227 pp.

Steenhof, K. 1983. Prey weights for computing percent biomass in raptor diets. Raptor Res. 17:15-27.

Steenhof, K. and M.N. Kochert. 1988. Dietary responses of three raptor species to changing prey densities in a natural environment. J. Anim. Ecol. 57:37-48.

Steenhof, K., Kochert, M.N. and J.H. Doremus. 1983. Nesting of subadult golden eagles in southwestern Idaho. $A u k$ 100:743-747.

Steenhof, K., M.N. Kochert and M.Q. Moritsch. 1984. Dispersal and migration of southwestern Idaho raptors. J. Field Ornithol. 55(3):357-368.

Sumner, E.L., Jr. 1929a. Notes on the growth and behavior of young golden eagles. Auk 46:161-169.

Sumner, E.L., Jr. 1929b. Comparative studies in the growth of young raptors. Condor 31(3):91-98.

Teresa, S. 1980. Golden eagles successfully breeding in subadult plumage. Raptor Res. 14(3):86-87.

Terres, J.K. 1980. The Audoban Society Encyclopedia of North American Birds. Alfred A. Knopf, New York. 1109 pp.

Thelander, C.G. 1974. Nesting territory utilization by golden eagles in California during 1974. Calif. Dept. of Fish and Game. Wildl. Management Branch Administrative Report No. 74-7. 19 pp. 
Thompson, S.P., R.S. Johnstone and C.D. Littlefield. 1982. Nesting history of golden eagles in Malheur-Harney Lakes Basin, southeastern Oregon. Raptor Res. 16(4):116-122.

Tjernberg, M. 1981. Diet of the golden eagle Aquila chrysaetos during the breeding season in Sweden. Holarct. Ecol. 4:12-19.

Tjernberg, M. 1983. Prey abundance and reproductive success of the golden eagle Aquila chrysaetos in Sweden. Holarct. Ecol. 6:17-23.

Tjernberg, M. 1985. Spacing of golden eagle Aquila chrysaetos in relation to nest site and food availability. Ibis 127:250-255.

Tomich, P.Q. 1962. The annual cycle of the California ground squirrel (Citellus beecheyi). Univ. Calif. Publ. Zool. 65:213-282.

Trent, T.T. and O.J. Rongstad. 1974. Home range and survival of cottontail rabbits in southwestern Wisconsin. J. Wildl. Manage. 38:459-472.

U.S. Dept. of the Interior. 1979. Snake River birds of prey special report to the Secretary. of Interior. Bureau of Land Management, Boise, ID. 142 pp.

Walker, D.G. 1987. Observations on the post-fledging period of the golden eagle Aquila chrysaetos in England. Ibis 129:92-96.

Walker, D.G. 1988. The behaviour and movements of a juvenile golden eagle Aquila chrysaetos in England in 1986. Ibis 130(4):564.

Watson, A. 1957. The breeding success of golden eagles in the northeast Highlands. Scot. Nat. 69:153-169.

Watson, A. and P. Rothery. 1985. Regularity in spacing of golden eagle Aquila chrysaetos nests used within years in northeast Scotland. Ibis 128:406-408.

Watson, J. 1992. Golden eagle Aquila chrysaetos breeding success and afforestation in Argyll. Bird Study 39:203-206.

Watson, J. and R.H. Dennis. 1992. Nest-site selection by golden eagles in Scotland. Brit. Birds 85:469-481.

Watson, J. and D.R. Langslow. 1989. Can food supply explain variation in nesting density and breeding among golden eagles (Aquila chrysaetos)? Pages 181-186 in B.-U. Meyburg and R.D. Chancellor [eds.], Raptors in the Modern World. Berlin: World Working Group on Birds of Prey and Owls. 
Watson, J., A.F. Leitch and R.A. Broad. 1992b. The diet of the sea eagle Haliaeetus albicilla and golden eagle Aquila chrysaetos in western Scotland. Ibis 134:27-31.

Watson, J., S.R. Rae and R. Stillman. 1992a. Nesting density and breeding success of golden eagles in relation to food supply in Scotland. J. Anim. Ecol. 61:543-550.

Wiley, R.W. and E.G. Bolen. 1971. Eagle-livestock relationships: livestock carcass census and wound characteristics. Southwest. Nat. 16(2): 151-169.

Williams, R.D. and E.W. Colson. 1989. Raptor associations with linear rights-of-way. Pages 173-192 in B.G. Pendleton, et al. [eds.], Proc. Western Raptor Management Symposium and Workshop. Natl. Wildl. Fed., Washington, D.C.

Woodgerd, W. 1952. Food habits of the golden eagle. J. Wildl. Manage. 16(4):457-459.

Zeiner, D.L., W.F. Landenslayer, Jr., K.E. Mayer and M. White. 1990. California's Wildlife. Vol. II. Birds. Calif. Dept. of Fish and Game, Sacramento, CA. 731 pp. 

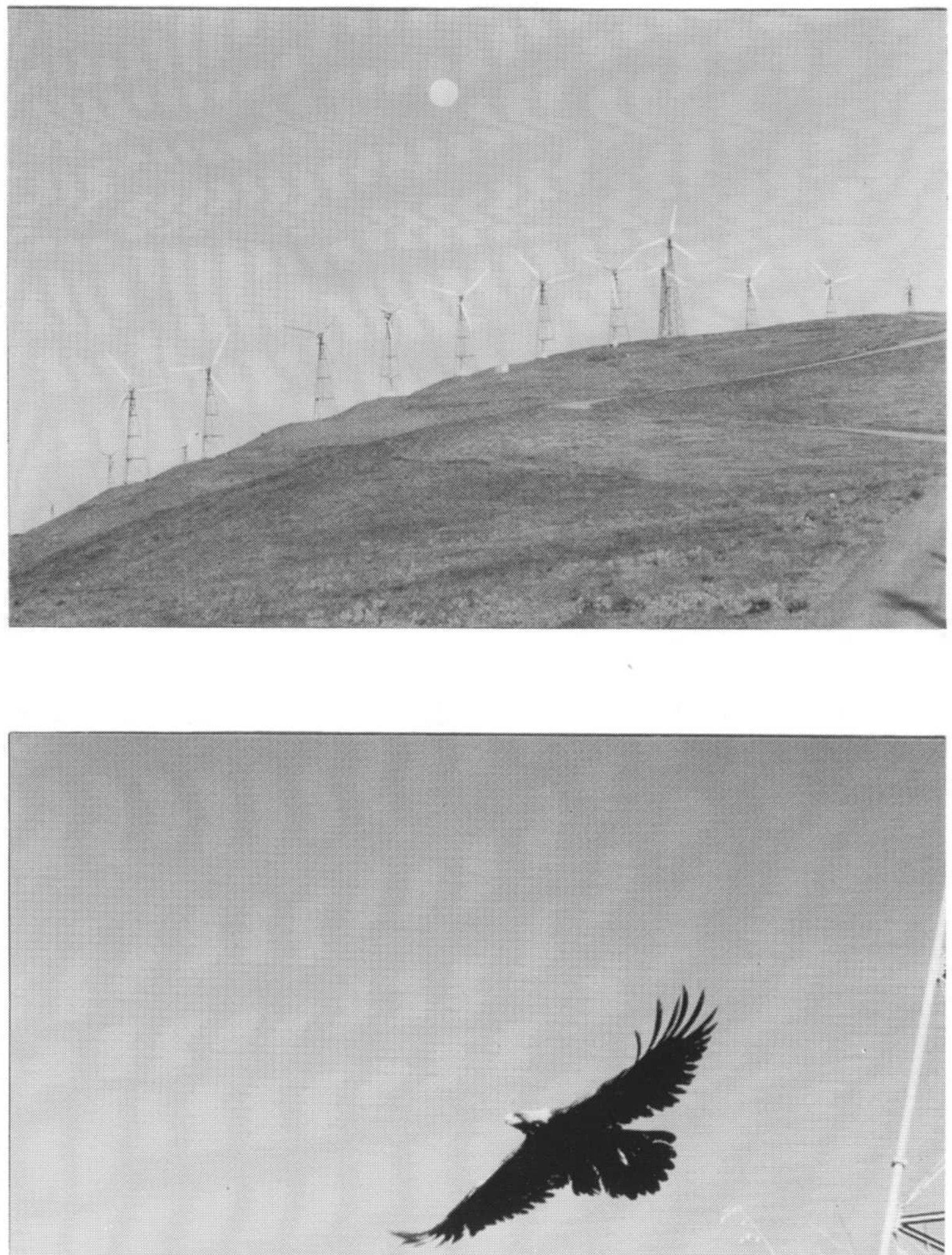


\section{APPENDIX C: FORMS USED IN DATA COLLECTION}

\section{OBSFORM INSTRUCTIONS}

The Observation Form ("Obsform") was used to record observations of golden eagles either during visual censuses, telemetry surveys, or incidental sightings when carrying out other tasks. In general, each time an eagle moved to a different location or began another activity regarded as significant to an understanding of WRA related mortality, a new data string was entered. Items left blank or given zeros indicated no data. We reviewed our forms at the end of the day, checking all entries for accuracy and completeness and initialed the form when satisfied. After computer entry, two people compared printouts with original forms for accuracy by reading every field of each data record aloud. Codes and instructions for each data field were as follows:

DATE: Month/Day/Year

BEGIN TIME: Enter time (in 24-hr clock) that observation, survey segment or waterfowl survey begins.

END TIME: Enter time that observation, survey segment or waterfowl survey ends.

DATA TYPE: Type of observation or data recorded in that particular string. $300=$ Site 300 survey-initial observation of an area or an individual bird $302=$ Site 300 survey-observation in an area already surveyed $\mathrm{AOB}^{*}=$ Additional observation of an individual already recorded APS $=$ Airplane survey CAS = Carcass survey

DAY = A comment pertaining to the day

INO = Incidental observation

MAS = Mammal survey

NEO = Nest observation (from a distance)

$\mathrm{NES}=$ Nest search

$\mathrm{NEV}=$ Nest climb

OTH $=$ Other (see comments)

POB $=$ Prey observation

$\mathrm{REF}=$ Researcher on foot

ROS = Road survey-initial observation of an area or an individual bird

RS2 = Road survey-observation in an area already surveyed

TNR = Intensive observation and tracking of a non-radioed golden eagle

TRK = Includes any golden eagles seen while tracking

TRK $=$ Tracking

TRP $=$ Trapping

WFC $=$ WRA census

WFS = Waterfowl survey 
NUMBER OF INDIVIDUALS: The number of birds referred to in the data string. *If an observation was recorded as data type $\mathrm{AOB}, \mathrm{AC}$ was entered in the number of individuals column, indicating that the individual had already been counted.

SPECIES: The species referred to in the string.
$\mathrm{A}=$ bald eagle
$\mathrm{B}$ = burrowing owl
$\mathrm{C}=$ cooper's hawk
$\mathrm{D}=$ red-shouldered hawk
$\mathrm{E}=$ peregrine
$\mathrm{F}=$ ferruginous hawk
$\mathrm{G}=$ golden eagle
$\mathrm{H}=$ northern harrier
$\mathrm{K}=$ American kestrel
$\mathrm{L}=$ rough-legged hawk
$\mathrm{M}=$ merlin
$\mathrm{N}=$ swainson's hawk
$\mathrm{O}=$ barn owl
$\mathrm{P}=$ prairie falcon
$\mathrm{R}=$ common raven
$S=$ sharp-shinned hawk
$\mathrm{T}=$ red-tailed hawk
$\mathrm{U}=$ unknown bird
$\mathrm{V}=$ turkey vulture
$\mathrm{W}=$ white-tailed kite
$\mathrm{X}=$ great-horned owl
$\mathrm{Y}=$ osprey

AGE:

$\mathrm{A}=$ adult

$\mathrm{J}=$ juvenile

$\mathrm{N}=$ near-adult

$\mathrm{S}=$ sub-adult

$\mathrm{U}=$ unknown

SEX:
$\mathrm{F}$ = female
$\mathrm{M}=$ male
$\mathrm{U}=$ unknown

FREQUENCY: Frequency of radio-transmitter, if appropriate. 
SIGHT-MODE:

$\mathrm{F}=$ used telemetry to find bird visually

$\mathrm{N}=$ nest discovery

$\mathrm{R}=$ bird's position verified by radio communication with another person

$\mathrm{T}=$ located by telemetry, bird never seen

$\mathrm{V}=$ visual sighting

$\mathrm{X}=$ could not visually or telemetrically locate radio-tagged eagle

\section{BREAK:}

$V=$ bird flies from view or observation terminates at end time

$\mathrm{X}=$ observation terminated at end time and activity is still in progress

$Y=$ see next observation

\section{ACTIVITY:}

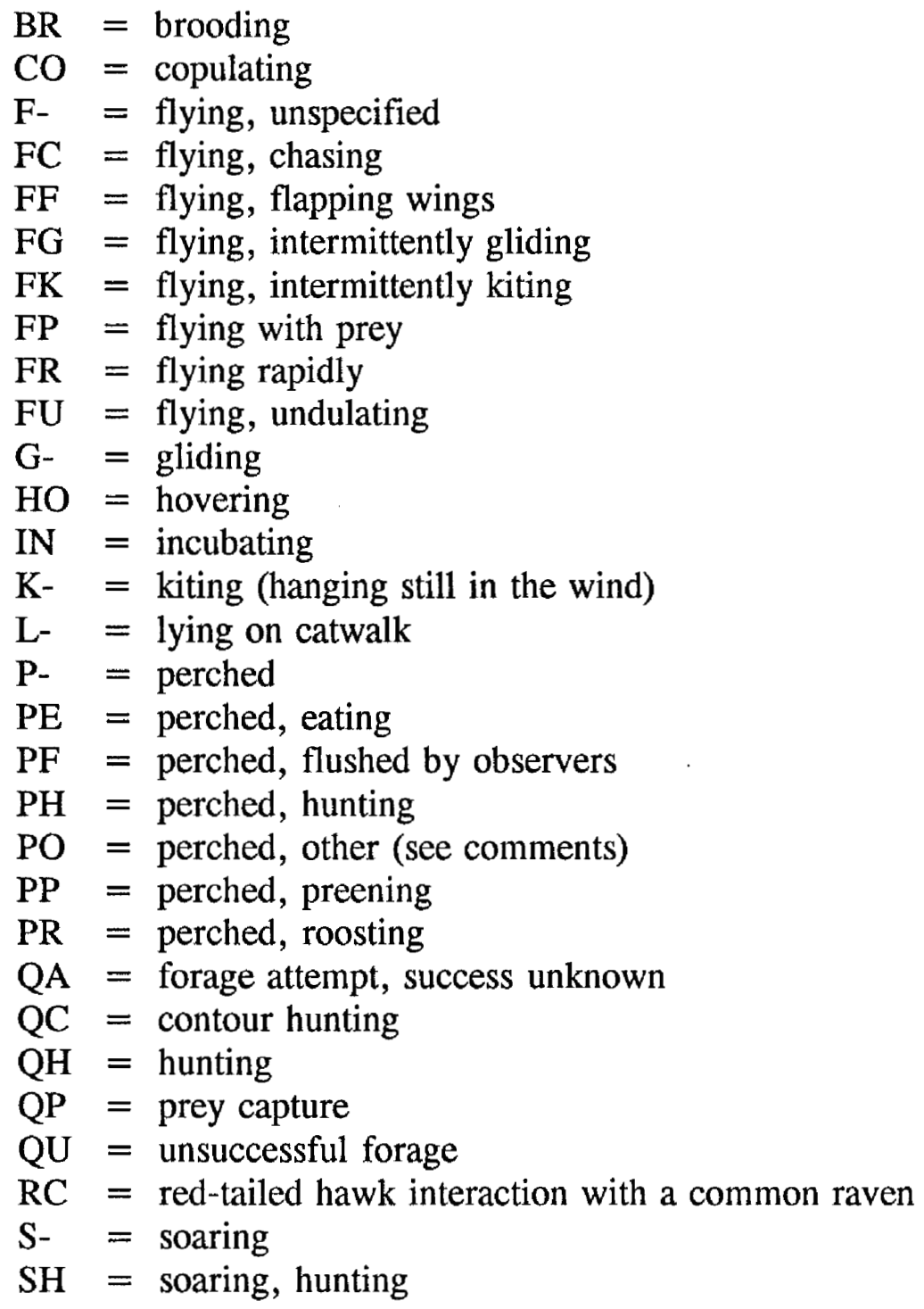




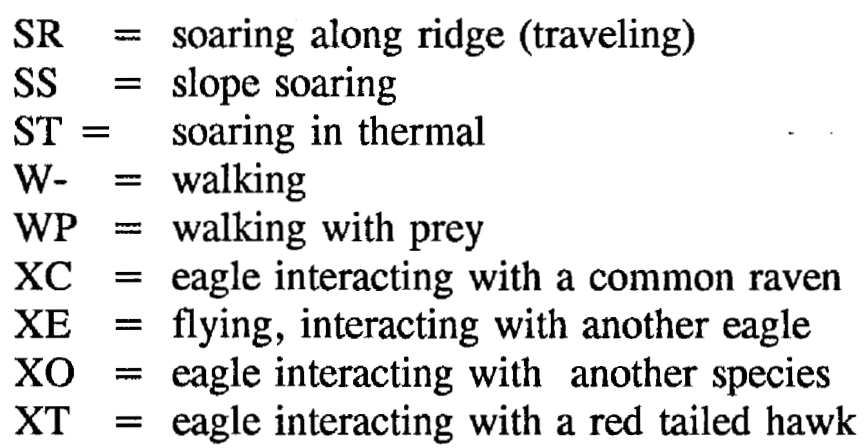

PERCH STRUCTURE: Type of structure on which bird is perched.

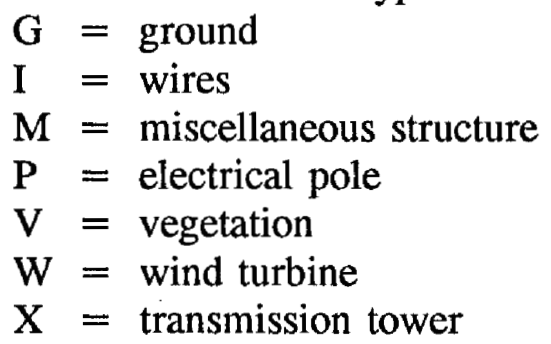

PERCH TYPE: Wind turbine structure perches:
$\mathrm{A} \quad=$ platform ("catwalk")
$\mathrm{B}=$ blade
$\mathrm{C}=$ catwalk (platform)
$\mathrm{CP}=$ catwalk with a perch guard
$\mathrm{D}=$ diagonal crossmember
DK = diagonal cable
DT = down tower box
$\mathrm{H}-\quad=$ horizontal crossmember, unspecified
$\mathrm{HR}=$ hand railing
$\mathrm{K}-\quad=$ central hanging cable
$\mathrm{LD}=$ ladder
$\mathrm{M}$ - $=$ mid-tower box
$\mathrm{N}-\quad=$ nacelle
$\mathrm{W}=$ wind turbine tower, unspecified
WA $=$ wind speed indicator arm
$1=1$ st horizontal member from the ground
$2=2$ nd horizontal member from the ground (etc.)

Electrical pole perches:

$\mathrm{P}_{-}=$undefined position on electrical pole (see comments)

$\mathrm{PA}=$ short arm bracket

$\mathrm{PB}=$ long arm bracket

$\mathrm{PC}=$ communication wire bracket

$\mathrm{PG}=$ perch guard

$\mathrm{PI}=$ insulator 


$$
\begin{aligned}
& \text { PJ }=\text { jumper lines } \\
& \text { PL }=\text { lower wooden bracket } \\
& \text { PM }=\text { metal bar bracket } \\
& \text { PR }=\text { pole top transformer } \\
& \text { PS }=\text { switch linkage } \\
& \text { PT }=\text { bare wood top } \\
& \text { PU }=\text { upper wooden bracket } \\
& \text { PW }=\text { wildlife boot } \\
& \text { PZ }=\text { only wooden bracket available }
\end{aligned}
$$

Miscellaneous perch sites:

$$
\begin{aligned}
& \mathrm{CV}=\text { culvert } \\
& \mathrm{E}-\quad=\text { nest tree } \\
& \mathrm{F}_{-}=\text {fence post } \\
& \mathrm{FB}=\text { barbed wire fence string } \\
& \mathrm{FO}=\text { forb } \\
& \mathrm{FR}=\text { fence railing } \\
& \mathrm{G}-\quad=\text { ground } \\
& \mathrm{GY}=\text { guy wire } \\
& \text { I- }=\text { wire of unknown type (associated with electrical lines) } \\
& \text { IC = communication wire } \\
& \text { IE = electrical phase (wire) } \\
& \text { L- }=\text { cliff } \\
& \mathrm{N}-=\text { nest } \\
& \mathrm{O}-\quad=\text { rocky outcropping } \\
& \mathrm{R}^{-} \quad=\operatorname{rock}(<1 \mathrm{~m} \text { diameter }) \\
& \mathrm{S}-\quad=\text { building structure } \\
& \mathrm{SB}=\text { shrub } \\
& \mathrm{SG}=\text { sign } \\
& \mathrm{SN}=\text { snag } \\
& \mathrm{T}-\quad=\text { tree } \\
& \mathrm{TF}=\text { transformer } \\
& \mathrm{U}-\quad=\text { boulder }(>1 \mathrm{~m} \text { diameter })
\end{aligned}
$$

ELECTRICAL POLE TYPE: What type of electrical pole is bird perched on?
$\mathrm{A}=$ riser pole
$\mathrm{B}=$ corner pole
$\mathrm{C}=$ double circuit tangent pole; triangular top circuit, straight bracket lower circuit
$\mathrm{D}=$ line switch pole
$\mathrm{E}=$ single circuit tangent pole; straight bracket
$\mathrm{F}=$ pole with top transformer
$\mathrm{G}=$ single circuit tangent pole; triangular top configuration
$\mathrm{H}=$ double circuit pole with perpendicular lines
$\mathrm{I}=$ telephone poles no longer in use
$\mathrm{J}=$ non-Kenetech pole 


$$
\begin{aligned}
& \mathrm{K}=\text { can't identify (see comments) } \\
& \mathrm{S}=\text { single circuit; staggered lines } \\
& \mathrm{T}=\text { double circuit; staggered lines }
\end{aligned}
$$

TURBINE TYPE: See turbine type sheet for diagrams. A four letter code was used to refer to turbines belonging to companies other than Kenetech and was written in the comments section of the data string.

TURBINE ACTIVITY: Recorded the activity of the turbine that was referred to in the string.

$$
\begin{aligned}
& 1=\text { not spinning } \\
& 2=\text { spinning very slowly } \\
& 3=\text { spinning slowly } \\
& 4=\text { spinning fast } \\
& 5=\text { spinning very fast } \\
& 6=\text { bladeless turbine }
\end{aligned}
$$

PERCHED BIRD'S EXPOSURE TO THE SUN: Recorded when the day was clear.

$$
\begin{aligned}
& \mathrm{F}=\text { full shade } \\
& \mathrm{P}=\text { partial shade } \\
& \mathrm{S}=\text { full sun }
\end{aligned}
$$

HEIGHT OF BIRD PERCHED ON A TOWER (turbine, transmission, weather station, etc.):

$$
\begin{aligned}
& 1=\text { lower third } \\
& 2=\text { middle third } \\
& 3=\text { uppermost third }
\end{aligned}
$$

\section{LOCATION OF BIRD PERCHED ON A TURBINE IN RELATION TO BLADES:}
$\mathrm{A}=$ at or above blade level
$\mathrm{B}=$ below blade level

TURBINE POSITION WITHIN THE ROW: Position of turbine referred to in the string

$\mathrm{E}=$ end-row turbine (use also for type 13 turbine adjacent to outermost type 23 turbine in a windwall)

$\mathrm{M}=$ mid-row turbine (use also for turbines in windwalls that aren't the outermost type 13 turbine)

$\mathrm{L}=$ lone turbine (turbine not located in a row)

ADJACENT TURBINE BLADE RATING (CODE): Is the turbine referred to surrounded by other turbines with blades?

$1=$ turbines with blades on each side

2 = turbine with blades on only one side, no turbine on the other side

3 = turbine with blades on only one side, bladeless turbine on the other side 
$4=$ bladeless turbine on one side, no turbine on the other side

$5=$ bladeless turbine on both sides

$6=$ no turbine on either side

WINDWALL TURBINE: Is the turbine referred to part of a windwall?

$\mathrm{N}=$ no

$\mathrm{Y}=$ yes

$1=1$ st turbine next to the outermost turbine of the windwall, part of a row extending out from the windwall

$2=2$ nd turbine from the outermost turbine of the windwall, part of a row extending out from the windwall

*Any other turbine in a row extending out from a windwall is considered to be outside the windwall, and is not described as having any reference to the windwall.

LOCATION OF BIRD FLYING WITHIN 50 M OF A TURBINE ROW: Used mostly for eagles and occasionally for other birds flying near a row of operating turbines.

1 = flying below level of blades on shortest turbine in the row

2 = flying within the level of the blades

3 = flying less than or equal to $20 \mathrm{~m}$ above blades on tallest turbine in the row

4 = flying greater than or equal to $20 \mathrm{~m}$ above blades on tallest turbine in the row

TERRAIN: Used to describe the location and view surrounding a perched bird. We are still developing this as a category. Terrain descriptions are currently recorded in the comments section of the data string.

LATITUDE: Recorded in degrees, minutes, and hundredths of minutes. Obtained whenever an eagle was sighted in close proximity to the observers.

LONGITUDE: See latitude.

COORDINATE CODE: Four digit or letter code for a location whose latitude and longitude are already known. These would include turbine numbers, waterfowl survey pond codes, landmark locations within road survey segments, and Site 300 observation point codes.

PRECISION: Used to describe the proximity of a bird to specific lat/long coordinates or a coordinate code.

$\mathrm{H}=$ hard location (bird within $100 \mathrm{~m}$ of specified coordinates or code)

$\mathrm{M}=$ medium location (bird within $500 \mathrm{~m}$ of specified coordinates or code)

$\mathrm{S}=$ soft location (bird within $1 \mathrm{~km}$ of specified coordinates or code)

$\mathrm{V}=$ very soft location (bird within $3 \mathrm{~km}$ of specified coordinates or code) 
HABITAT: Dominant habitat type where a bird was located. During road surveys and Site 300 surveys, habitat type was listed generally as "windfarm" (WRA) or "Site 300."

$\mathrm{CH}=$ chaparral

F- $=$ forest, closed canopy

$\mathrm{FC}=$ forest, coniferous

$\mathrm{FD}=$ forest, hardwood

$\mathrm{FL}=$ farmland-agricultural

G- $=$ grassland

$\mathrm{GD}=$ grassland, dry

$\mathrm{GG}=$ grassland, green

$\mathrm{PA}=$ pasture, e.g. dairy or horse

$\mathrm{PN}=$ near a pond

$\mathrm{RP}=$ riparian

S- $=$ savannah, oak

S3 = Site 300

$\mathrm{SB}=$ savannah, blue oak

$\mathrm{SG}=$ short grass, $<1$ foot

$\mathrm{SL}=$ savannah, live oak

$\mathrm{SV}=$ savannah, valley oak

$\mathrm{TG}=$ tall grass, $>1$ foot

$\mathrm{W}-$ = woodland, oak

$\mathrm{WF}=$ WRA (windfarm)

$\mathrm{XX}=$ see comments

ENTRY NUMBER: Filled in during computer entry.

COMMENTS: Comments were written next to the letter designation for the data string. Comments consisted of a brief summary of the data string, terrain features pertaining to the data string, and any other information of interest especially as regarded wind turbine association, foraging, human-eagle interactions, etc. When additional space was needed for more lengthy comments, they were carried over to the notebook of an observer.

PERCENT OF VISIBLE TURBINES OPERATING IN THE SEGMENT: Recorded at the beginning of every segment, as well as when a change was noticed. Operating was defined as spinning at cut in speed or greater.

$$
\begin{aligned}
1 & =\text { none } \\
2 & =1-25 \\
3 & =26-50 \\
4 & =51-75 \\
5 & =76-100
\end{aligned}
$$


WEATHER: Recorded at the beginning of every segment as well as when a change occurred.

$$
\begin{aligned}
& \mathrm{CL}=\text { clear (no clouds) } \\
& \mathrm{DR}=\text { drizzle/mist (steady, light) } \\
& \mathrm{FL}=\text { light fog (visibility }>500 \mathrm{~m} \text { ) } \\
& \text { FM }=\text { moderate fog (visibility } 100-500 \mathrm{~m} \text { ) } \\
& \text { FO }=\text { dense fog (visibility }<100 \mathrm{~m} \text { ) } \\
& \text { FW }=\text { fog over water only } \\
& \text { HA }=\text { hail } \\
& \text { HO }=\text { high thin overcast } \\
& \text { HR }=\text { heavy persistent rain } \\
& \text { OC }=\text { overcast }(>70 \% \text { clouds) } \\
& \text { PC }=\text { partly cloudy }(21-70 \%) \\
& \text { RA }=\text { rain (steady, moderate) } \\
& \text { SC }=\text { scattered clouds }(1-20 \%) \\
& \text { SH }=\text { shower (intermittent, moderate) } \\
& \text { SL }=\text { sleet } \\
& \text { SN }=\text { snow } \\
& \text { SP }=\text { sprinkle (intermittent, light) } \\
& \text { TS }=\text { thunderstorm (heavy, intermittent) }
\end{aligned}
$$

TEMPERATURE: Recorded at the beginning of every segment as well as when a change occurred. Temperature was approximated in degrees Fahrenheit, using a thermometer.

$10=$ plus $10 \mathrm{~s}$

$20=$ plus 20 s (etc.)

$90=$ plus 90 s

$100=100$ or hotter

WIND SPEED: Recorded at the beginning of every segment as well as when a change occurred. Wind speed was approximated by an observer.

$$
\begin{aligned}
& \mathrm{C}=\text { calm }(<5 \text { knots, or }<6 \mathrm{mph}) \\
& \mathrm{G}=\text { gale }(>36 \text { knots, or }>40 \mathrm{mph}) \\
& \mathrm{L}=\text { light }(6-10 \text { knots, or } 7-12 \mathrm{mph}) \\
& \mathrm{M}=\text { moderate }(11-20 \text { knots, or } 13-23 \mathrm{mph}) \\
& \mathrm{S}=\text { strong }(21-35 \text { knots, or } 24-40 \mathrm{mph})
\end{aligned}
$$

WIND DIRECTION: Recorded at the beginning of every segment as well as when a change occurred. Wind direction was recorded using a compass, always with magnetic orientation.

$$
\mathrm{N}=\text { North, (etc.) }
$$

OBSERVER: Initials of an observer present. 
OBS-LOC: Observer location. Recorded at the beginning of every segment or when a change occurred. A survey segment (01-16 for the WRA or AA, AB for Site 300) was entered as indicated on color maps of the WRA or Site 300 survey route. Other specific two character codes were developed as needed.

$96=$ researcher in road vehicle

$97=$ nest view

$99=$ see notes (etc.)

TALLIES OF FLYING RAPTORS AND RAVENS: Non-eagle raptors and common ravens we saw flying were recorded by means of a tally per survey segment. The number seen were recorded in the right hand margin of the obsform, noting the appropriate date, species, age, data type and observer location.

WATERFOWL SURVEY: We conducted waterfowl surveys weekly during our road surveys in the WRA. Where present, we chose one pond per segment on the basis of our impression of suitable habitat and ease of visibility. We surveyed the ponds from fixed points or while driving. Data recorded on the obsform included date, beginning and end time of the survey, data type (WFS), pond coordinate code, habitat, observer, observer location, and weather information. In the comments section we entered the species of waterfowl and the number of each seen. Codes for the common waterfowl types were as follows:
$\mathrm{AA}=$ american avocet
$\mathrm{GB}=$ great blue heron
$\mathrm{GD}=$ gadwall
$\mathrm{GE}=$ great egret
$\mathrm{MD}=$ mallard
$\mathrm{PB}=$ pied-billed grebe
$\mathrm{RD}=$ ruddy duck
$\mathrm{SE}=$ snowy egret
$\mathrm{KD}=$ killdeer
$\mathrm{PE}=$ shorebirds, unspecified
$\mathrm{XX}=$ unidentified 


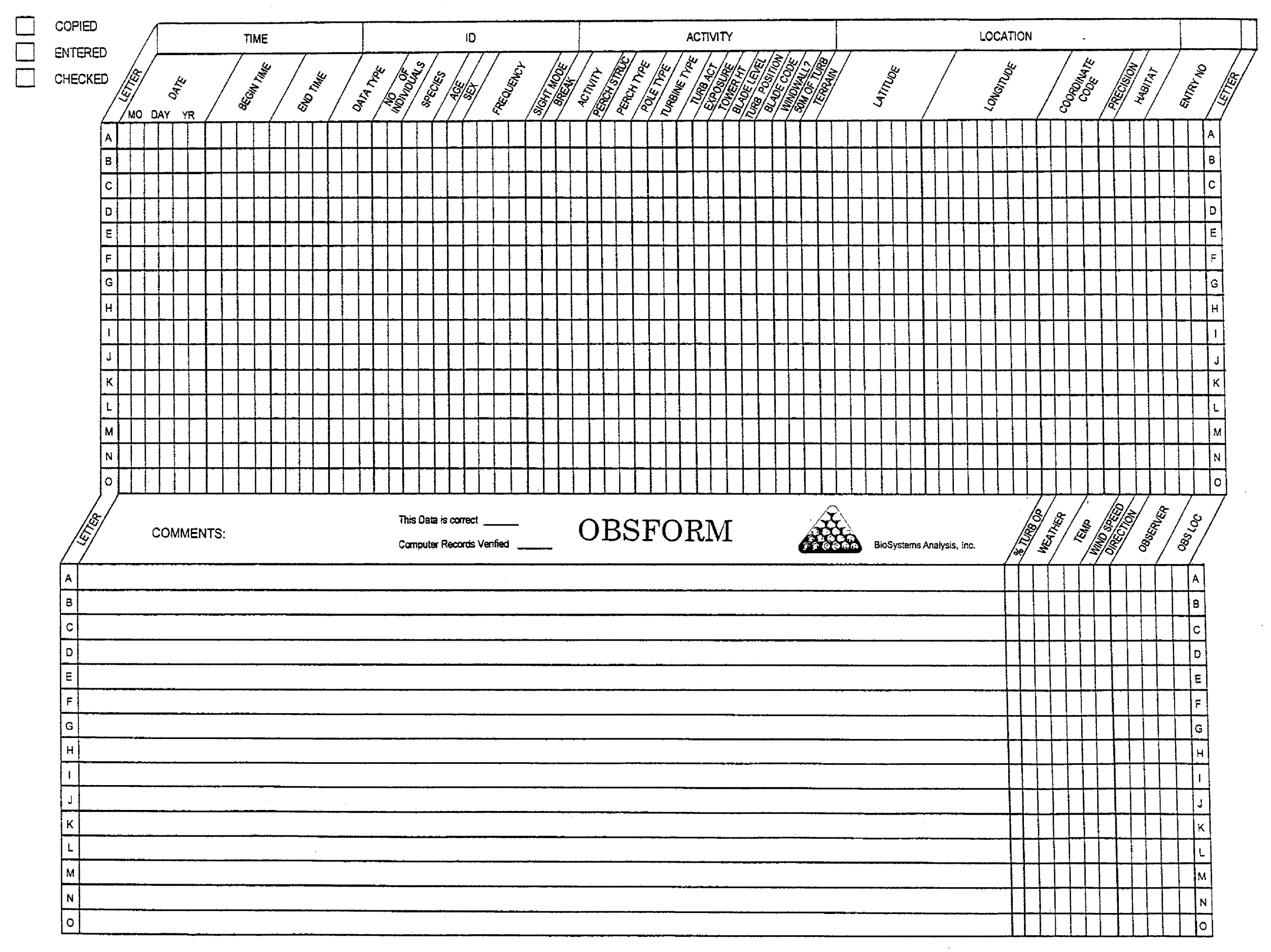


1 HOLEK/POLENKO (Dutch)

Size of Turbine: $\quad 100 \mathrm{~kW}$

Rotor Dianieter: $\quad 59 \mathrm{ft}$

Cut-in Speed: $\quad 14 \mathrm{mph}$

Rated Wind Speed: $\quad 31 \mathrm{mpls}$

Cut-out Speed: $\quad 67 \mathrm{mpls}$

Number Installed: $\quad 12$

Description:

Operator:

Upwind, fixed pitch, dual yaw rotors, self-supporting tubular tower

Thompson Engineering

Management

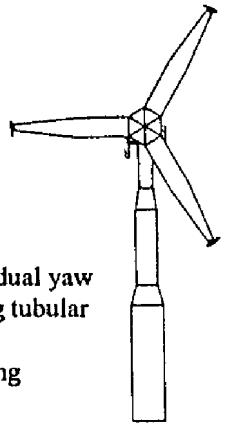

2 HOLEC/WINDMATIC (Danish)

Size of Turbine: $\quad 65 \mathrm{~kW}$

Rotor Diameter: $\quad 48 \mathrm{ft}$

Cut-in Speed: $\quad 12 \mathrm{mph}$

Rated Wind Speed: $\quad 35 \mathrm{mph}$

$\begin{array}{ll}\text { Cutt-out Speed: } & 56 \mathrm{mph} \\ \text { Number Installed: } & 26\end{array}$

Number Installed: $\quad 26$

Description:

Operator:

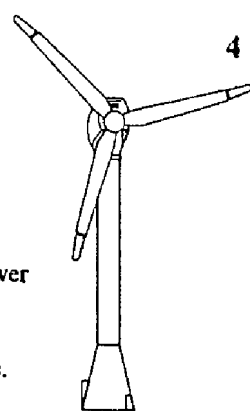

MrCON (Danish)

Size of Turbine:

Rotor Diameter:

Cut-in Speed:

Rated Wind Speed:

Cut-out Speed:

Number Installed:

Description:

Operator: with conical base

Altamont Energy Corp.

Howden Wind Parks, Inc.
Upwind, fixed pitch, dual yaw rotors, self-supporting lattice tower

Thompson Engineering

Management

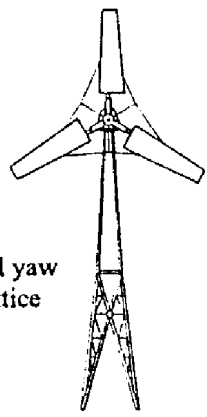

$60 \mathrm{~kW}$

$52 \mathrm{ft}$.

$9 \mathrm{mph}$

$34 \mathrm{mph}$

None

221

Upwind, fixed pitch, selfsupporting steel tubular tower with inside ladder to nacelle SeaWest Energy Group, Inc.

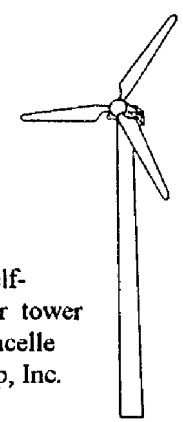

5 NORDTANK (Danish)

Size of Turbine:

Rotor Diameter:

Cut-in Speed:

Rated Wind Speed:

Cutrout Speed:

Number Installed:

Description:

Operator:
$65 \mathrm{~kW}$

$52 \mathrm{ft}$.

$8 \mathrm{mph}$

$34 \mathrm{mph}$

None

394

Upwind, fixed pitch. steel tubular tower

Altamont Energy Corp.

LFC Power Systems Corp.

Wintec Lud.

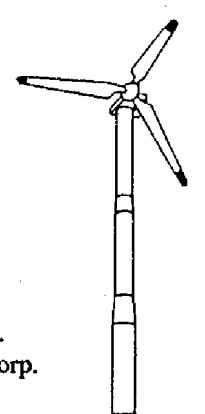

6 VESTAS (Danish)

Size of Turbine:

Rotor Diameter:

Cut-in Speed:

Rated Wind Speed:

Cut-out Speed:

Number Installed:

Description:

Operator:
7 HMZ-WINDMASTER (Belgian)

Size of Turbine:

Rotor Diameter:

Cut-in Speed:

Rated Wind Speed:

Cut-out Speed:

Number Installed:

Description:

Operator:

9 FLOWIND

Size of Turbine:

Rotor Diameter:

Cut-in Speed:

Rated Wind Speed:

Cut-out Speed:

Number Installed:

Description:

Developer:
$75200250 \quad 300 \mathrm{~kW}$

$\begin{array}{lllll}72 & 72 & 76 & 82 \mathrm{ft} .\end{array}$

$1011 \quad 11 \quad 11 \mathrm{mph}$

$20 \quad 33 \quad 32 \quad 34 \mathrm{mph}$

50 $50 \quad 56 \quad 56 \mathrm{mph}$

$\begin{array}{llll}5 & 129 & 30 & 15\end{array}$

Upwind, hydraulically pitched, blades, tubular tower with inside

ladder to nacelle

WindMaster

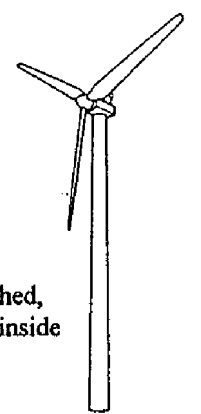

8

Size of Turbine:

Rotor Diameter:

Cut-in Speed:

Rated Wind Speed:

Cut-out Speed:

Number Installed:

Description:

Operator:
$65 \mathrm{~kW} \quad 100 \mathrm{~kW}$

$50 \mathrm{ft} . \quad 56 \mathrm{ft}$.

$7 \mathrm{mph} \quad 8 \mathrm{mph}$

$34 \mathrm{mph} 42 \mathrm{mph}$

$50 \mathrm{mph} 62 \mathrm{mph}$

2

Upwind, lattice tower

Altamont Energy Corp.

Zond Systems, Inc.

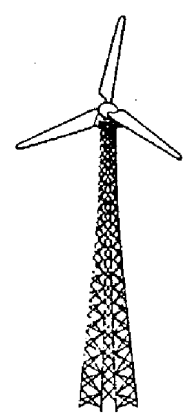

10 ENERTECH

Size of Turbine:

Rotor Diameter:

Cut-in Speed:

Rated Wind Speed:

Cut-out Speed:

Number Installed:

Description:

Operator:

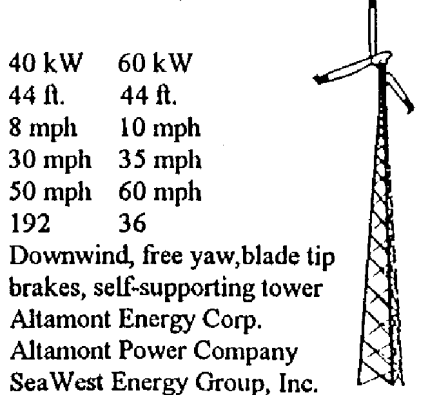


11 WIND POWER SYSTEMS

Size of Turbine: $\quad 40 \mathrm{~kW}$

Rotor Diameter: $\quad 39 \mathrm{ft}$.

Cut-in Speed: $\quad 11 \mathrm{mph}$

Rated Wind Speed: $\quad 30 \mathrm{mph}$

Cut-out Speed: $\quad 60 \mathrm{mph}$

Number Installed: $\quad 20$

Description:

Operator:
Downwind, tilt-down lattice

tower, no nacelle

Anserican Windpower, Inc.
12 KENETECH

Size of Turbine:

Rotor Diameter:

Cut-in Speed:

Rated Wind Speed:

Cut-out Speed:

Number Installed:

Description:

Operator:
$300 \mathrm{~kW}-400 \mathrm{~kW}$

$108 \mathrm{ft}$.

$9 \mathrm{mph}$

29 mph - 32 mph

Variable

38

Upwind, variable speed,

variable pitch, variable power

factor, microprocessor-based

turbine control system, $80 \mathrm{ft}$.

lattice tower

Kenetech Windpower

\section{KENETECH}

Size of Turbine:

Rotor Diameter:

Cut-in Speed:

Rated Wind Speed:

Cut-out Speed:

Number Installed:

Description:

Operator:

\section{$100 \mathrm{~kW}$}

$59 \mathrm{ft}$.

$12 \mathrm{mph}$

$29 \mathrm{mph}$

$44 \mathrm{mph}$

3,500

Downwind, free yaw, variable pitch blades, remote computer control, $60 \mathrm{ft}$. tripod tower Kenetech Windpower

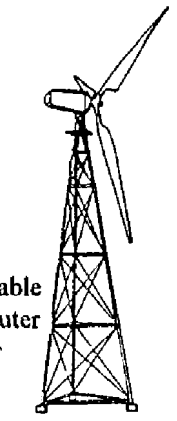

Operator:
14 DANISH WIND TECHNOLOGY (Danish)

Size of Turbine:

Rotor Diameter:

Cut-in Speed:

Rated Wind Speed:

Cut-out Speed:

Number Installed:

Description:

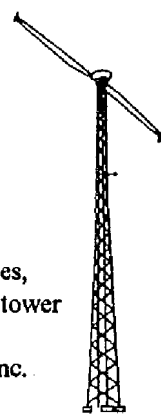

16 FAYETTE

Size of Turbine:

Rotor Diameter:

Cut-in Speed:

Rated Wind Speed:

Cut-out Speed:

Number Installed:

Description:

Operator:
$300 \mathrm{~kW}$

$97 \mathrm{ft}$.

$12 \mathrm{mph}$

$30 \mathrm{mph}$

$56 \mathrm{mph}$

3

Downwind, free yaw with hydraulic damping, variable pitch, computer control, steel tubular tower with inside ladder

Atkinson Mechanical

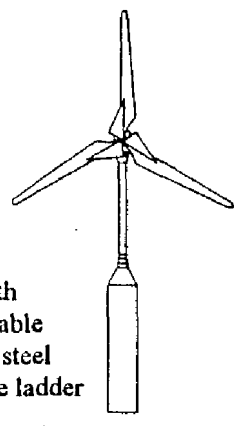

Cut-in Speed:

Cut-out Speed:

Description:

$55 \quad 55 \quad 55 \mathrm{mph}$

$\begin{array}{lll}99 & 96 \quad 109\end{array}$

Downwind, blade tip brakes free yaw, tilt-down lattice towe Altamont Energy Corp. SeaWest Energy Group, Inc. TERA

$\begin{array}{lll}75 & 95 & 250 \mathrm{~kW} \\ 33 & 36 & 80 \mathrm{ft} \\ 12 & 12 & 12 \mathrm{mph} \\ 40 & 37 & 35 \mathrm{mph} \\ \text { none } & & \\ 222 & 1202 & 30\end{array}$

Downwind, free yaw, blade tip brakes, guyed pipe tower Altamont Energy Corp. American Energy Projects, Inc. Arcadian Renewable Power Corp.
17 DANWIN (Danish)

Size of Turbine:

Rotor Diameter:

Cut-in Speed:

Rated Wind Speed:

Cut-out Speed:

Number Installed:

Description:

Operator:
$110 \mathrm{~kW}$

$62.3 \mathrm{ft}$.

$7.8 \mathrm{mph}$

$30 \mathrm{mph}$

$57 \mathrm{mph}$

25

Upwind, tubular tower

Flowind

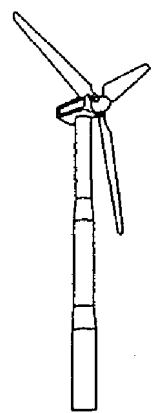

18 BSW/W AGNER (German)

Size of Turbine:

Rotor Diameter:

Cut-in Speed:

Rated Wind Speed:

Cut-out Speed:

Number Installed:

Description:

Operator:

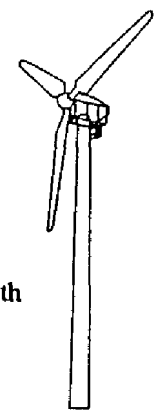

20 W.E.G. (Brittish)

Size of Turbine:

Rotor Diameter:

Number of blades:

Cut-in Speed:

Rated Wind Speed:

Cut-out Speed:

Number Installed:

Description:

$65 \mathrm{~kW}$

$56 \mathrm{ft}$.

$8 \mathrm{mph}$

$30 \mathrm{mph}$

$67 \mathrm{mph}$

15

Upwind, fixed pitch, driven yaw, lattice tower

Energy Projects, Inc.

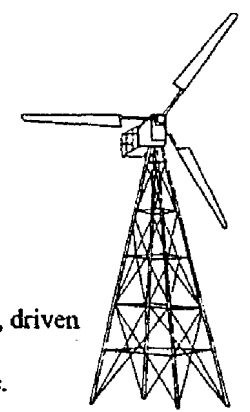

Operator:

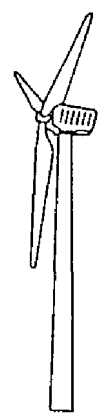




\section{KENETECH}

Size of Turbine:

Rotor Diameter:

Cut-in Speed:

Rated Wind Speed:

Cut-out Speed:

Number Installed:

Description:

Operator:

\section{KENETECH}

Size of Turbine:

Rotor Diameter:

Cut-in Speed:

Rated Wind Speed:

Cut-out Speed:

Number Installed:

Description:

Operator:
$100 \mathrm{~kW}$

$59 \mathrm{ft}$.

$12 \mathrm{mph}$

$29 \mathrm{mph}$

$44 \mathrm{mph}$

nd

Downwind, free yaw, variable pitch blades, remote computer control, $80 \mathrm{ft}$. lattice tower

Kenetech Windpower

$100 \mathrm{~kW}$

$59 \mathrm{ft}$.

$12 \mathrm{mph}$

$29 \mathrm{mph}$

44 mphe

nd

Downwind, free yaw, variable pitch blades, remote computer control, $140 \mathrm{ft}$. lattice tower

Kenetech Windpower
22 KENETECH

Size of Turbine:

Rotor Diameter:

Cut-in Speed:

Rated Wind Speed:

Cut-out Speed:

Number Installed:

Description

Operator:

24 KENETECH

Size of Turbine:

Rotor Diameter:

Cut-in Speed:

Rated Wind Speed:

Cut-out Speed:

Number Installed:

Description:

Operator:

26 KENETECH

Size of Turbine:

Rotor Diameter:

Cut-in Speed:

Rated Wind Speed:

Cut-out Speed:

Number Installed:

Description:

Upwind, variable speed, variable pitch, variable power

factor, microprocessor-based

turbine control system,

$120 \mathrm{ft}$. tubular tower

Operator:

Operator:
$100 \mathrm{~kW}$

$59 \mathrm{ft}$.

$12 \mathrm{mph}$

$29 \mathrm{mph}$

$44 \mathrm{mph}$

nd

Downwind, free yaw, variable pitch blades, remote computer control, $80 \mathrm{ft}$. tripod lattice tower Kenetech Windpower
$300 \mathrm{~kW}-400 \mathrm{~kW}$

$108 \mathrm{ft}$.

$9 \mathrm{mph}$

$29 \mathrm{mph}-32 \mathrm{mph}$

Variable

Upwind, variable speed,

variable pitch, variable power

factor, microprocessor-based turbine control system, 80-ft. modified tubular tower

Kenetech Windpower

$300 \mathrm{~kW}-400 \mathrm{~kW}$

$108 \mathrm{ft}$

$9 \mathrm{mph}$

29 nuph - 32 mph

Variable

Upwind, variable speed, variable pitch, variable power factor, microprocessor-based turbine control system.

$120 \mathrm{ft}$. lattice tower

Kenetech Windpower

nd $=$ no data available

This information was obtained from the Altamont Pass Wind Power Plant brochure prepared through the cooperative efforts of the Pacific Gas and Electric Company and Kenetech Windpower, Inc., April 1992. Current information was not available regarding the number installed and numbers may have changed. 
Computer Entry Date

BREEDING ADULT: USFWS Left

ALL OTHER EAGLES: USFWS Right

\section{GOLDEN EAGLE CAP FORM}

Bird Number

Breeding Area

Capture Location

Estimated Age (Years): Adult, 4.0, 3.5, 3.0, 2.5, 2.0, 1.5, 1.0,

Personnel

Time: Captured Handling

USFWS Band Number

Transmitter: Type Frequency
Secured

Position

Pulse/Min: Normal
Date

Bird Name

Capture Technique

Total

Leg: Right, Left

Pulse/Min: Norma

Sex: Male, Female, Unknown

Slides

Released

Morphology:

Right

Number

Mortality

Hallux Length (mm)

Tarsus Width - Dorsal/Ventral (mm)

Tarsus Width - Lateral (mm)

Wing Chord Length $(\mathrm{cm})$

Eighth Primary Length $(\mathrm{cm})$

Central Retrix Length $(\mathrm{cm})$

Culmen Length (mm)

Weight $(\mathrm{kg})$

Girth $(\mathrm{cm})$

Sternum:

1.0) Keel bladed - minimal breast muscle

Beak Depth (mm)

Crop: Full, Partial, Empty

2.0) Keel bladed - more prominent breast muscle

(Normal)

3.0) Keel protrudes slightly above breast muscle

4.0) Keel flush with breast muscle

5.0) Keel inundated in breast muscle

Iris: Yellow-Gold, Gold, Orange-Brown, Light Brown, Brown, Sepia, Other

Feather Lice: . None, One, Several, Many

New Primaries: $\quad$ Right: $\quad \begin{array}{llllllllll}1 & 2 & 3 & 4 & 5 & 6 & 7 & 8 & 9 & 10\end{array}$

Left: $\quad \begin{array}{llllllllll}1 & 2 & 3 & 4 & 5 & 6 & 7 & 8 & 9 & 10\end{array}$

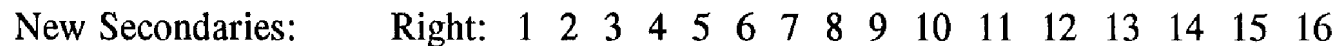

$\begin{array}{lllllllllllllllll}\text { Left: } & 1 & 2 & 3 & 4 & 5 & 6 & 7 & 8 & 9 & 10 & 11 & 12 & 13 & 14 & 15 & 16\end{array}$

New Tertiaries: $\quad$ Right: $1 \begin{array}{llll}1 & 2 & 3 & 4\end{array}$

Left: $\begin{array}{llll}1 & 2 & 3 & 4\end{array}$

New Retrices: $\quad$ Right: $1 \begin{array}{lllllll}1 & 2 & 3 & 4 & 5 & 6\end{array}$

Left: $\quad \begin{array}{llllll}1 & 2 & 3 & 4 & 5 & 6\end{array}$

Comments:

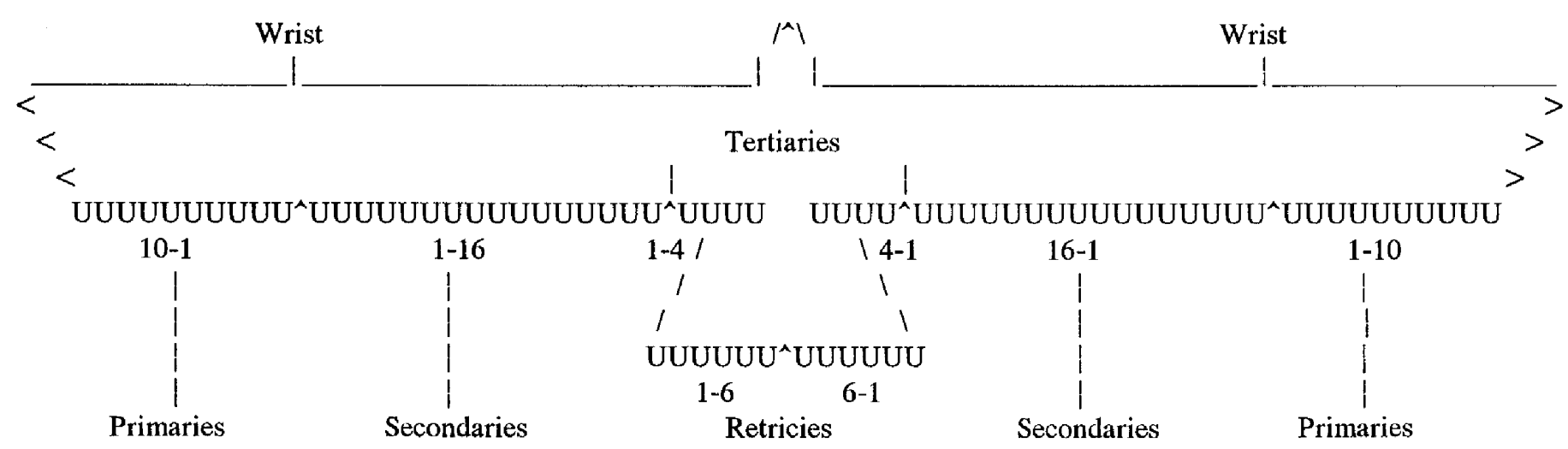


Bird Number

Breeding Area

Nest Number

Climbing Technique

Time: Near Nest

Secured

Handling

$\longrightarrow$

Bird Name

Sex: Male, Female, Unknown

Estimated Age

Personnel

USFWS Band Number

Transmitter: Type

Frequency

Position

Pulse/Min: Normal

Leg: Right, Left

Total

Left Area

Total

Processed

Total

Morphology:

Hallux Length (mm)

Tarsus Width - Dorsal/Ventral (mm)

Tarsus Width - Lateral (mm)

Wing Chord Length $(\mathrm{cm})$

Eighth Primary Length (cm)

Central Retrix Length $(\mathrm{cm})$ :

Culmen Length (mm)

Girth (cm)

Crop: Full, Partial, Empty

Number

Sternum: $\quad 1.0)$ Keel bladed - minimal breast muscle

1.5

2.0) Keel bladed - more prominent breast muscle

2.5

(Normal)

3.0) Keel protrudes slightly above breast muscle

3.5

4.0) Keel flush with breast muscle

4.5

5.0) Keel inundated in breast muscle

Feather Lice: None, One, Several, Many

Whole Eggs: Collected, Number

Eggshell Fragments: Collected, Sets

Prey Remains In Nest: Collected, Not Collected, None Found

Below Nest: Collected, Not Collected, None Found

Mexican Chicken Bugs: High, Moderate, Low, None Found

Foreign Matter In Nest

Below Nest

Comments: 
Breeding Area Climbing Technique

Time: Near Nest Climbing: Start Left Area

Nest Number Personnel Total Total

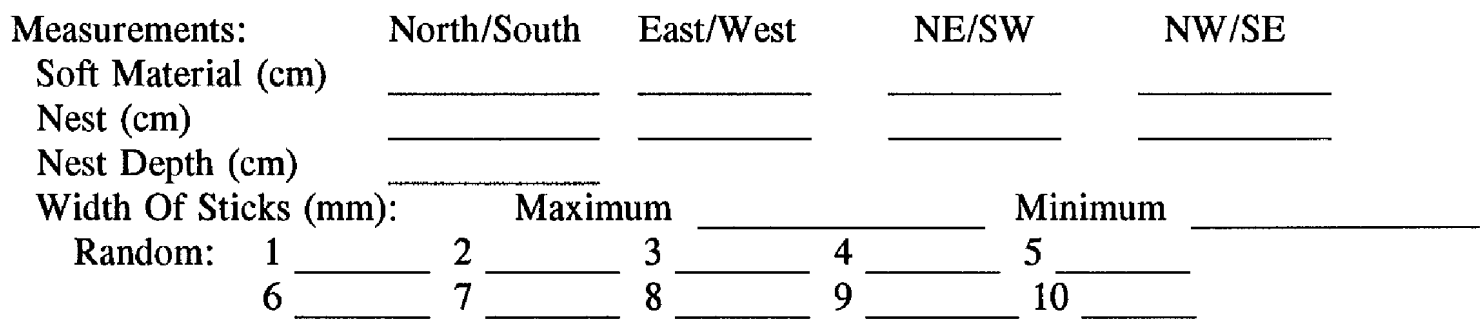

Distance Between Major Branches At Nest Level (cm):

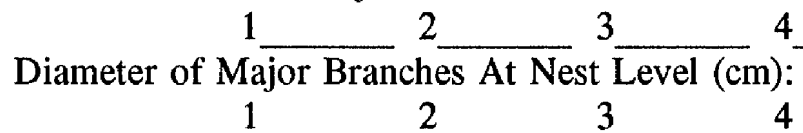

Diameter of Tree or Branch At Base of Nest (cm): $4 \quad 5$ 6

Nest Condition: Good, Poor, Remnant, Fallen

Nest Shade: Full, Partial, None

Nest Accessibility: Walk In, Rope, Spikes, Technical Climb

Nest Type: Cylinder, Bowl, Inverted Cone, Disk

Nest Material:

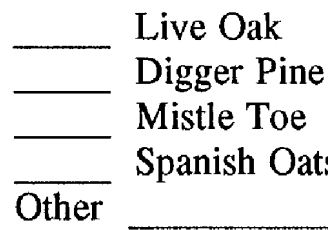
Valley Oak Blue Oak
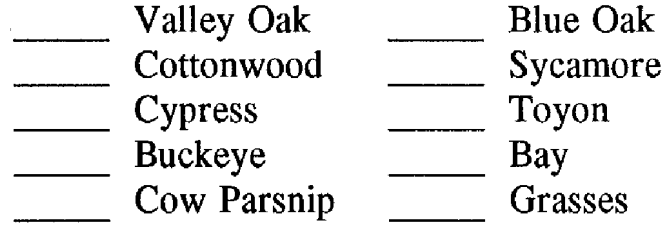

Whole Eggs: Collected, Number Eggshell Fragments: Collected, Sets None Found

Prey Remains In Nest: Collected, Not Collected, None Found Below Nest: Collected, Not Collected, None Found Mexican Chicken Bugs: High, Moderate, Low, None Found Foreign Matter In Nest Below Nest

Comments: 
GOLDEN EAGLE NEST FORM (continued) Date

Breeding Area

Nest Number

Habitat: $\quad$ Major Habitat Within $0.5 \mathrm{~km}$ of Nest Major Habitat Within $1.0 \mathrm{~km}$ of Nest

Elevation (MSL) Grazed: Yes No

Buildings: Yes No Degree of Slope

Slope Aspect: North, South, East, West, NW, NE, SW, SE True

Wind Exposure: North, South, East, West, NW, NE, SW, SE True Latitude - Longitude _ _ ${ }^{\circ}$ _ _ - _ _ _ Property Owner

Ground Squirrel Density Within:

$1 / 2 \mathrm{~km}$ of Nest

$1 \mathrm{~km}$ of Nest

Probable Range of Pair
1) Low
1) Low
2)
2)
3) Moderate
4) $\mathrm{High}$
3) Moderate
4)
5) High

1) Low

2)

3) Moderate

4)

5) High

Nest Tree: Species

Tree: Live, Dead-Top, \% Canopy

Tree: Isolated, In Grove Area of Grove

Height

Snag: Hard, Soft

Distance To Nearest Large Tree (m)

Diameter of Tree At Breast Height (DBH) (cm):

Nest Location: On Trunk, On Limb

Horizontal Distance From Trunk To Nest

Distance From Tree Top To Nest Level

Height of Nest (Ground To Base) 



\section{APPENDIX D: PREY ITEMS IDENTIFIED FROM 20 GOLDEN EAGLE NESTS IN THE DIABLO RANGE, 1994}

Table 1. Number and estimated biomass (grams) of prey identified from remains collected in the Adelaide golden eagle nest on 21 May 1994.

\begin{tabular}{lccrr}
\hline \hline Species & No. & $\%$ & Biomass & $\%$ \\
\hline California Ground Squirrel & 4 & 57.1 & 2,900 & 49.9 \\
California Meadow Mouse & 1 & 14.3 & 50 & 0.9 \\
Striped Skunk & 1 & 14.3 & 2,688 & 46.2 \\
\hline Mammal Subtotal & 6 & 85.7 & 5,638 & 96.9 \\
\hline Yellow-billed Magpie & 1 & 14.3 & 178 & 3.1 \\
\hline Total & 7 & 100.0 & 5,816 & 100.0 \\
\hline \hline
\end{tabular}


Table 2. Number and estimated biomass (grams) of prey identified from remains collected in the Calaveras Creek golden eagle nest on 8 June 1994.

\begin{tabular}{lrrrr}
\hline \hline Species & No. & $\%$ & Biomass & $\%$ \\
\hline California Ground Squirrel & 9 & 60.0 & 6,525 & 46.4 \\
Badger & 1 & 6.7 & 4,130 & 29.3 \\
Striped Skunk & 1 & 6.7 & 2,688 & 19.1 \\
\hline Mammal Subtotal & 11 & 73.3 & 13,343 & 94.8 \\
\hline California Quail & 1 & 6.7 & 173 & 1.2 \\
Yellow-billed Magpie & 1 & 6.7 & 178 & 1.3 \\
\hline Bird Subtotal & 2 & 13.3 & 351 & 2.5 \\
\hline Unidentified Snake & 2 & 13.3 & 380 & 2.7 \\
\hline Total & 15 & 100.0 & 14,074 & 100.0 \\
\hline
\end{tabular}

Table 3. Number and estimated biomass (grams) of prey identified from remains collected in the Camino Diablo golden eagle nest on 3 and 15 June 1994.

\begin{tabular}{lcccc}
\hline \hline Species & No. & $\%$ & Biomass & $\%$ \\
\hline California Ground Squirrel & 76 & 97.4 & 55,100 & 99.0 \\
\hline Barn Owl & 1 & 1.3 & 466 & 0.8 \\
Western Meadowlark & 1 & 1.3 & 98 & 0.2 \\
\hline Bird Subtotal & 2 & 2.6 & 564 & 1.0 \\
\hline Total & $\mathbf{7 8}$ & $\mathbf{1 0 0 . 0}$ & $\mathbf{5 5 , 6 6 4}$ & 100.0 \\
\hline \hline
\end{tabular}


Table 4. Number and estimated biomass (grams) of prey identified from remains collected in and below the Eagle's Run Tower golden eagle nest on 1 July 1994.

\begin{tabular}{lcccc}
\hline \hline Species & No. & $\%$ & Biomass & $\%$ \\
\hline Cottontail & 1 & 14.3 & 650 & 14.9 \\
California Ground Squirrel & 5 & 71.4 & 3,625 & 82.9 \\
\hline Mammal Subtotal & 6 & 85.7 & 4,275 & 97.8 \\
\hline Western Meadowlark & 1 & 14.3 & 98 & 2.2 \\
\hline Total & 7 & $\mathbf{1 0 0 . 0}$ & $\mathbf{4 , 3 7 3}$ & 100.0
\end{tabular}

Table 5. Number and estimated biomass (grams) of prey identified from remains collected in the Foley golden eagle nest on 6 June 1994.

\begin{tabular}{lcccc}
\hline \hline Species & No. & $\%$ & Biomass & $\%$ \\
\hline California Ground Squirrel & 4 & 100.0 & 2,900 & 100.0 \\
\hline Total & 4 & 100.0 & 2,900 & 100.0 \\
\hline \hline
\end{tabular}


Table 6. Number and estimated biomass (grams) of prey identified from remains collected in the High Corral golden eagle nest on 7 and 29 June 1994.

\begin{tabular}{lcccc}
\hline \hline Species & No. & $\%$ & Biomass & $\%$ \\
\hline Rabbit (Leporidae) & 3 & 23.1 & 4,146 & 38.2 \\
California Ground Squirrel & 9 & 69.2 & 6,525 & 60.1 \\
\hline Mammal Subtotal & 12 & 92.3 & 10,671 & 98.3 \\
\hline Unidentified Snake & 1 & 7.7 & 190 & 1.7 \\
\hline Total & 13 & 100.0 & 10,861 & 100.0 \\
\hline \hline
\end{tabular}

Table 7. Number and estimated biomass (grams) of prey identified from remains collected in the Indian Creek golden eagle nest on 15 June 1994.

\begin{tabular}{|c|c|c|c|c|}
\hline Species & No. & $\%$ & Biomass & $\%$ \\
\hline California Ground Squirrel & 3 & 21.4 & 2,175 & 22.8 \\
\hline California Meadow Mouse & 2 & 14.3 & 100 & 1.0 \\
\hline Black-tailed Deer (fawn) & 1 & 7.1 & 3,780 & 39.6 \\
\hline Mammal Subtotal & 6 & 42.9 & 6,055 & 63.4 \\
\hline Black-shouldered Kite & 2 & 14.3 & 666 & 7.0 \\
\hline Common Raven & 1 & 7.1 & 1,199 & 12.5 \\
\hline Mallard & 1 & 7.1 & 1,082 & 11.3 \\
\hline Northern Flicker & 1 & 7.1 & 142 & 1.5 \\
\hline Yellow-billed Magpie & 1 & 7.1 & 178 & 1.9 \\
\hline Scrub Jay & 1 & 7.1 & 176 & 1.8 \\
\hline Unidentified Passerine & 1 & 7.1 & 56 & 0.6 \\
\hline Bird Subtotal & 8 & 57.1 & 3,499 & 36.6 \\
\hline Total & 14 & 100.0 & 9,554 & 100.0 \\
\hline
\end{tabular}


Table 8. Number and estimated biomass (grams) of prey identified from remains collected in and below the Lindl golden eagle nest on 2 June 1994.

\begin{tabular}{|c|c|c|c|c|}
\hline Species & No. & $\%$ & Biomass & $\%$ \\
\hline California Ground Squirrel & 13 & 76.5 & 9,425 & 94.6 \\
\hline California Meadow Mouse & 1 & 5.9 & 50 & 0.5 \\
\hline Mammal Subtotal & 14 & 82.4 & 9,475 & 95.1 \\
\hline Yellow-billed Magpie & 1 & 5.9 & 178 & 1.8 \\
\hline American Kestrel & 1 & 5.9 & 116 & 1.2 \\
\hline Bird Subtotal & 2 & 11.8 & 294 & 3.0 \\
\hline Unidentified Snake & 1 & 5.9 & 190 & 1.9 \\
\hline Total & 17 & 100.0 & 9,959 & 100.0 \\
\hline
\end{tabular}

Table 9. Number and estimated biomass (grams) of prey identified from remains collected in and below the Los Vaqueros golden eagle nest on 31 May and 8 June 1994.

\begin{tabular}{lrrrr}
\hline \hline Species & No. & $\%$ & Biomass & $\%$ \\
\hline Black-tailed Jackrabbit & 1 & 9.1 & 2,114 & 12.2 \\
California Ground Squirrel & 7 & 63.6 & 5,075 & 29.3 \\
Gray Fox & 2 & 18.2 & 6,350 & 36.7 \\
Black-tailed Deer (fawn) & 1 & 9.1 & 3,780 & 21.8 \\
\hline & & & & \\
Total & 11 & $\mathbf{1 0 0 . 0}$ & $\mathbf{1 7 , 3 1 9}$ & 100.0 \\
\hline \hline
\end{tabular}


Table 10. Number and estimated biomass (grams) of prey identified from remains collected in and below the Mines Road golden eagle nest on 2 June 1994.

\begin{tabular}{lcrrr}
\hline \hline Species & No. & $\%$ & Biomass & $\%$ \\
\hline California Ground Squirrel & 5 & 71.4 & 3,625 & 90.8 \\
Yellow-billed Magpie & 1 & 14.3 & 178 & 4.5 \\
Unidentified Snake & 1 & 14.3 & 190 & 4.7 \\
\hline Total & 7 & 100.0 & 3,993 & 100.0 \\
\hline \hline
\end{tabular}

Table 11. Number and estimated biomass (grams) of prey identified from remains collected in the Morgan Territory golden eagle nest on 26 May 1994.

\begin{tabular}{|c|c|c|c|c|}
\hline Species & No. & $\%$ & Biomass & $\%$ \\
\hline California Ground Squirrel & 3 & 25.0 & 2,175 & 15.9 \\
\hline Black-tailed Jackrabbit & 1 & 8.3 & 2,114 & 15.5 \\
\hline Domestic Cow & 1 & 8.3 & 4,130 & 30.2 \\
\hline Mammal Subtotal & 5 & 41.7 & 8,419 & 61.6 \\
\hline Black-shouldered Kite & 2 & 16.7 & 666 & 4.9 \\
\hline Red-tailed Hawk & 1 & 8.3 & 1,126 & 8.3 \\
\hline Turkey Vulture & 1 & 8.3 & 1,467 & 10.8 \\
\hline Great Horned Owl & 1 & 8.3 & 1,355 & 9.9 \\
\hline American Crow & 1 & 8.3 & 448 & 3.3 \\
\hline Scrub Jay & 1 & 8.3 & 176 & 1.3 \\
\hline Bird Subtotal & 7 & 58.3 & 5,238 & 38.3 \\
\hline Total & 12 & 100.0 & 13,657 & 100.0 \\
\hline
\end{tabular}


Table 12. Number and estimated biomass (grams) of prey identified from remains collected in the Mt. Allison golden eagle nest on 4 June 1994.

\begin{tabular}{|c|c|c|c|c|}
\hline Species & No. & $\%$ & Biomass & $\%$ \\
\hline California Ground Squirrel & 9 & 42.9 & 6,525 & 62.3 \\
\hline California Meadow Mouse & 5 & 23.8 & 250 & 2.4 \\
\hline Rabbit (Leporidae) & 1 & 4.8 & 1,382 & 13.2 \\
\hline Mammal Subtotal & 15 & 71.4 & 8157 & 77.9 \\
\hline Great Horned Owl & 1 & 4.8 & 1,355 & 12.9 \\
\hline Yellow-billed Magpie & 1 & 4.8 & 178 & 1.7 \\
\hline Bird Subtotal & 2 & 9.5 & 1,533 & 14.6 \\
\hline Gopher Snake & 2 & 9.5 & 404 & 3.9 \\
\hline Unidentified Snake & 2 & 9.5 & 380 & 3.6 \\
\hline Reptile Subtotal & 4 & 19.1 & 784 & 7.5 \\
\hline Total & 21 & 100.0 & 10,474 & 100.0 \\
\hline
\end{tabular}


Table 13. Number and estimated biomass (grams) of prey identified from remains collected in the Niles Canyon golden eagle nest on 7 June 1994.

\begin{tabular}{lcccc}
\hline \hline Species & No. & $\%$ & Biomass & $\%$ \\
\hline California Ground Squirrel & 6 & 50.0 & 4,350 & 54.8 \\
\hline & 1 & 8.3 & 2,390 & 30.1 \\
Great Blue Heron & 1 & 8.3 & 466 & 5.9 \\
Barn Owl & 1 & 8.3 & 333 & 4.2 \\
Black-shouldered Kite & 1 & 8.3 & 176 & 2.0 \\
Scrub Jay & 1 & 8.3 & 56 & 0.7 \\
Unidentified Passerine & & & & \\
\hline & 5 & 41.7 & 3,421 & 42.9 \\
Bird Subtotal & 1 & 8.3 & 190 & 2.4 \\
\hline Unidentified Snake & 12 & 100.0 & 7,961 & 100.0 \\
Total & & & & \\
\hline \hline
\end{tabular}


Table 14. Number and estimated biomass (grams) of prey identified from remains collected in and below the Pipe Cross golden eagle nest on 5 and 14 June 1994.

\begin{tabular}{|c|c|c|c|c|}
\hline Species & No. & $\%$ & Biomass & $\%$ \\
\hline California Ground Squirrel & 10 & 50.0 & 7,250 & 69.4 \\
\hline California Meadow Mouse & 2 & 10.0 & 100 & 1.0 \\
\hline Muskrat & 1 & 5.0 & 1171 & 11.2 \\
\hline Mammal Subtotal & 13 & 65.0 & 8,521 & 81.6 \\
\hline Black-shouldered Kite & 1 & 5.0 & 333 & 3.2 \\
\hline California Quail & 1 & 5.0 & 173 & 1.7 \\
\hline Barn Owl & 1 & 5.0 & 466 & 4.5 \\
\hline Yellow-billed Magpie & 1 & 5.0 & 178 & 1.7 \\
\hline Bird Subtotal & 4 & 20.0 & 1,150 & 11.0 \\
\hline Rattlesnake & 1 & 5.0 & 393 & 3.8 \\
\hline Unidentified Snake & 2 & 10.0 & 380 & 3.6 \\
\hline Reptile Subtotal & 3 & 15.0 & 773 & 7.4 \\
\hline Total & 20 & 100.0 & 10,444 & 100.0 \\
\hline
\end{tabular}


Table 15. Number and estimated biomass (grams) of prey identified from remains collected in the Sibley golden eagle nest on 6 June 1994.

\begin{tabular}{|c|c|c|c|c|}
\hline Species & No. & $\%$ & Biomass & $\%$ \\
\hline Black-tailed Jackrabbit & 7 & 46.7 & 14,798 & 83.3 \\
\hline California Ground Squirrel & 1 & 6.7 & 725 & 4.1 \\
\hline Fox Squirrel & 1 & 6.7 & 544 & 3.1 \\
\hline Unidentified Rodent & 1 & 6.7 & 50 & 0.3 \\
\hline Mammal Subtotal & 10 & 66.7 & 16,117 & 90.7 \\
\hline Red-tailed Hawk & 1 & 6.7 & 1,126 & 6.3 \\
\hline Mourning Dove & 1 & 6.7 & 119 & 0.7 \\
\hline Bird Subtotal & 2 & 13.3 & 1,245 & 7.0 \\
\hline Unidentified Snake & 2 & 13.3 & 380 & 2.1 \\
\hline Alligator Lizard & 1 & 6.7 & 21 & 0.1 \\
\hline Reptile Subtotal & 3 & 20.0 & 401 & 2.3 \\
\hline Total & 15 & 100.0 & 17,763 & 100.0 \\
\hline
\end{tabular}

Table 16. Number and estimated biomass (grams) of prey identified from remains collected in the Tunnel Creek golden eagle nest on 11 August 1994.

\begin{tabular}{lcccc}
\hline \hline Species & No. & $\%$ & Biomass & $\%$ \\
\hline California Ground Squirrel & 3 & 100.0 & 2,175 & 100.0 \\
\hline Total & 3 & 100.0 & 2,175 & 100.0 \\
\hline \hline
\end{tabular}


Table 17. Number and estimated biomass (grams) of prey identified from remains collected in the South Del Valle Dam golden eagle nest on 1 June 1994.

\begin{tabular}{lcccc}
\hline \hline Species & No. & $\%$ & Biomass & $\%$ \\
\hline California Ground Squirrel & 4 & 40.0 & 2,900 & 22.7 \\
Black-tailed Deer (fawn) & 1 & 10.0 & 3,780 & 29.6 \\
Black-tailed Deer & 1 & 10.0 & 4,130 & 32.4 \\
Rabbit (Leporidae) & 1 & 10.0 & 1,382 & 10.8 \\
\hline Mammal Subtotal & 7 & 70.0 & 12,192 & 95.6 \\
\hline Yellow-billed Magpie & 1 & 10.0 & 178 & 1.4 \\
Unidentified Snake & 2 & 20.0 & 380 & 3.0 \\
\hline Total & 10 & 100.0 & 12,750 & 100.0 \\
\hline \hline
\end{tabular}

Table 18. Number and estimated biomass (grams) of prey identified from remains collected in the Vasco Road golden eagle nest on 27 May 1994.

\begin{tabular}{lcccc}
\hline Species & No. & $\%$ & Biomass & $\%$ \\
\hline California Ground Squirrel & 52 & 94.5 & 37,700 & 99.3 \\
& & & 116 & 0.3 \\
American Kestrel & 1 & 1.8 & 82 & 0.2 \\
Starling & 1 & 1.8 & 63 & 0.2 \\
Brewer's Blackbird & 1 & 1.8 & 261 & 0.7 \\
\hline \multirow{2}{*}{ Bird Subtotal } & 3 & 5.5 & $\mathbf{3 7 , 9 6 1}$ & 100.0 \\
\hline
\end{tabular}


Table 19. Number and estimated biomass (grams) of prey identified from remains collected in the Wally's golden eagle nest on 23 May 1994.

\begin{tabular}{lrrrc}
\hline \hline Species & No. & $\%$ & Biomass & $\%$ \\
\hline California Ground Squirrel & 8 & 66.7 & 5,800 & 60.7 \\
$\begin{array}{l}\text { Black-tailed Jackrabbit } \\
\text { Rabbit (Leporidae) }\end{array}$ & 1 & 8.3 & 2,114 & 22.1 \\
& 1 & 8.3 & 1,382 & 14.5 \\
\hline Mammal Subtotal & 10 & 83.3 & 9,296 & 97.4 \\
\hline Brewer's Blackbird & 1 & 8.3 & 63 & 0.6 \\
Unidentified Snake & 1 & 8.3 & 190 & 2.0 \\
\hline Total & 12 & 100.0 & 9,549 & 100.0 \\
\hline \hline
\end{tabular}

Table 20. Number and estimated biomass (grams) of prey identified from remains collected in the Welch Creek golden eagle nest on 27 May and 3 June 1994.

\begin{tabular}{lcccc}
\hline \hline Species & No. & $\%$ & Biomass & $\%$ \\
\hline California Ground Squirrel & 2 & 33.3 & 1,450 & 19.8 \\
Rabbit (Leporidae) & 1 & 16.7 & 1,382 & 18.9 \\
Cow & 1 & 16.7 & 4,130 & 56.4 \\
\hline Mammal Subtotal & 4 & 66.7 & 6,962 & 95.1 \\
\hline Yellow-billed magpie & 2 & 33.3 & 356 & 4.9 \\
\hline Total & 6 & $\mathbf{1 0 0 . 0}$ & $\mathbf{7 , 3 1 8}$ & 100.0 \\
\hline \hline
\end{tabular}


APPENDIX E: RELOCATIONS OF FOUR RADIO-TAGGED BREEDERS AS DETERMINED BY AERIAL ROLLCALL SURVEYS IN THE 30-KM ZONE 


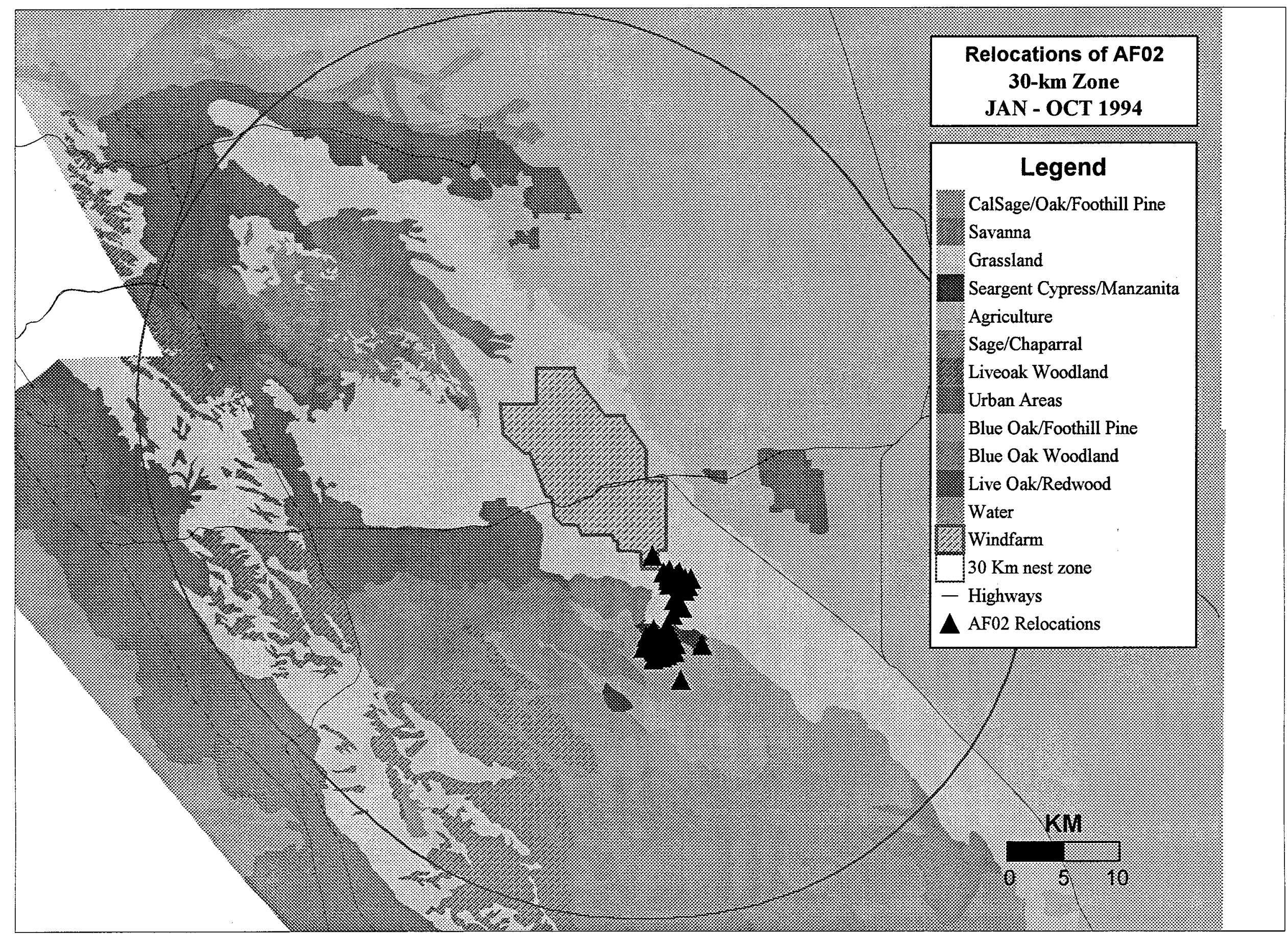




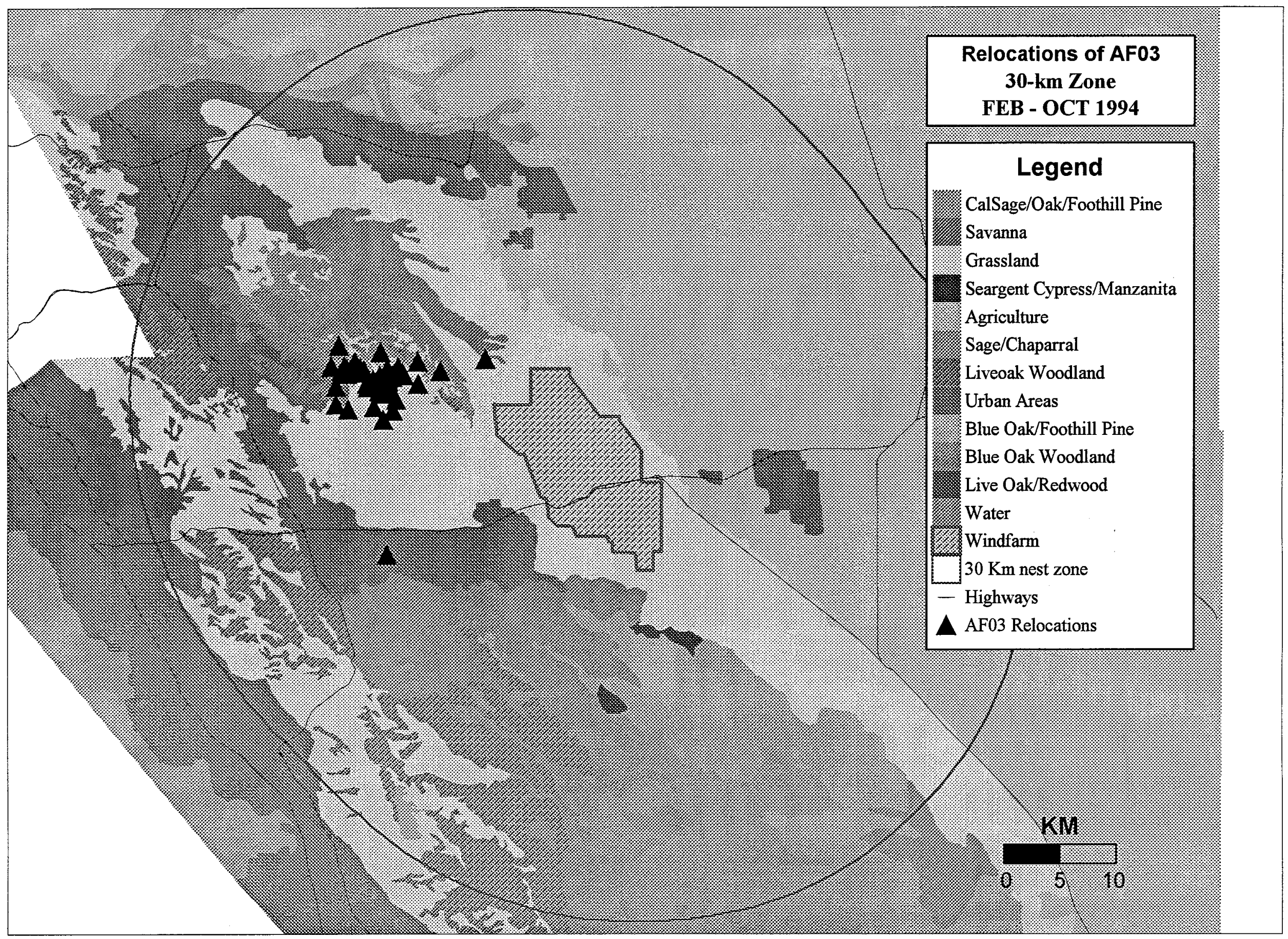




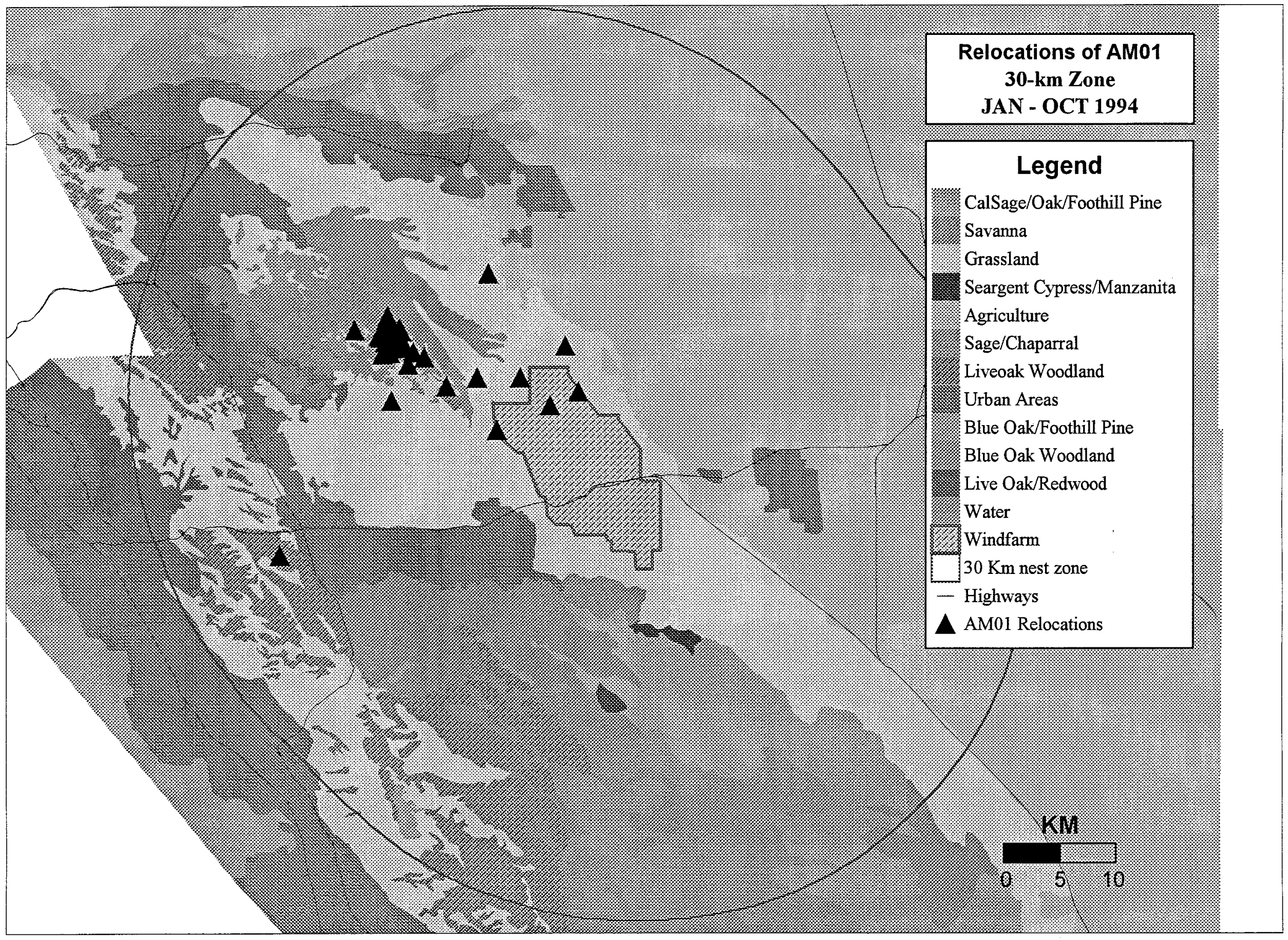




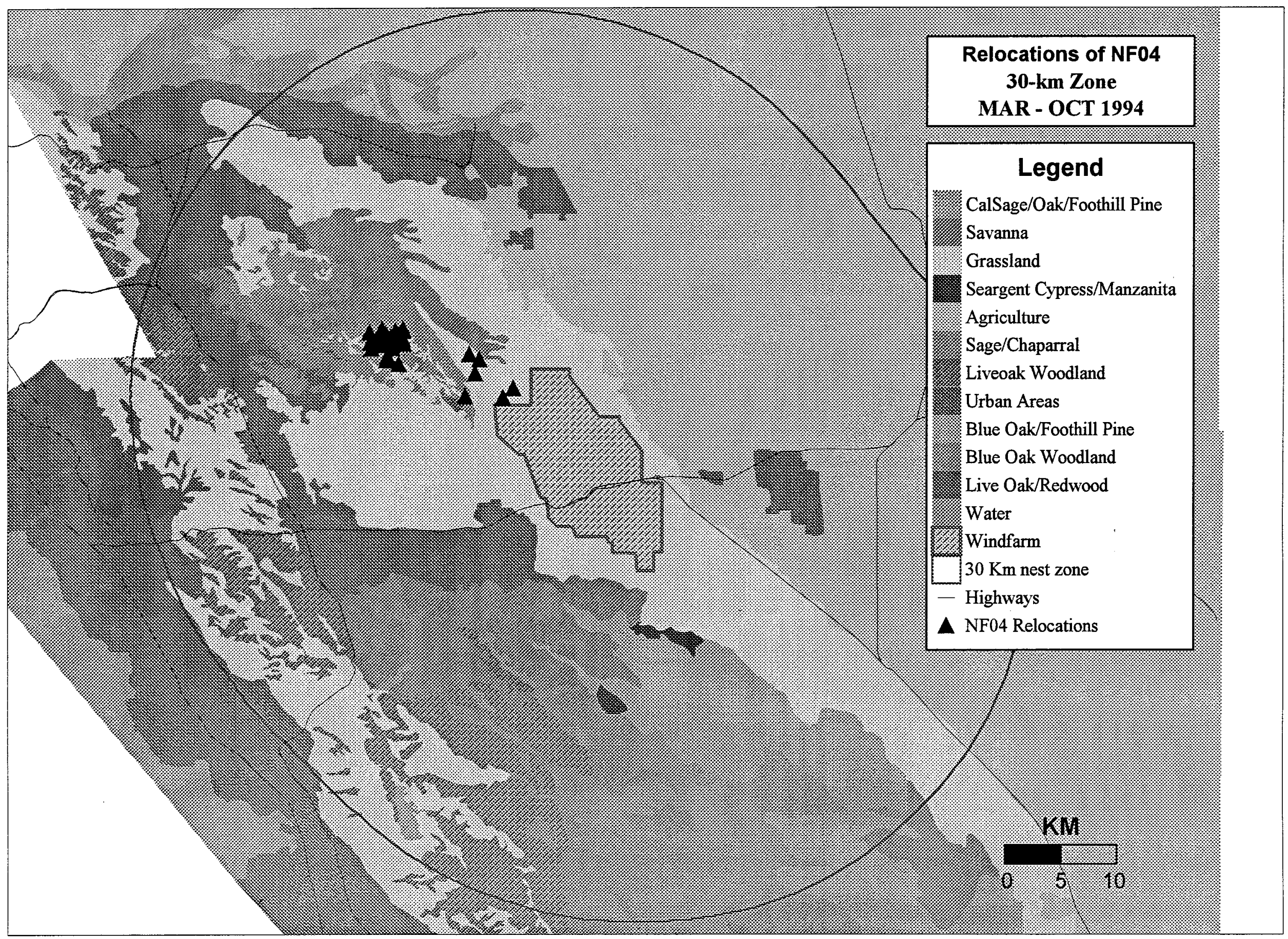




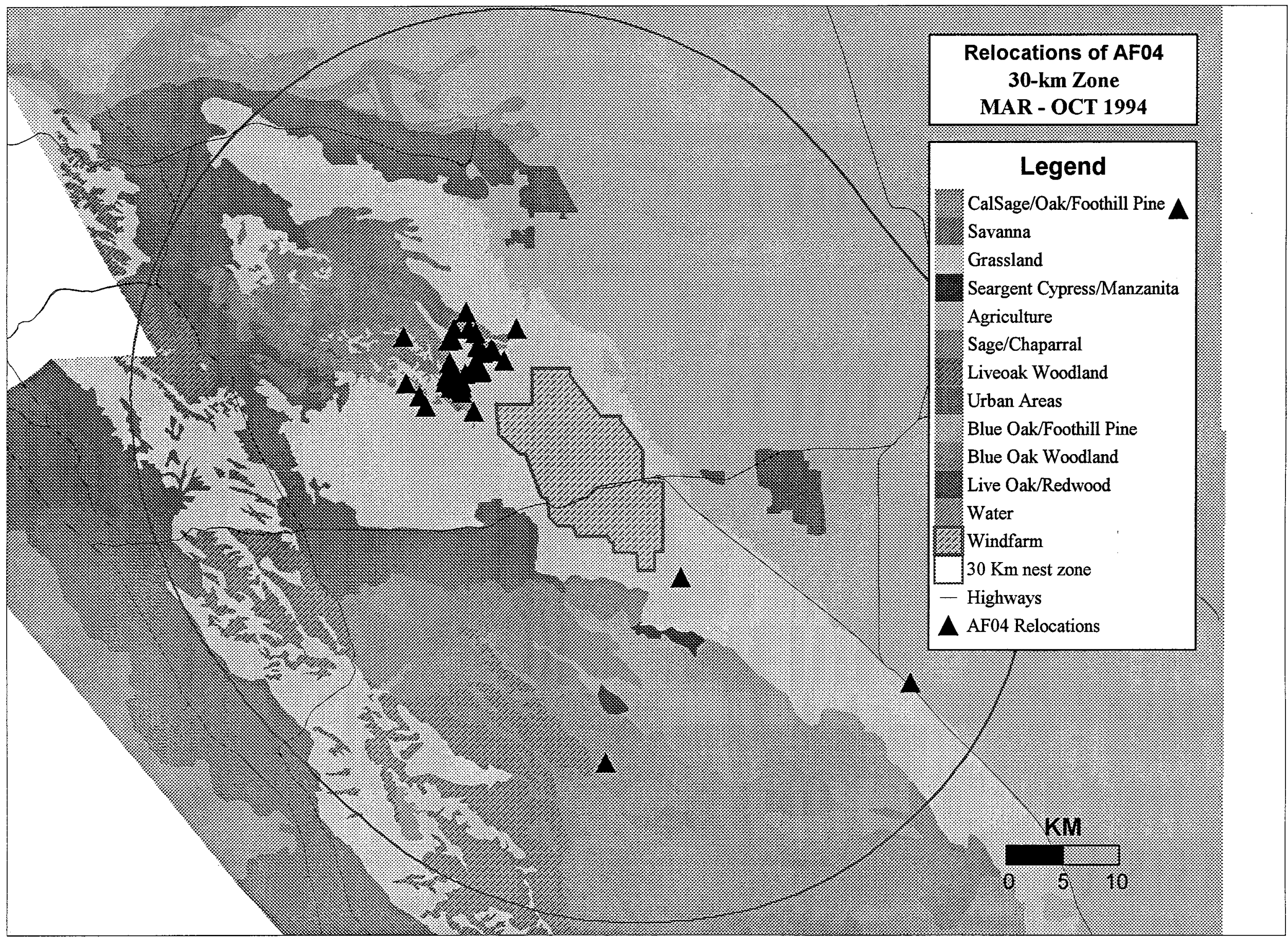




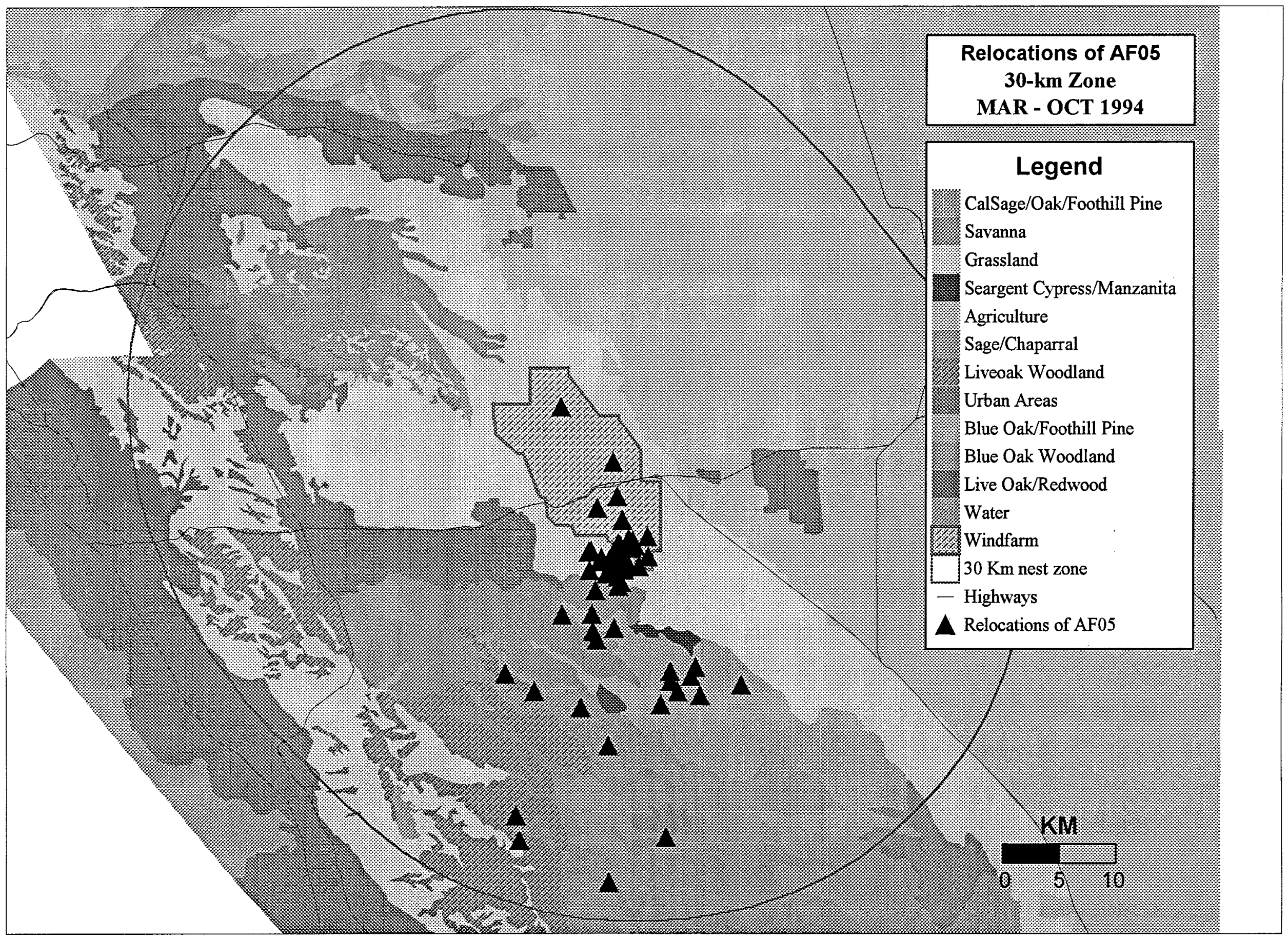




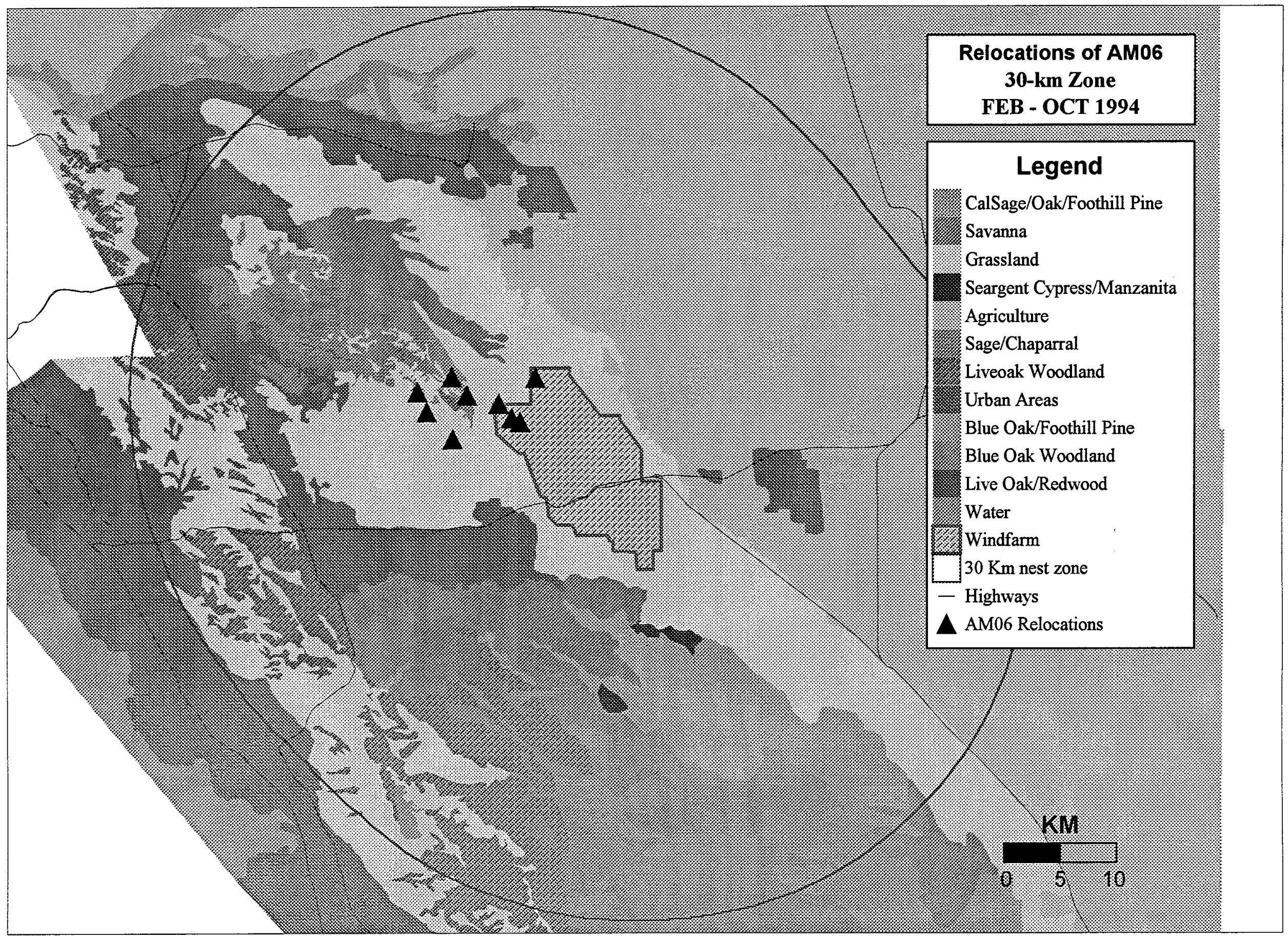




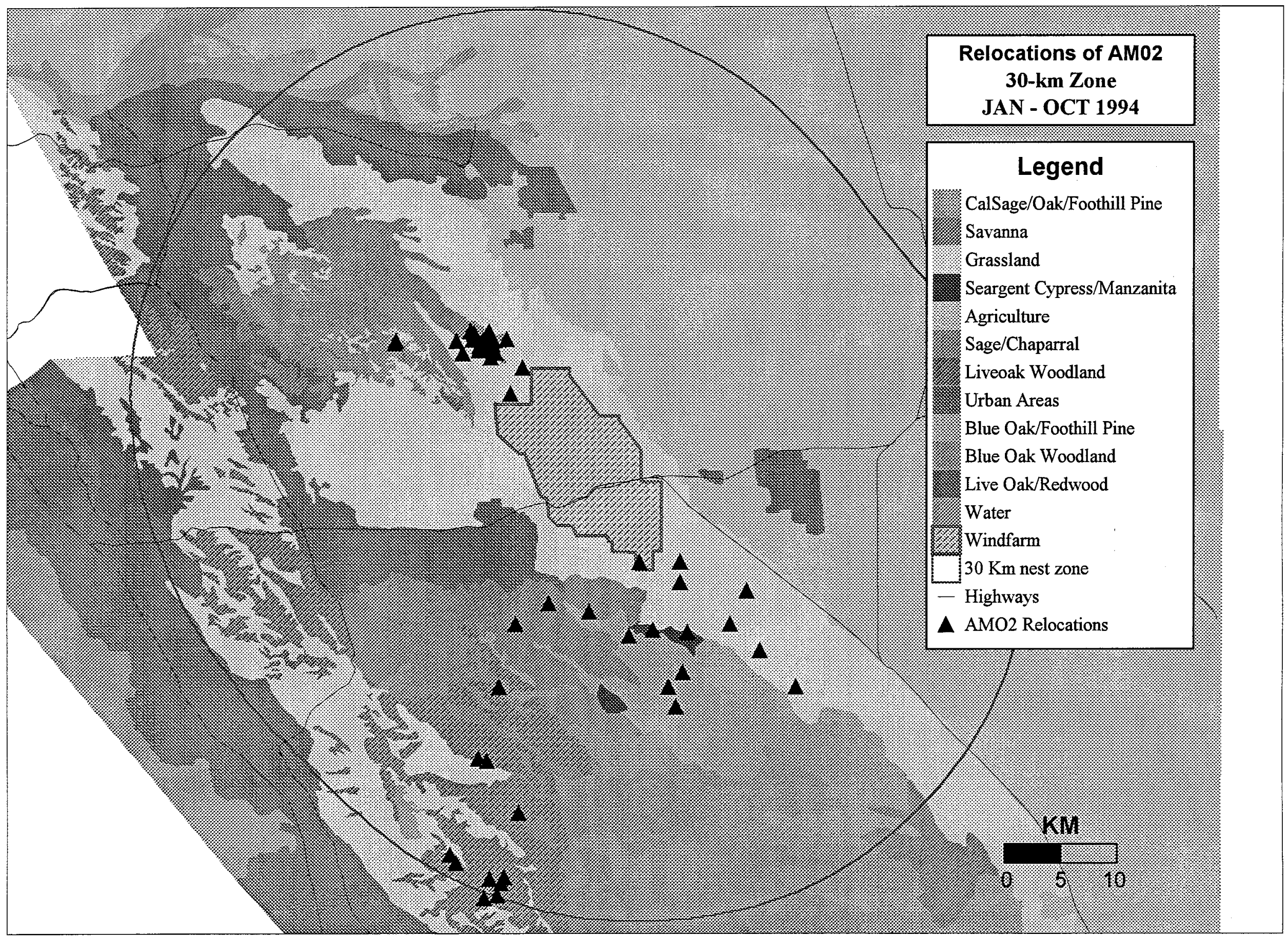




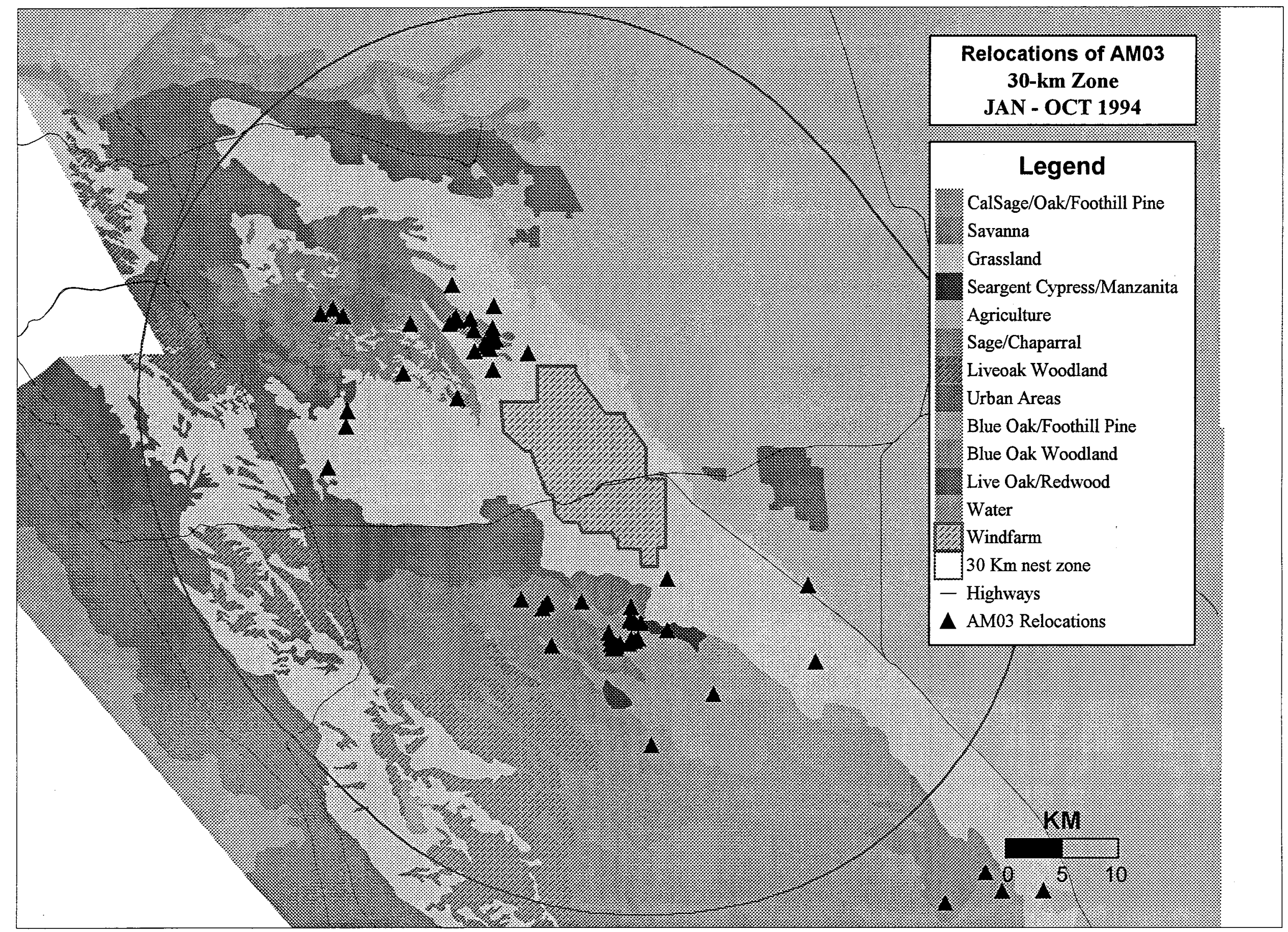




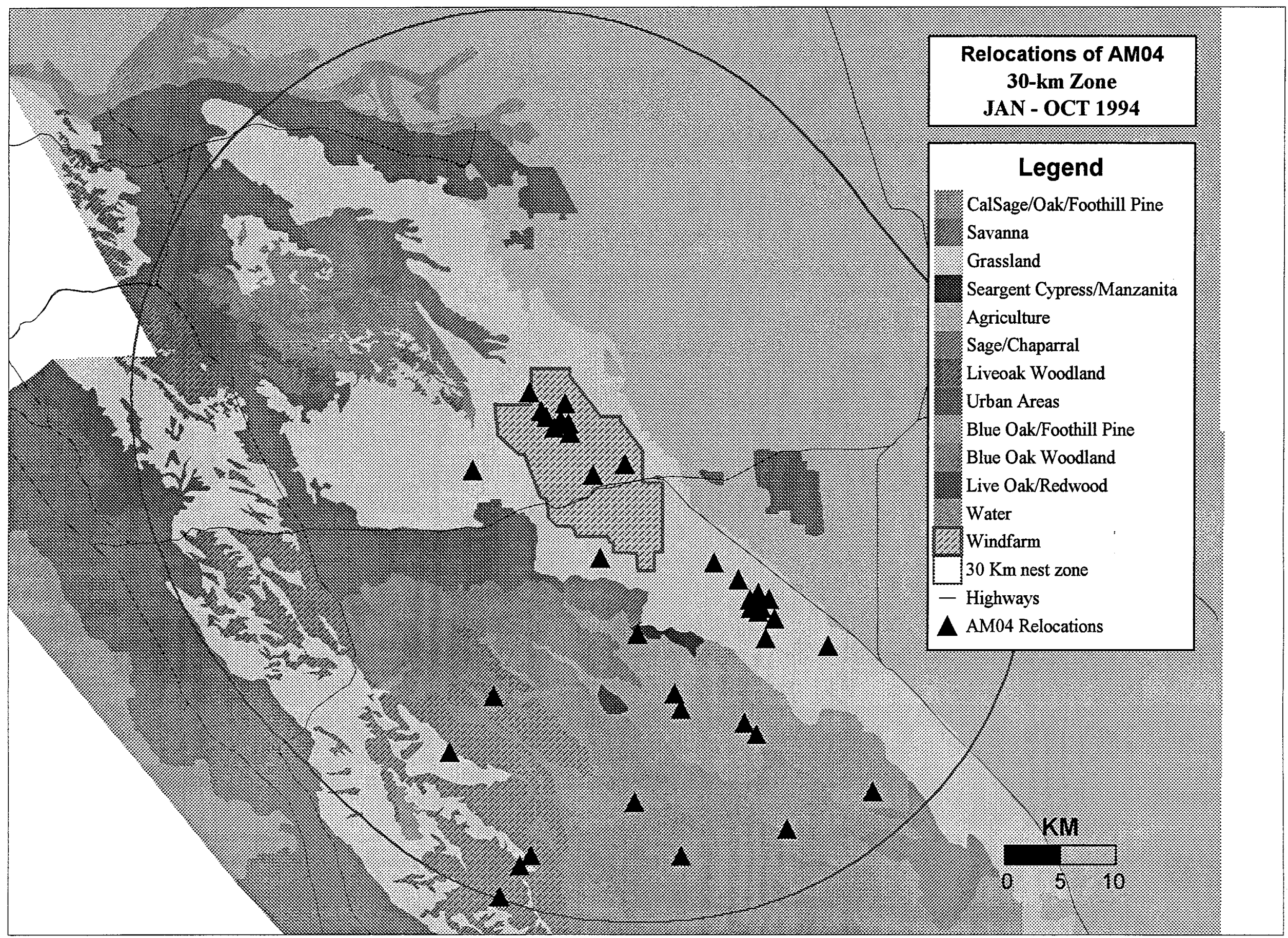




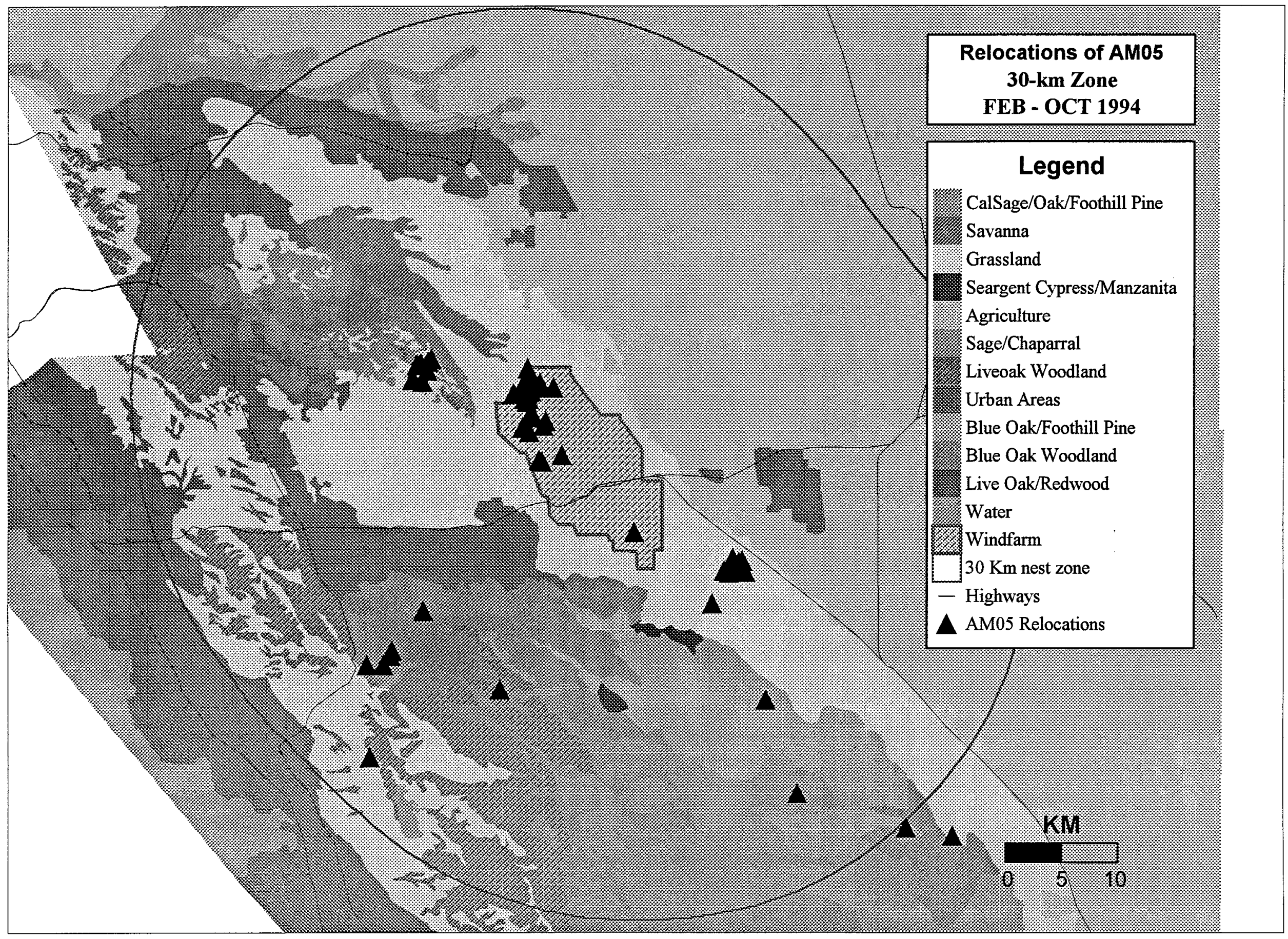


APPENDIX G: RELOCATIONS OF 20 RADIO-TAGGED SUBADULTS AS DETERMINED BY AERIAL ROLL-CALL SURVEYS IN THE 30-KM ZONE 


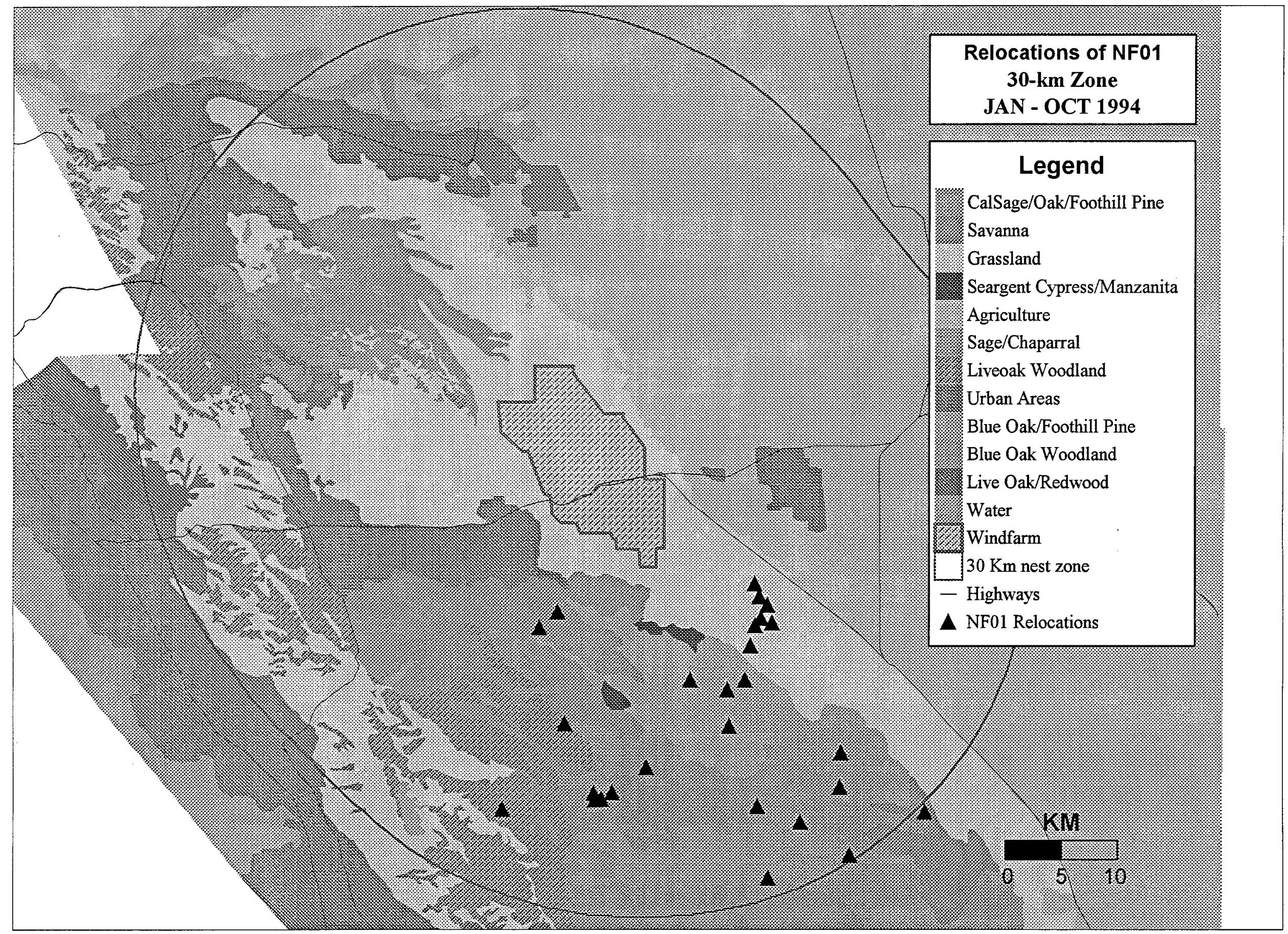




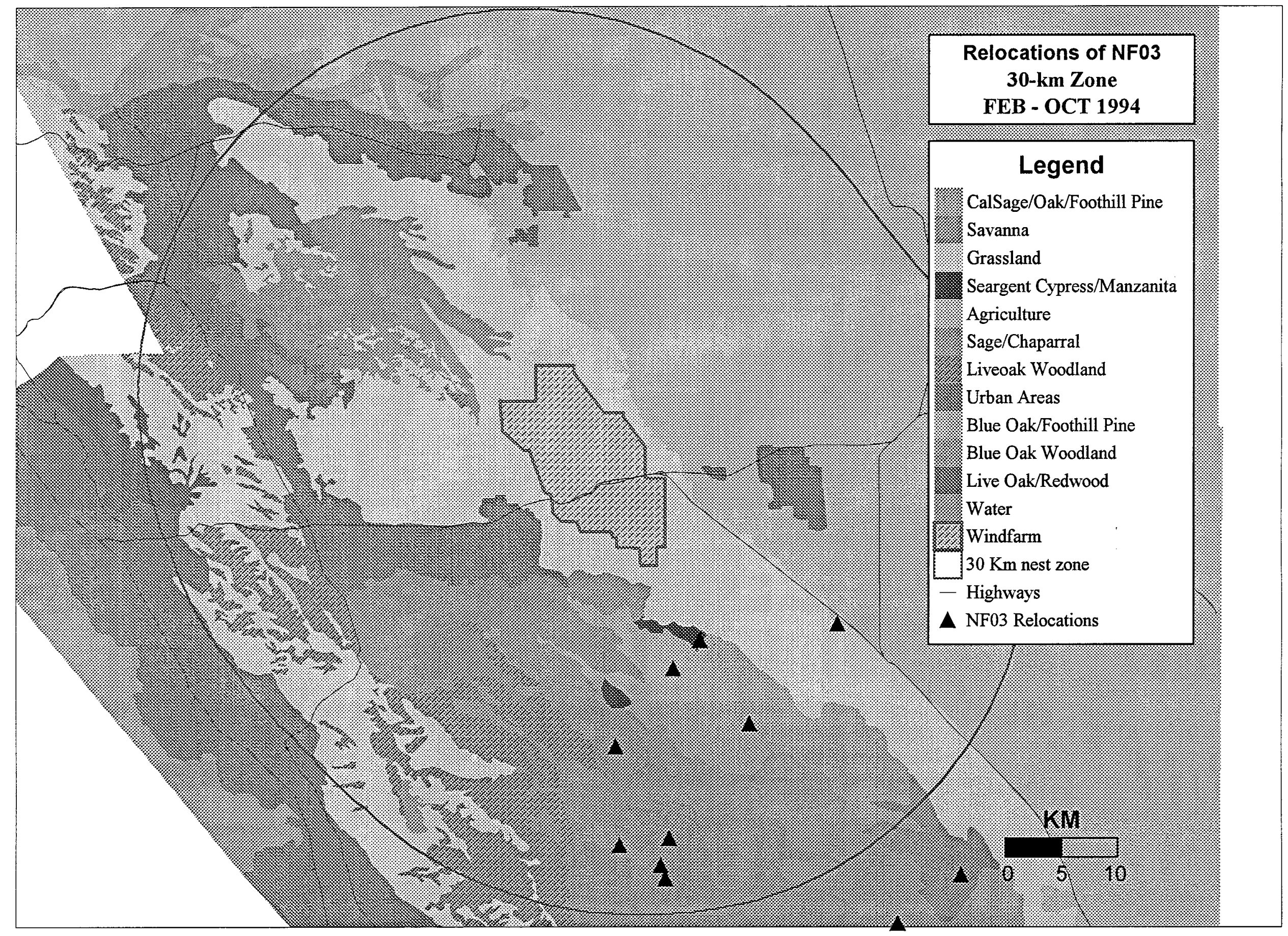




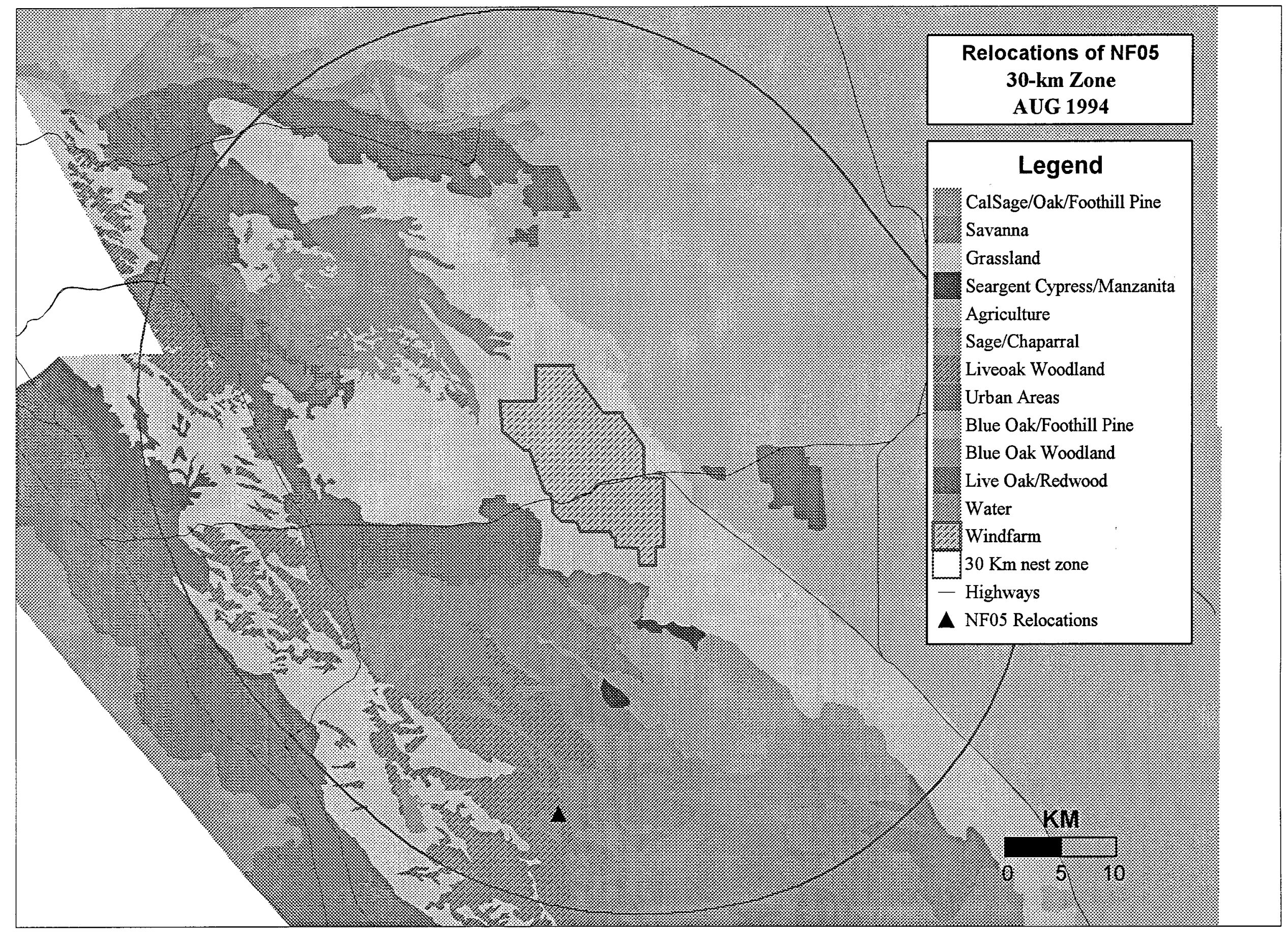




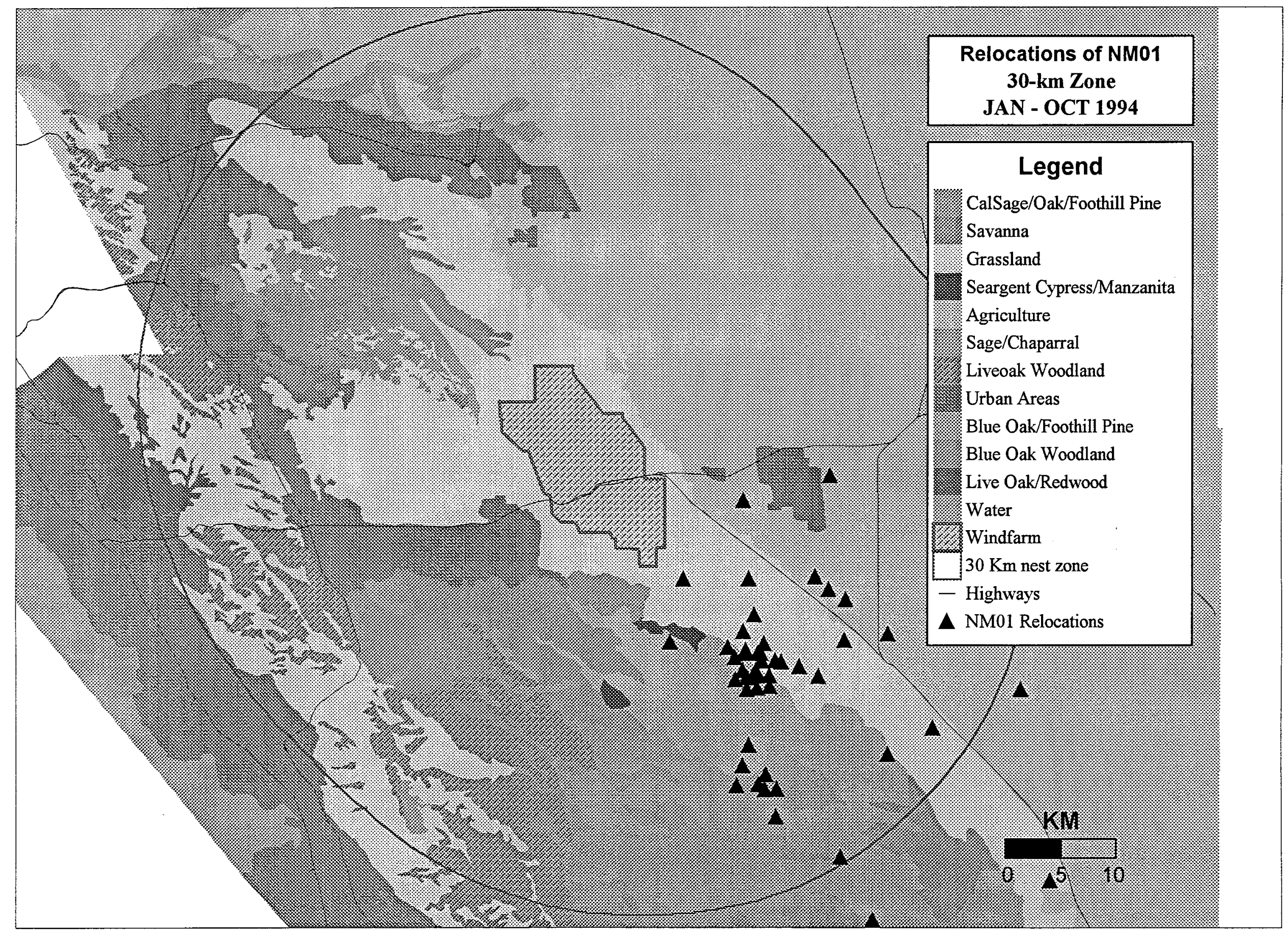




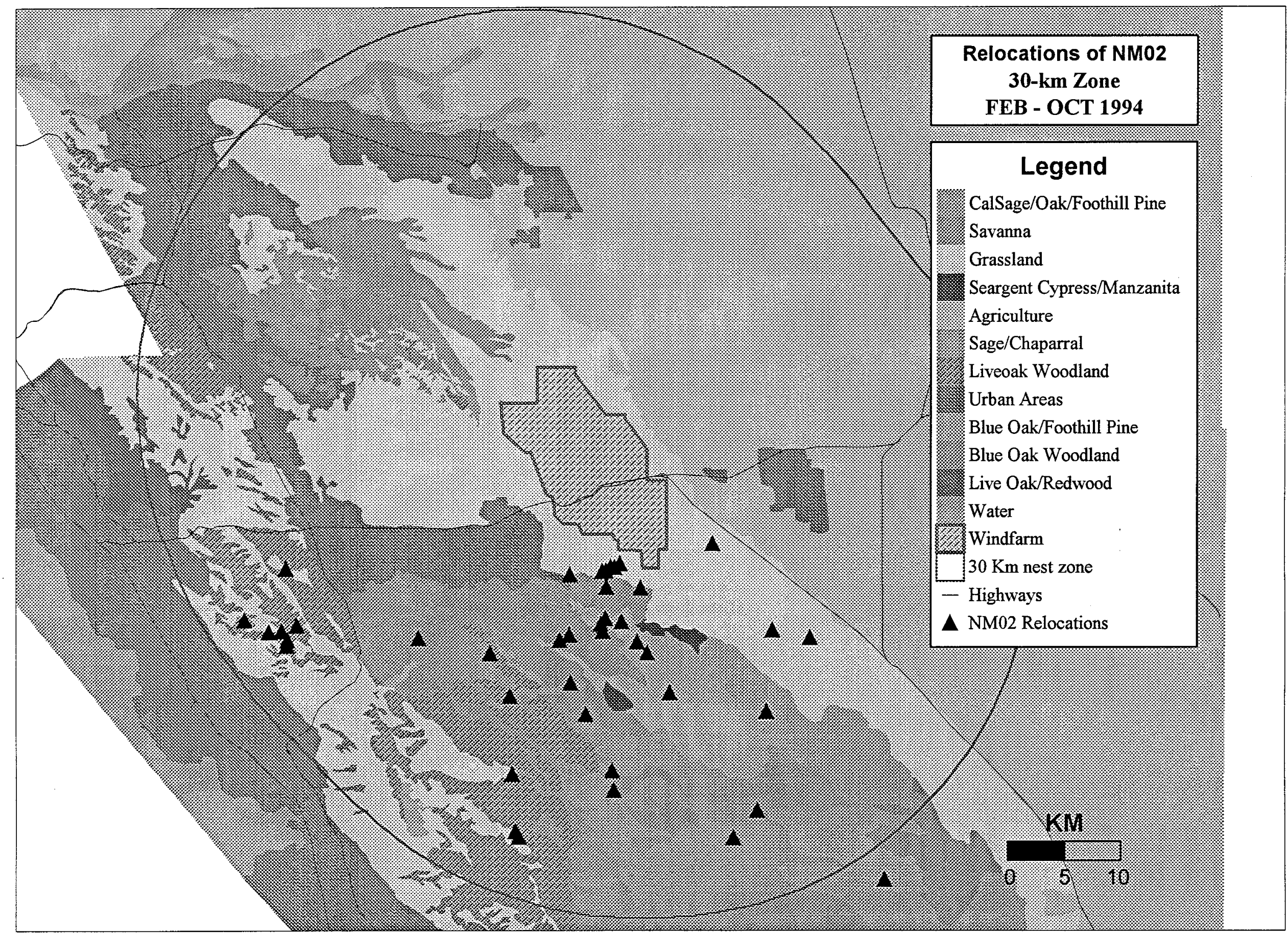




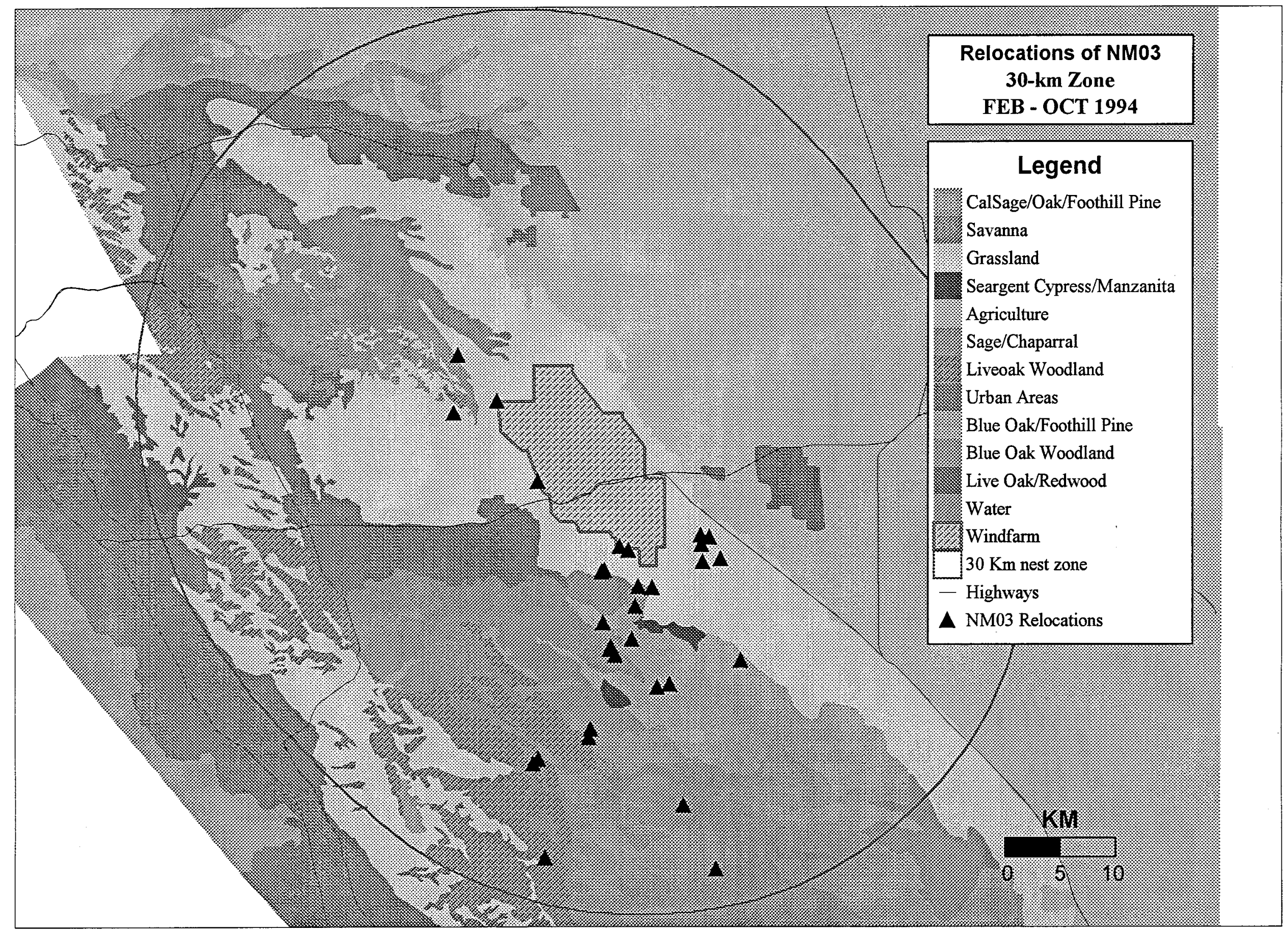




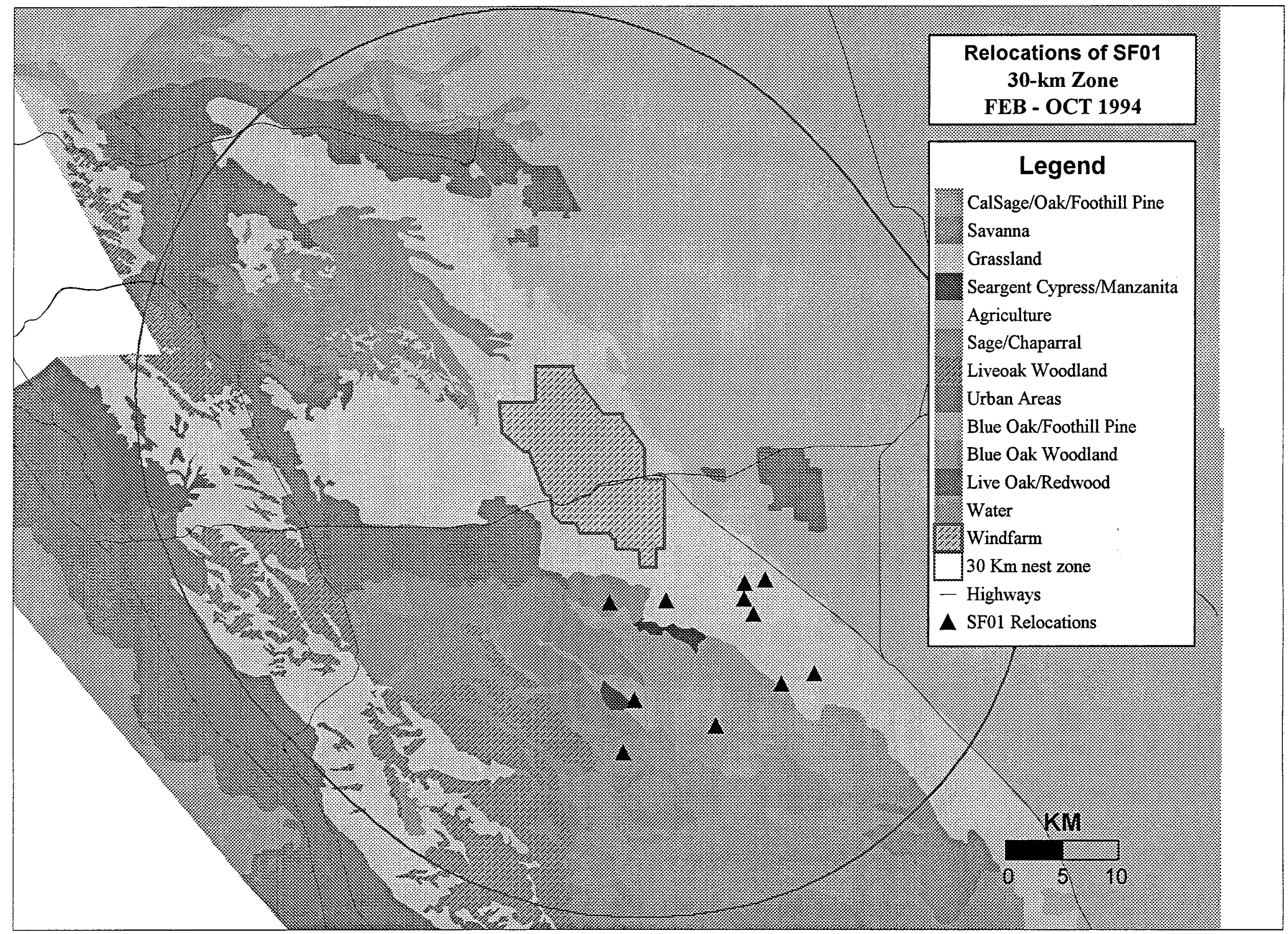




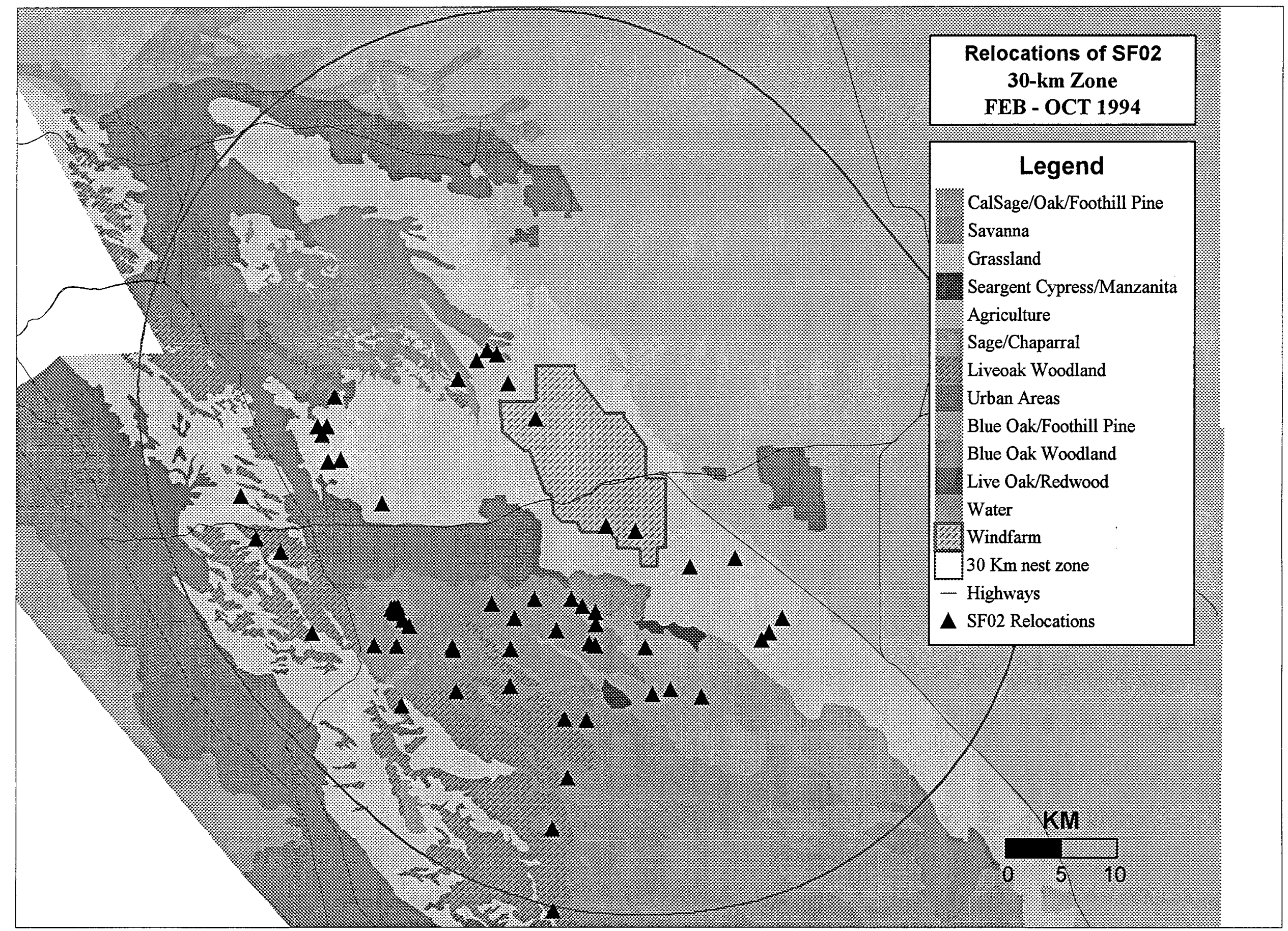




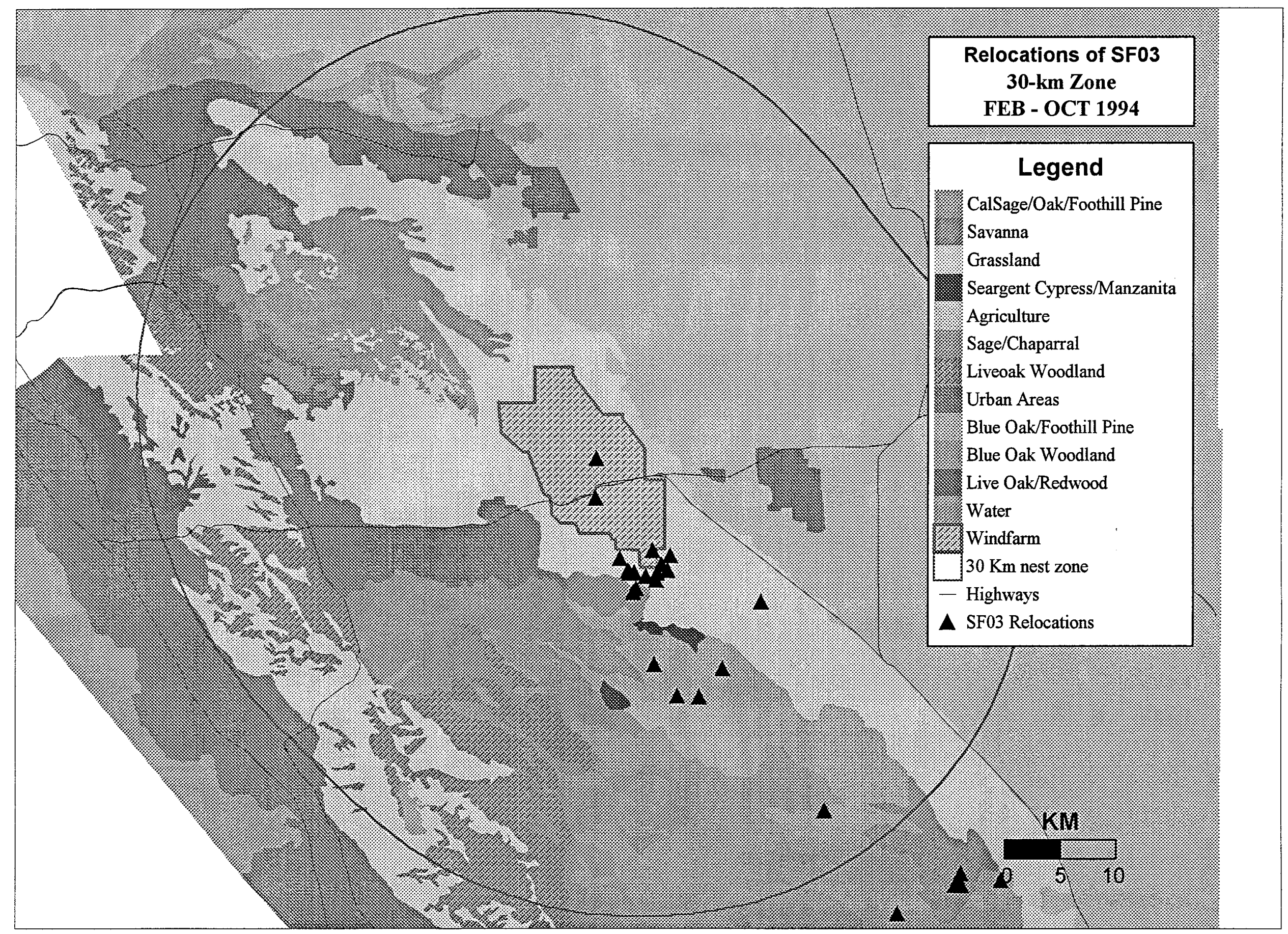




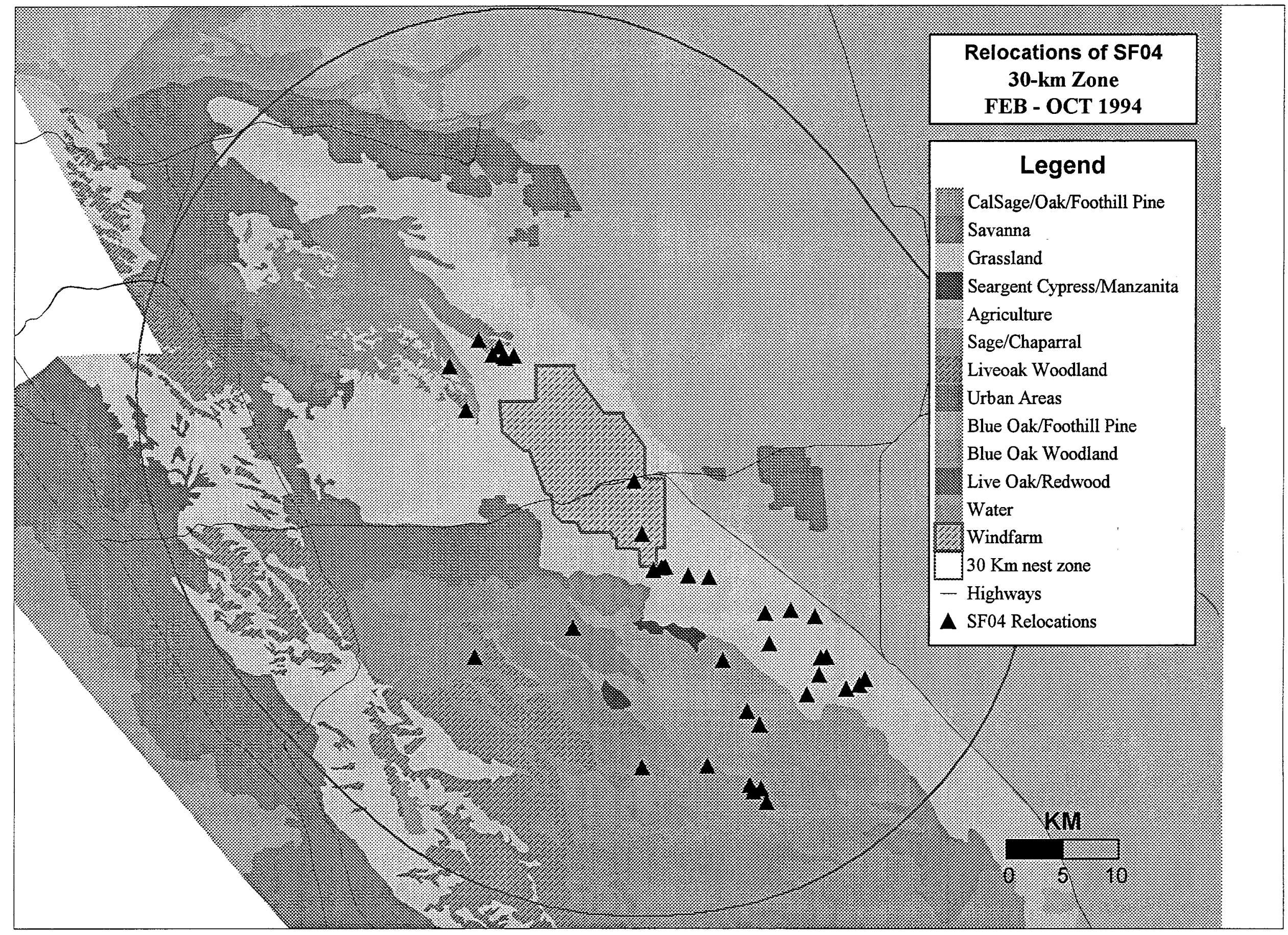




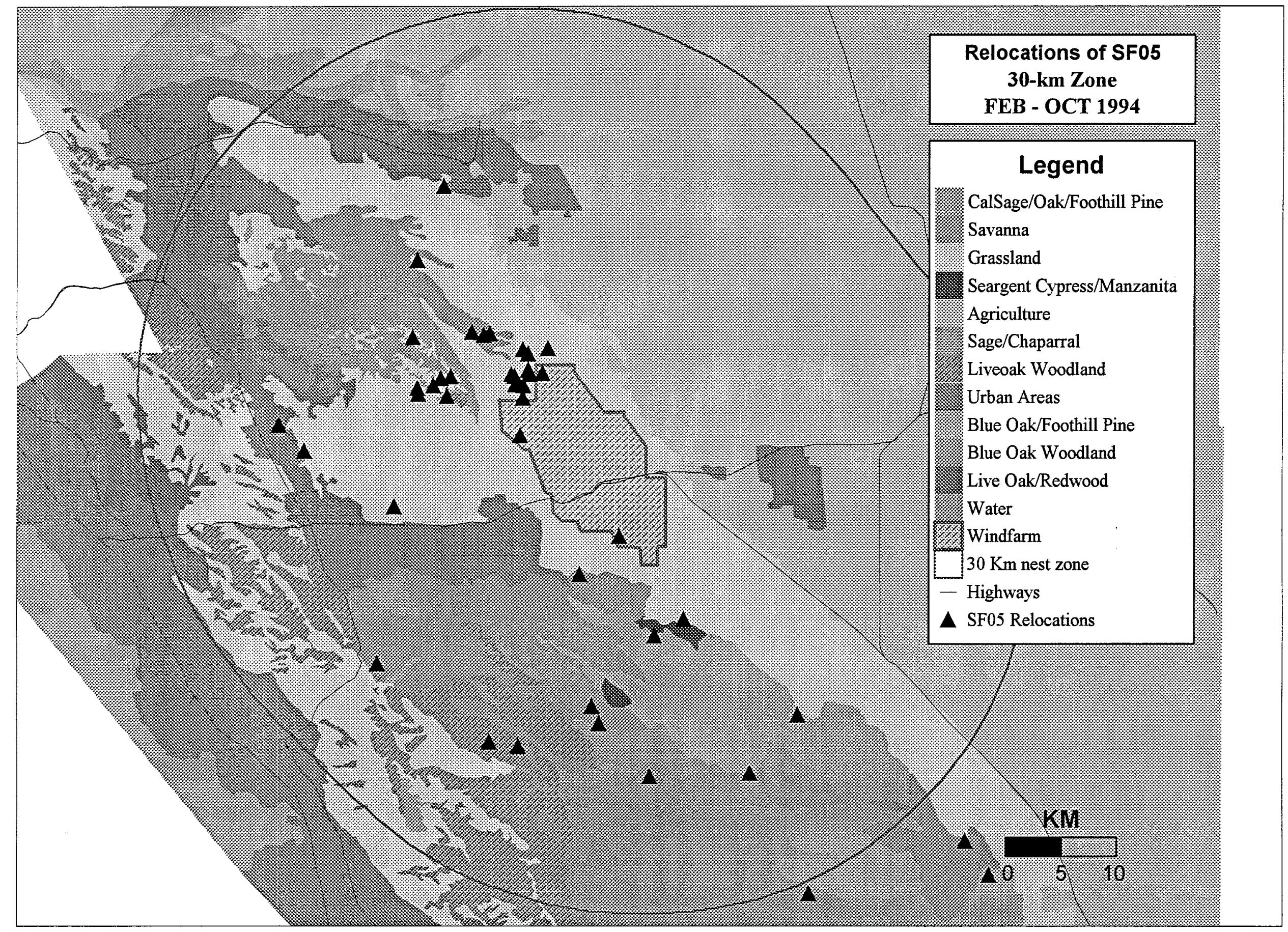




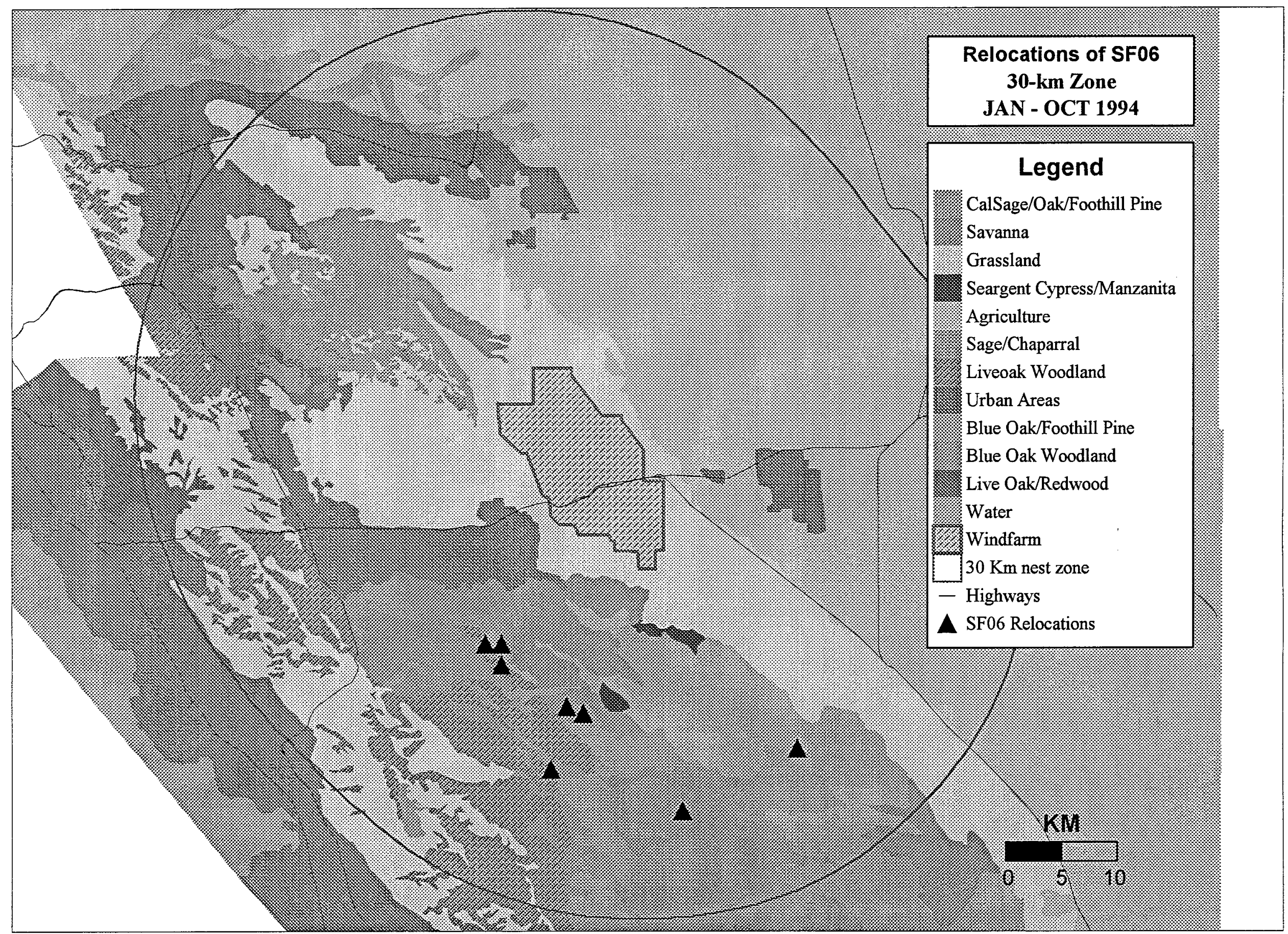




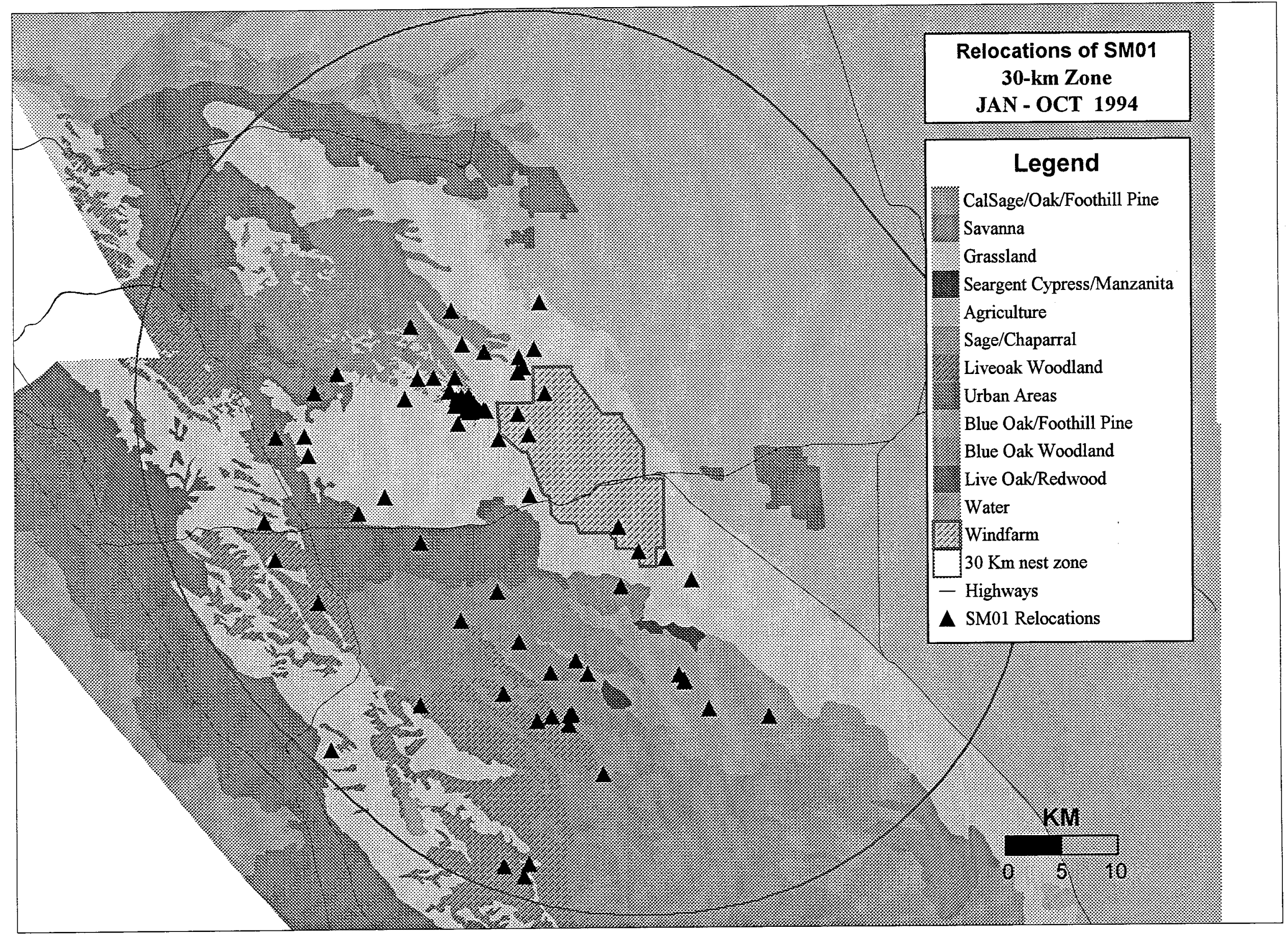




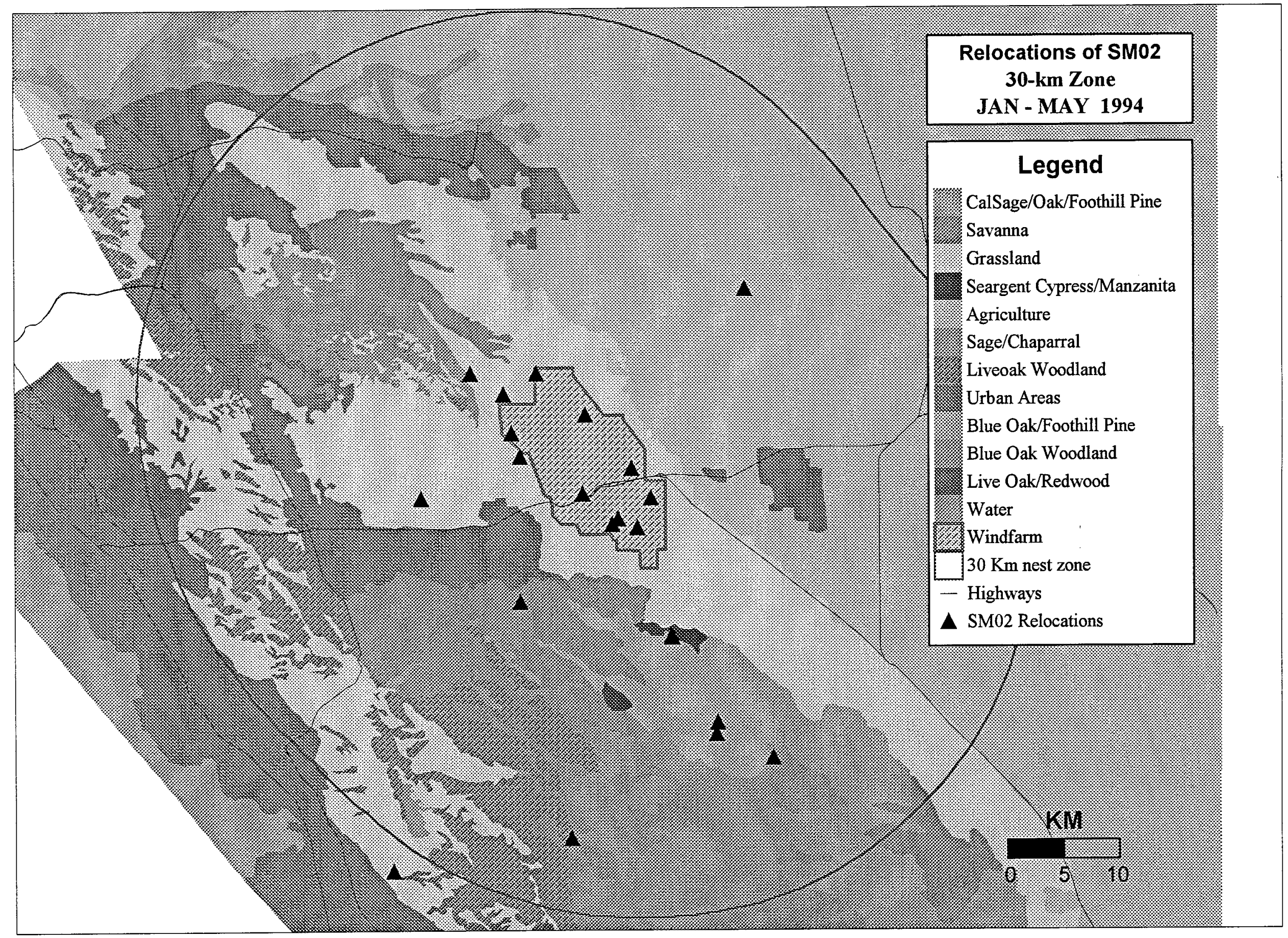




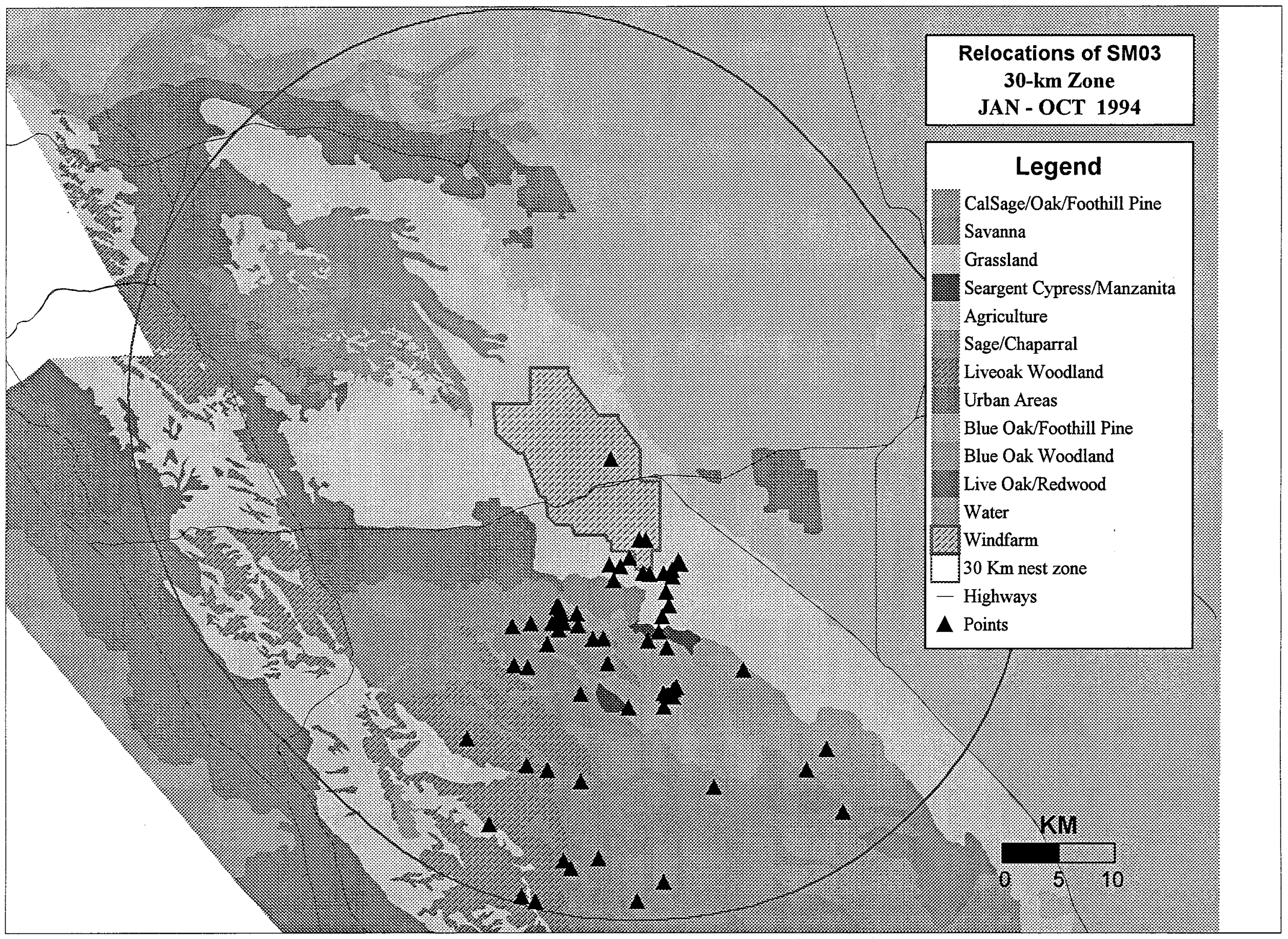




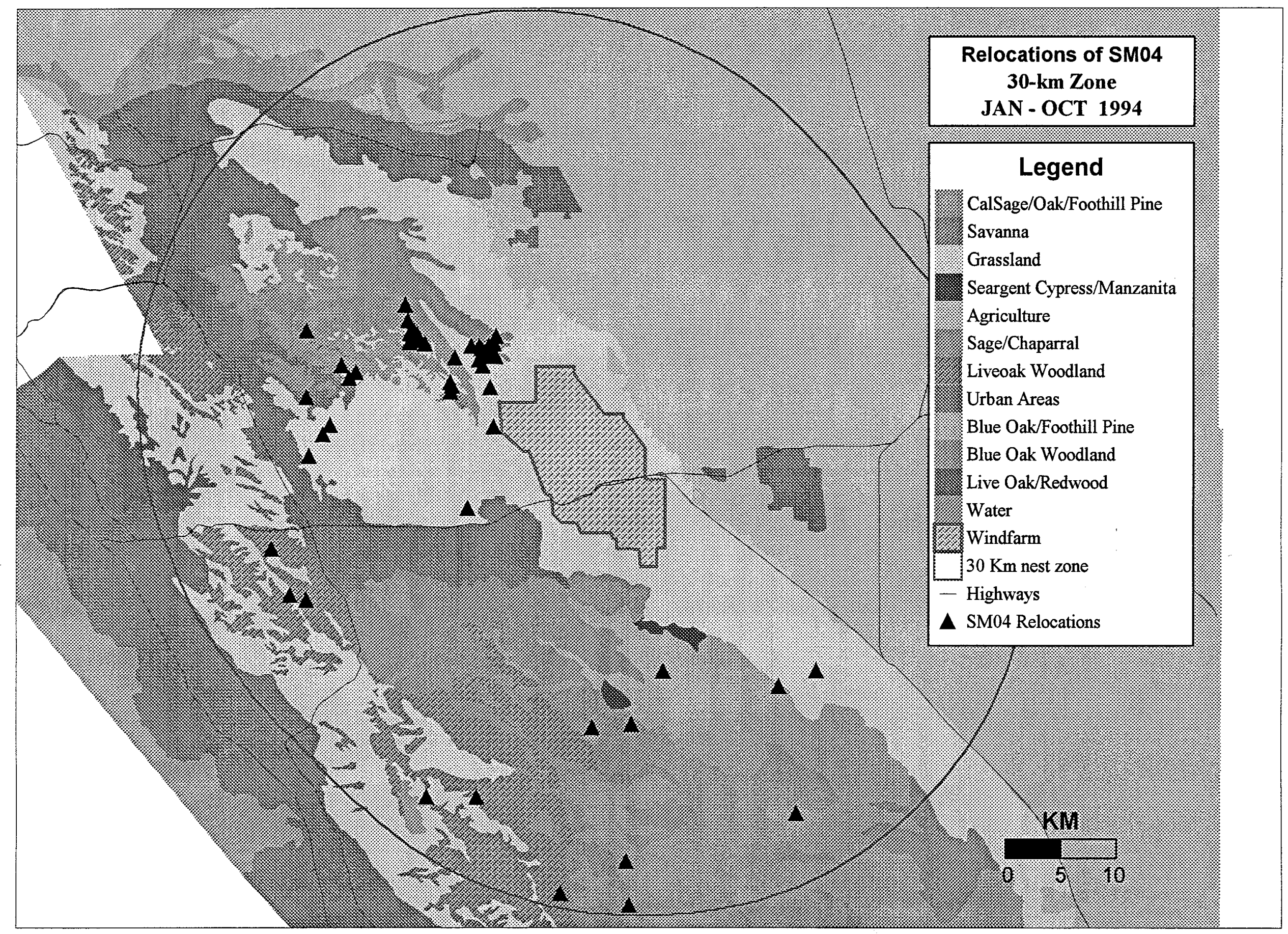




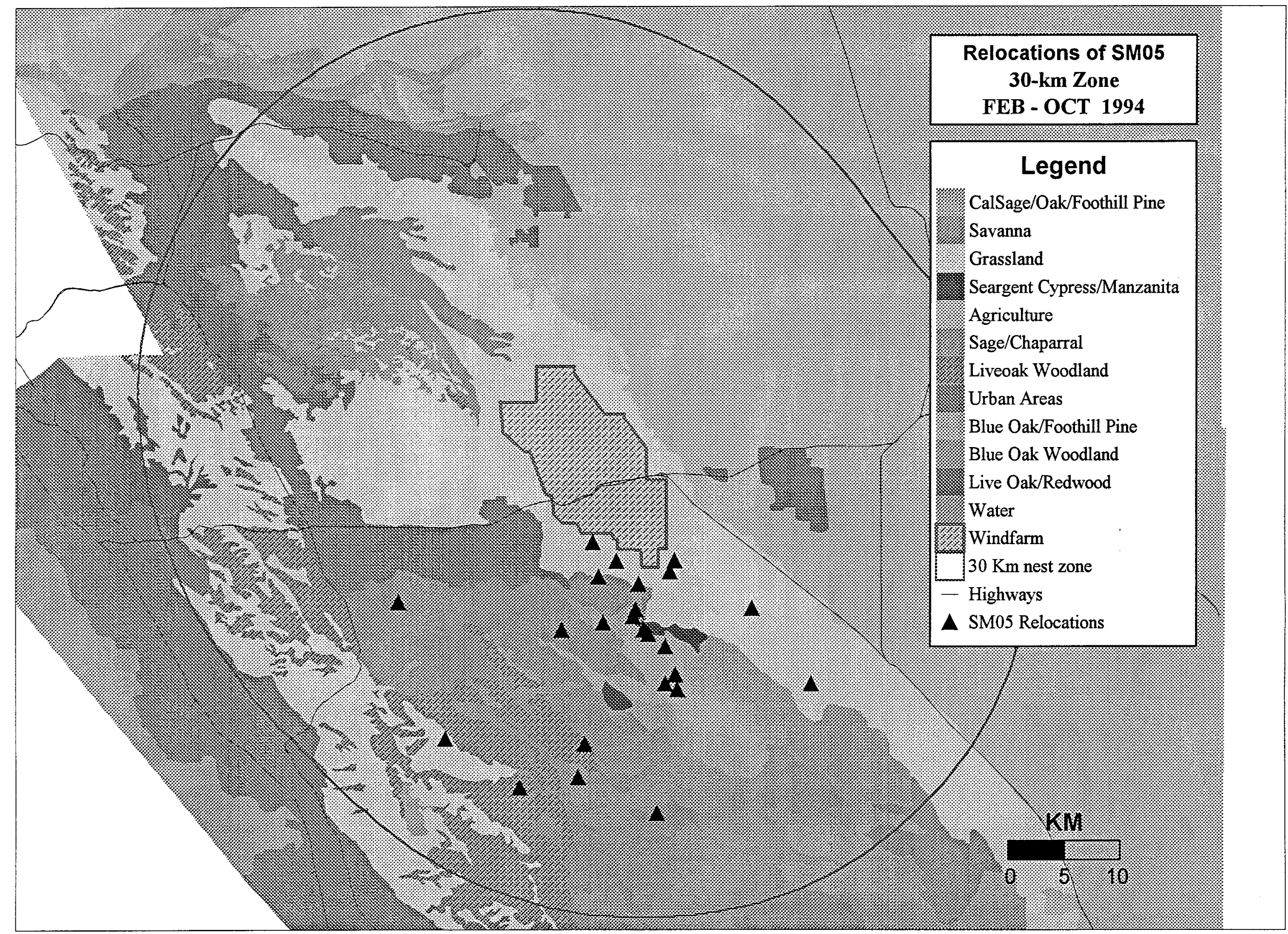




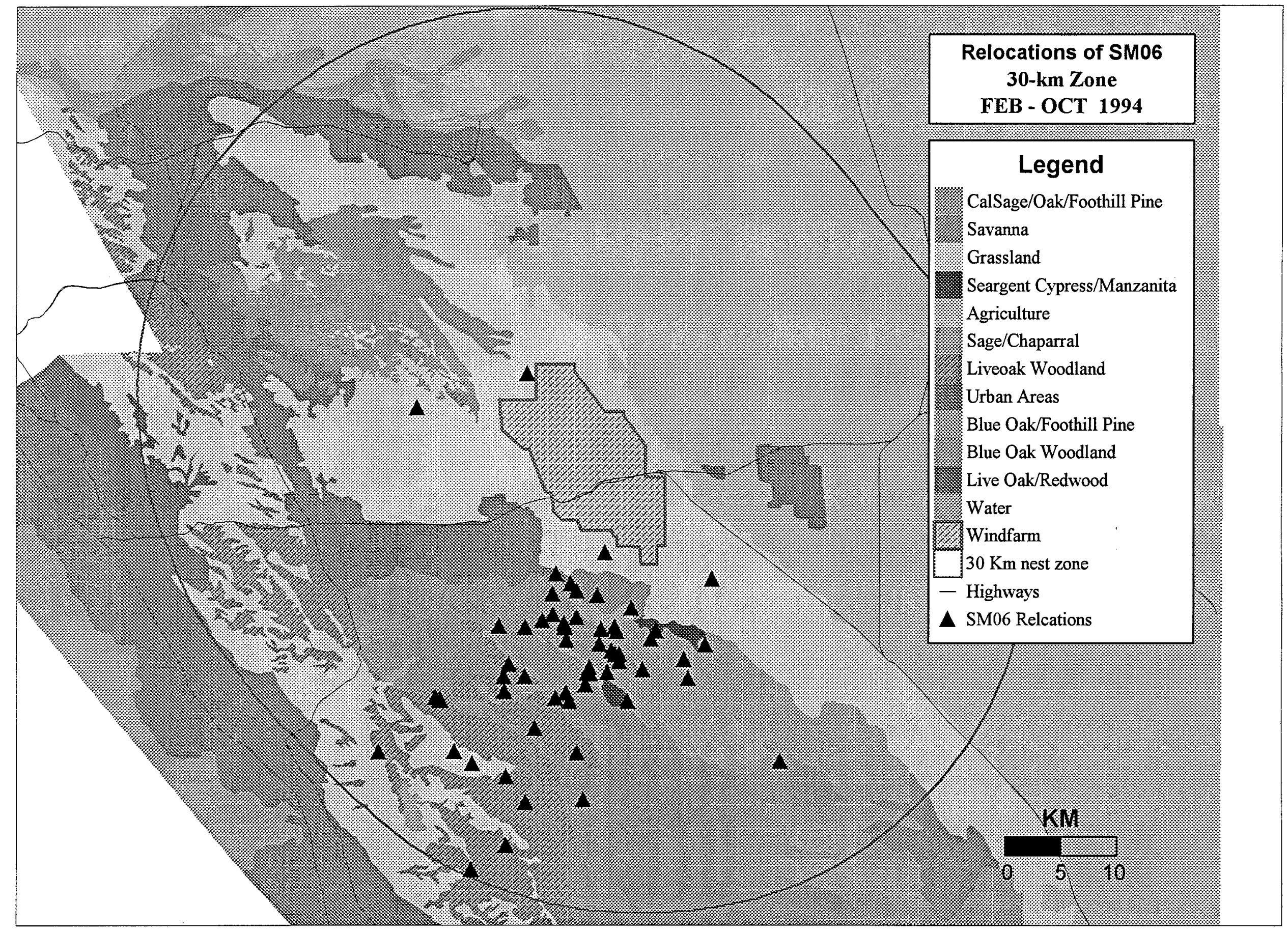




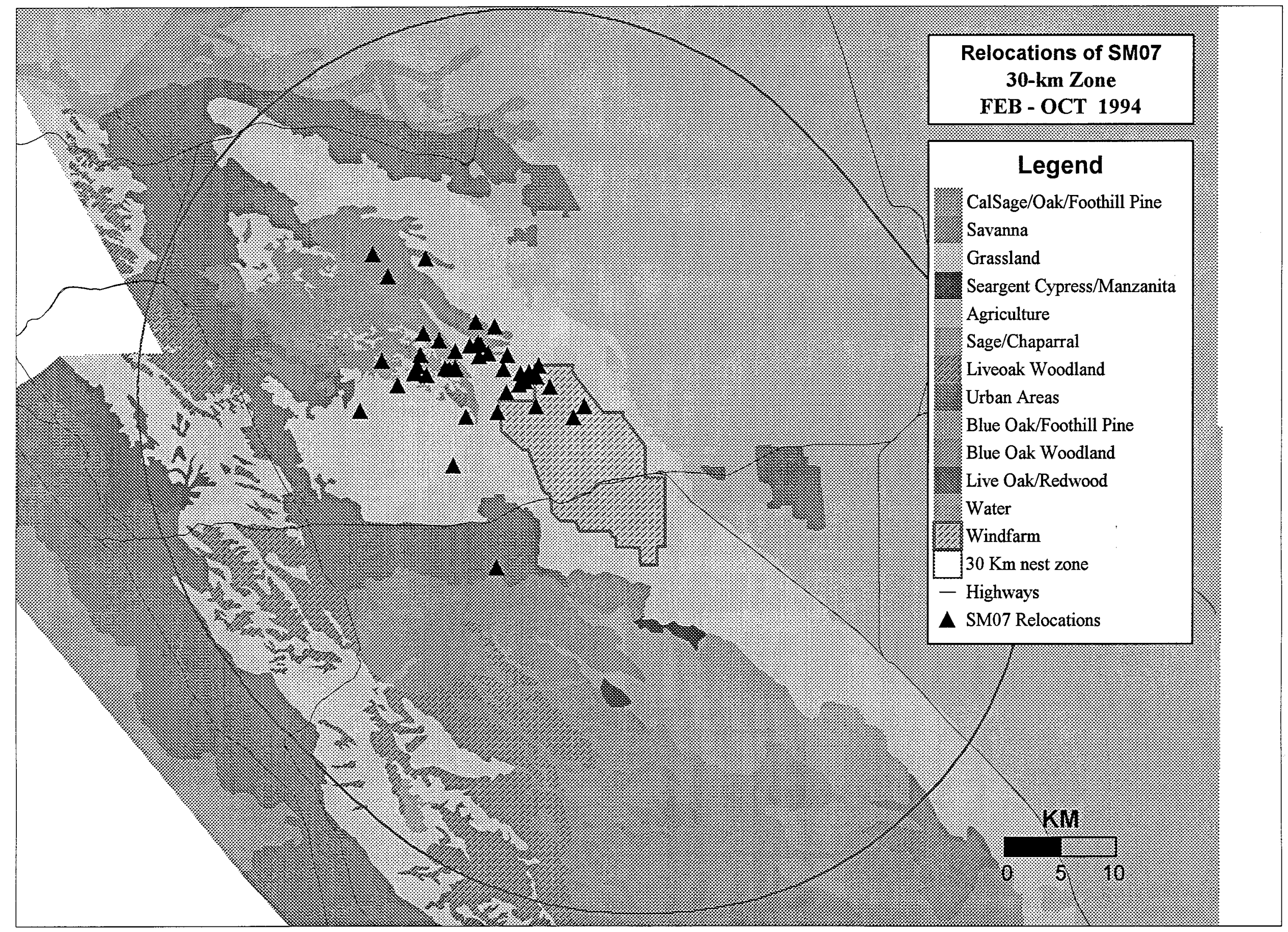




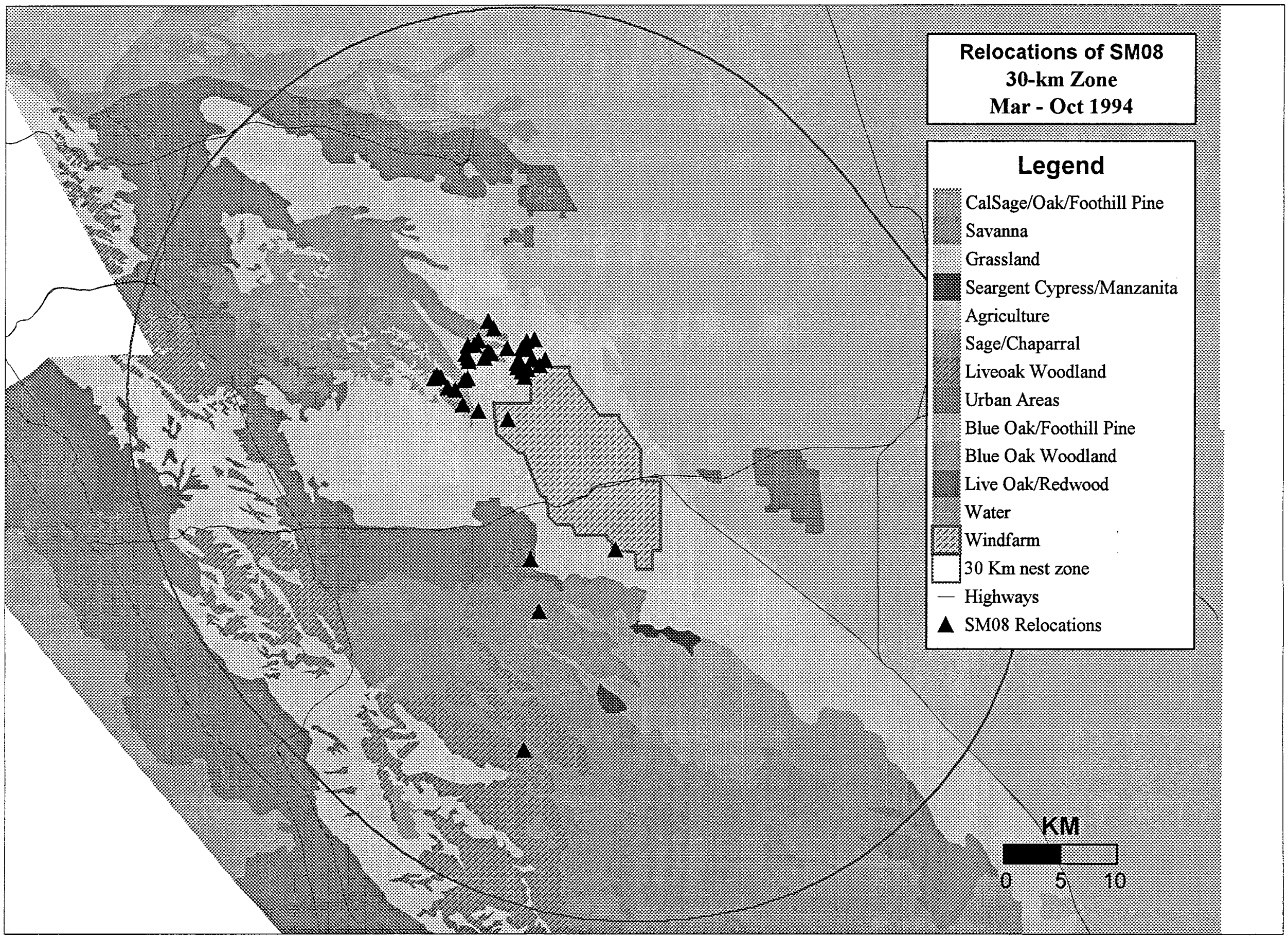


APPENDIX H: DISPERSAL OF 22 RADIO-TAGGED JUVENILE GOLDEN EAGLES IN THE DIABLO RANGE 


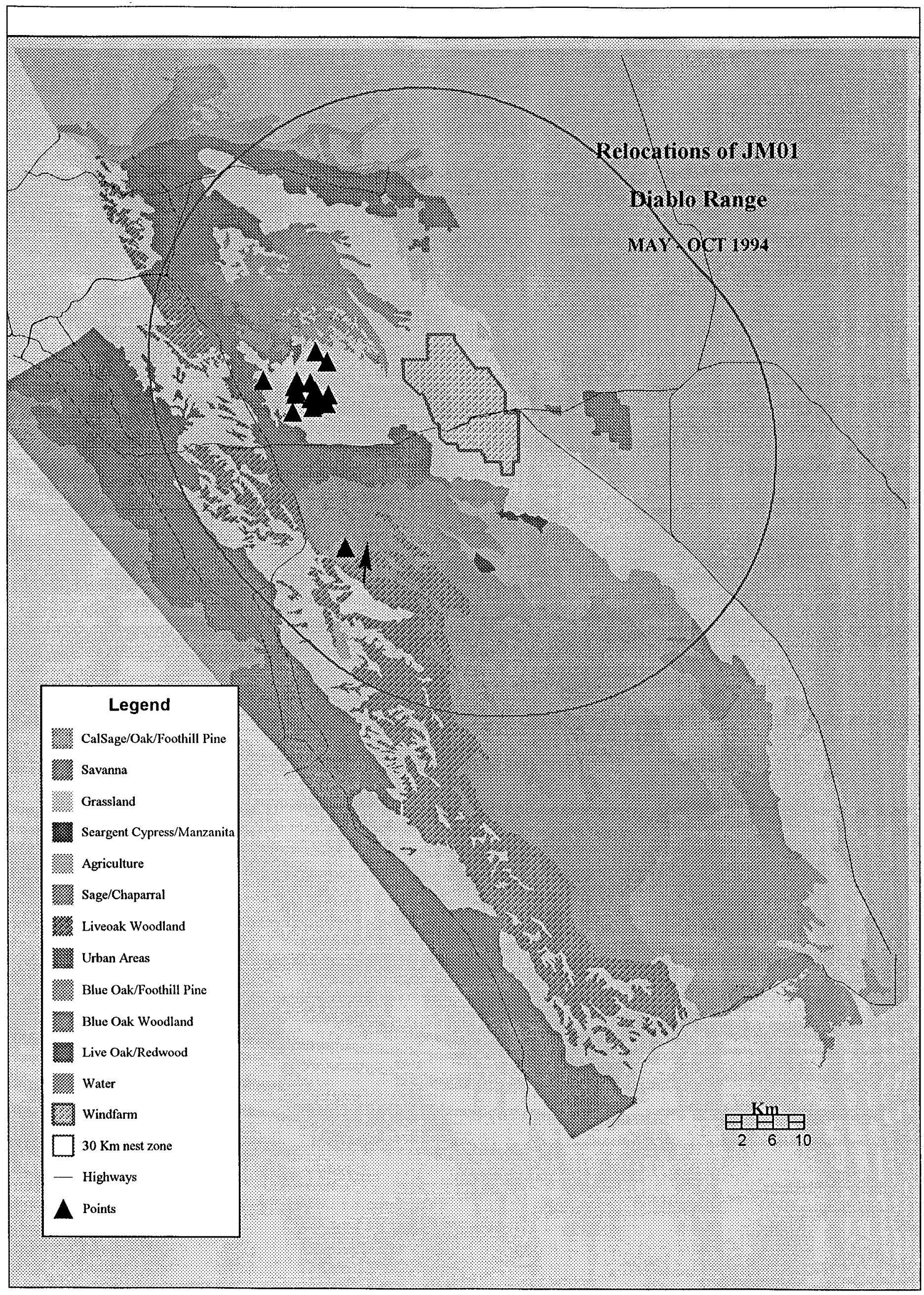




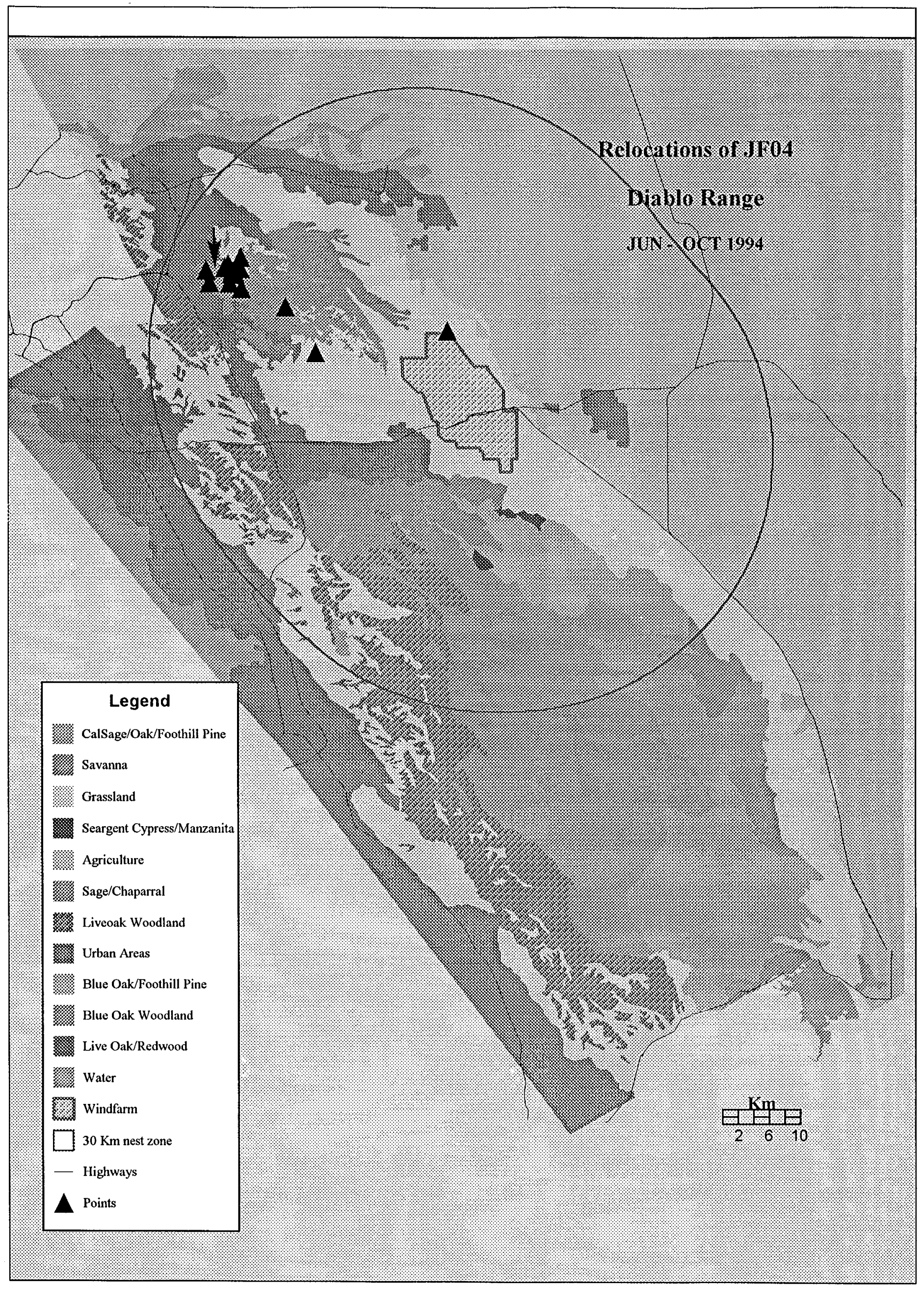




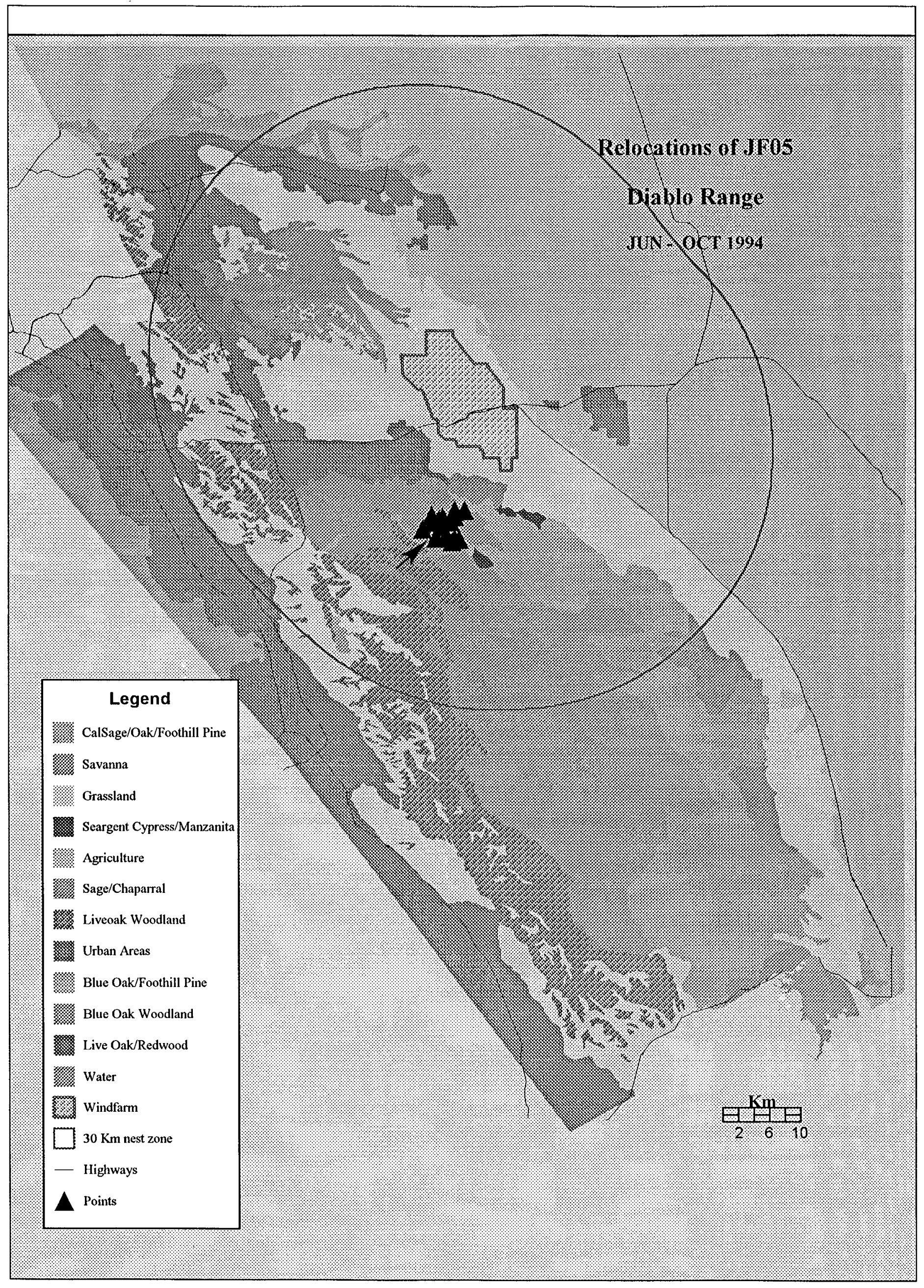




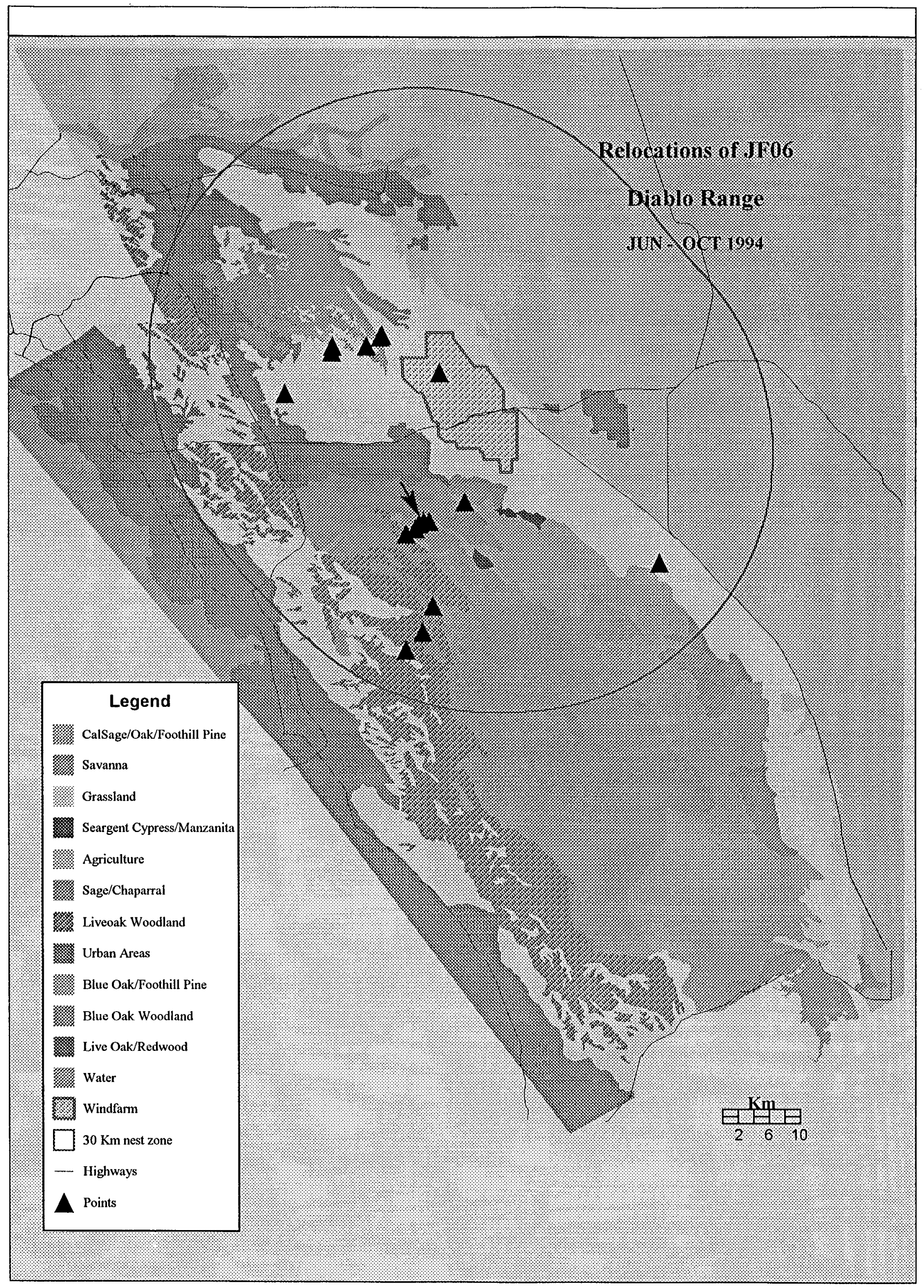




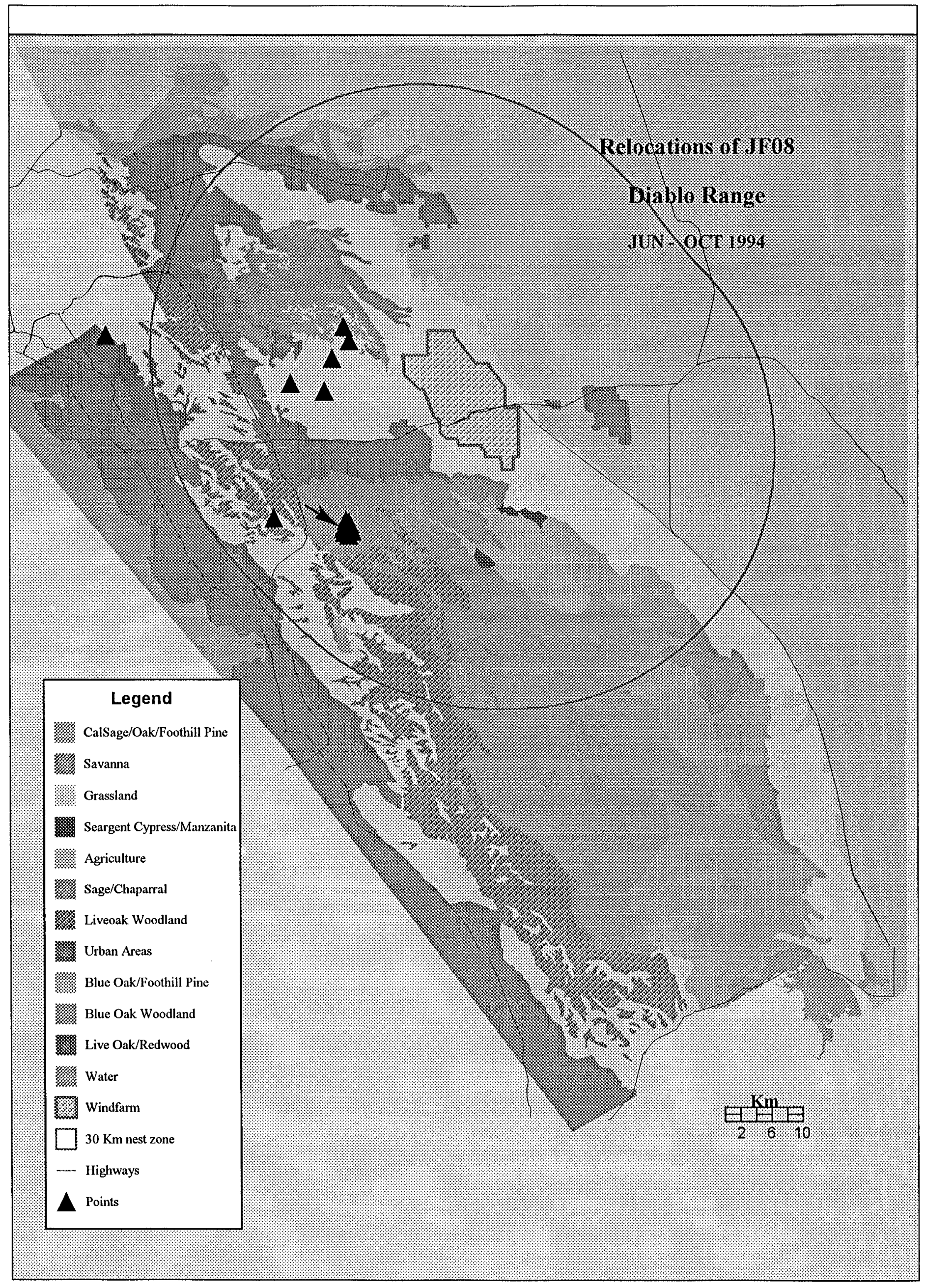




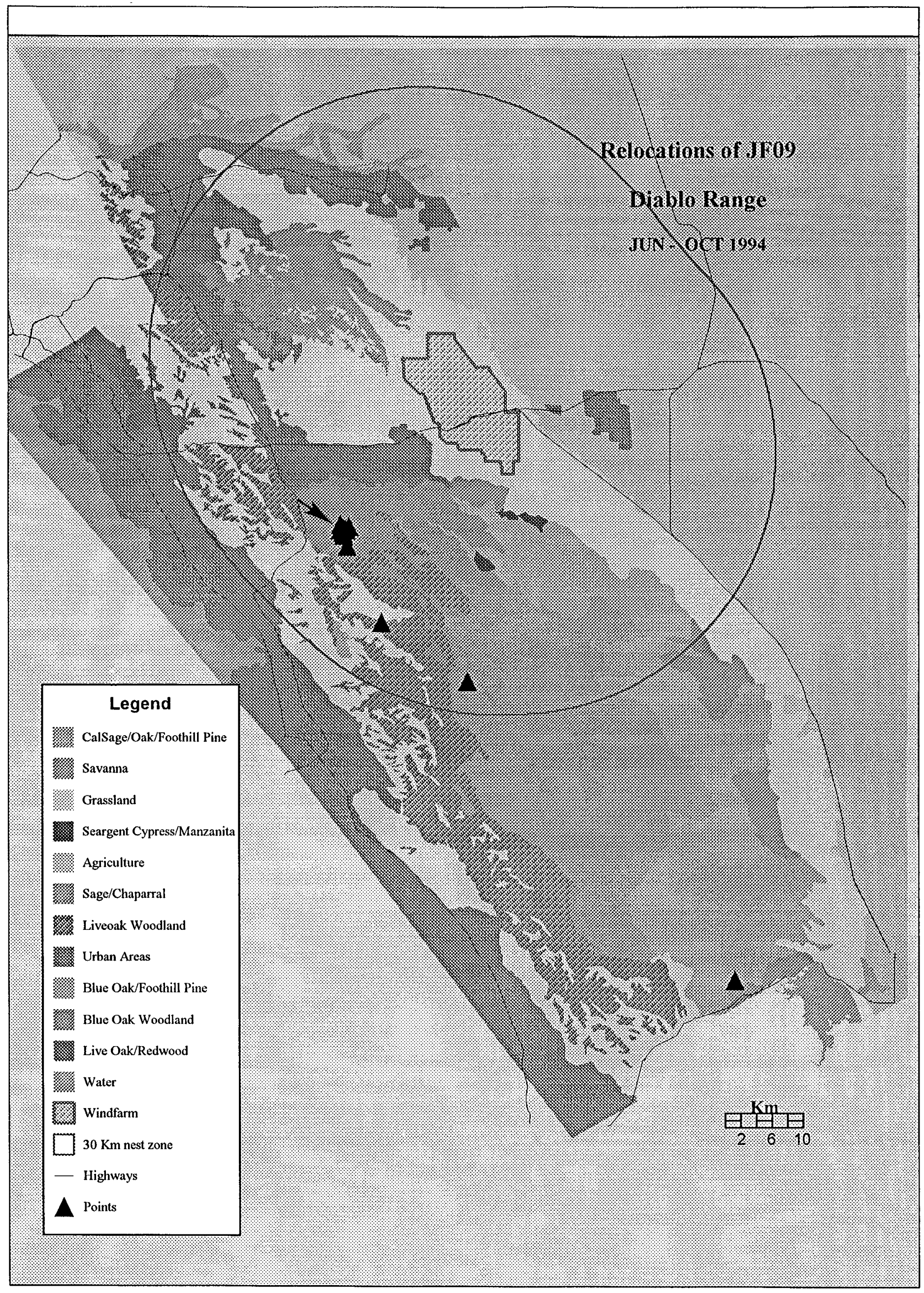




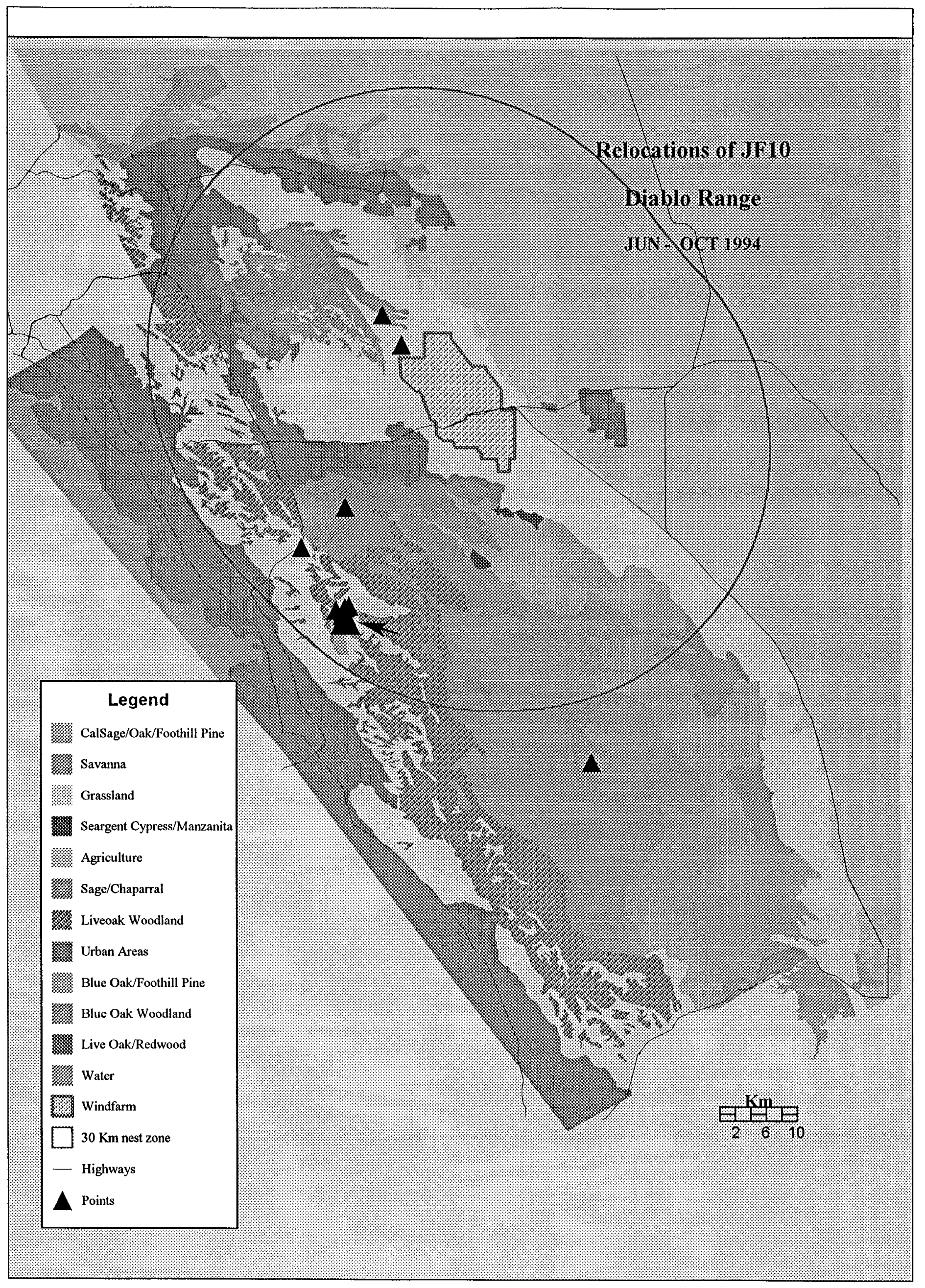




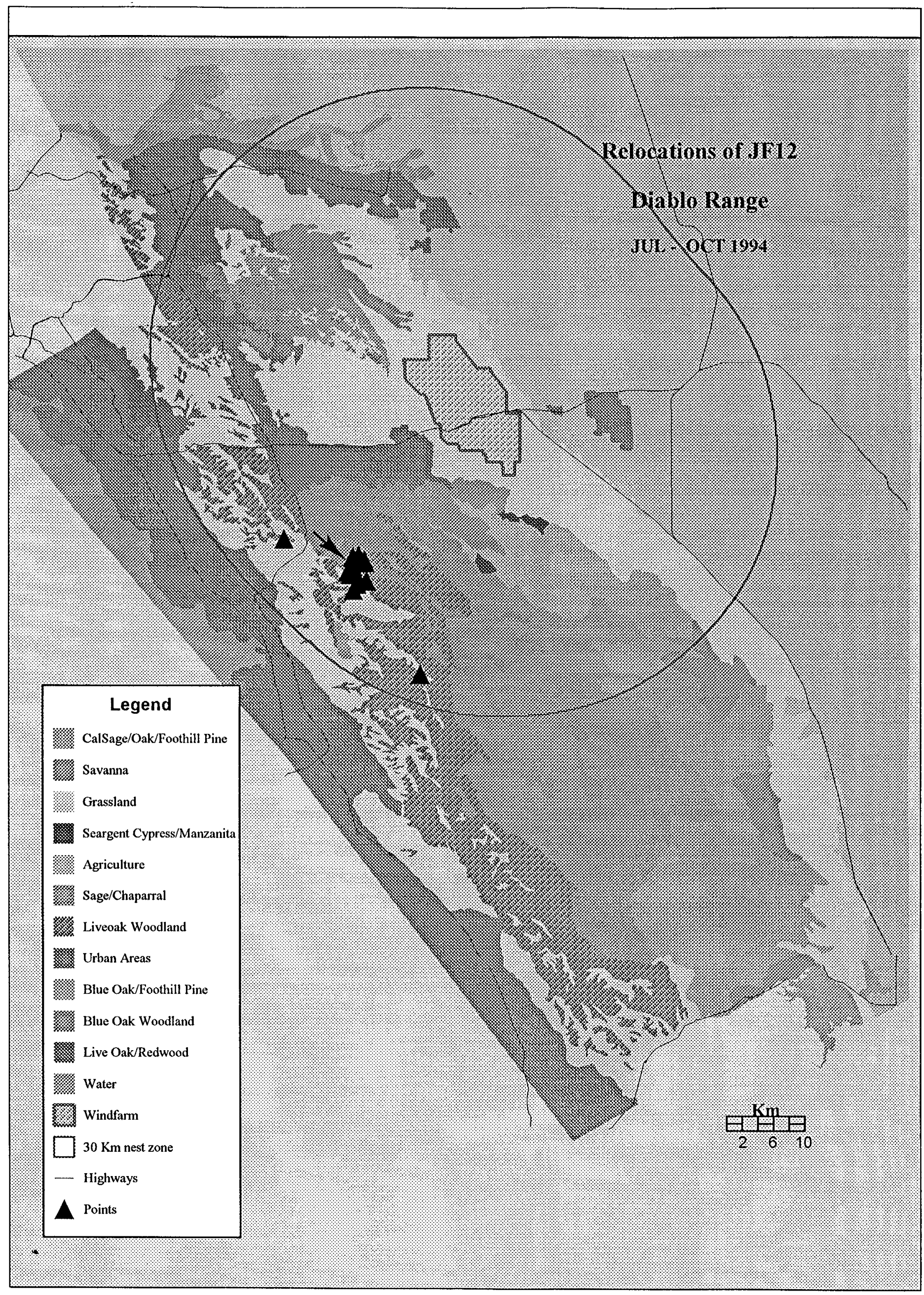




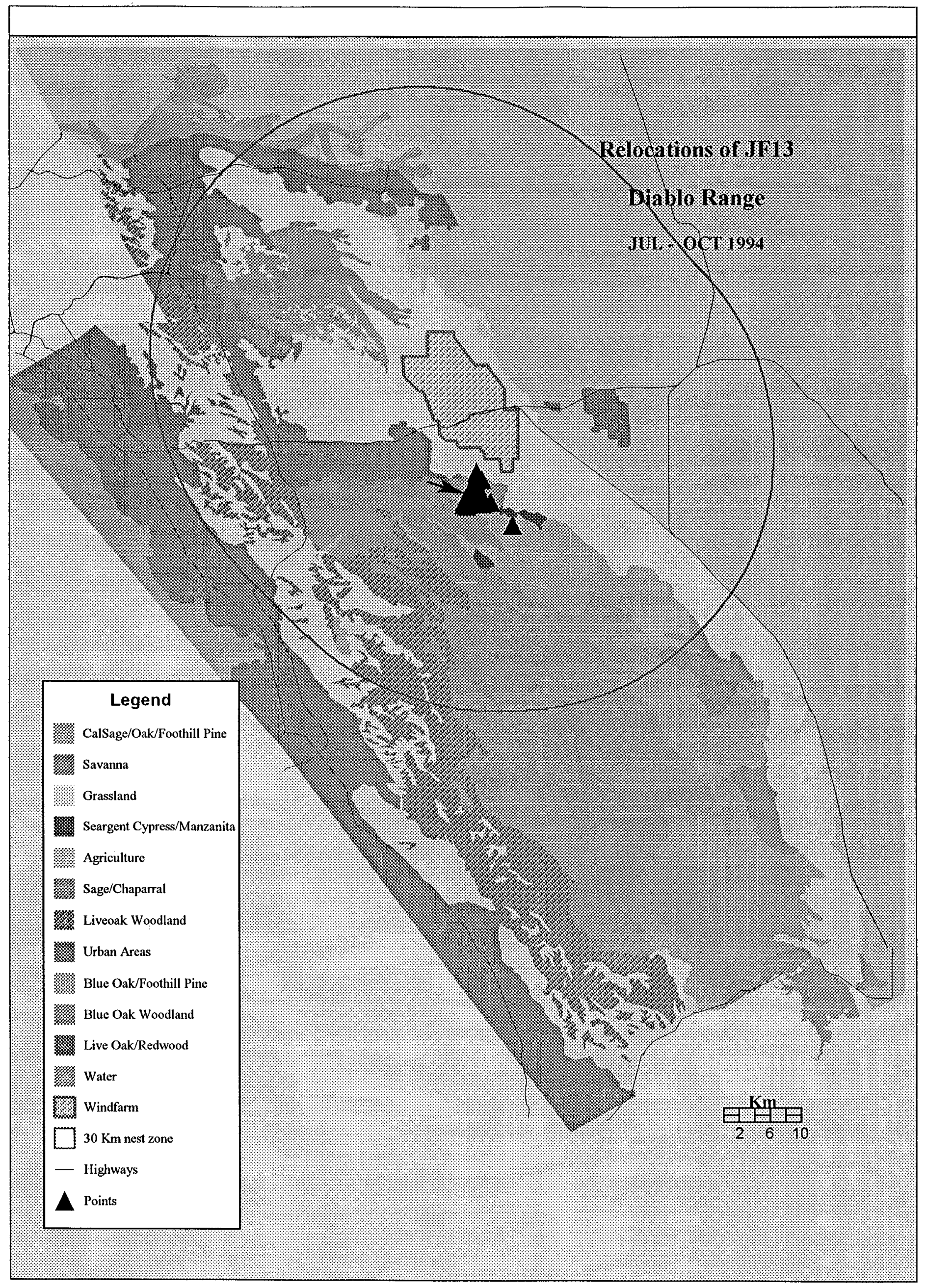




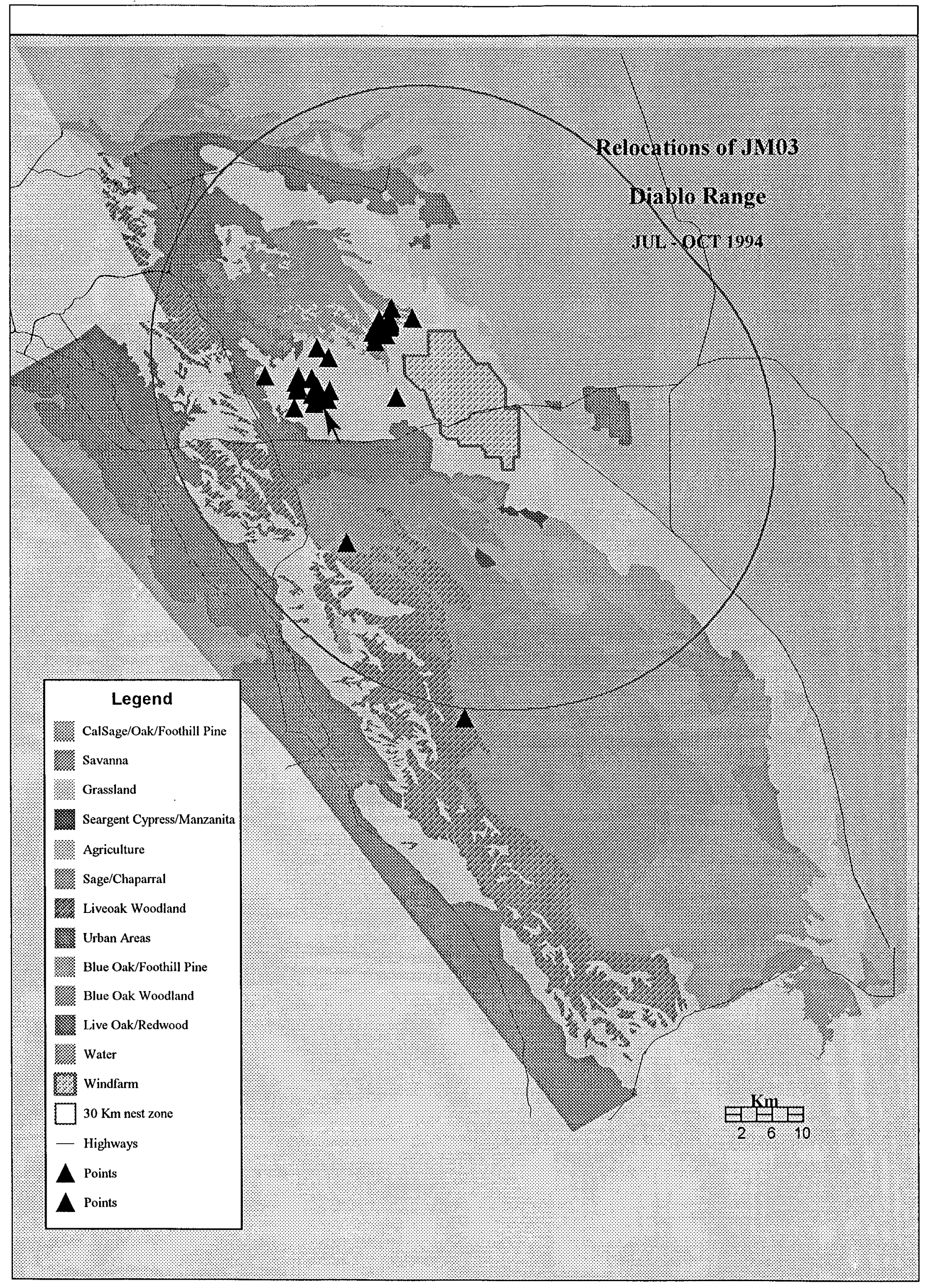




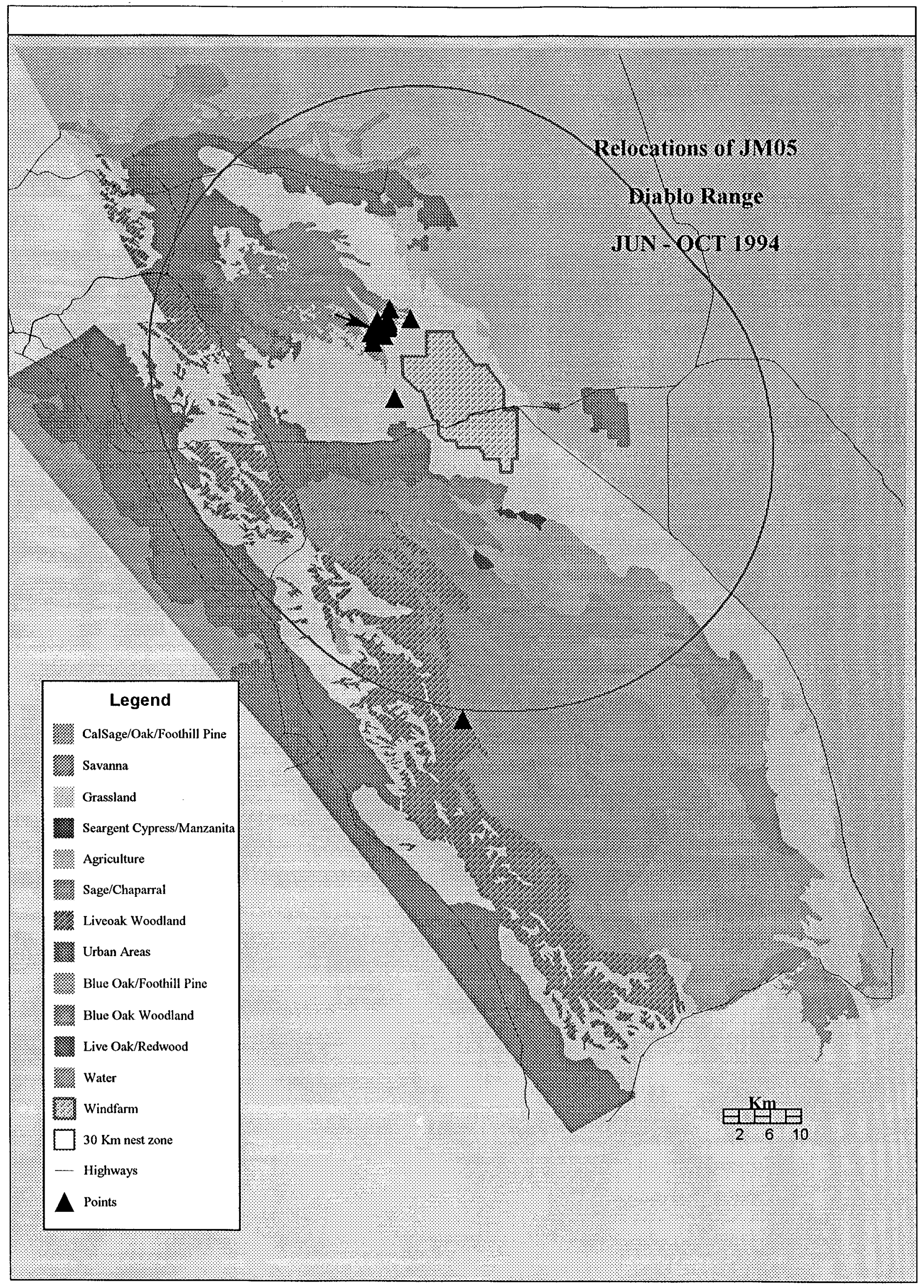




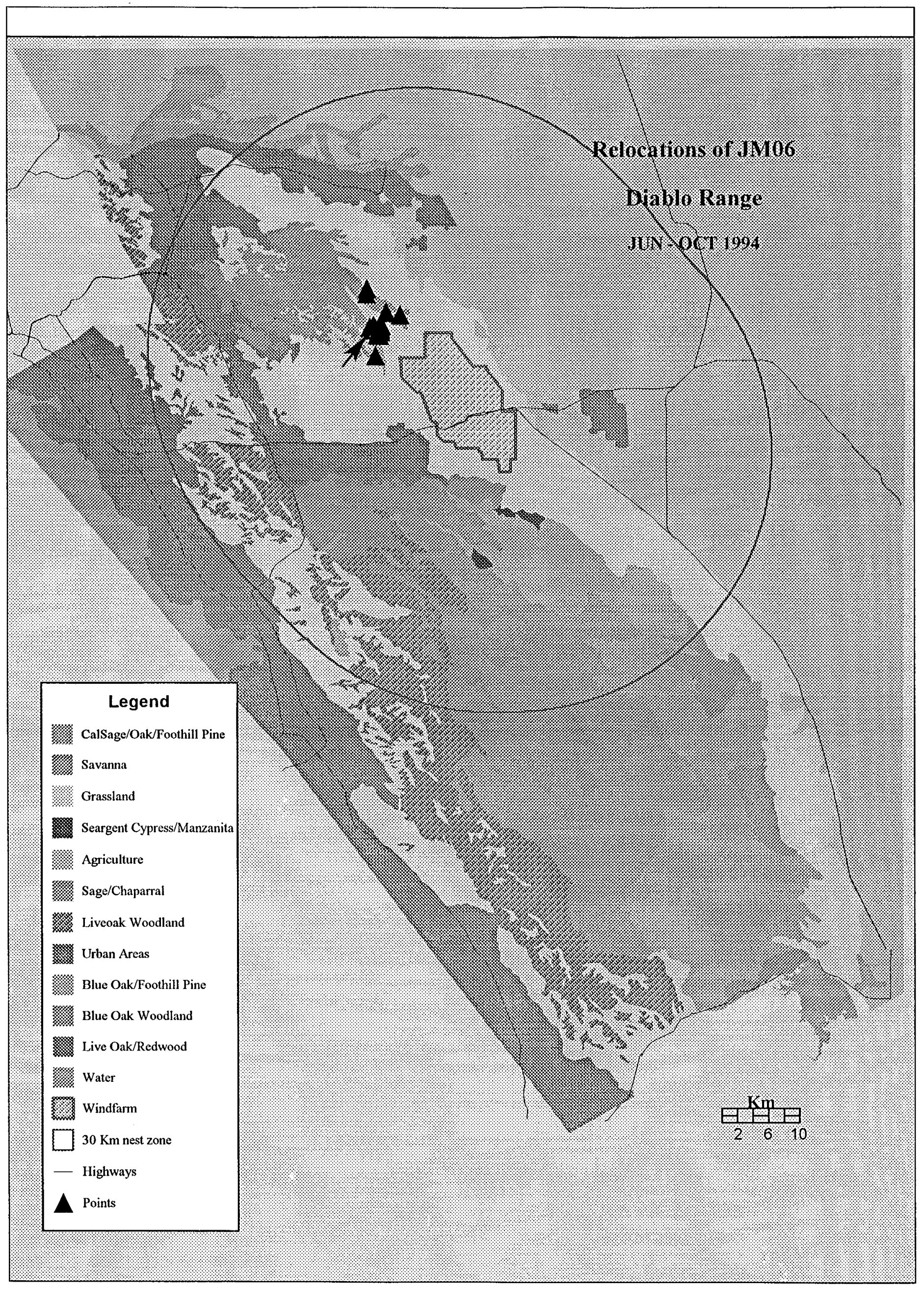




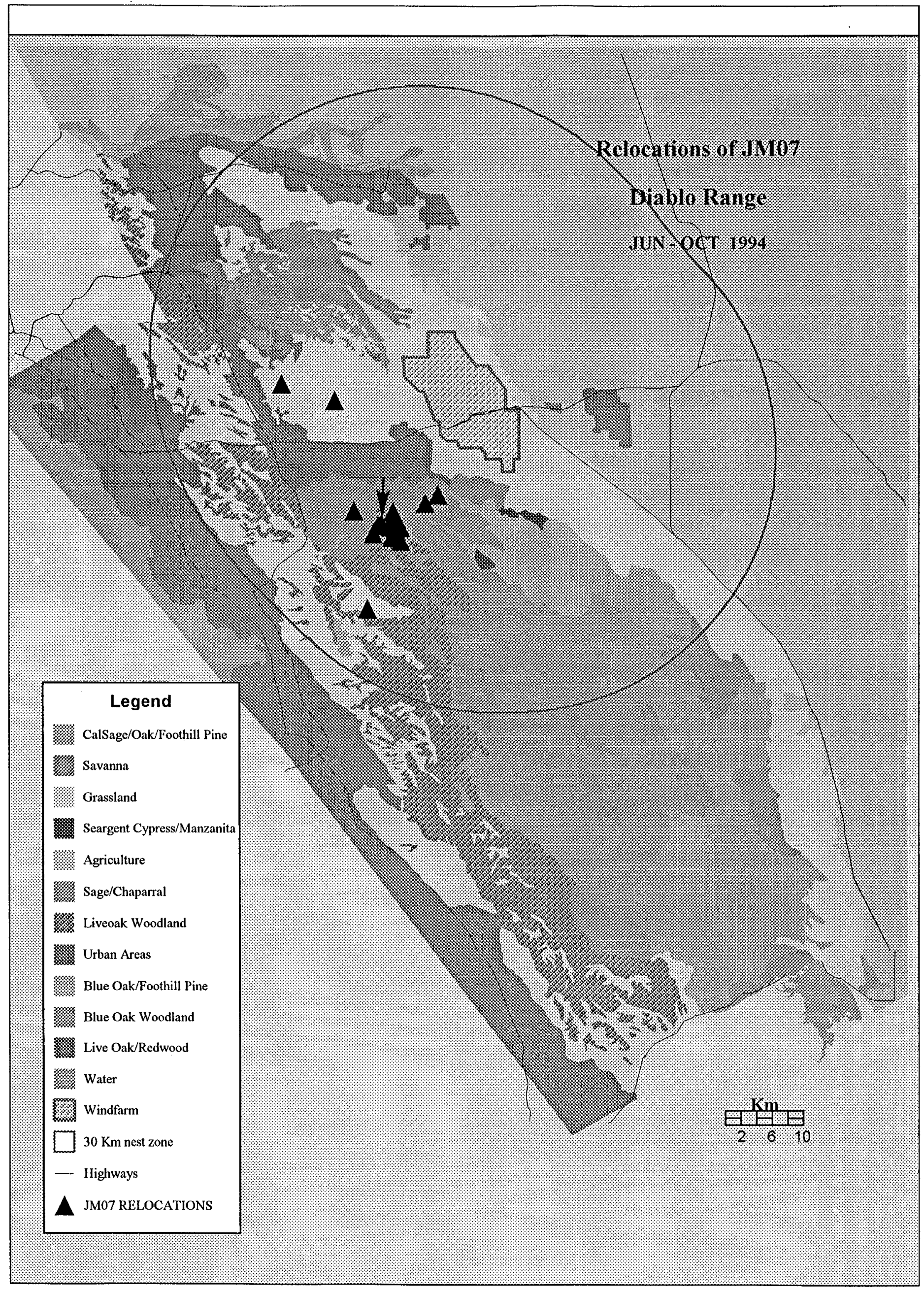




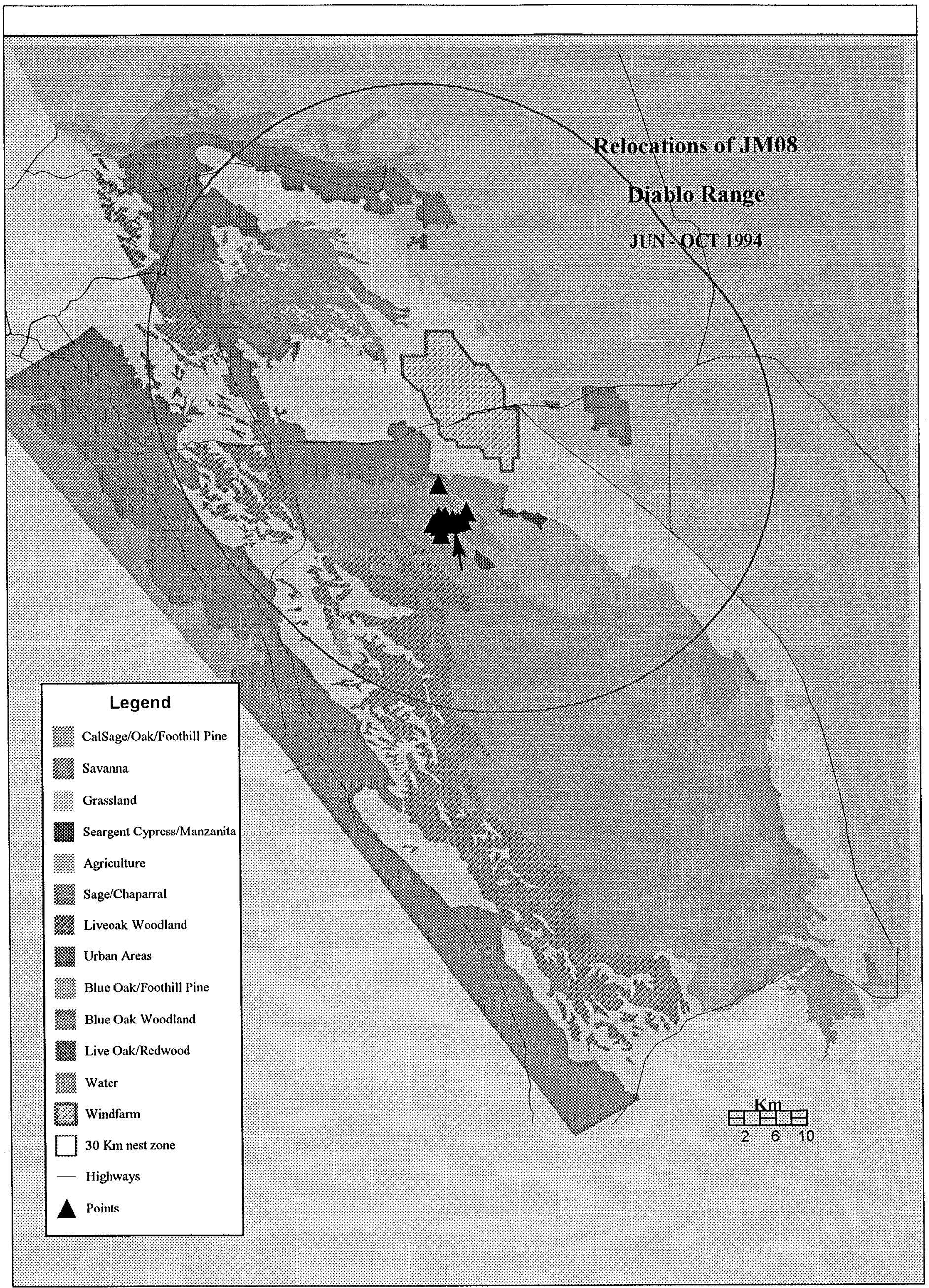




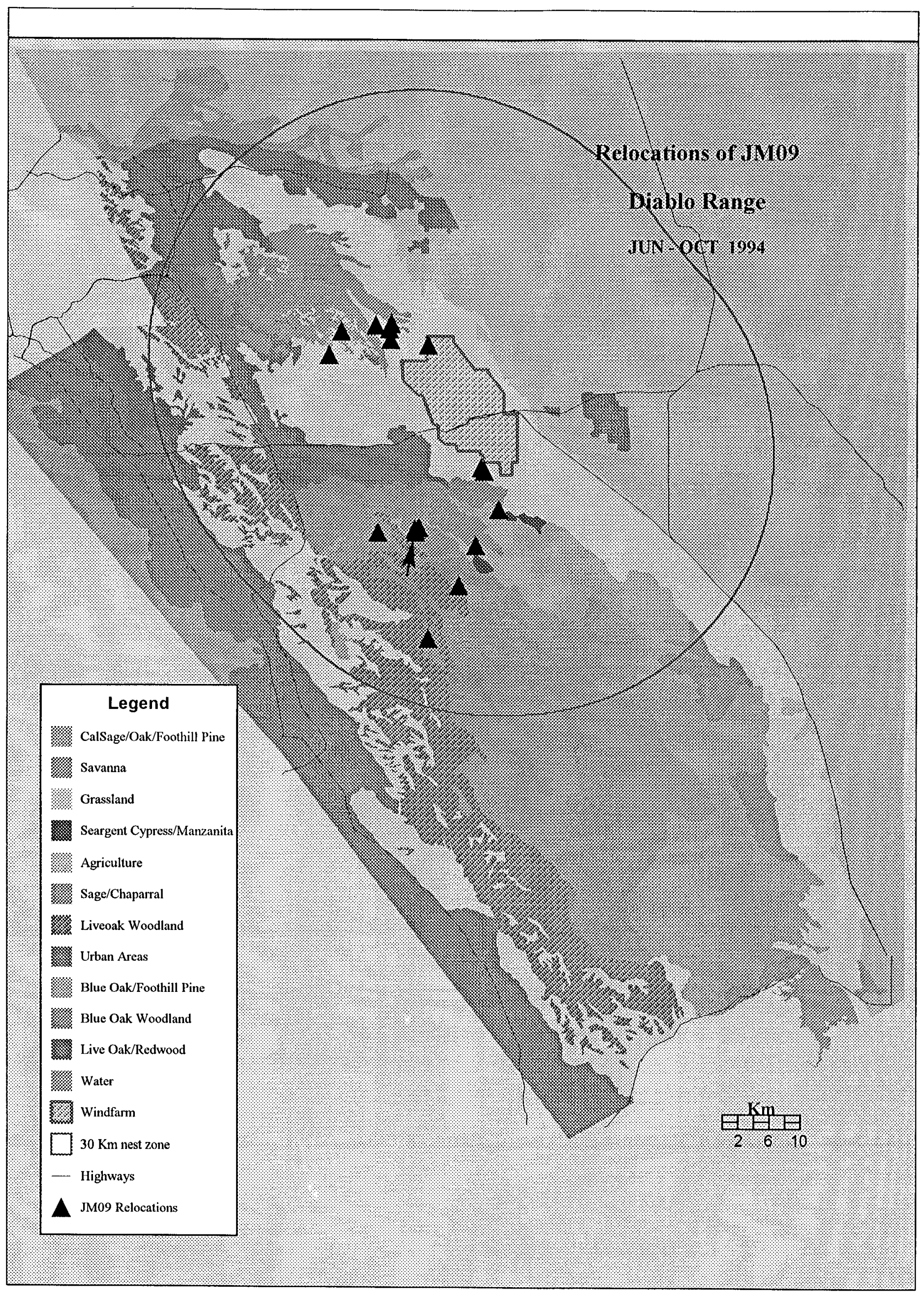




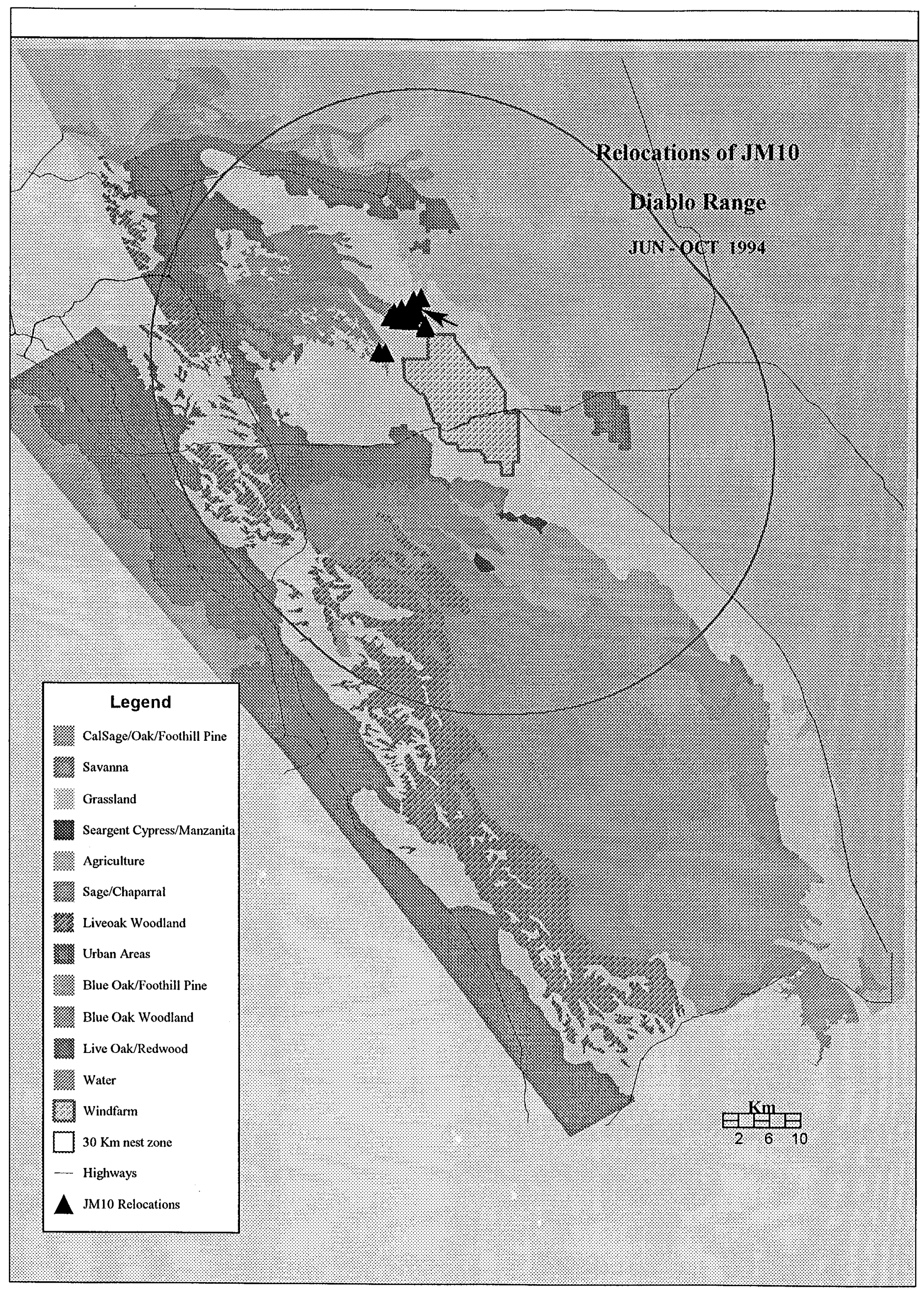




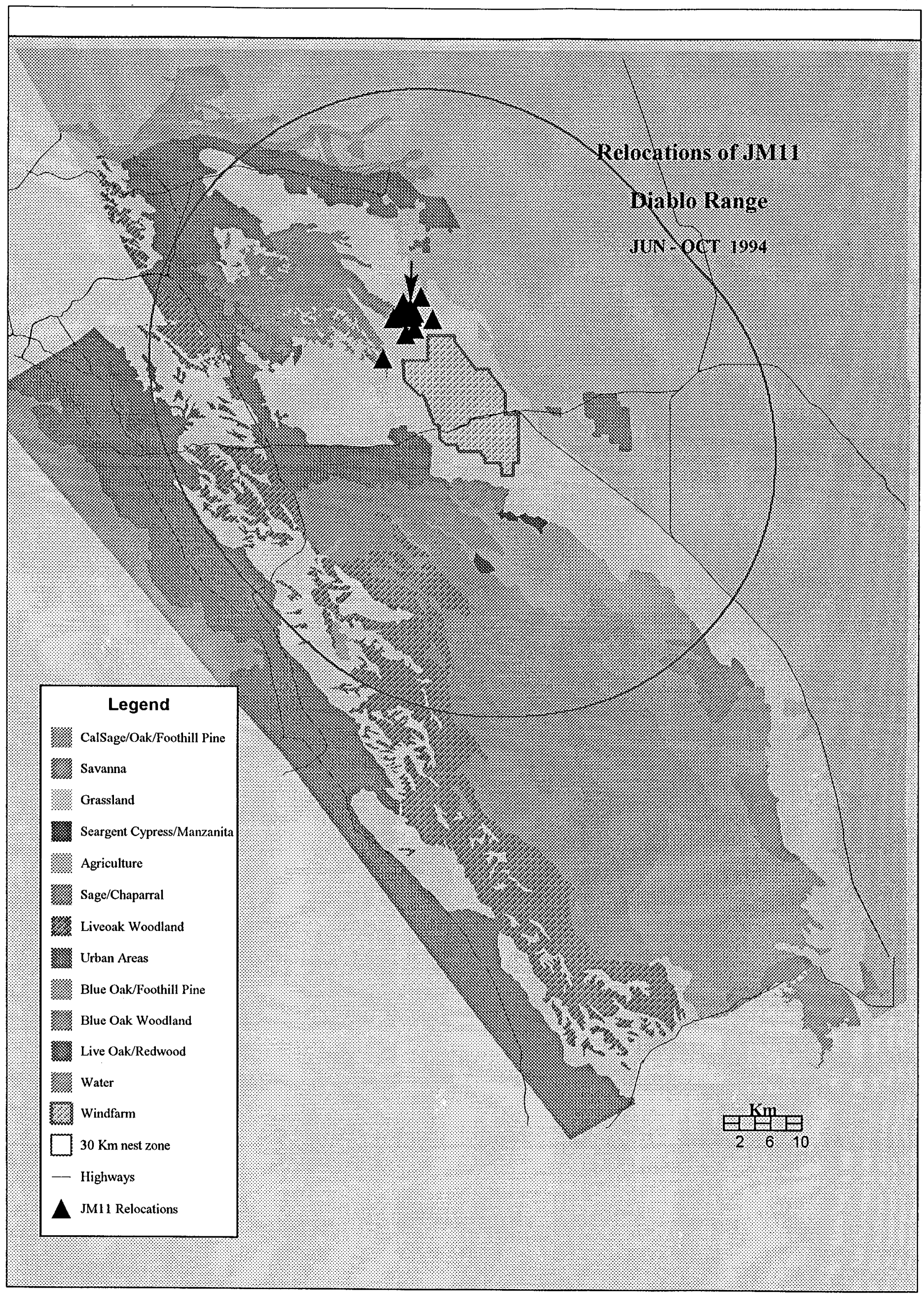




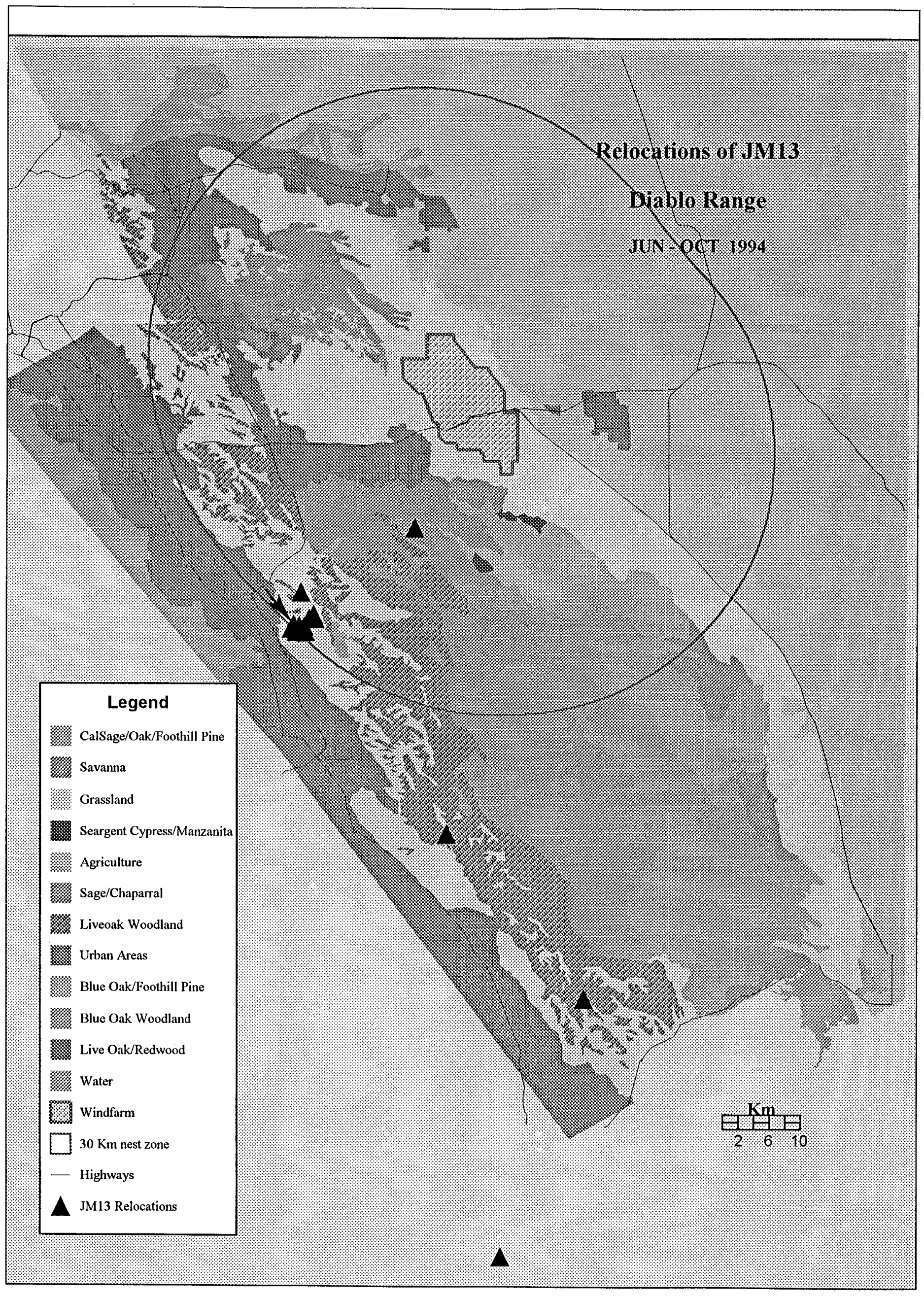




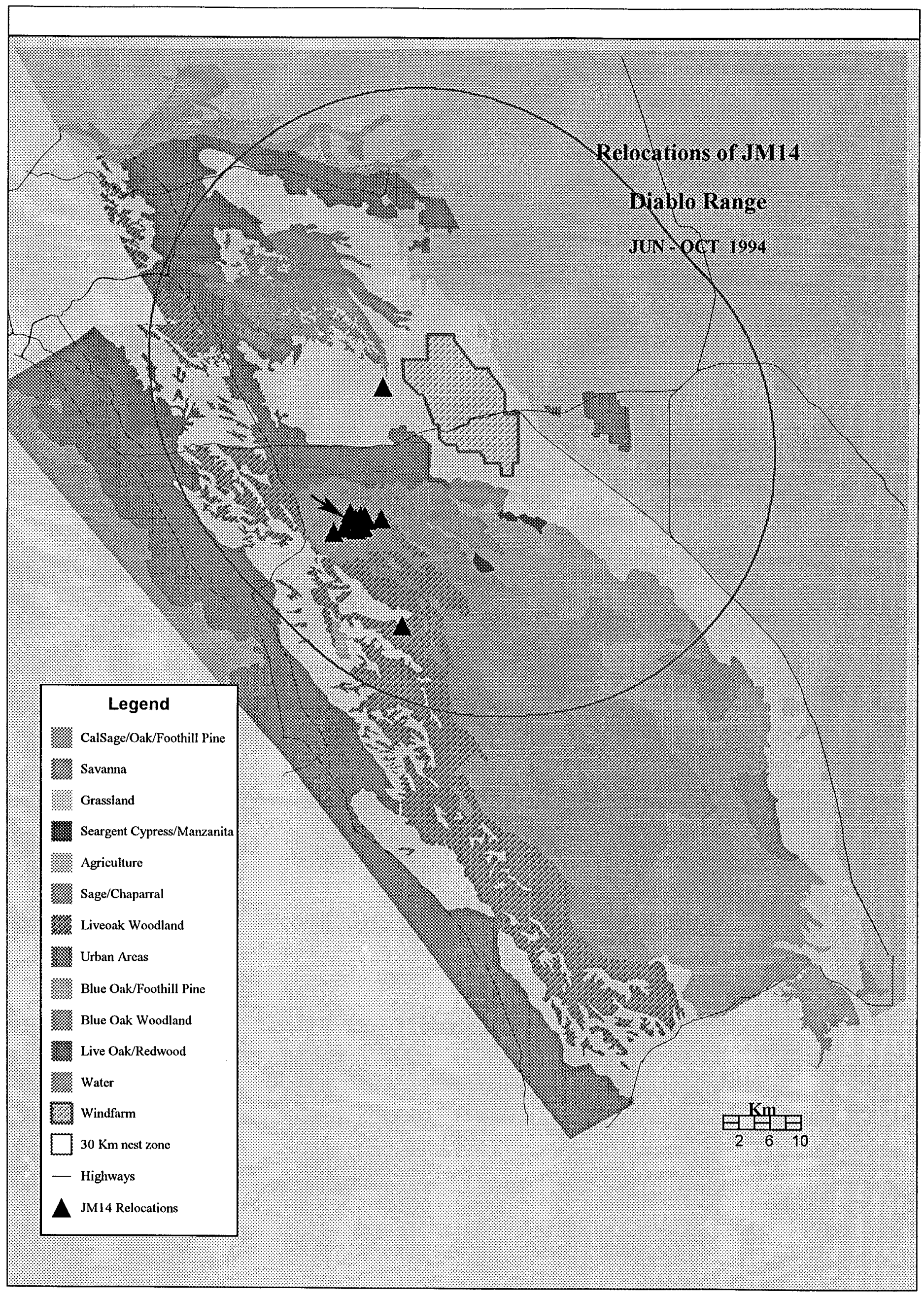




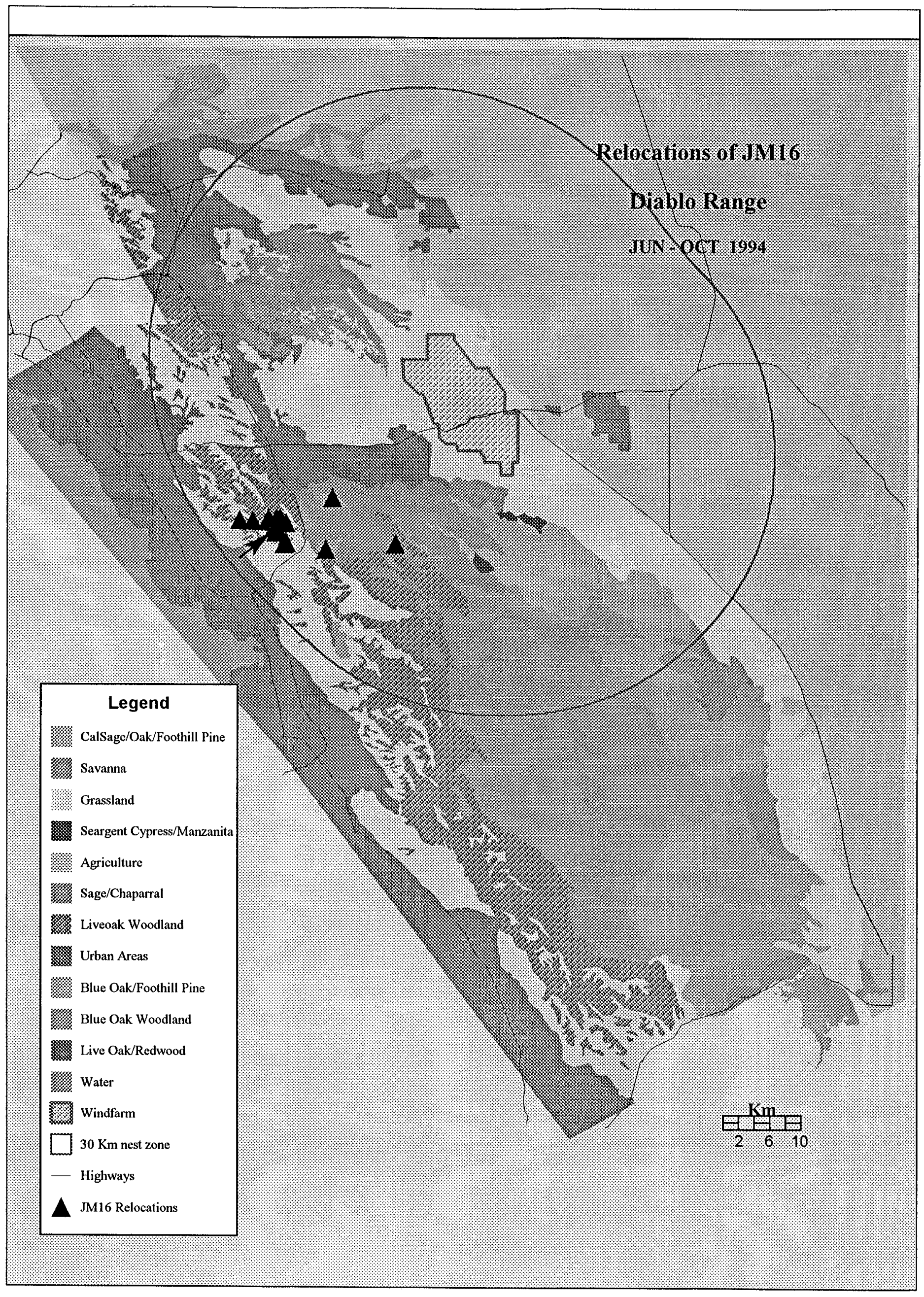




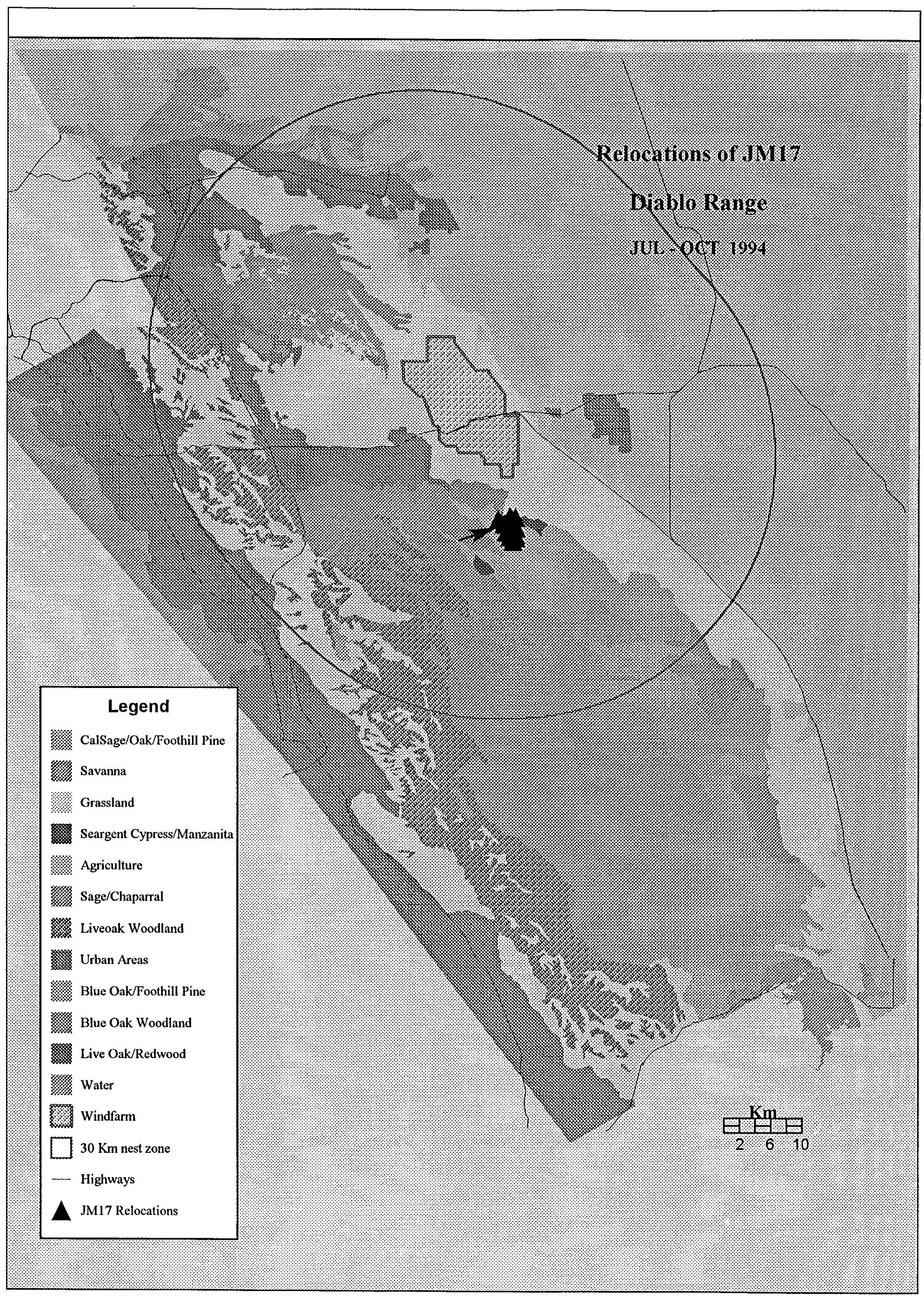




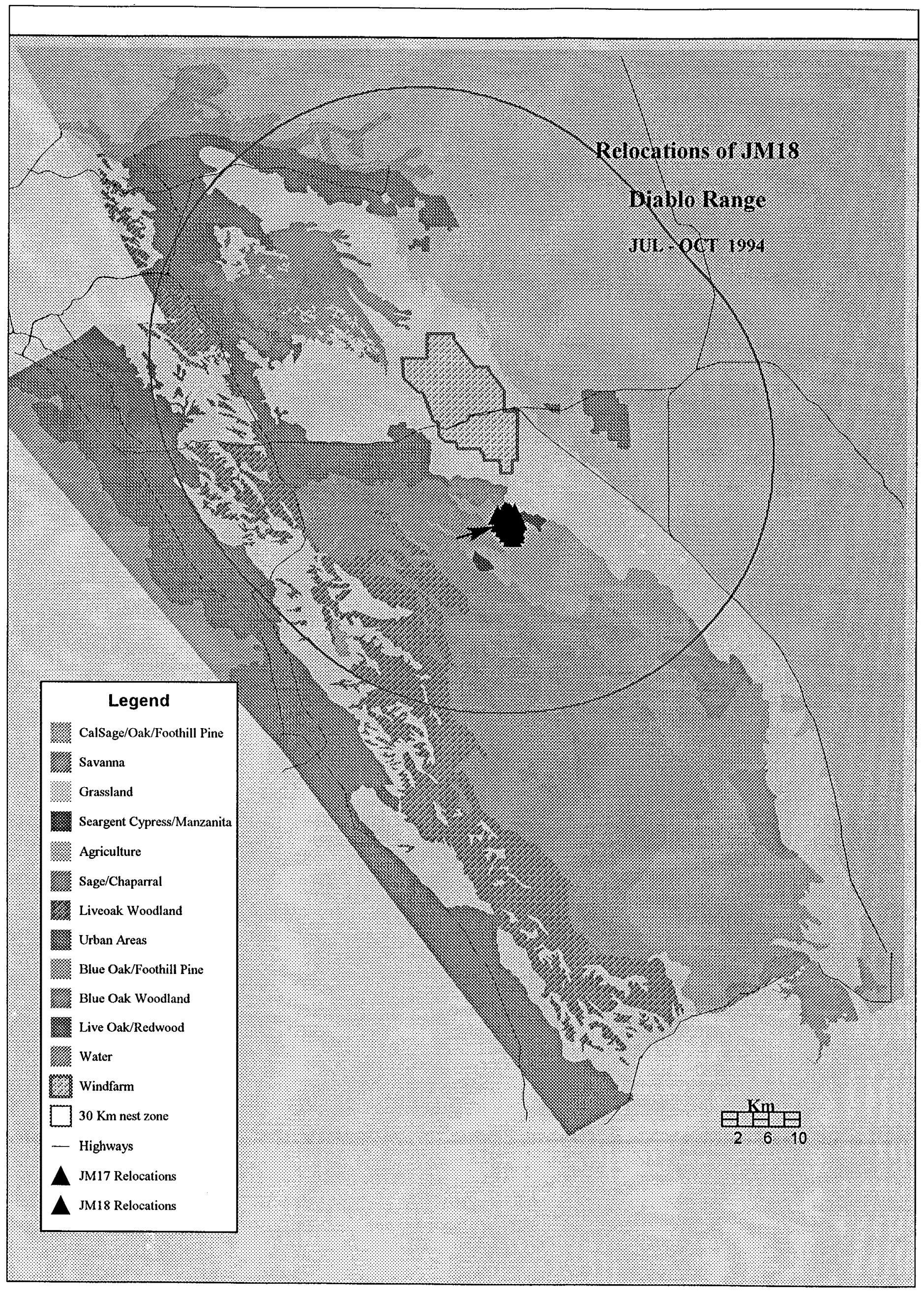




\section{APPENDIX I: HOW WE ESTIMATED THE PROPORTION OF FLOATERS IN THE POPULATION}

In Section 8, we estimated floater-to-breeder ratios on the basis of our very preliminary data on survival and fecundity and by making some assumptions about the constancy of these values over long periods. While the actual results are not to be taken seriously, we believe that predicting changes in the proportion of floaters is a far more sensitive and revealing measure of population response to a mortality influence than focusing solely on changes in growth rate. It is not sufficient to conclude that a population showing a positive growth rate has not been significantly impacted by human-induced mortality. Rather, the population, by losing part of its floating segment, may have become more vulnerable to factors influencing mortality or natality in the future. A reduction in floaters in one population may stem the flow of recruits to another with less favorable demographic potential. Areas of extraordinary habitat, like the Livermore Valley, probably generate robust floating segments that buffer the stability of breeding populations throughout the larger region.

For several reasons, eagles are ideal birds with which to obtain estimates of population structure. Large body size aids in survival rate approximation in that the birds can carry long-lived and powerful radio transmitters; for example, ours are expected to last at least five years. Because of territorial spacing, the numbers of occupied territories tend to remain constant from year to year rather than vary with annual differences in demographic rates. Natality in eagles is far more easily quantified than for birds with volatile breeding segments. Eagles are conspicuous in their territories and their young are easily counted.

In estimating floater proportions we assumed that survival and fecundity rates for each population segment remained constant year after year and that the number of nesting pairs did not change. To justify these assumptions we relied on, (1) the body of literature on territory stability in the Genus Aquila, and (2) the expectation that food supplies would not show strong annual variation, not unreasonable for the California ground squirrel in the mild climate around Altamont Pass. Whether annual fecundity is directly affected by weather influences remains to be seen.

We began by projecting a life table from an initial cohort of 101 fledglings. We obtained this value by multiplying the estimated number of breeding pairs (80) by the average fecundity per nest (1.27). An assumed juvenile survival rate of 0.70 reduced the cohort to 71 individuals by the end of the first year. With the application of a subadult survival rate of 0.78 , these were further reduced to 55 individuals by the end of the second year and 43 by the third. After age four, we used the figure 0.88 , a ballpark estimate of the adult survival rate. We truncated the life table at 20 years, at which point only five members would remain from the original cohort of 101 .

To model the age structure for a population with annual variation in demographic parameters (e.g., resulting from food supply instability, weather influences, or those arising from density- 
dependent feedback), one may construct a series of parallel life tables until a stable age distribution develops (see table below). However, because we have assumed constancy in cohort size and survival rates, each successive life table in the matrix is identical, and so a stable age distribution is apparent in the survival trajectory of the first cohort. To obtain the number of floaters, we simply sum the adult contingent of the first life table and subtract the 160 breeders.

Life Tables for Yearly Cohorts

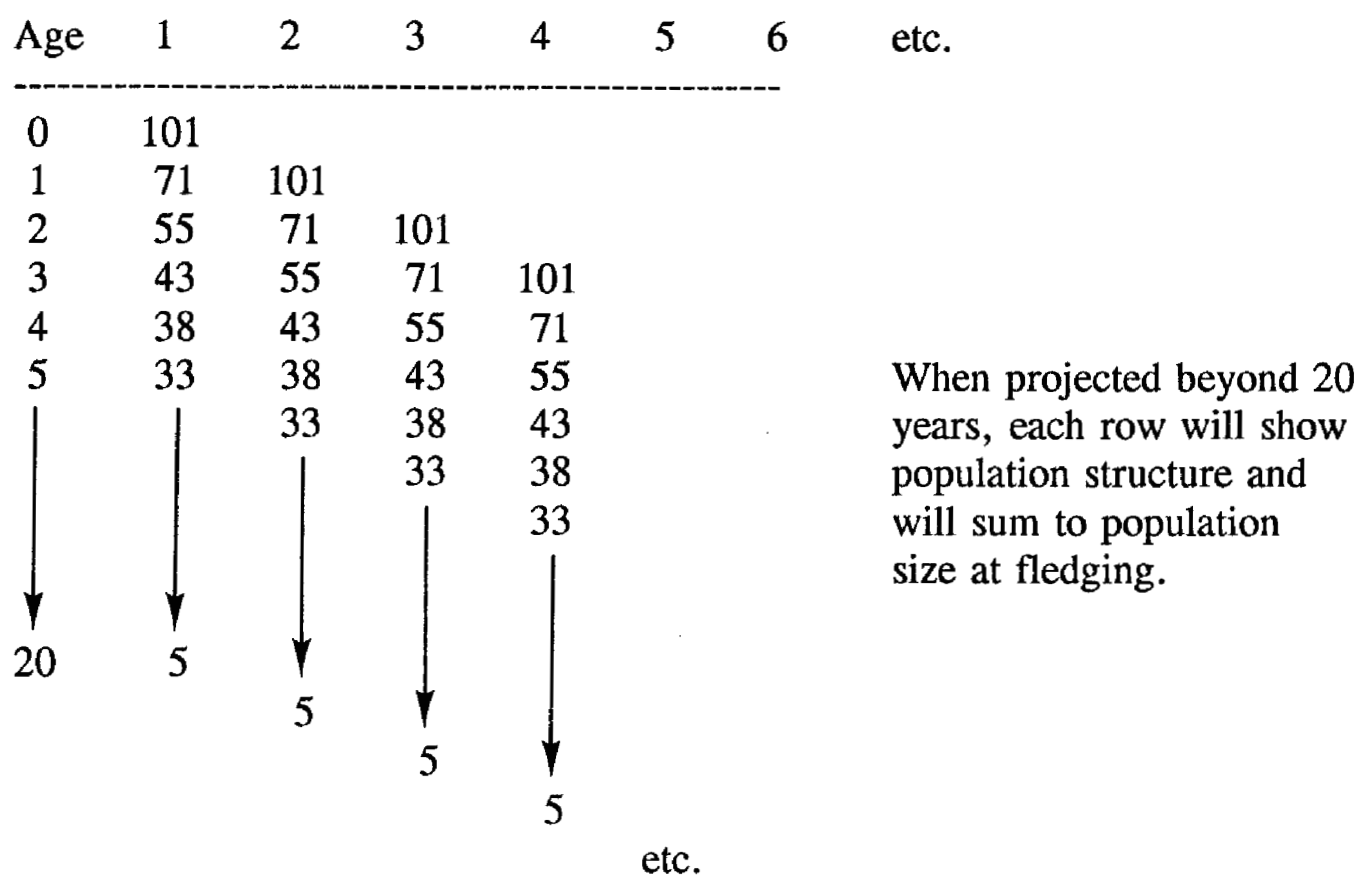

If demographic parameters remain constant, each successive life table will be identical and any single column or row (beyond physiological longevity) will yield population size and structure. 


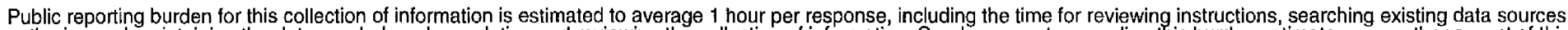

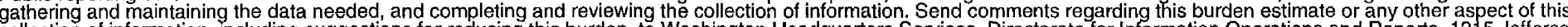
Davis Highway, Suite 1204, Arlington, VA 22202-4302, and to the Office of Management and Budget, Paperwork Reduction Project (0704-0188), Washington, DC 20503.
1.
2. REPORT DATE
May 1995
3. REPORT TYPE AND DATES COVERED Subcontract Report, 1994

4. TITLE AND SUBTITLE

A Pilot Golden Eagle Population Study in the Altamont Pass Wind Resource Area

California

5. FUNDING NUMBERS

C: $X C G-4-14200$

6. AUTHOR(S)

Predatory Bird Research Group

TA: WE517030

7. PERFORMING ORGANIZATION NAME(S) AND ADDRESS(ES)

Predatory Bird Research Group

Long Marine Laboratory

University of California

Santa Cruz, California 95064

8. PERFORMING ORGANIZATION REPORT NUMBER

9. SPONSORING/MONITORING AGENCY NAME(S) AND ADDRESS(ES)

10. SPONSORING/MONITORING AGENCY REPORT NUMBER

National Renewable Energy Laboratory

1617 Cole Blvd.

TP-441-7821

Golden, CO 80401-3393

DE95009220

\section{SUPPLEMENTARY NOTES}

NREL Technical Monitor: Holly Davis

12a. DISTRIBUTION/AVAILABILITY STATEMENT

National Technical Information Service

U.S. Department of Commerce

5285 Port Royal Road

Springfield, VA 22161

12b. DISTRIBUTION CODE

UC-1210

13. ABSTRACT (Maximum 200 words)

The report details the results of field studies conducted during 1994 in Altamont Pass. (KENETECH Windpower provided start up funding during January and February 1994. NREL support began March 1, 1994.) The primary purpose of the investigation is to lay the groundwork for determining whether or not turbine strikes and other hazards related to energy at Altamont Pass may be expected to affect golden eagles on a population basis. The authors also seek an understanding of the physical and biotic circumstances which attract golden eagles to the Altamont Pass Wind Resource Area within the context of the surrounding landscape and the conditions under which they are killed by wind turbines. Such knowledge may suggest turbine-related or habitat modifications that would result in a lower incidence of eagle mortality.

14. SUBJECT TERMS

15. NUMBER OF PAGES

Wind energy —environmental impacts, avian interactions; Altamont Pass; golden eagles

16. PRICE CODE

17. SECURITY CLASSIFICATION OF REPORT Unclassified
18. SECURITY CLASSIFICATION OF THIS PAGE Unclassified
19. SECURITY CLASSIFICATION OF ABSTRACT Unclassified
20. LIMITATION OF ABSTRACT

UL

NSN 7540-01-280-5500

Standard Form 298 (Rev. 2-89) Prescribed by ANSI Std. Z39-18 